\title{
TRANSFORMANDO LA FORMACIÓN DE INGENIEROS EMPRENDEDORES
}

\section{Mónica Zambrano Garza}
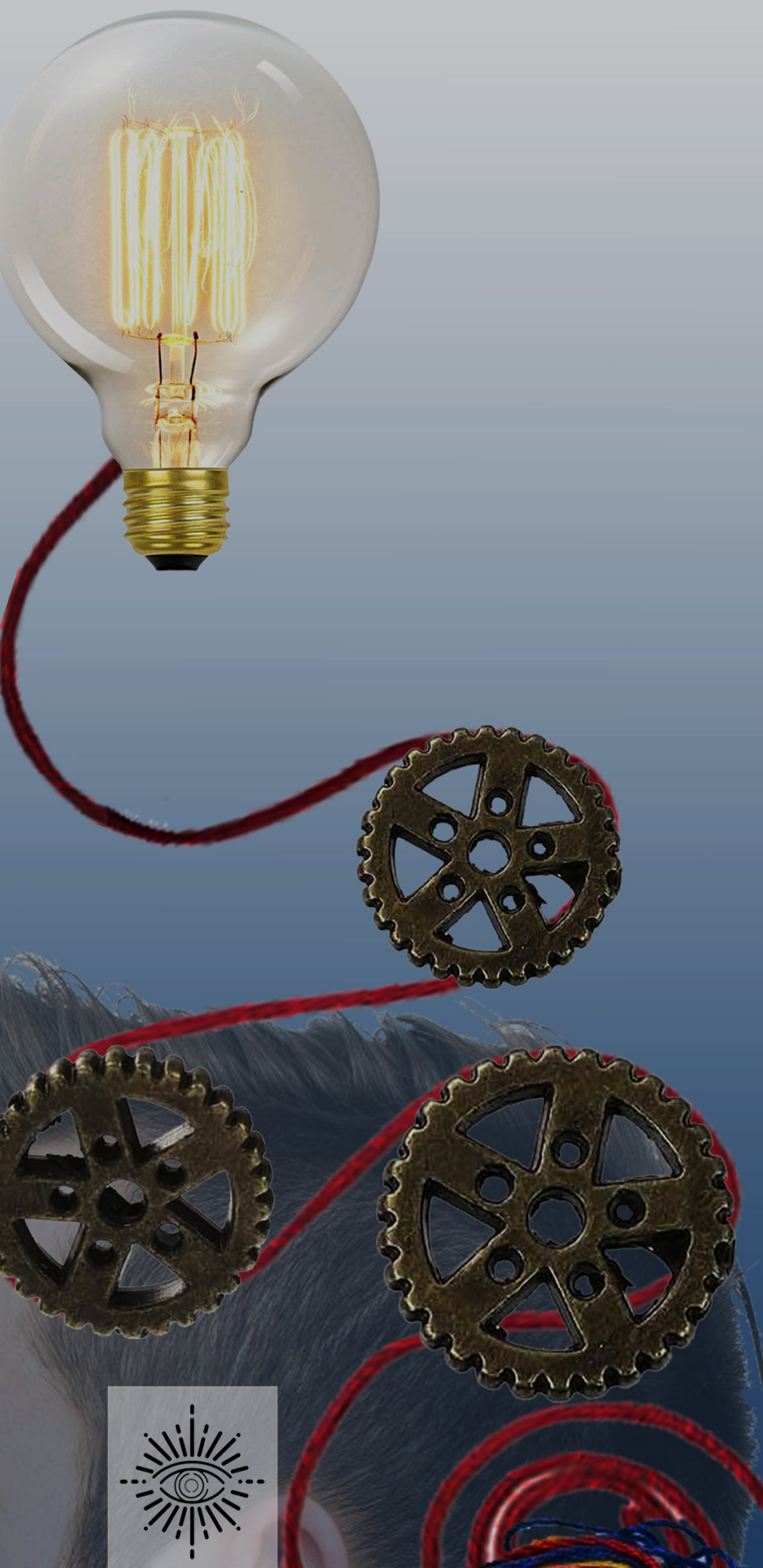


\section{Transformando la formación de ingenieros emprendedores}

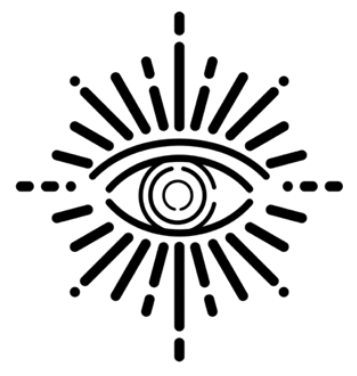


Esta investigación, arbitrada por pares académicos, se privilegia con el aval de las instituciones editoras. La edición fue revisada bajo el criterio de pares ciegos.

Labýrinthos editores. General Mariano Escobedo, N.L. 66055

www.labyrinthoseditores.com

Universidad Autónoma de Nuevo León/ Facultad de Ingeniería Mecánica y Eléctrica

Av. Universidad s/n, Ciudad Universitaria 66455, San Nicolás de los Garza, N.L., México

Teléfono: +52 (818) $3294000 \mid 3294020$

Dr. Santos Guzmán López, Rector de la Universidad Autónoma de Nuevo León

Dr. Celso José Garza Acuña, Secretario de Extensión y Cultura

Dr. Arnulfo Treviño Cubero, Director de la Facultad de Ingeniría Mecánica y Eléctrica

Primera edición 2022

Tiraje: 1000 ejemplares

(C) 2022 Labýrinthos editores

(C) 2022 Universidad Autónoma de Nuevo León

(C) 2022 Mónica Zambrano Garza

ISBN: 978-607-99076-9-3

Impreso y hecho en México

Diseño de portada: Equipo editorial Labýrinthos, imagen de portada Lic.

Roberto Mendoza Leyva; interiores: Labýrinthos editores

Revisor Editorial: Dr. Eduardo Loredo Guzmán 


\title{
Transformando la formación de ingenieros emprendedores
}

\author{
Mónica Zambrano Garz̨a
}

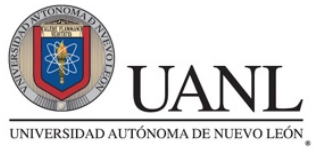




\section{Índice}

Agradecimientos 7

Prólogo. Dr. Salvador Valtierra Gallardo 9

Introducción 13

I. Bases conceptuales del emprendimiento 17

1.1 Evolución de la investigación en emprendimiento 19

1.2. Propuesta de un marco teórico para el emprendimiento 25

1.2.1 Un marco teórico integrador 27

1.2.2 El proceso de emprendimiento 31

1.2.3 Tipos de emprendedor $\quad 32$

1.2.4 Mentalidad emprendedora 33

1.2.5 Identificación de una oportunidad de negocio 36

1.2.6 Pensamiento de diseño como herramienta para el 38 emprendedor

1.2.7 Metodologías activas para la construcción del modelo de $\quad 40$ negocio

1.2.8 Recursos para emprender 41

1.2.9 Obtención de recursos $\quad 42$

1.2.10 Esquemas de flujos de ingresos 43

1.2.11 Fuentes de financiamiento $\quad 45$

1.2.12 Un modelo de negocio innovador $\quad 47$

1.2.13 Estrategia de entrada al mercado $\quad 50$

1.2.14 Modelos económicos para emprendimientos 51

1.2.15 Tipos de emprendimientos 53

1.2.16 Etapas del ciclo de vida de la empresa 54

1. 3. El impacto de la historia en la comprensión del 57 emprendimiento

II. La mentalidad emprendedora y su impacto en el 59 emprendimiento y la innovación

2.1 Conceptos básicos: emprendedor y mentalidad 63 emprendedora

2.1.1 Teorías sobre los factores del entorno que impactan al $\quad 65$ emprendedor

2.1.2 Teorías sobre los factores individuales que impactan al $\quad 66$ emprendedor

2.1.3 Educación de la mentalidad emprendedora

2.2 Impacto de la mentalidad emprendedora en la intención $\quad 71$

2.2.1 Competencias que favorecen la mentalidad 73 emprendedora

2.3 Impacto de la mentalidad emprendedora en el 76 emprendimiento 
2.3.1 Los emprendimientos estimulan el crecimiento 77 económico creando empleos

2.3.2 Los emprendimientos mejoran la productividad $\quad 82$

2.3.3 Los emprendimientos generan un cambio social $\quad 84$

2.3.4 La mentalidad emprendedora impulsa la innovación $\quad 86$

2.4 La innovación $\quad 88$

2.4.1 Recursos de innovación $\quad 91$

III. La importancia del emprendimiento en la formación 103 de ingenieros

3.1 Universidad y emprendimiento: conceptos y elementos 106

3.1.1 Emprendimiento como concepto 109

3.1.2 Elementos del emprendimiento y la educación 117 emprendedora

3.2 Situación de la educación emprendedora 122

3.2.1 Rutas de la ingeniería hacia la educación emprendedora $\quad 130$

3.3 Razones para fomentar la educación emprendedora en 133 programas universitarios de ingeniería

IV Redefinición de la formación de ingenieros 137 emprendedores

4.1 Ingenieros emprendedores 142

4.2 La universidad emprendedora 148

4.3 La eficiencia en los procesos de formación de ingenieros $\quad 154$

4.4 La transformación de la educación de ingenieros 161

V Innovación en el aula: transformación de la educación 167 emprendedora

5.1 Planteamiento del problema 168

5.2 Los orígenes del pensamiento de diseño y su propuesta de $\quad 174$ aplicación al contexto emprendedor

5.3 Transición del modelo tradicional al modelo de aprendizaje $\quad 182$ activo en la educación emprendedora

5.4 Modelo de diseño instruccional para la propuesta de 189 transformación

5.4.1 Fundamentos del diseño instruccional propuesto 191

5.4.2 Fase 1. Análisis 193

5.4.3 Fase 2. Diseño 195

5.4.4 Fase 3. Desarrollo 204

5.4.5 Fase 4. Implementación 205

5.4.6 Fase 5. Evaluación 206

5.5 Reflexiones finales 207

Referencias bibliográficas 209 


\section{Agradecimientos}

Este libro es el producto de grandes esfuerzos y de muchas voluntades. Muchas personas han colaborado, algunas conscientemente, otras sin quererlo, intentaré mencionarlas por respeto a su valioso aporte.

Debo comenzar agradeciendo a Dios por la oportunidad de hacerlo, y que conforme a sus tiempos haya sido posible concluirlo.

No puedo dejar de agradecer a la persona más importante en mi vida, Oscar, por sus palabras y su paciencia para ayudarme a descifrar las partes económicas del proyecto, con léxicos y ejemplos que pudiera presentar para facilitar los procesos. A Deya, porque sus sonrisas y distracciones me permitieron muchas veces retomar las ideas y el camino de la escritura. A Gilberto y Deyanira, quienes siempre han estado en mi esquina. A Mine por ser ejemplo de buen docente.

Agradezco la colaboración de colegas y profesores con quienes he tenido oportunidad de trabajar, de aprender de ellos y de compartir experiencias, pues esto ha construido la estructura de mi propia práctica docente, y que derivó en el análisis descrito en estas páginas. En particular, a Lizbeth, a Neydi y a Nivia, quienes han sido mis pares pedagógicos, visitando mis aulas y exponiendo las áreas de oportunidad, para trabajarlas al paso de los últimos años, además que son grandes compañeras de investigación a quienes admiro.

A Mendoza por su asistencia y por enseñarme a diseñar gráficos claros. Al Dr. Valtierra por sus palabras y su orientación experta. Al Dr. Treviño por su liderazgo y ejemplo como docente preocupado y aplicado en el beneficio del estudiante y la mejora continua. Al Mtro. Báez porque siempre está dispuesto a compartir sus experiencias y conocimiento. A la Universidad Autónoma de Nuevo León, en particular a mi FIME (Facultad de Ingeniería Mecánica y Eléctrica), porque como familia, siempre está para respaldar. 


\section{Prólogo}

Este libro tiene como finalidad el proporcionar una amplia descripción del proceso y las bases del emprendimiento, estableciendo que el espíritu emprendedor es un comportamiento que permite combinar o redistribuir los recursos innovadores, de emprendimiento, de toma de decisiones y de riesgo de un emprendedor a fin de crear un nuevo valor (producto o servicio), como establece Peter Drucker, la Innovación y emprendimiento "no es magia, no es misterioso y no tiene nada que ver con los genes. Es una disciplina y, como cualquier disciplina, se puede aprender". Para ello, propone una metodología por medio de un marco institucional, que facilite y propicie una cultura emprendedora para su implementación exitosa en las universidades, especialmente en los programas de ingeniería, donde esta propuesta debe ser cubierta de forma transversal en un programa educativo completo, de modo que se promueva el espíritu emprendedor más allá de sólo una asignatura y una calificación, y que sea aplicable también en las demás facultades incluidas las de humanidades. La influencia de estos programas integrales es relevante, y los beneficiados son los estudiantes, la universidad y en general la sociedad.

Para lograr este propósito, el autor utiliza lo que podríamos llamar ingeniería de acción, identificando las características de los problemas con los que a diario se enfrenta el ingeniero, mediante el uso del proceso fundamental (análisis del proyecto, búsqueda de información, experimentación, análisis y discusión de resultados), basado no solamente en las competencias duras (matemáticas, ingeniería, física, química), sino también en educación empresarial y en las competencias del siglo XXI (pensamiento crítico y resolución de problemas, multilingüismo y conocimiento cultural, comunicación efectiva y colaboración, agilidad, adaptabilidad y capacidad para el aprendizaje continuo, iniciativa, autodirección y emprendimiento, creatividad e innovación). 
La organización general del libro se estructura de manera muy lógica con las bases conceptuales del emprendimiento muy detallas, seguido por los factores y las competencias que impactan en el emprendedor y su mentalidad innovadora, así como los elementos que justifican la formación de estos programas integrales en las universidades, especialmente formando ingenieros emprendedores para que sean empresarios que conozcan los procesos para el diseño y creación de modelos de negocio, la legislación aplicable, los riesgos asociados, los diversos modelos de gestión, y que su aprendizaje los sumerja en conocimientos aplicados a la vida real, no solo para navegar en la teoría, sino que les implique y sensibilice de los problemas que aquejan a la sociedad, y se involucren en el diseño de soluciones eficaces, que vivan las experiencias y pierdan el miedo a intentarlo.

El capítulo final es muy interesante y establece la aplicación en un modelo educativo funcional, contextualizando el contenido teórico expuesto en los capítulos anteriores, y dominando el grado de especificidad necesario, según sea el caso, de manera que pueda integrarse en otras materias de los programas educativos, siempre atendido de manera transversal y no aislado en una sola asignatura.

Aquí el autor propone que el pensamiento de diseño (design thinking), sea el modelo implementado como base para la promoción de la mentalidad emprendedora, porque favorece la transversalidad, y es dirigida por los docentes quienes rediseñan sus cursos aplicando nuevos enfoques pedagógicos, como el aprendizaje activo, generando impactos favorables en la formación profesional de los estudiantes universitarios.

Establece el escenario ideal dentro de un ecosistema emprendedor en la institución de educación superior donde se aplique, facilitando el uso del pensamiento de diseño en la creación y entrega de programas educativos, donde el emprendimiento sea transversal a estos, y no solo tomando una asignatura aislada pues el impacto no es suficiente. 
Propone una transformación de la perspectiva de enseñanza de emprendimiento para ingenieros adaptada en el entorno actual, y como se vio en la pandemia, el aprendizaje ya no debe estar estrictamente ligado a tiempo y lugar, además que el papel del docente debe cambiar a ser coach de los estudiantes en su formación.

Al estudiante de ingeniería, suele resultarle complicado estimar la importancia de los diversos cursos que debe tomar, sobre todo si no son de competencias duras, o de la relevancia que estos tengan en su vida profesional, uno de ellos es el emprendimiento, el cual el autor trata de manera muy detallada, de tal forma que este trabajo bien puede ser usado como texto básico en estrategia y definición de programas educativos, ya que autor procura que la terminología usada sea lo suficientemente elemental, a fin de que esté al alcance de los estudiantes de ingeniería, sin embargo, algunos de los conceptos no son tan elementales, debido a la particularidad del mismo trabajo. Así mismo el autor hace una conexión muy interesante del proceso de emprendimiento y la aplicación de técnicas que deberían dar lugar a un profesional completo, con las competencias para afrontar la vida como un emprendedor con capacidad de definir la viabilidad, en primer lugar, y el éxito o fracaso potencial de su proyecto.

Finalmente felicito a la Doctora Mónica Zambrano Garza por el acierto de dedicarle mucho tiempo a la elaboración de este excelente libro, y esperemos que sea un pilar en la estrategia y definición de programas de emprendimiento en las universidades.

Dr. Salvador Valtierra Gallardo

Saltillo, enero 2022 


\section{Introducción}

"Lo llaman coaching, pero es enseñanza. No solo les dices, les muestras las razones". Vince Lombardi

Un día, un grupo estudiantes sugirieron que este libro debía escribirse. Al término del curso reconocieron que las clases que habían llevado sobre emprendimiento eran distintas y les habían sido muy útiles, y que debía haber una suerte de manual que explicara la forma de hacerlo para que otros estudiantes y docentes pudieran también, beneficiarse de ello. En ese momento, este proyecto inició y de eso hace ya algunos años (de hecho, en 2017). Se comenzaron a llevar analítica de datos, no había que dar muchas vueltas, si el propósito era aumentar las posibilidades de éxito y el impacto de una educación emprendedora en ingenieros, era necesario medir y tomar evidencias. Las posibilidades de establecer indicadores, medir el desempeño docente, el impacto de las estrategias didácticas aplicadas, la mejora del rendimiento de los estudiantes era lo que seguía.

Las posibilidades de la analítica de datos en el aprendizaje son inmensas, esto ha facultado la mejor toma de decisiones y ha permitido observar lo que funciona y lo que no, ha permitido explorar nuevas metodologías, ha facultado estar al tanto de los conocimientos previos de los estudiantes, los perfiles que tienen, sus necesidades, los enfoques y métodos de estudio que usan, en fin, ha permitido construir este libro, comprendiendo mejor a los estudiantes, construyendo un perfil docente más adecuado, mejorando la calidad de la enseñanza, el aprendizaje y el asesoramiento.

Para transformar significativamente la práctica docente, es necesario asumir responsabilidades, tanto el docente como el estudiante tienen responsabilidades, incluso la institución las tiene. Cuando cada parte asume las que le corresponden y hace algo para mejorarlas, las posibilidades son infinitas. 
Cuando un docente replica su curso una y otra vez sin modificar ni los contenidos, ni las estrategias didácticas aplicadas, ni las actividades, y que, además, en su planeación del curso no considera a sus estudiantes, porque cree que no es necesario, los resultados serán desastrosos. En los tiempos que vivimos, y con el auge de las TIC (tecnologías de la información y la comunicación), TAC (tecnologías del aprendizaje y del conocimiento) y TEP (tecnologías para el empoderamiento y la participación), el contexto ha cambiado, y luego de la pandemia, es mayormente importante entender que no es posible continuar formando ingenieros de la misma forma.

Ha sido un privilegio escribir este libro, porque cuenta las experiencias vividas, suma evidencias de lo que funciona y lo que no, presenta un proyecto de programa integral que favorece la educación emprendedora en la formación de ingenieros.

Con el convencimiento de que la promoción del espíritu emprendedor estimula el desarrollo económico y la generación de empleo, es que se analizó cada uno de los elementos del marco teórico integrador que se describe en el capítulo primero. La importancia del emprendimiento en la formación de ingenieros, es el enfoque central del segundo capítulo, pues se considera un instrumento clave para incrementar las intenciones emprendedoras. El capítulo tercero, describe el modo en que la mentalidad emprendedora tiene impacto en la intención y la innovación, analizando las competencias que la favorecen y los recursos que se requieren. El capítulo cuarto, ahonda en la redefinición de la formación de ingenieros emprendedores, y el camino que se sugiere para transformar esta educación. Para cerrar con el capítulo quinto, que muestra una propuesta de programa integrador de emprendimiento con base a metodologías activas como el pensamiento de diseño, la construcción de 
equipos multidisciplinarios y el desarrollo de modelos de negocio aplicando la metodología CANVAS.

La discusión en torno al impacto de los programas de educación emprendedora es de gran interés y está profundamente analizado en el capitulado, algunos se centran en los contenidos y sus objetivos a nivel cognitivo y socioeconómico. Sin embargo, en este libro se ha buscado dar un mayor énfasis a la importancia del perfil del docente y su práctica, pues esta debe ser innovadora, debe mantenerse actualizada en actividades, contenidos y estrategias, debe centrarse en el estudiante, en aras de ser adecuada. De modo que la implementación exitosa de esta educación, depende en gran medida, de las intervenciones preparadas y bien planeadas del docente.

Este libro está centrado en la práctica docente bajo indicadores medibles, evidencias científicas, análisis de datos y percepciones de los estudiantes a lo largo de más de 3 años. $\mathrm{Ha}$ fortalecido la práctica docente de quienes han estado involucrados en el proyecto, y ha beneficiado a los estudiantes que han pasado por estas aulas. Se ha expuesto en un lenguaje sencillo y gráficamente descrito, para favorecer su aplicación. Es el deseo auténtico del autor, que esto sea de beneficio para todo aquel quien lo lea, ya sea docente o estudiante. 


\section{Bases conceptuales del emprendimiento}

El emprendimiento ha tomado mayor importancia y ha evolucionado con el paso del tiempo, para comprender cómo se ha desarrollado, es pertinente remitirnos un poco a su historia. Durante los primeros tres cuartos del siglo pasado, la importancia de las pequeñas empresas no se centraba en su eficiencia económica, sino más bien a su alcance social y político. En una era en la que las grandes empresas aún no ganaban la poderosa posición que alcanzarían durante el último cuarto del siglo pasado, las pequeñas empresas eran entonces, la principal proveeduría de empleo y, por ende, de estabilidad social y política de su tiempo. Académicos, como Chandler (1977), Galbraith (1967) y Schumpeter (1942), habían convencido a una generación de economistas, intelectuales, políticos y a la sociedad en general, que el futuro estaba en manos de las grandes corporaciones y que esas pequeñas empresas se desvanecerían como víctimas de sus propias ineficiencias al paso del tiempo.

Ciertamente el famoso modelo sueco de política económica vio la desaparición de la pequeña empresa como algo inevitable. La política en los Estados Unidos se dividió entre permitir la desaparición de las pequeñas empresas por motivos económicos, como un camino viable, por un lado, y preservando al menos algo parecido a un sector de la pequeña empresa por razones sociales y políticas por el otro lado. La pequeña empresa, se argumentó en su momento, era esencial para mantener la democracia estadounidense en la tradición político-social conocida hasta entonces (jeffesroniana). Sólo como ejemplo, podemos ver que la aprobación de la Ley Robinson-Patman en 1936 como enmienda a la Ley Antimonopolio Clayton de 1914 (Foer, 2001), tenía el propósito de prohibir la discriminación de precios y evitar la competencia desleal, aunque ha sido acusada de proteger a los competidores y no a la competencia (Bork, 1978), y la creación de la Administración de Pequeñas Empresas de los 
Estados Unidos, fue la respuesta para proteger a las pequeñas empresas menos eficientes y mantener su viabilidad. Lo que significa que los consensos existían en aquellos años; sólo en la necesidad de proteger a la pequeña empresa porque era importante para la economía.

En años más recientes, empero, la forma en que las pequeñas empresas importan terminó por cambiar. Ahora se considera que tienen un gran vínculo con el emprendimiento, contribuyendo no sólo a la generación de empleo, sino también a la estabilidad social y, por ende, a la política, pues coadyuba en términos de poder innovador y de competencia económica. Esto significa que se ha convertido en un bien social que debe mantenerse como un costo económico, pues existe nueva evidencia econométrica (Audretsch \& Thurik, 2000; Audretsch, Carree, Van Stel \& Thurik, 2002; Carree \& Thurik, 1999; Carree, Van Stel, Thurik \& Wennekers, 2002; Audretsch, Carree \& Thurik, 2001) que sugiere que el espíritu emprendedor es un determinante vital del crecimiento económico. Según Audretsch, Carree, Van Stel \& Thurik (2002), se incurrirá en un costo en términos del crecimiento económico por la falta de emprendimiento. El vínculo positivo y estadísticamente sólido entre el espíritu emprendedor y el crecimiento económico se ha verificado indiscutiblemente en un amplio espectro de unidades de observación, que abarca el establecimiento, la empresa, la industria, la región y el país. Por lo tanto, aunque la pequeña empresa siempre ha sido importante para los responsables de la formulación de políticas públicas, la forma en que se ha determinado su importancia ha evolucionado drásticamente con los años.

Frente a las crecientes preocupaciones sobre el empleo, el crecimiento y la competitividad internacional en el mundo de los mercados, los formuladores de políticas han respondido a esta nueva evidencia con un mandato que sugiere promover la creación de nuevas empresas, es decir promover el espíritu 
emprendedor a todos los niveles (Reynolds, Hay \& Camp,1999). Inicialmente las políticas públicas en países europeos tardaron en reconocer estos vínculos, pero desde mediados de la década de los años noventa han cobrado impulso rápidamente en la elaboración de enfoques adecuados, sin embargo, sin una precisa y organizada estrategia, no queda claro dónde y cómo se manifiesta el espíritu emprendedor, por ello la variación de respuestas en el tema.

\subsection{Evolución de la investigación en emprendimiento}

Es un hecho de la vida que todo cambia y evoluciona. El emprendimiento no es diferente, y los emprendedores exitosos son aquellos que aprenden y aceptan esos cambios y se adaptan. Esto puede sorprender, ya que la definición básica de emprendedor no ha cambiado mucho al paso de los años, sigue siendo esencialmente una persona que inicia un negocio a pesar de los riesgos financieros implícitos, con la esperanza de obtener rendimientos superiores al promedio y sobrevivir en el mercado. Pero, si bien, la definición no ha cambiado, el entorno empresarial y cultural en general sí lo ha hecho como pudimos advertirlo en párrafos anteriores.

La noción del individuo que, a menudo en contra de grandes obstáculos, desarrolla e implementa un concepto único e innovador aprovechando una oportunidad, no es nuevo. No obstante, el espíritu emprendedor en el siglo XXI tiene sus características distintivas (Morris, 1998), aunque hay más actividad emprendedora en general, mucho se debe a que las barreras de entrada al espíritu emprendedor son generalmente más bajas en la actualidad de lo que han sido históricamente. El dinero está más disponible para los emprendimientos, existen diversos financiamientos lo que los hace más abundantes, los riesgos han ido disminuyendo además que son menos severos, en general los emprendedores en la actualidad pueden hacer mucho más con menos, o se puede pensar en términos de los recursos que realmente posee y 
controla. Por otro lado, también son más capaces de iniciar y hacer crecer un negocio de proporciones considerables en un periodo relativamente corto. Y todo esto porque vivimos en la era del espíritu emprendedor, definido como una actividad que va en aumento y que representa un cambio fundamental en las formas de pensar los negocios, la vida y los entornos en los que las personas y las empresas funcionan, comparado con los antecedentes históricos, como se ha visto.

El punto central en todo esto es la responsabilidad individual y la elección personal, en el microcosmos, más que en el macrocosmos, donde los enfoques son de abajo hacia arriba y no viceversa, y las empresas pequeñas en alianza unas con otras, pueden superar a grandes organizaciones que dependen del mercado a gran escala y del control (Miner, 2000; Morris, 1998; Timmons, 1999). Términos como devolución, reducción, descentralización y empoderamiento intentan fortalecer este movimiento en la evolución, y se dirige hacia la diversidad del individuo.

La influencia generalizada del espíritu emprendedor ha tenido implicaciones tanto para aquellos que inician empresas, como para los directivos de organizaciones ya establecidas. Aunque las empresas ya constituidas han encontrado diversidad de formas en las que el espíritu emprendedor se proyecta (por ejemplo, la investigación y desarrollo [I+D] tradicional, nuevas divisiones de riesgo, nuevos equipos de desarrollo empresarial, start ups internas, entre otros). Esta evidencia sugiere entonces que, las organizaciones que aprenden a facilitar un ambiente de emprendimiento al interior y en sus diversas formas, son más competitivas y se desempeñan mejor que aquellas que no lo hacen (Zahra \& Covin, 1995). Por otro lado, los directivos de empresa se involucran cada vez más en la adquisición de organizaciones emprendedoras, perdiendo posición de mercado frente a ellas, a escindirlas, a dividirlas, a obtener licencias de ellas, creando nuevas empresas a través de acuerdos o convenios con exempleados 
y participando con ellos en nuevas joint ventures (empresas de riesgo compartido). En consecuencia, es importante que los directivos de todo nivel comprendan cómo y por qué se produce el fenómeno del emprendimiento.

Los intentos en la literatura por definirlo y estudiarlo de manera sistemática son bastante recientes. Por lo tanto, si bien el término "espíritu emprendedor" se ha usado por más de trescientos años, como disciplina, aún se encuentra en su etapa de desarrollo. Expertos y especialistas continúan debatiendo cuestiones tan fundamentales como la definición de espíritu emprendedor, la naturaleza del emprendedor, sus características, las unidades de análisis que se han de estudiar para determinarlo, los indicadores de medida, el propósito de dichas investigaciones, las condiciones ambientales $\mathrm{O}$ ecosistemas que lo promueven, entre otros (Amit, Glosten \& Muller, 1993), es decir, aún existen temas en donde los consensos no parecen divisarse.

El volumen de investigaciones sobre emprendimiento ha aumentado significativamente en la última década, pero muchas continúan notando una falta de desarrollo teórico, pues se ha limitado al desarrollo de marcos conceptuales útiles, sin lugar a duda, pero, con una ausencia de rigor en algunas de las investigaciones, y una incapacidad para extraer generalizaciones del trabajo empírico que se analiza (Ratnatunga \& Romano, 1997; Shane, 2000). De hecho, gran parte de lo que constituye el estudio del emprendimiento en la actualidad se ha tomado de otras disciplinas o se ha adaptado de ellas.

A continuación, se presenta el análisis de una serie de marcos teóricos que explican el emprendimiento tal como se manifiesta en la literatura del siglo XXI. El propósito es generar una discusión de perspectiva integradora, que a su vez reconozca la importancia que el espíritu emprendedor ha generado, particularmente en las últimas dos décadas por investigadores, académicos, formuladores de políticas 
públicas, directivos de empresa, instituciones financieras y el público en general.

- Cada vez es más aceptado el concepto de que el emprendedor y los dominios de gestión no son mutuamente excluyentes, pero que se superponen. El primero es mayormente impulsado por las oportunidades, mientras que el segundo es impulsado por la conservación de recursos (Wang, Yueh \& Wen, 2019; Stewart, Watson, Carland \& Carland, 1999).

- La disponibilidad de financiamiento de riesgo, incluyendo el capital de riesgo, el financiamiento de inicio, microfinanzas y diversas técnicas de financiamiento innovadoras, surgieron en un nivel sin precedentes durante la década de los años 90, alimentando tanto a la acelerada germinación de nuevos emprendimientos como a una extensa investigación académica (Amit, Brander \& Zott, 1998: Fried, Burton \& Hisrich, 1998).

- El emprendimiento en grandes organizaciones o también conocido como intraemprendimiento, así como la necesidad de emprendimientos culturales ha tomado mucha atención en los últimos años (Busenitz \& Barney, 1997; Kuratko \& Hornsby, 1996; Zahra \& Covin, 1995).

- Se han identificado estrategias de entrada empresarial que muestran algunos denominadores comunes importantes, como el tema de las compensaciones (Ireland \& Hitt, 1999).

- La gran variedad entre los diversos tipos de emprendedores y los métodos que han empleado para lograr el éxito, han generado líneas de investigación orientadas a descubrir los aspectos psicológicos que impactan en el éxito futuro de los emprendimientos (Stam \& Van Stel, 2011; Aulet \& Murray, 2013; Hechavarría \& Welter, 2015; Baron, 1998).

- Los riesgos y las compensaciones asociados a un emprendimiento, particularmente su naturaleza altamente 
demandante y en ocasiones estresante, han forjado gran interés en el campo de la investigación buscando información relevante para los emprendedores (Krueger, Kickul, Gundry, Verma \& Wilson, 2009; McGrath, MacMillan \& Scheinberg, 1992).

- Han surgido emprendimientos generados desde o para minorías como por ejemplo las mujeres, y se han incrementado sin precedentes. Esto ha generado líneas de investigación que han encontrado que los obstáculos y dificultades que estos enfrentan son diferentes de otros emprendimientos (Ramadani, Gërguri-Rashiti \& Fayolle, 2015; Shim \& Eastlick, 1998).

- El espíritu emprendedor es universal, a juzgar por el enorme crecimiento e interés por el emprendimiento alrededor del mundo durante los últimos años (Hall, 2015; D 'Mello, 2019; Ang \& Hong, 2000; Kim \& Park, 2014; Caruana, Moris \& Vella, 1998).

- Se ha demostrado que las contribuciones económicas y sociales de los emprendimientos y las empresas de nueva creación, son inmensamente desproporcionadas en cuanto a la generación de empleo, la renovación económica y la innovación, si se compara con las 500 empresas más grandes del mundo (Van Stel, Carree \& Thurik, 2005; Dennis, 1993).

- La educación emprendedora representa un área de crecimiento acelerado en escuelas de negocio y de ingeniería. El número de escuelas que tienen en sus programas educativos cursos de formación de emprendedores ha pasado de dos docenas a más de 700 en 20 años, siendo muchos de ellos programas transversales, y fuertemente fundamentados para promover el espíritu emprendedor entre sus estudiantes (Momete, 2015; Katz, 2003; Laukkanen, 2000; Plaschka \& Welsch, 1990; Vesper \& Gartner, 1997). 
A pesar de las tendencias evidenciadas, o quizás debido a ellas, el campo de investigación del espíritu emprendedor ha evolucionado de una manera algo desconectada y aleatoria. Por ejemplo, Ratnatunga y Romano (1997) realizaron un análisis de 725 artículos y 16,720 citas en seis revistas líderes en el tema del emprendimiento y aunque fueron capaces de identificar los temas principales y algunas líneas de investigación claramente definidas, ellos caracterizaron el campo del espíritu emprendedor como un "modelo de bote de basura" en el que estas áreas temáticas reflejan una colección suelta de ideas en oposición a una estructura coherente con un paradigma intelectual compartido.

Poco de lo que se publica y encuentra en la literatura se posiciona dentro de un paradigma teórico en particular, tampoco puede considerarse que la mayoría de los trabajos publicados y analizados intenten formular algún modelo teórico. Parece entonces que se tienen hechos aislados, exitosos sí, pero no ratifican principios generalizados que puedan replicarse en un modelo teórico, pues muchas de las ideas más interesantes sobre el espíritu emprendedor son aún oscuras o difíciles de estudiar empleando técnicas tradicionales de estudio de casos, encuestas a gran escala o análisis secundarios de conjuntos de datos comerciales y gubernamentales (MacMillan \& Katz, 2002). El espíritu emprendedor se ha desarrollado como una disciplina de negocios tomando prestados y adaptando conceptos teoréticos de campos como la sociología, la psicología, la antropología, el marketing, la gestión empresarial, las finanzas, el comportamiento organizacional y la ingeniería (Morris, Kuratko \& Schindehutte, 2001).

Si las investigaciones en torno al emprendimiento han de lograr los resultados que se han obtenido en otras ciencias, el campo debe comenzar a desarrollar sus propios marcos teóricos cohesivos, replicables y verificables. Shane (2000) señaló desde hace 20 años que, en lugar de explicar y predecir 
un conjunto único de datos empíricos, el fenómeno del emprendimiento se había convertido en una etiqueta amplia bajo la cual se albergaban una mezcla de investigaciones sin un hilo conductor estructurado y sistemático. Lo que parece constituir un eje común entre las investigaciones recientes del emprendimiento son aspectos aislados del entorno (como, por ejemplo, pequeñas empresas o nuevas empresas), en lugar de un dominio conceptual único y transversal. Como resultado de esto, se complica el identificar contribuciones diferenciadas, socavando la legitimación del campo. Por lo tanto, para que el emprendimiento como campo de las ciencias sociales tenga utilidad, debe contar con un marco conceptual particular y sistemático.

En la actualidad, ante el volumen de investigaciones en el campo del emprendimiento, es posible construir un marco teórico integrador del proceso, donde se pueden identificar 6 grandes áreas con 14 rubros clave que constituyen una imagen más completa e integrada como se verá más adelante.

\subsection{Propuesta de un marco teórico para el emprendimiento}

Merriam-Webster (2004) define un marco como una estructura conceptual básica (a partir de ideas), siendo esta una lógica y sistemática forma de organizar los fenómenos. Sirve también para identificar las variables o componentes relevantes que constituyen algún área temática de interés, mientras que también brindan orden o estructura a estos componentes en términos de las formas en que se relacionan entre sí. Un marco conceptual le brinda a un directivo un plano que convierte lo abstracto en orden, le permite priorizar las variables o problemas y le ayuda a identificar las relaciones para encontrar soluciones. Esto les brinda a los expertos la base sobre la cual se puede formular una hipótesis, desarrollar modelos y construir y probar teorías. 
Los marcos teóricos pueden ser explicativos o predictivos, pueden ser descriptivos o normativos. En el mejor de los casos, un buen marco teórico puede tener implicaciones importantes en los resultados organizacionales (Magistretti, Dell'Era \& Doppio, 2020; Miller, 2011; Sánchez, 1993). Son conceptuales en su naturaleza, aunque es posible tratar un marco como una teoría siempre que posteriormente se someta a pruebas empíricas rigurosas (Doty \& Glick, 1994). Los marcos pueden ser desarrollados a priori o como respuesta a evidencia empírica. Una vez desarrollados, pueden sugerir nuevas categorías o subclases del fenómeno de interés.

Prácticamente todos los campos del espectro intelectual contienen marcos. Como ejemplo, podemos considerar al marketing como disciplina. En la medida en que el marketing pueda definirse como el conjunto de actividades que faciliten las transacciones de compra y venta, la pregunta entonces se centra en identificar esas actividades. Por supuesto, el conjunto de actividades que posiblemente podrían causar que una transacción suceda son ilimitadas, y esos límites sólo se encuentran ajustados a la creatividad del especialista en marketing. El problema es encontrar una manera de organizar todas estas posibilidades de un modo organizado y fácil de gestionar para ser significativo. Para ello, continuando con el ejemplo, se han promulgado las 4 p's que constituyen una mezcla de marketing típico (marketing mix como se conoce comúnmente en la jerga), siendo éstas el precio, el producto, la promoción y la plaza (Londhe, 2014), y que, a través de este marco o lógica, se puede categorizar el abanico de posibilidades.

Al hacer un balance de lo que se sabe sobre el campo del emprendimiento, se han elaborado varios marcos teóricos, algunos de los cuales han logrado una aceptación bastante amplia. Lo más notable es la variedad de marcos o tipologías utilizadas para distinguir entre los diferentes tipos de emprendedores (Aulet \& Murray, 2013; Stam \& Van Stel, 
2011; Diandra \& Azmy, 2020; Hechevarría \& Welter, 2015). Como ejemplo, analicemos el caso de Miner (2000), quien distingue los tipos de personas que hacen emprendimientos efectivos usando un marco teórico de cuatro vías en psicología, y ha encontrado que esta tipología se puede ampliar para incluir la fase de inicio de la empresa además de la etapa de crecimiento y rendimiento de la organización. Además, establece que este marco teórico es útil para predecir medidas de apego emprendedor y la habilidad de desarrollo de un buen Plan de Negocio. Como tal, su investigación proporciona apoyo a la teoría básica sobre la personalidad emprendedora.

Para comprender el fenómeno del espíritu emprendedor, es necesario primero establecer un marco teórico integrador del proceso de emprendimiento. Para ello, se analizaron los distintos marcos existentes, el progreso y evolución que han tenido con el objetivo de establecer una tipología holística lo suficientemente sólida que respalde los esfuerzos para construir teorías y estructuras teoréticas irrefutables y replicables de emprendimiento. El propósito, por lo tanto, no es expandir la teoría, sino desarrollar una descripción general sistemática de los elementos críticos aplicables para explicar y predecir la actividad emprendedora.

\subsubsection{Un marco teórico integrador}

Para efectos de esta investigación se han identificado 14 rubros clave dentro de 6 grandes áreas que capturan de forma integradora, el patrón, el ritmo y la sincronización del proceso de emprendimiento en diversas contextos y condiciones. Es importante destacar que cada uno de ellos aborda un aspecto sin el cual el emprendimiento no pudiera ocurrir. El conjunto colectivo captura el fenómeno general de emprendimiento, los elementos son internamente consistentes y cada uno tiene una amplia aplicabilidad probada con el tiempo. 
El espíritu emprendedor es el resultado de las interacciones entre una serie de variables. El marco teórico representado en la Figura 1, captura las seis principales variables o grandes áreas que son primero, el proceso mismo de emprendimiento; segundo, el emprendedor; tercero, el ecosistema; cuarto, los recursos; quinto, el concepto de negocio; y sexto, el contexto organizacional.

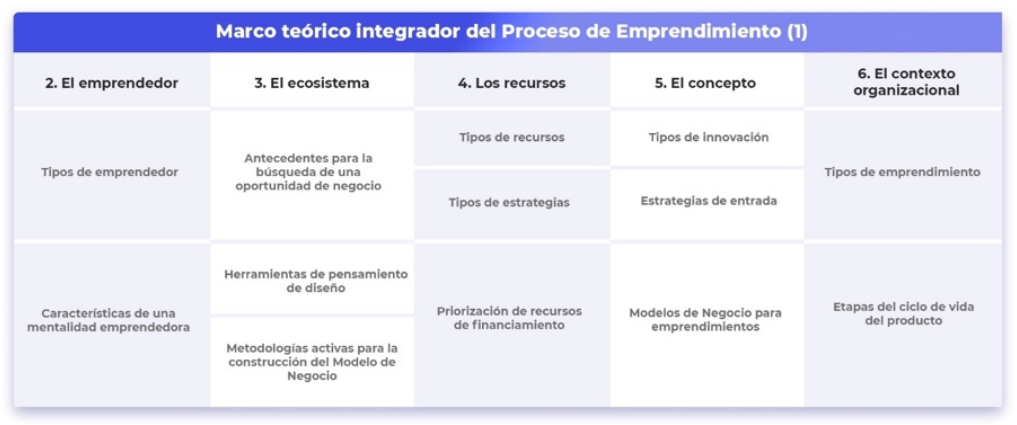

Figura 1. Marco teórico integrador del Proceso de Emprendimiento. Fuente: Adaptado de: Morris, M. H., Kuratko, D. F., \& Schindehutte, M. (2001). Towards integration: understanding entrepreneurship through frameworks. The international journal of entrepreneurship and innovation, 2(1), 35-49.

\section{A. El proceso de emprendimiento}

Puede advertirse en la Figura 1, que el proceso es el primero de las seis principales variables y se encuentra englobando las demás áreas por ser el centro del que parten los demás. Es generalmente aceptado por los expertos y académicos que el emprendimiento implica un proceso, y específicamente, el de crear valor al diseñar un paquete único de recursos para aprovechar una oportunidad y atender una necesidad (Moroz, \& Hindle, 2012; Baron \& Shane, 2007; Kuratko, 2016).

\section{B. El emprendedor}

La persecución del proceso que se ha visto en el punto anterior requiere de un emprendedor, que se vuelve la segunda variable, esta persona puede haber originado la idea 
o concepto de negocio o no, pero es quien persevera para adaptarlo e implementarlo y alcanzar algún grado de éxito o fracaso.

La literatura de investigación sobre el emprendedor se ha desarrollado en la identificación de las características sociológicas y psicológicas de estos individuos (Diandra \& Azmy, 2020; Nair \& Pandey, 2006; Giacomin, Janssen, Guyot \& Lohest, 2011). La evidencia sugiere que existen diversos tipos de emprendedor, que es uno de los dos elementos dentro de esta variable, y que estos no necesariamente nacieron con talentos que le predisponen genéticamente al emprendimiento, como se consideró hace muchos años (Daley, 2013) y que, por el contrario, algún nivel de potencial emprendimiento reside en cada individuo, por supuesto, dependiendo de este que lo desarrolle. El segundo elemento de esta variable son las características de una mentalidad emprendedora (Sahut \& Peris-Ortiz, 2014; Gartner, 1990).

\section{El ecosistema}

La tercera variable se refiere al ecosistema emprendedor, que engloba el entorno que le rodea, donde se encuentran las condiciones particulares para que el emprendedor pueda echar a andar su Modelo de Negocio (Wang, Ali, Kim, Lee \& Hernandez-Perlines, 2021; Alexoaei, 2020; Gieure, del Mar Benavides-Espinosa \& Roig-Dobón, 2019; Spigel \& Harrison, 2018). En el perfeccionamiento de las habilidades o talentos del emprendedor, dentro de esta variable se analizan tres importantes elementos, el primero se refiere a los antecedentes que el emprendedor tiene para la evaluación de una oportunidad, el segundo elemento tiene que ver con las metodologías activas para la construcción del Modelo de Negocio, y el último elemento se refiere a las herramientas de pensamiento de diseño que el emprendedor puede emplear para construir su modelo. 


\section{Los recursos}

El Modelo de Negocio de un emprendimiento representa una combinación única de recursos, que es la cuarta variable, y que dan como resultado un producto nuevo o mejorado, un nuevo servicio o proceso, una nueva estructura organizacional o la penetración de un mercado hasta ese momento desconocido. Por ello se considera que el Modelo de Negocio es un paquete de valor total, consecuentemente, elementos como el enfoque de precios, los recursos, las estrategias de entrada o la priorización de recursos de financiamiento son indispensables para que el modelo sea exitoso (Marshall, Meek, Swab \& Markin, 2020).

\section{E. El concepto}

La capacidad de hacer coincidir el Modelo de Negocio, como concepto que es la quinta variable, con la oportunidad, es influenciada por los recursos que el emprendedor es capaz de tener al alcance o reunir. Si bien los recursos financieros tienden a recibir la mayor atención de parte de las investigaciones en la literatura, las habilidades para identificar y adquirir el talento humano experto, los tipos de innovación, las estrategias de entrada y la elección del adecuado modelo de negocio, suelen ser más críticos en el éxito o fracaso de un emprendimiento.

\section{F. El contexto organizacional}

La mentalidad emprendedora requiere, además, una estructura y contexto organizacional, que es la sexta variable. Este contexto tiene implicaciones para el tipo de emprendimiento, así como el momento de esta (Yi, 2021). Ejemplos de estos contextos puede ser si se abre una franquicia, si el negocio nace en la cochera de la casa del emprendedor, si en un coworking, qué tipo de sociedad lo opera, entre otros. 


\subsection{2 $\mathrm{El}$ proceso de emprendimiento}

El proceso de emprendimiento puede observarse en el Figura 2, y lo describe en un marco de seis etapas. Las primeras dos, se corresponden con: identificar una oportunidad y desarrollar el Modelo de Negocio como concepto, representan el proceso de ideación del proyecto, donde el emprendedor está intentando identificar patrones o fuerzas en su entorno que le representen el potencial de ganancias y le permitan desarrollar un medio creativo para capitalizar ese potencial.

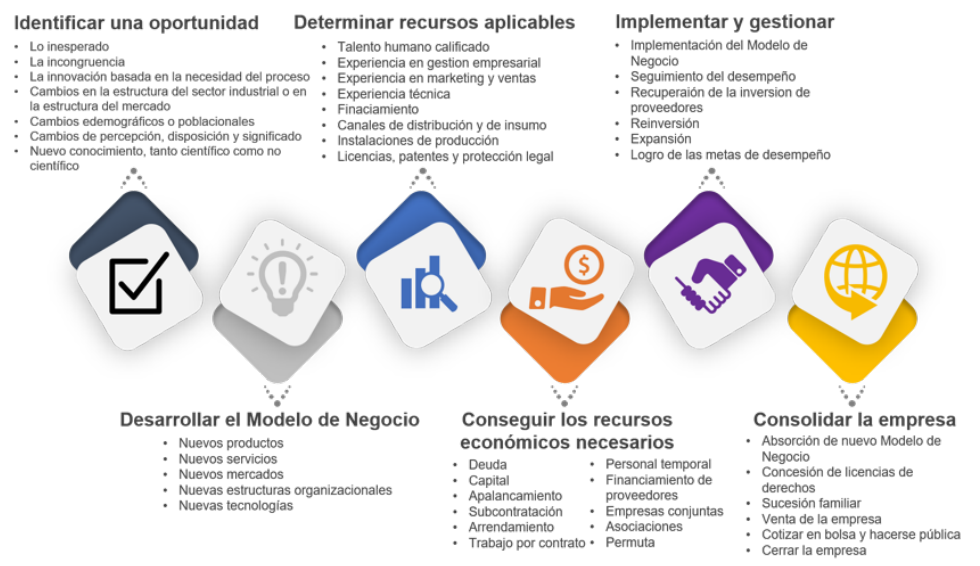

Figura 2. Etapas del Proceso de Emprendimiento.

Fuente: Elaboración propia con información de la investigación.

La Figura 2 representa el proceso de emprendimiento que consiste en seis etapas. Las cuatro etapas restantes se refieren a la implementación, de modo que el emprendedor evalúa y adquiere los recursos necesarios, ejecuta el concepto de Modelo de Negocio, gestiona el mismo, y finalmente consolida la empresa. Si bien la creatividad es quizás la etapa más asociada en la literatura en el inicio del proceso y especialmente en el desarrollo del Modelo de Negocio como concepto (Chen, Chang, Wang \& Chen, 2017; Dimitriadis, Anastasiades, Karagiannidou \& Lagaki, 2017), son las etapas 
posteriores las que requieren mayor creatividad innovadora y un comportamiento de mayor riesgo para el emprendedor.

La Figura 2, que se acaba de analizar, también provee ejemplos de decisiones clave para el emprendedor, así como variables o alternativas que entran en juego en cada una de las etapas del proceso. De lo más destacable es la identificación de oportunidades. Por lo general se considera que las oportunidades para emprendimientos deben surgir de innovaciones que rompen paradigmas, cuando bien pueden derivar de cambios demográficos o frustraciones no resueltas, o variables incorrectas en mercados saturados, para ello es necesario que el emprendedor desarrolle un talento para observar y estar abierto a ellas.

\subsubsection{Tipos de emprendedor}

Cuando se analiza la variable "emprendedor", surge la pregunta ¿quién es el emprendedor? Existe suficiente literatura sobre los tipos de emprendedores, mucho más que de otras de las variables del proceso de emprendimiento (Miller, 1983; Stam \& Stel, 2011; Aulet \& Murray, 2013). Existe evidencia que sugiere que los emprendedores tienen ciertas características en común, como mayores niveles de motivación hacia el logro, el autocontrol y una mayor tolerancia al fracaso, aunque también se encuentra evidenciado que no existe sólo un tipo de emprendedor (Bird, 2019), la clasificación de los diversos tipos de emprendedor es influenciada no sólo por la innovación, sino por la motivación, que bien puede ser el deseo de liderazgo o la búsqueda de soluciones a problemas existentes.

Las investigaciones coinciden en que los emprendedores son quienes convierten las ideas audaces en realidad. Crean puestos de trabajo y contribuyen a la economía, sin embargo, existen diferentes tipos de emprendedores y cada uno tiende a elegir su propio camino de éxito en función de su 
personalidad, sus habilidades y el entrono que les rodea pues les brinda diferentes recursos.

Si bien un individuo emprendedor puede caer en más de un tipo o categoría, el marco que se presenta en la Figura 3 sugiere la coincidencia entre el tipo de emprendedor y el arquetipo de emprendimiento que persigue. Además, la comprensión del modelo de emprendimiento puede decir algo sobre la necesidad de control y, por consiguiente, la estructura de propiedad y gestión que prefiere a medida que evoluciona la empresa. Del mismo modo, este marco tiene implicaciones para el énfasis relativo al crecimiento, la forma en que se financia la empresa, el tipo de mercado en los que la empresa debe entrar, y una variedad de otras decisiones estratégicas que tienen relación directa con el tipo de emprendedor.

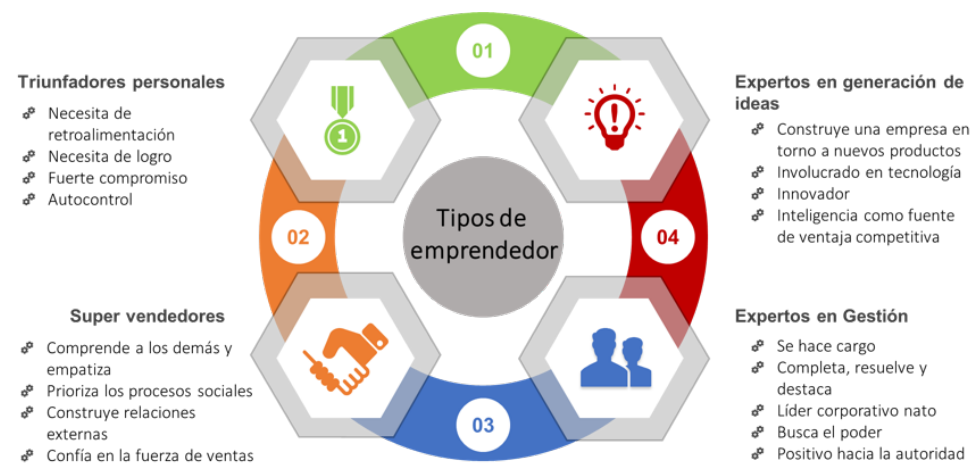

Figura 3. Los tipos de emprendedor.

Fuente: Tomado de los cuatro tipos de emprendedor con base en una adaptación de Miner, J. B. (2000), 'Testing a psychological typology of entrepreneurship using business founders', Journal of Applied

Behavioral Science, Vol 36, No 1, pp 43-70.

\subsubsection{Mentalidad emprendedora}

Dentro de la variable del emprendedor en el proceso de emprendimiento, el primer elemento a analizar es la mentalidad emprendedora, misma que indica una forma de pensar sobre el negocio y las oportunidades que capturan 
beneficios aún en la incertidumbre. Senges (2007) retrata a la innovación como la búsqueda enérgica de oportunidades que facilita acciones encaminadas a aprovecharlas. Por lo que establecer una mentalidad emprendedora es importante para mantener la competitividad de las organizaciones económicas y el estilo de vida socioeconómico de la población, a través de la creación de valor y la generación de empleo.

Este panorama fomenta que los partidarios de la innovación puedan establecer emprendimientos con nuevas y valiosas ideas, con facilidad para dotarlas de recursos y desarrollar sus proyectos en una cultura y contexto generadores $y$ motivantes. Existen estudios que han establecido la importancia de promover el emprendimiento en las juventudes (Fayolle, Gailly \& Lassas-Clerc, 2006), igualmente sobre la necesidad de formarlos con una mentalidad emprendedora a través de una educación en emprendimiento, promover que descubran sus talentos, que sean más creativos que busquen la innovación atendiendo problemas reales y observando su entorno, a fin de que construyan aprovechando oportunidades.

La perspectiva de promover la educación emprendedora concuerda con lo establecido por McGrath y MacMillan (2000), respecto a que el futuro será exitoso cuando existan estrategas que exploten la mentalidad emprendedora con experiencia y preparación, que tengan la capacidad de sentir, de actuar y de movilizarse rápidamente, incluso bajo condiciones de incertidumbre porque saben lo que se debe hacer. Los mismos autores afirman, como puede advertirse en la Figura 4, que los emprendedores capturan los beneficios de la búsqueda y explotación de las oportunidades con alto potencial, pues las persiguen con disciplina y de manera sistémica, centrándose en la ejecución y aprovechando los talentos de quienes participan. La figura 4 representa las cinco características de una mentalidad emprendedora. 


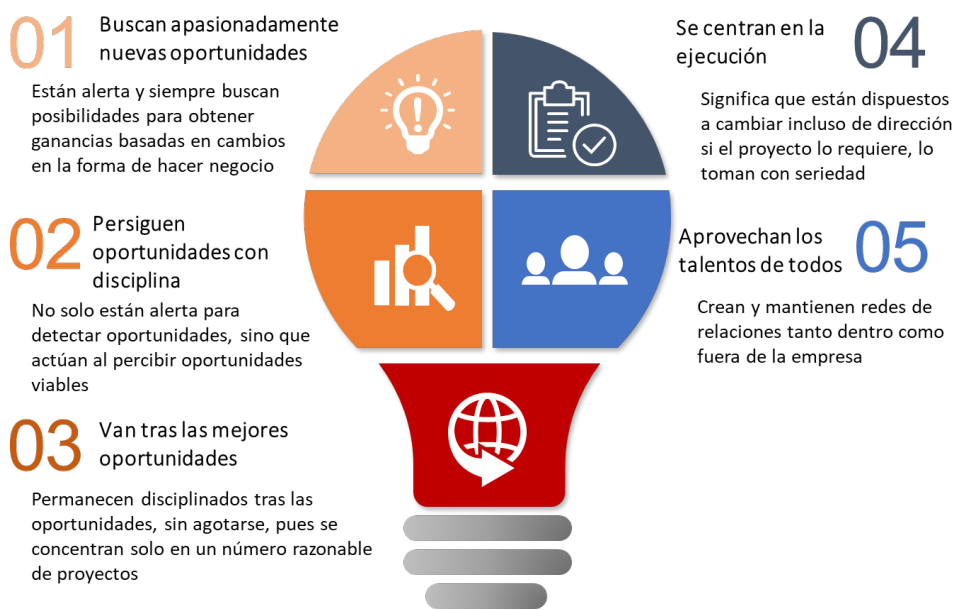

Figura 4. Características de una mentalidad emprendedora.

Fuente: Adaptación de McGrath, R. G., \& MacMillan, I. C. (2000). The entrepreneurial mindset: Strategies for continuously creating opportunity in an age of uncertainty (Vol. 284). Harvard Business Press.

En opinión de Mitchell, Smith, Seawright y Morse (2000), la mentalidad emprendedora de los estudiantes después de haber tomado un curso formal de educación emprendedora, son capaces de aplicar diversas técnicas de autoconocimiento para poder identificar y desarrollar sus talentos y mentalidad emprendedora. Tal reconocimiento es importante pues sugiere que la investigación en emprendimiento debiera tener un propósito en esa dirección, fomentar la mentalidad emprendedora mediante educación y aprendizaje.

En la perspectiva de Rugtvedt (2006), la educación emprendedora se considera un proceso permanente de aprendizaje que fomenta el desarrollo de cualidades y habilidades para permitir a un estudiante sobrevivir en el mundo de los negocios con un proyecto emprendedor exitoso. Esta relación positiva entre la educación emprendedora y la creación de empresas debe ser promovida para maximizar el rendimiento de los nuevos emprendimientos. 
La educación emprendedora es una estrategia para reforzar una capacidad del individuo para ver y explotar oportunidades con una perspectiva económica, social y cultural, y que debe ser empleada como una maniobra para construir emprendedores, organizaciones y sociedades con mejores perspectivas de vida.

\subsubsection{Identificación de una oportunidad de negocio}

Continuando con el marco teórico integrador del proceso de emprendimiento, y ahora nos adentramos en la variable el ecosistema y los elementos dentro de esta. La mentalidad emprendedora es el primer elemento que se analiza dentro de esta variable. se basa fundamentalmente en la identificación y aprovechamiento de las oportunidades de negocio. Por lo que el reconocimiento de esta oportunidad de negocio constituye la sustancia de la investigación en emprendimiento, aportando un signo característico a este campo de estudio (Shane \& Venkatamaran, 2000).

Debido a su importancia, es necesario comenzar con la propia conceptualización a fin de sustentar de forma correcta la investigación. En opinión de Casson (2003), la oportunidad es aquella situación en la que nuevos productos, servicios, materias primas y modelos organizativos pueden ser lanzados al mercado a un precio superior de su costo promedio de producción. Es decir, que para que una oportunidad sea considerada como tal, es necesario que ésta genere rentabilidad, lo que según Singh (2001), limita las posibilidades de investigación empírica al tema, pues para que exista este análisis, debiera ser analizada desde las primeras etapas del proceso, antes incluso de que el emprendimiento sea lanzado y genere dividendos, por lo que esto complica un estudio sistematizado.

Para efectos de esta investigación, consideraremos una oportunidad como un conjunto favorable de circunstancias que crean una necesidad o una apertura de posibilidades para 
generar rendimientos. La pregunta concluyente entonces es la determinación de qué es lo que hace como buena a una oportunidad de negocio. En la Figura 2, se analizaron las etapas del proceso de emprendimiento, donde en la primera se encontraron las ocho diferentes áreas donde puede encontrarse una oportunidad de negocio.

Timmons, Smollen y Dingee (1985) consideran cuatro conjuntos de situaciones que se presentan al analizar una oportunidad, y que se describe e la Figura 5, donde cada una consta de una serie de consideraciones.

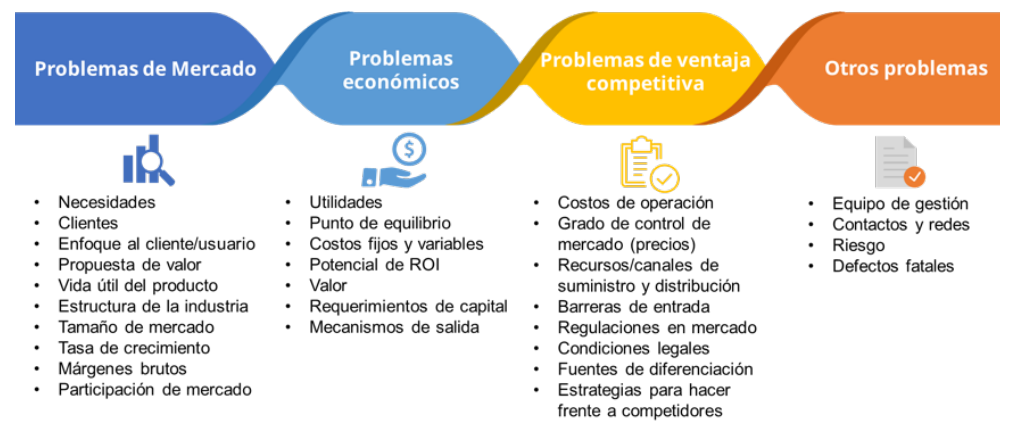

Figura 5. Consideraciones en la identificación de una oportunidad de negocio.

Fuente: Adaptado de Timmons, J., Smollen, L., \& Dingee, A.L. (1985).

New venture creation (2nd ed). Homewood, Irwin.

El primer conjunto de problemas o dificultades que se presenta se refiere al mercado, incluida la claridad con la que se identifica la necesidad real de los clientes, el tamaño del mercado y la tasa de crecimiento de este, así como la estructura de la industria. El segundo conjunto se relaciona con los problemas económicos que pueden presentarse al emprendedor, como son el punto de equilibrio, la tasa de retorno de la inversión (ROI) y los requerimientos de capital. En el tercer conjunto, se consideran las cuestiones de ventaja competitiva, que incluyen consideraciones como el control de precios en el mercado, el poder de los proveedores, las fuentes de diferenciación y las barreras de entrada al mercado. Y en 
último caso, Timmons et al. (1985) consideran en un conjunto los demás problemas que pudiera enfrentar el emprendedor, que incluyen aquellos como el desarrollo y aprovechamiento de redes de contactos.

Lo interesante del análisis de una oportunidad son las combinaciones que pueden surgir de entre las diversas variables como criterios en la toma de decisiones. Por lo que una mejor oportunidad se asocia, por ejemplo, con clientes que no han establecido lealtad con ningún competidor, una industria bien segmentada en la que se pueden crear barreras de entrada a nuevos competidores, un ROI potencial mayor al 25\% anual, requisitos de capital que sean modestos y la disponibilidad de sustanciales fuentes de diferenciación.

\subsubsection{Pensamiento de diseño como herramienta para el emprendedor}

A medida que se avanza en el marco teórico integrador, es momento de analizar el concepto de pensamiento de diseño, el cual es complejo y ha sido documentado al paso de los últimos años puede observarse en la Figura 6, donde vienen descritos los diversos conceptos de pensamiento de diseño según autor y año, mismos que serán ampliamente descritos en capítulos posteriores, sin embargo, de manera general, se considera un estilo de pensamiento o el estudio de procesos cognitivos que posteriormente se manifiestan en la acción de diseño, incluso es generalizada la percepción de que la aplicación del pensamiento de diseño es la capacidad de combinar empatía con creatividad, así como, racionalizar para analizar y adecuar soluciones a problemáticas y necesidades particulares. La figura 6 representa una línea de tiempo con los conceptos por autor.

Dentro del diálogo académico (Dunne \& Martin, 2006; Linton \& Klinton, 2019; Von Kortzfleisch, Zerwas \& Mokanis, 2013; Daniel, 2016), se ha descrito y reflexionado sobre cómo piensan los diseñadores, incluso algunas de las 
investigaciones han encontrado que los diseñadores se enfrentan a problemas mal definidos y que por lo tanto dentro de la creatividad en el diseño de soluciones deben iniciar con el correcto levantamiento de las necesidades para la reestructuración del propio problema a fin de dar una solución adecuada. Por lo que entonces, la definición del problema es parte de la habilidad profesional que los diseñadores deben desarrollar.

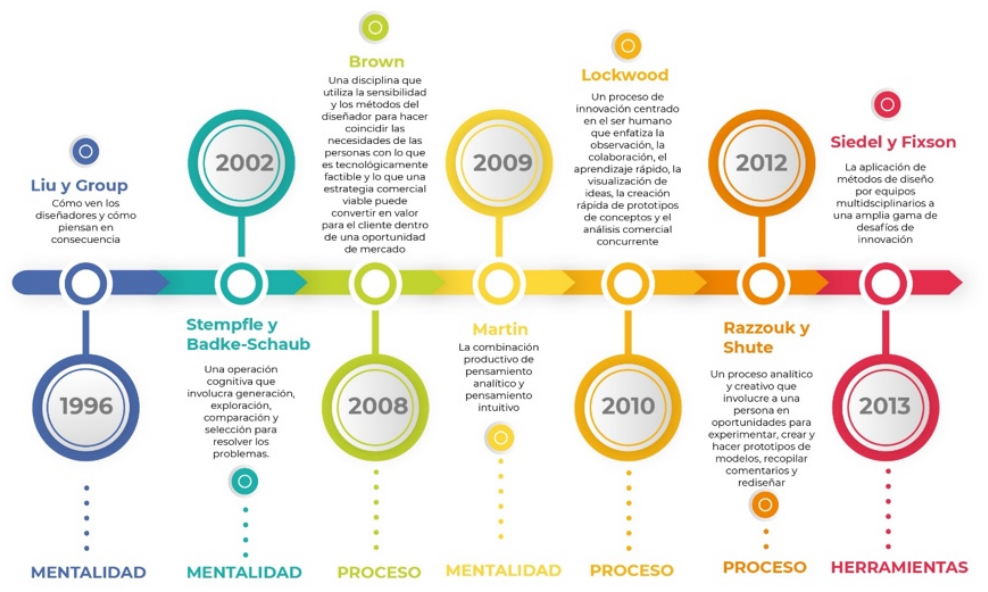

Figura 6. Conceptos de pensamiento de diseño por autor y año. Fuente: Elaboración propia con información de las fuentes consultadas.

Más recientemente el pensamiento de diseño se ha relacionado con la innovación, y la discusión sobre su aplicación está muy extendida tanto en los círculos de diseño, como en aquellos de ingeniería y de gestión. Este cambio de enfoque, fuertemente influido por la tendencia de la propia industria y respaldada por IDEO (una firma consultora de innovación en diseño) y la Escuela D de Stanford (Instituto de Diseño de la Universidad de Stanford), quienes conceptualizaron el pensamiento de diseño como una forma específica en la que los no diseñadores evalúan y emplean métodos de diseño para la solución de problemas complejos 
con propuestas de solución creativas y empáticas (JohanssonSköldberg, Woodilla \& Çetinkaya, 2013).

A medida que el pensamiento de diseño se adapta al panorama empresarial, las universidades han buscado mantener el ritmo enseñando y apoyando enfoques multidisciplinarios para la resolución de problemas. Algunas de las escuelas que lo aplicaron en primera instancia fueron el Instituto de Diseño de Stanford y el Instituto Hasso-Plattner en Postdam, Alemania. Estas escuelas educan a sus estudiantes de diversas disciplinas como ingeniería, negocios, medicina, humanidades y pedagogía, para trabajar juntos en la resolución de grandes problemas que aquejan a la sociedad trabajando conjuntamente en proyectos con equipos multidsciplinarios. Este enfoque de proyectos humaniza la problemática y busca la empatía, lo que tiene como resultado proyectos con soluciones sustentables y centradas en el ser humano.

\subsubsection{Metodologías activas para la construcción del modelo de negocio}

El tercer elemento dentro de la variable de ecosistema es el empleo de metodologías activas para la construcción del modelo de negocio. Para ello es necesario remitirse al tema de la enseñanza emprendedora y la aplicación de metodologías activas en el desarrollo de proyectos de emprendimiento. Luego de haber observado la aplicación del pensamiento de diseño en la enseñanza, el siguiente punto es el de abordar el empleo de metodologías activas para que los estudiantes, no sólo desarrollen una mentalidad emprendedora y empaticen planteando soluciones más humanas y sostenibles, sino que, además, puedan emplear estas metodologías activas, colaborativas y experienciales a fin de construir proyectos de gran impacto.

En capítulos posteriores analizaremos una propuesta en particular sobre tres metodologías activas para la 
construcción de modelos de negocio, mientras tanto, es importante sentar las bases sobre el impacto del aprendizaje activo en la formación de emprendedores. El aprendizaje experiencial ocurre cuando los estudiantes participan en experiencias relacionadas con su campo de estudio y, además, tienen la oportunidad de reflexionar sobre ellos. Estas actividades generan conocimiento mediante una reflexión social y empresarial (Clark \& White, 2010).

El enfoque de aprendizaje activo parte de la creencia de que los estudiantes aprenden mejor haciendo, y no siendo instruidos por el docente y simplemente observar el proceso de instrucción (Leonard \& Lang, 2010), como consecuencia pone énfasis en la realización de actividades y casos reales, con consecuencias existentes, partiendo de escenarios hipotéticos y riesgos potenciales, usando problemas en tiempo real y trabajando colaborativamente en las soluciones dentro de equipos multidisciplinarios.

Aplicando adecuadamente las metodologías activas en la enseñanza emprendedora, puede convertirse en un poderoso vehículo para facilitar el aprendizaje significativo y desarrollar potenciales emprendedores.

\subsubsection{Recursos para emprender}

En el análisis del Marco teórico integrador del proceso de emprendimiento, es necesario ahora estudiar la variable "recursos", donde el primer elemento se refiere a los tipos de recursos y cómo obtenerlos. Es necesaria una diversidad de recursos para lograr emprender.

Los emprendedores usualmente tienden a poner mayor énfasis en el dinero, sin embargo, aún los emprendedores que cuentan con una fuente de financiamiento asegurado no garantizan el éxito de sus proyectos si no prestan atención a los demás recursos. Es necesario identificar otros recursos que son igualmente importantes, como puede advertirse en la Figura 7, y que contribuyen a la consecución de objetivos en 
un proyecto emprendedor, como por ejemplo los recursos intelectuales y el talento humano, la vinculación con el entorno y la industria, y demás recursos que son inminentes para que sea posible que el emprendedor entregue su propuesta de valor al cliente.

El desafío es doble: primero es necesario determinar la naturaleza de los recursos, y, en segundo lugar, es importante encontrar formas creativas de obtener estos recursos.

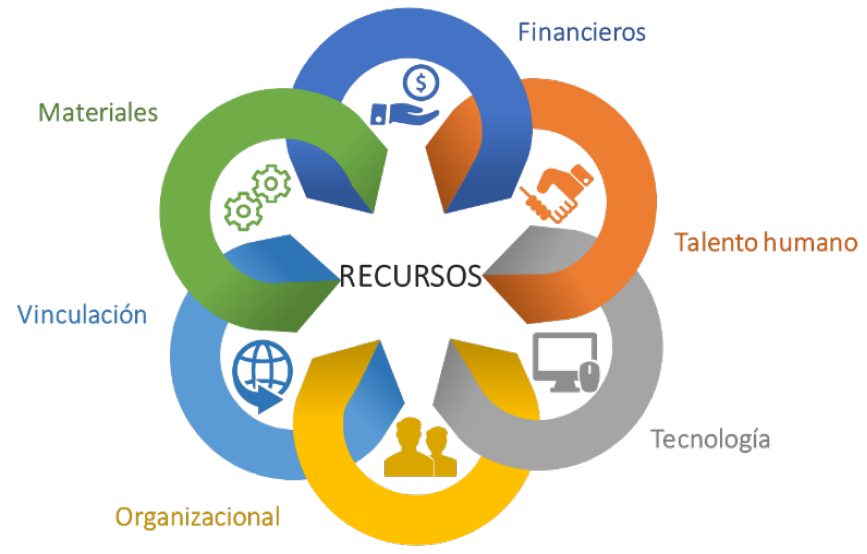

Figura 7. Recursos para emprendimiento.

Fuente: Elaboración propia.

\subsubsection{Obtención de recursos}

En el tema de la obtención de recursos estos pueden ir desde los enfoques más convencionales como la compra directa y el arrendamiento, hasta solicitar un financiamiento, otorgar licencias o incluso compartir recursos. En la Figura 8 pueden observarse una serie de opciones para obtener recursos para un emprendimiento. Es importante resaltar que la variedad presenta diversas oportunidades a los emprendedores de encontrar cómo es que pueden adquirir recursos de manera efectiva, como por ejemplo a través del financiamiento interno, como cuando se aceleran los ingresos, se estiran los 
pagos o se factorizan los activos y el capital puede entregarse a cambio de activos críticos.

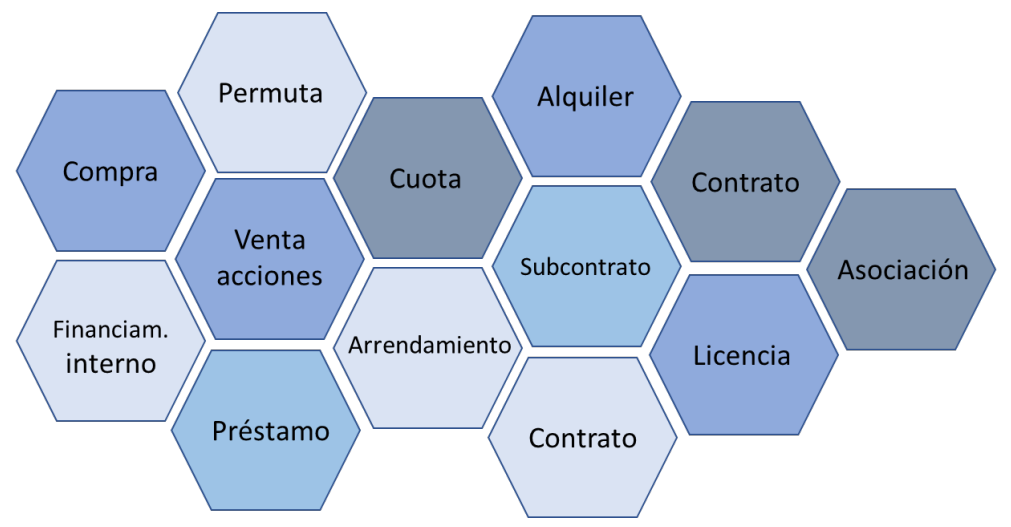

Figura 8. Figuras para la obtención de recursos

Fuente: Elaboración propia.

Para aquellos que buscan iniciar y hacer crecer empresas en el siglo XXI, una estrategia muy socorrida es la de apalancamiento, donde los recursos de otros se emplean para mejorar o aumentar los recursos propios, y/o controlados por el emprendedor.

\subsubsection{Esquemas de flujos de ingresos}

Es importante que el emprendedor tenga un esquema de flujos de ingresos en mente al iniciar un emprendimiento. Morris, Kuratko y Schindehutte (2001) presentan una propuesta de tres esquemas de flujo de ingresos, a saber: esquema de sustitución de ingreso, el esquema de crecimiento y el de especulación o de corto plazo.

Según puede observarse en la Figura 9, en el primero de los tres esquemas, el esquema de sustitución de ingreso, el emprendedor considera al emprendimiento como una posibilidad para sustituir los ingresos que tiene en ese momento, de modo que, luego de lanzado el proyecto y el periodo de puesta en marcha, en un plazo razonablemente corto, la empresa esté en condiciones de proveer un flujo 
regular de ingresos que respalde el nivel de vida del emprendedor de forma definitiva y entonces, incluso pueda prescindir de sus ingresos iniciales.

En el segundo esquema, el de crecimiento, el emprendedor considera al emprendimiento, en su etapa inicial, como una acción de alto crecimiento que paga pocos dividendos, pero que sostenido en un pazo de alrededor de cinco años pueda representar una importante plusvalía. Por lo tanto, el emprendedor acepta las condiciones de cero ingresos en los primeros años, incluso de mayor inyección de capital en determinado momento, seguro que eso representará una recompensa significativa a largo plazo.

En el tercer esquema, el especulativo o de corto plazo, como su nombre lo indica, es una representación en la que el emprendedor básicamente quiere iniciar el proyecto aventurándose a demostrar la viabilidad económica de mercado, sólo para luego venderlo al mejor postor. Este tipo de movimientos se perciben más comúnmente en los emprendimientos de base tecnológica. La figura 9 representa una propuesta de tres esquemas de flujo de ingresos para emprendimientos.
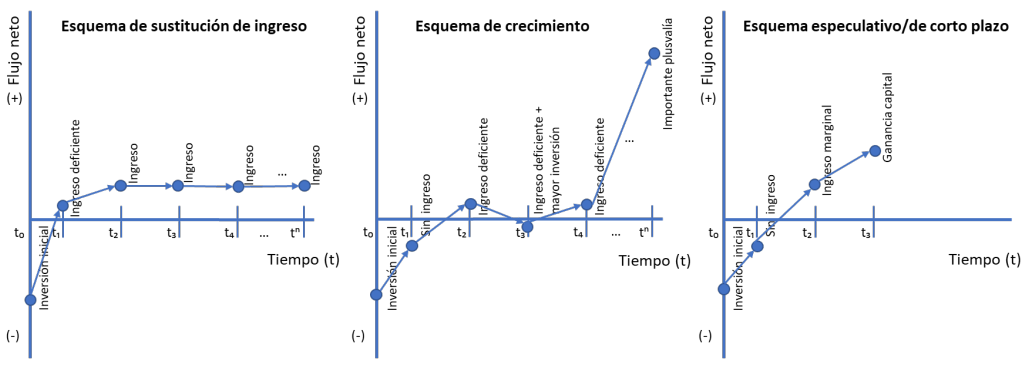

Figura 9. Esquemas de flujo de ingresos.

Fuente: Adaptado de Morris, M. H., Kuratko, D. F., \& Schindehutte, M. (2001). Towards integration: understanding entrepreneurship through frameworks. The international journal of entrepreneurship and innovation, 2(1), 35-49. 
Estos esquemas de flujo de ingresos también tienen implicaciones importantes en la estructura de la propia organización. Por ejemplo, existen negocios que inician como proyecto familiar, donde papá y mamá invierten los ahorros de una vida de trabajo e incluso a costa de deuda personal, y esto es muy común en los esquemas de sustitución de ingreso. Sin embargo, en el caso de los esquemas de crecimiento, son más propensos a ellos aquellos emprendedores que pueden ceder el control a ejecutivos especialistas que se hagan cargo de la operación del proyecto y depender económicamente de otros negocios o financiamiento de capital, por ello no es difícil para ellos poder soportar que no exista retorno de utilidades en los primeros años.

\subsubsection{Fuentes de financiamiento}

Continuando con el último elemento en la variable recursos del proceso de emprendimiento, es importante analizar cómo se determina el financiamiento adecuado para un emprendimiento. Si bien es posible que las finanzas no sean el recurso más crítico, como se ha visto anteriormente, obtenerlo es sin lugar a dudas vital y requiere de una considerable cantidad de tiempo y planeación de parte del emprendedor.

No importa qué tan buena es la idea de negocio y el modelo mismo, un elemento esencial del éxito de un emprendimiento es su capacidad de obtener los fondos suficientes para iniciar y hacer crecer el negocio. Aunque muchos emprendedores financian sus nuevas empresas con capital propio o a través del endeudamiento, existen otras opciones disponibles, como puede advertirse en la Figura 10. La figura 10 representa una propuesta como ejemplo de las fuentes de financiamiento para emprendedores.

En la Figura 10 encontramos un punto de partida sugerido por Morris et al. (2001) para abordar los complejos cuestionamientos relacionados con el financiamiento de un 
emprendimiento. Algunos de los criterios tienen fuertes implicaciones para las finanzas, como es el caso del control que busca tener el emprendedor, el riesgo para la empresa, la inversión inicial, el potencial al alza del negocio, el tipo y características de la industria, así como las posiciones negociadoras del emprendedor y el inversionista. Por lo que el riesgo y la necesidad de control varían de mayor a menor mientras que la industria varía de madura y consolidada a emergente y fragmentada.

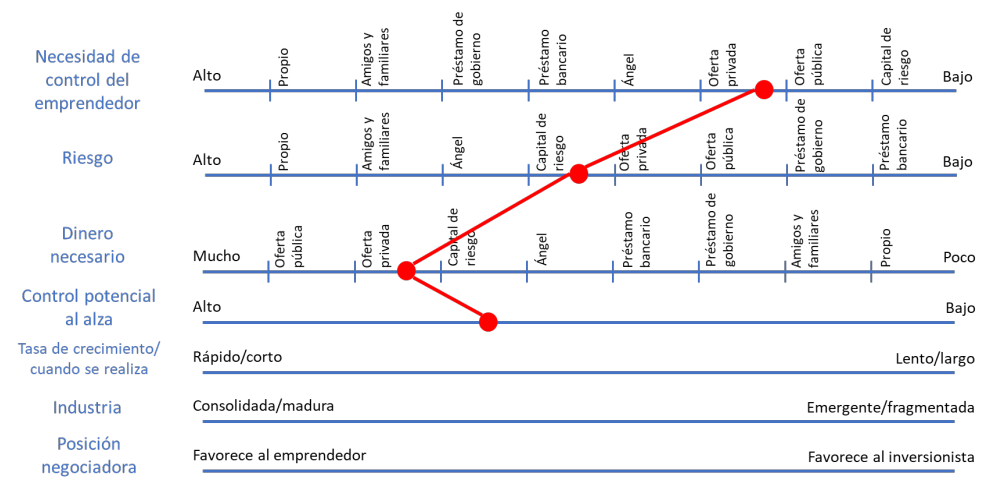

Figura 10. Marco teórico propuesto por Morris et al. (2001) para priorizar el financiamiento

Fuente: Adaptado de Morris, M. H., Kuratko, D. F., \& Schindehutte, M. (2001). Towards integration: understanding entrepreneurship through frameworks. The international journal of entrepreneurship and innovation, 2(1), 35-49.

Este marco permite al emprendedor identificar las posibles fuentes de financiamiento y priorizar cada una de ellas conforme a los primeros dos elementos que son la necesidad de control y el riesgo. Como ejemplo, si la necesidad de control es alta, entonces las fuentes de financiamiento deben ser más hacia la inversión propia o apoyado de amigos y familiares como las opciones más lógicas, mientras que una empresa de capital de riesgo es menos apropiada y no recomendable. 
Si se necesita poco porcentaje de inversión inicial, entonces los amigos y familiares son la mejor apuesta, mientras que las empresas que requieren una gran inversión inicial deberán buscar otras alternativas, aunque esto incremente el riesgo. Las combinaciones deben ser bien estudiadas y analizadas por el emprendedor a fin de encontrar el mejor modelo de financiamiento.

En el caso particular descrito en la Figura 10, se trata de una empresa en la que el emprendedor requiere menos control, el riesgo es moderado y las necesidades financieras son altas. De modo que siguiendo los puntos podemos determinar el perfil de las fuentes de financiamiento para cada caso, de ahí la practicidad del modelo de Morris et al. (2001).

\subsubsection{Un modelo de negocio innovador}

Es oportunidad de analizar ahora una nueva variable, la del "concepto", donde el primer elemento tiene que ver con los tipos de innovación. El modelo emprendedor que se utilice para capitalizar una oportunidad requiere de un elemento de singularidad o innovación. Esta singularidad se puede reflejar en la oferta de productos o servicios de la empresa, o en algunos aspectos operativos de la empresa, como por ejemplo la distribución o el método o enfoque de precios. Para mayor claridad, consideraremos el término innovación de procesos para describir enfoques únicos a los problemas operativos de la empresa.

En la Figura 11 se expone el marco de los diez tipos de innovación de Keeley, Walters, Pikkel y Quinn (2013), el cual consideran es una herramienta que se puede emplear para analizar y promover la innovación dentro de una oportunidad y evaluar a la competencia.

Este marco de los diez tipos de innovación se divide en tres categorías, a saber: configuración, oferta y experiencia. Donde la primera define los tipos de innovación que se concentran en los mecanismos internos de una empresa y su dinámica 
corporativa. La segunda categoría, la oferta, se centra en los bienes, servicios o cobranza centrales de una empresa. Y finalmente, la tercera categoría, la experiencia, se concentra en los aspectos del cliente de la empresa y de su sistema empresarial.

El éxito económico de la empresa se fundamenta en su viabilidad, que no es otra cosa que tener un modelo de negocio firme que le permita tener un sólido esquema para mantener la rentabilidad. Para ello el empresario debe evaluar la estructura de costos de la empresa para determinar si el apalancamiento operativo o la proporción de costos totales son sostenibles. Además, los márgenes de contribución promedio en productos y servicios deben estimarse a fin de conocer si son razonables, y si dejan margen para la creatividad y los movimientos para inversión y crecimiento que se traduzcan en términos de valor. La figura 11 representa las tres categorías que contiene los diversos tipos de innovación.
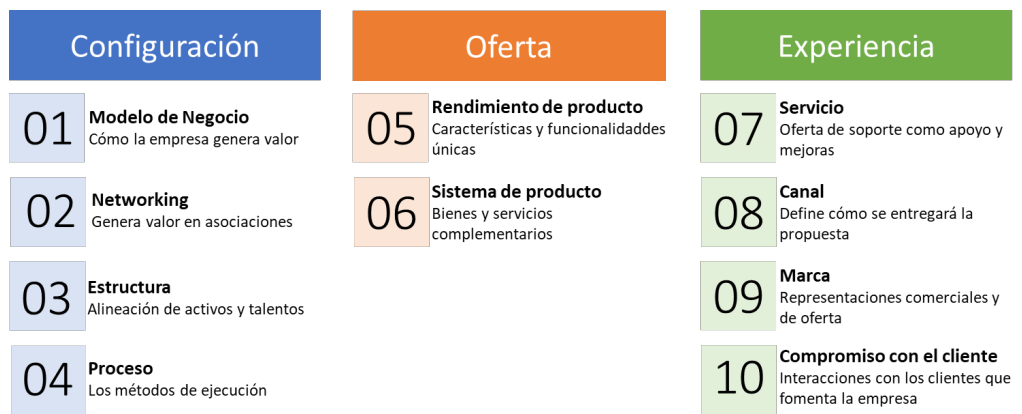

Figura 11. Los diez tipos de innovación

Fuente: Adaptado de Keeley, L., Walters, H., Pikkel, R., \& Quinn, B. (2013). Ten types of innovation: The discipline of building breakthroughs. John Wiley \& Sons.

El emprendedor debe evaluar el modelo de negocio conforme a la estructura de costos y el propio mercado, a fin de determinar si el apalancamiento operativo, o la proporción de 
los costos totales son altos, medios o bajos. Al mismo tiempo, es necesario conocer los márgenes de contribución promedio en los productos y servicios, y los volúmenes probables. Podría analizarse un ejemplo como el de una empresa que vende computadoras, donde los volúmenes son altos pero los márgenes son bajos, pues el producto se ha vuelto más comercial y puede encontrarse en diferentes lugares lo que hace que se encuentre en un mercado altamente competido.

La importancia del modelo de negocio que decida el emprendedor puede brindarle una oportunidad en el mercado, si hace los ajustes necesarios a la combinación de tipos de innovación. En el caso del ejemplo, el modelo de negocio deseable es que se enfatice en la venta de computadoras (producto) a costo, pero con márgenes de ganancia saludables en el ofrecimiento de servicio y soporte postventa. Por lo tanto, los ingresos se pueden dividir a tasas iguales entre los equipos de computadora y los servicios, mientras que las utilidades procederán mayormente de los servicios, pues será el diferenciador del modelo de negocio. De modo que el emprendedor puede hacer rentable un modelo de negocio cuando hace combinaciones adecuadas e innovadoras, aún en productos conocidos en el mercado.

El modelo de negocio es lo que le permite al emprendedor capitalizar una oportunidad de negocio, y es necesario que tenga un elemento de diferenciación y singularidad, a esto se refiere la innovación. Es importante destacar que esta diferenciación se puede reflejar, no sólo en la nueva oferta de productos o servicios, sino también en el modelo de negocios o incluso, en la forma de gestionar el negocio. Para poder definir la singularidad o innovación es importante asegurarse que cumpla con algunos de los siguientes conceptos:

a. Nuevo producto o servicio para el mundo,

b. Nuevo producto o servicio para el país, o el mercado donde competirá,

c. Nuevo sistema o procedimiento administrativo, 
d. Nuevo método de producción,

e. Nuevo enfoque de mercadeo o ventas,

f. Nuevo programa de atención y seguimiento a clientes,

g. Nuevo canal o método de distribución,

h. Nuevo enfoque logístico,

i. Nuevas tecnologías,

j. Nuevo método de financiamiento,

k. Nuevo enfoque de precios, o

1. Nueva estructura organizacional.

Estas singularidades no son únicas existen algunas otras o pueden surgir nuevas con la evolución del mercado, sin embargo, son las que mayormente se encuentran y pueden estar disponibles para nuevos emprendimientos hasta el momento.

\subsubsection{Estrategia de entrada al mercado}

El segundo elemento de la variable "concepto" en el proceso de emprendimiento es la estrategia de entrada al mercado, misma que está relacionada directamente con el modelo pues es el mecanismo en el que se basa el emprendedor para lanzar su proyecto al mercado. Vesper (1990) ha acuñado el término "cuña de entrada competitiva" para describir los mecanismos para lograrlo. Los cuatro mecanismos principales para ingresar a los mercados comienzan primeramente con un emprendimiento con un innovador producto o servicio, el segundo es entrando con la imitación de una oferta existente, el tercero es mediante una franquicia, y el cuarto es adquiriendo una empresa en marcha. Sin embargo, existen otras estrategias de entrada, como el marco propuesto por Morris et al. (2001) y que puede observarse en la Figura 12. Por ejemplo, puede ocurrir que el emprendedor sea adepto a viajar, y que en alguno de ellos haya encontrado un modelo de negocio que considerara podría funcionar en su lugar de origen, y decida comprarlo y transferirlo a otra ubicación geográfica; otro caso puede ser que un comprador pueda garantizar al emprendedor determinadas compras mensuales 
y que eso sea suficiente para entrar al mercado; o bien el emprendedor puede entrar al mercado con una licencia o un joint venture (empresas de riesgo compartido) en acuerdo conjunto con otra empresa.

La Figura 12 proporciona un marco teórico propuesto por Morris et al. (2001) para capturar los métodos primarios y complementarios de entrada al mercado. Estos marcos se presentan como una matriz, a fin de que los suplementarios puedan en algunos casos ser parte de más de uno de los métodos principales. Las marcas $(\sqrt{ })$ indican las estrategias primarias con las que las complementarias pueden coincidir o se puedan asociar, de modo que puede verse en paralelo, por ejemplo, que la imitación a una oferta existente de la competencia representa el mayor número de marcas.

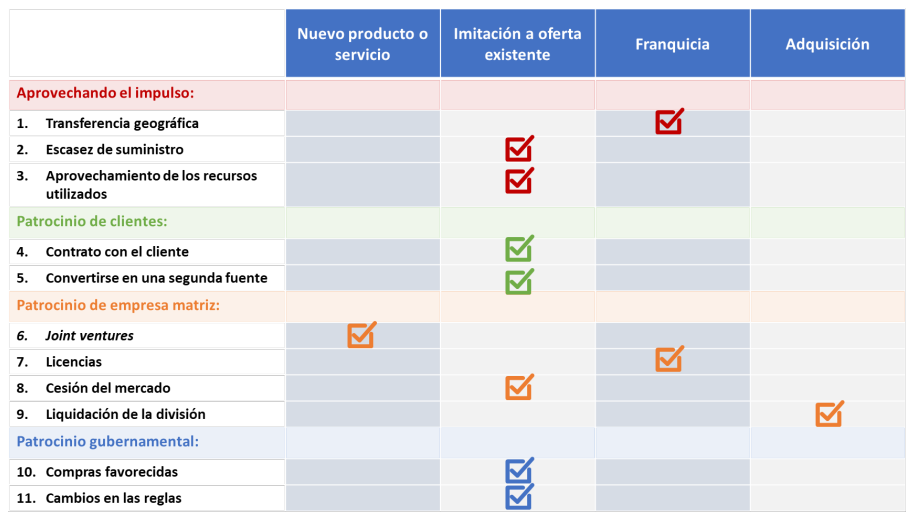

Figura 12. Marco teórico propuesto por Morris et al. (2001) sobre las estrategias de entrada al mercado.

Fuente: Adaptado de Morris, M. H., Kuratko, D. F., \& Schindehutte, M. (2001). Towards integration: understanding entrepreneurship through frameworks. The international journal of entrepreneurship and innovation, 2(1), 35-49.

\subsubsection{Modelos económicos para emprendimientos}

Los modelos económicos representan los diversos tipos de empresa que pueden existir. La Figura 13 proporciona un marco teórico propuesto por Morris et al. (2012), donde 
distingue a empresas basadas en el tamaño y aspiraciones del emprendedor contrastando con los elementos del mercado y el entorno, así como los requerimientos de capital y el manejo de operaciones. Una clasificación básica de modelos económicos para la empresa, la constituye aquella que la mide conforme a su tamaño, que es: a) microempresa, b) pequeña, c) mediana, y d) grandes organizaciones. Sin embargo, esta clasificación no aplica a los emprendimientos pues se hacen conforme al número de empleados o los volúmenes de ingresos, y estos indicadores varían, o bien pueden ni siquiera son aplicables para proyectos emprendedores. Por lo tanto, la clasificación para emprendimientos debe ir en términos del crecimiento, y la sugerencia de los autores es: a) supervivencia, b) estilo de vida, c) crecimiento administrado, y d) crecimiento acelerado (Morris, 2001).

\begin{tabular}{|c|c|c|c|c|}
\hline & Supervivencia & Estilo de vida & $\begin{array}{l}\text { Crecimiento } \\
\text { administrado }\end{array}$ & Crecimiento agresivo \\
\hline Índice de crecimiento anual & Nominal & 45 porciento & 10-15 porciento & 20 porciento \\
\hline Horizonte de tiempo & Día a día & $\begin{array}{c}\text { Operaciones semanales } y \\
\text { mensuales }\end{array}$ & $1 \cdot 2$ años & $2-5$ años \\
\hline Enfoque de gestión & Vendo lo que tenga & $\begin{array}{l}\text { Mantenimiento del Modelo de } \\
\text { Negocios en funcionamiento }\end{array}$ & $\begin{array}{l}\text { Crecimiento estratégico } \\
\text { incremental }\end{array}$ & Escalabilidad \\
\hline Estilo de gestión & Reactivo & Táctico & Estratégico & Estratégico y proactivo \\
\hline Orientación emprendedora & Muy bajo & Bajo & Moderado & Elevado \\
\hline Inversión en tecnologia & Ninguna & Limitada & Moderada & Elevada \\
\hline $\begin{array}{l}\text { Vulnerabilidad ante la } \\
\text { competencia }\end{array}$ & Significativo & Significativo & Menos significativo & Insignificante \\
\hline Fuente de financiamiento & Propio & Propio, familia y amigos, banco & $\begin{array}{l}\text { Propio, familia y amigos, banco, } \\
\text { inversionistas privados }\end{array}$ & $\begin{array}{l}\text { Banco, inversionistas privados, } \\
\text { empresas de capital de riesgo, } \\
\text { mercados públicos }\end{array}$ \\
\hline Enfoque de salida & Cerrar & Cerrar, vender, transferir & Vender, fusionar, transferir & Vender, fusionar, hacer público \\
\hline Habilidades de gestión & Haciendo, vendiendo & $\begin{array}{l}\text { Habilidades operativas, } \\
\text { administración básica }\end{array}$ & $\begin{array}{l}\text { Planeación, elaboración de } \\
\text { estrategias, delegar, } \\
\text { apalancamiento }\end{array}$ & $\begin{array}{l}\text { Planeación, innovación, gestión } \\
\text { de flujo de caja, negociación }\end{array}$ \\
\hline Estructura & Poco a nada & Sencillo & Funcional, centralizado & $\begin{array}{l}\text { Funcional, con base en producto } \\
\text { y mercado }\end{array}$ \\
\hline Motivos económicos & $\begin{array}{l}\text { Sostenerse a si mismo, y a la } \\
\text { familia }\end{array}$ & Sustitución de ingresos & Creación de riqueza & Creación de riqueza \\
\hline Énfasis en la recompensa & Ingresos semanales & Salario, bonos & $\begin{array}{l}\text { Salario, incentivos por } \\
\text { desempeño, acciones }\end{array}$ & Acciones, ganancia de capital \\
\hline
\end{tabular}

Figura 13. Cuatro tipos económicos para emprendimientos propuesto por Morris et al. (2012).

Fuente: Adaptado de Morris, M. H., Pryor, C. G., \& Schindehutte, M. (2012). Entrepreneurship as experience: How events create ventures and ventures create entrepreneurs. Edward Elgar Publishing. 
El análisis del marco presentado en la Figura 13 es detallado, y puede entenderse que los tipos de emprendimientos varían en cuanto al término de sus objetivos, la sofisticación de la operación, los requisitos de recursos para su funcionamiento y la naturaleza de los desafíos.

\subsubsection{Tipos de emprendimientos}

Para concluir con el análisis del marco teórico integrador del proceso de emprendimiento, es necesario que nos adentremos en la última de las variables "el contexto organizacional", donde se encuentran dos elementos, el primero es los tipos de emprendimientos.

Las empresas se conforman en formas y esquemas variados, en la Figura 14 podemos observar cómo es que los tipos de emprendimientos consideran por un lado los modelos económicos de crecimiento que vimos en el punto anterior, y los modelos tradicionales.

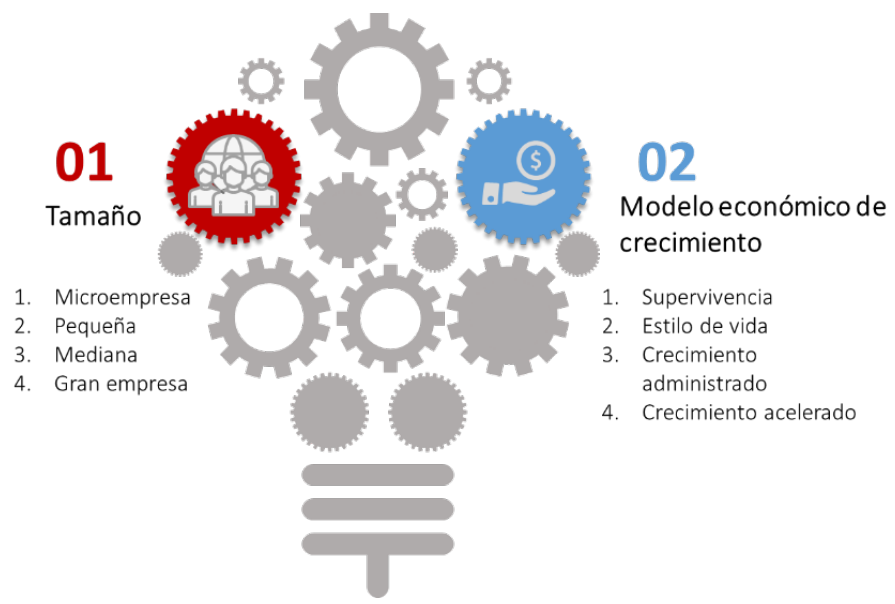

Figura 14. Tipos de emprendimientos

Fuente: Adaptado de Morris, M. H., Kuratko, D. F., \& Schindehutte, M. (2001). Towards integration: understanding entrepreneurship through frameworks. The international journal of entrepreneurship and innovation, 2(1), 35-49. 
En cuanto al tamaño, como se ha visto, su clasificación varía dependiendo de la industria, por ejemplo, una empresa de venta al por menor contra una en el ramo de tecnología, o puede variar también dependiendo del país en el que esté asentada, por ejemplo, en Estados Unidos una pequeña empresa puede tener hasta 500 empleados, mientras que, en México, las pequeñas empresas suelen tener hasta 50 empleados y una gran empresa es aquella que tiene más de 250 empleados. Pero más relevante que el tamaño, es la distinción del modelo económico de crecimiento, que se vio con detenimiento en el punto anterior, y que se dividen entre supervivencia, estilo de vida, crecimiento administrado y crecimiento acelerado.

Es necesario que exista una relación entre el tipo de modelo empleado por el emprendedor (ver Figura 9) y el tipo de emprendimiento que se crea, aunque pueden existir excepciones. El emprendedor puede tener un deseo para el crecimiento, pero quizás carezca de las capacidades requeridas para gestionar ese crecimiento. Por ello es importante que el emprendedor conozca los diversos modelos a fin de determinar con base en sus objetivos y capacidades, cuál es el tipo de emprendimiento que mejor se ajusta a su propio modelo de negocio.

\subsubsection{Etapas del ciclo de vida de la empresa}

Las empresas no se quedan estáticas, evolucionan a través del tiempo derivado de los propios movimientos del mercado y el resultado de sus operaciones. Estos movimientos se reflejan en las etapas del ciclo de vida de la organización, y van desde que la empresa inicia su actividad, hasta que cesa en la misma. Cada una de estas etapas tiene una serie de características que la define, así como, el grado de desarrollo de la compañía.

A muchos emprendedores les preocupa que su proyecto se encuentre varios años estancados y que no terminen por 
despegar, por ello es importante conocer las etapas del ciclo de vida de la empresa a fin de determinar en cuál de ellas se encuentran, y poder establecer estrategias para los movimientos que se requieren. Cada emprendimiento es distinto, se ha visto la trascendencia del impacto que tiene el tamaño de la organización, la industria en la que se encuentra, incluso el país donde se asienta, además, existen algunas que crecen muy rápido y otras que lo hacen de forma más lenta pero quizás con mayor margen de actuación en su etapa de madurez.

Lo cierto es que el objetivo de cualquier emprendimiento es vender y generar rentabilidad. Sin embargo, para conseguir estos objetivos los emprendimientos han de seguir por las mismas etapas como puede observarse en la Figura 15, aunque cada una de ellas tendrá sus propias particularidades.

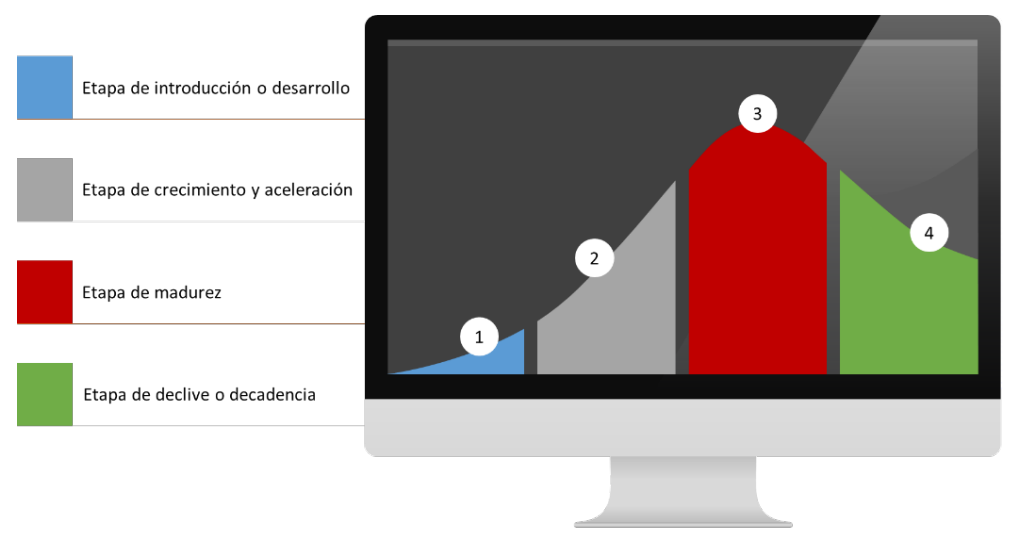

Figura 15. Etapas del ciclo de vida de la empresa.

Fuente: Elaboración propia.

En la etapa de introducción o desarrollo, los emprendedores inician con una idea innovadora que quieren poner en marcha, y se dejan influenciar por la emoción que genera la expectativa de que vendrá el éxito en determinado momento. Sin embargo, es importante diseñar una estrategia bien definida sentada sobre la propuesta de valor como base y objetivos alcanzables de corto, mediano y largo plazo. En esta etapa del 
ciclo de vida de la empresa es donde debe validarse la idea de negocio y asegurarse que satisfaga las necesidades de los clientes, quizás a través de cuestionarios de satisfacción, de modo que estén evidencias de la retroalimentación de los propios usuarios. En esta primera etapa prácticamente todo lo que la empresa genera se reinvierte más allá del punto de equilibrio, y es necesario que se cubran las deudas de financiamiento.

En la etapa de crecimiento y aceleración, es aquella en la que se puede comenzar a obtener rentabilidad, pues ya se tiene una estrategia de negocio definida y un modelo validado, se conoce al cliente y los indicadores reflejan estadísticas positivas. Aunque todo parece marchar bien, es necesario continuar con las inyecciones de capital ahora en las optimizaciones del producto o servicio, así como en el plan de mercadeo. De este modo, el emprendedor puede estar en posibilidad de comprobar las proyecciones de mercado, es necesario comenzar a delegar algunas de las tareas y consolidar un buen equipo de trabajo profesionalizado.

En la etapa de madurez, la empresa, así como el producto o servicio que ofrece están consolidados en el mercado, la empresa cuenta con una estructura sólida y un buen nicho de mercado. Sin embargo, comienzan a generarse estancamientos en las métricas, por lo que, para crecer, se deberá invertir en tecnología e innovación, probar nuevos canales y optimizar los que se tienen, o desarrollar nuevos servicios alrededor del producto con el objetivo de ampliar el segmento de clientes.

En la etapa de declive o decadencia, la empresa ya no es capaz de adaptarse al mercado, el problema principal es la falta de capacidad de adaptación a los nuevos requerimientos, si las empresas en esta etapa no hacen algo, con seguridad se anuncia su fracaso. Demasiada burocracia, o estructuras no acordes a la modernidad, pueden ser factores que aceleren el proceso de fracaso. 


\section{3. El impacto de la historia en la comprensión del emprendimiento}

El emprendimiento es un fenómeno complejo, que como se ha podido percibir, involucra múltiples variables, elementos, circunstancias e intereses, así como una serie de indicadores que pueden y deben combinarse de innumerables formas a fin de adaptarse a los mercados, al paso del tiempo y superando una serie de barreras y limitaciones, todo aunado a un creciente nivel de incertidumbre con respecto a los resultados.

La capacidad de captar todas estas complejidades que realzan los marcos teóricos que se han analizado, pone orden a la identificación de los seis factores críticos del modelo integrador que se propone, de modo que en conjunto estos constituyan el proceso de emprendimiento. Ninguno de estas variables puede ser ignorada, primeramente, porque estos factores capturan todas las variables que inciden en la ocurrencia de un emprendimiento. La importancia de este capítulo radica en la necesidad de conocer el marco teórico integral, a fin de poder establecer un modelo pedagógico de aplicación en la educación emprendedora.

El individuo que ha de emprender invirtiendo en un proyecto fomenta el espíritu emprendedor, y por consiguiente debe evaluar sistemáticamente cada una de estas seis variables. Hacerlo no sólo le permitirá apreciar la naturaleza de un emprendimiento, sino también comprender sus propias motivaciones, capacidades y requisitos para lograrlo. Al reconocer el papel crítico del desempeño del emprendedor en la toma de decisiones, se está mejor capacitado para evaluar, establecer expectativas y diseñar estrategias para lograrlo. 


\section{La mentalidad emprendedora y su impacto en el emprendimiento y la innovación}

Existe una creciente importancia en el estudio de la mentalidad emprendedora y el espíritu emprendedor y su impacto en el establecimiento de empresas para contribuir al crecimiento económico, no sólo en nuestro país, sino en el mundo entero, como se ha establecido ya en el primer capítulo. El espíritu emprendedor y el desarrollo de nuevos emprendimientos se ha convertido en un valioso elemento para el desarrollo económico según Stamboulis \& Barlas (2014), y aseguran que la educación emprendedora es un tema académico altamente discutido.

La discusión no es relativa a determinar si es o no importante, sino que parte de que, por serlo, se requiere discutir sobre la diversidad de teorías, metodologías, vertientes, estrategias e incluso visiones que buscan potenciar en las universidades, la función de permitirle al estudiante encontrar su(s) talento(s) y orientarlo a que, en la práctica, pueda desarrollar una mentalidad emprendedora, basado en los fundamentos teóricos que corresponden.

Según Da Silva, Costa y Barros (2015), desde la década de los años 60, la cantidad de cursos que se ofertan en las universidades ha ido en incremento exponencial, principalmente debido a la priorización de los gobiernos por impulsar la creación de nuevas empresas y subsanar el grave problema del desempleo.

Sin embargo, no es una tarea sencilla, alguno de los temas que están sobre la mesa como pendientes para las universidades, es precisamente la capacidad de cultivar en los estudiantes no sólo la mentalidad emprendedora, sino el promover el desarrollo de la habilidad de adaptarse a la transformación económica que les toque vivir, independientemente de cuando esto ocurra. 
Los profesores universitarios tienen la responsabilidad de formar a los jóvenes quienes son clave del futuro de la sociedad y la inversión en ellos hoy es una inversión en el futuro de una nación (Pereznieto \& Harding, 2013), este es un fuerte argumento a favor de la intensificación de la inversión en el desarrollo de la juventud, no sólo en competencias duras en la rama en la que se encuentren, sino de competencias blandas y habilidades transversales, como el emprendimiento, sugeridas y apoyadas por organismos a nivel internacional como es el caso de la OIT (Organización Internacional del Trabajo [OIT], 2015). La mayoría de los jóvenes del mundo (casi el 85\%) vive en países en desarrollo como el nuestro y para el año 2025 , se proyecta que el número de jóvenes que viven en estos países crecerá al 89\%. Esta es hoy una llamada de alerta para reconocer lo mucho que aún se tiene que hacer, pues estos jóvenes, si son bien preparados, pueden cambiar el rumbo de las diversas economías.

El espíritu emprendedor ha ganado reconocimiento como motor de progreso en todo el mundo (Carree \& Thurik, 2010; Farashah, 2013), y debido a su capacidad para crear empleos y mejorar la vida, se ha considerado recientemente como una valiosa solución para el desempleo juvenil y exclusión social. Los académicos han considerado promover el espíritu emprendedor y la mentalidad emprendedora como un medio para mejorar los medios de vida de los jóvenes en países en desarrollo (Awogbenle \& Iwuamadi, 2010; Cheraghi, Setti, Ashourizadeh \& Schøtt, 2014). 2014), y han reconocido el valor de la educación, la formación en emprendimiento en la identificación y el fomento del potencial emprendedor entre estos jóvenes (Rasheed, 2002; OIT, 2015; Mohamad, Lim, Yusof \& Soon, 2015).

Aprovechar los talentos innovadores y estimular el espíritu emprendedor es fundamental para fomentar la participación de esta juventud en el crecimiento económico y el desarrollo, pues es una herramienta estratégica que ha dado buenos 
resultados en otras naciones (Mahadea, Ramroop \& Zewotir, 2011; Muhammad, Akbar \& Dalziel, 2011). Por lo que, los países en todo el mundo han comenzado a formular diversas políticas para mantener el espíritu emprendedor dentro de la educación formal (Farashah, 2013).

La intención emprendedora es una señal clave de inminentes comportamientos emprendedores (Krueger, Reilly \& Carsrud, 2000). En consecuencia, explorar qué influencias puede tener esta intención emprendedora es un factor crítico en la investigación sobre educación emprendedora. Investigaciones en la literatura (Franke \& Lüthje, 2004; Caliendo \& Kritikos, 2019) han discutido ampliamente los factores determinantes de la intención emprendedora vinculados a la persona y al entorno. De la misma forma, estudios han abordado los factores que influyen en la intención emprendedora (Chen, Weng \& Hsu, 2010; David \& Naomi, 2013; Majumdar \& Varadarajan, 2013; Tolentino, 2014).

Kakouris (2016) determinó que, más allá de las dependencias esperadas de la iniciativa emprendedora individual, las competencias y los motivos, los estudiantes universitarios suelen mostrar variaciones en los puntos de vista que puede reducirse mediante la educación emprendedora. Walter y Block (2016) contribuyen con una visión institucional de la educación para el emprendimiento, y establecieron cómo esta educación tiene más posibilidades de resultar en una actividad empresarial, aún en un entorno no propicio o amigable al espíritu emprendedor, esa contribución favorece el seguir apoyando la educación emprendedora, más allá de simples unidades de aprendizaje, sino consideradas como competencias transversales.

Es ampliamente aceptado que el espíritu emprendedor y la creación de nuevas empresas son las fuerzas impulsoras del crecimiento económico, como se estableció desde el primer capítulo (Millman, Li, Matlay \& Wong, 2010). En la era de la 
economía del conocimiento, promover el desarrollo del espíritu emprendedor y mejorar los sistemas de innovación nacionales, son las claves para promover la productividad, la competitividad y el crecimiento económico de un país (Chen, Weng \& Hsu, 2010). Algunos países en desarrollo, como India, China y Malasia, han comenzado a reconocer el espíritu emprendedor como un enfoque para los gobiernos, las instituciones financieras y las instituciones académicas (Goel, Vohra, Zhang \& Arora, 2007; Mohamad, Lim, Tysof \& Soon, 2015). Por lo que puede advertirse, tanto los académicos como los profesionales de la gestión de negocios, han aumentado sus esfuerzos para estimular una perspectiva y un espíritu emprendedor dentro de la sociedad, debido a su naturaleza significativa (Gallant, Majumdar \& Varadarajan, 2010; Davey, Plewa \& Struwig, 2011).

En cierta medida, una comprensión adecuada de los elementos que influyen en las actitudes hacia el emprendimiento y la intención de emprender podría acelerar el desarrollo efectivo de estas iniciativas. Las intenciones son predictores consistentes de la acción emprendedora; por lo tanto, es imperativo comprender los factores relacionados con las intenciones emprendedoras del individuo (Krueger, Reilly \& Carsrud, 2000).

Goel, Vohra, Zhang \& Arora (2007) afirman que la perspectiva hacia el espíritu emprendedor es la base esencial para la puesta en marcha de la acción emprendedora. Según los autores, esto se vería afectado por los antecedentes familiares y el desarrollo emprendedor del individuo, incluido el sistema educativo de la región. La interacción de las características personales (asunción de riesgos, creatividad y la necesidad de logro) con las percepciones de las competencias y la familiaridad (experiencia empresarial, conocimiento, conciencia e interés), se vuelve fundamental evaluar la capacidad potencial para el emprendimiento de los estudiantes (Majumdar \& Varadarajan, 2013). 
Existen investigaciones que constatan que los factores demográficos como el género y los ingresos familiares se relacionan positivamente con las intenciones explícitas de emprendimiento en Internet de los estudiantes en China (Millman, Li, Matlay \& Wong, 2010), mientras que las características individuales, en estudiantes universitarios, pueden conducir a un comportamiento emprendedor si las condiciones ambientales lo permiten (Busenitz, West, Shepherd, Nelson, Chandler \& Zacharakis, 2003).

Shane, Locke \& Collins (2003) asumieron en su investigación, que el espíritu emprendedor no es completamente el resultado de la intervención humana, sino que existen factores externos que también juegan un papel importante y que es necesario reconocerlos. Schwarz, Wodowiak, Almer-Jarz \& Breitenecker (2009) establecen en los resultados de sus investigaciones en estudiantes en Austria, que las características de personalidad de los individuos destacan en el emprendimiento, en particular, la necesidad de logro, la asunción de riesgos, el autocontrol y el potencial emprendedor. Otro estudio de Majumdar \& Varadarajan (2013), expone que en efecto existen algunos rasgos de personalidad que impactan en la elección de carrera y propensión al emprendimiento en hombres y mujeres jóvenes en los Emiratos Árabes Unidos.

\subsection{Conceptos básicos: emprendedor y mentalidad emprendedora}

La palabra emprendimiento viene del francés entrepreneur, que significa pionero; y se refiere a la capacidad de una persona de realizar un esfuerzo adicional para alcanzar una meta o iniciar una nueva empresa o proyecto. Este término se atribuye también a aquellas personas que son innovadoras o agregan valor a un producto o servicio ya existente (Jaramillo, 2008). El término entrepreneur fue introducido en la literatura económica por primera vez en los inicios del siglo XVIII por el economista francés Richard Cantillon (2017). Su aportación 
ha sido verdaderamente relevante para comenzar a comprender el concepto de emprendedor y el papel que juega el emprendimiento en la economía (Cantillon \& Van den Berg, 2015).

Burnett (2000) indica que, años después, en 1804, el economista francés Jean-Baptiste Say, hizo una interesante aportación a la definición de Cantillon. Say afirmó que el entrepreneur es un individuo líder, previsor, que asume riesgos y evalúa proyectos, y que moviliza recursos desde una zona de bajo rendimiento a una zona de alta productividad. Say rescata el hecho de que el éxito emprendedor no sólo es importante para un individuo, sino también lo es para la sociedad en su conjunto (Say, 2001). El británico John Stuart Mill, destacó más la importancia del emprendimiento para el crecimiento económico. Este autor enfatiza que el desarrollo del entrepreneurship requiere de habilidades no comunes y lamentó la inexistencia de una palabra en el idioma inglés con el mismo significado que el término francés entrepreneur (Mill, 1951). No obstante, la necesidad del entrepreneurship para la producción fue formalmente reconocida por primera vez por Alfred Marshall (1879), quien consideró que los emprendedores son líderes por naturaleza, dispuestos a actuar bajo las condiciones de incertidumbre que causa la ausencia de información completa y poseedores de numerosas habilidades y talentos especiales.

Joseph Schumpeter (2001) retoma años después, el concepto de Say, evaluando la importancia de la persona emprendedora, pero desde el planteamiento de la existencia del desequilibrio dinámico, causado por el empresario innovador, al que considera un agente activo y creador, que rompe paradigmas y que hace que la economía no permanezca estática, pues no se adapta a las circunstancias del contexto, sino que las cambia disruptivamente generando innovación (Schumpeter, 2013). 
Frank Knight plantea su concepto (Dold \& Rizzo, 2021), centrándose en el estudio de las capacidades que poseen los emprendedores para los negocios y estableciendo que su éxito depende de tres elementos principalmente: capacidad, esfuerzo y algo de suerte. En esta misma línea de Knight, se puede advertir que Ludwig Von Mises (McCaffrey \& Salerno, 2011) identifica tres características que considera esenciales para que un individuo sea considerado emprendedor. La primera la define como un evaluador, la segunda característica es la de empresario, y, por último, considera que el emprendedor debe de alguna forma poder manejar la incertidumbre, puesto que actúa en función del futuro y no conoce exactamente las acciones que otros tendrán. De modo que el emprendimiento es, en consecuencia, una forma de pensar, razonar y actuar centrada fundamentalmente en las oportunidades, aunque en ocasiones también en las necesidades del entorno, y que son planteadas con visión global y llevadas a cabo mediante un liderazgo equilibrado y la gestión de un riesgo calculado. Por ende, el resultado es la creación de un modelo de negocio que genera valor a la sociedad y la economía.

La evolución del concepto de emprendimiento ha favorecido la aparición de diferentes teorías que han intentado explicar este fenómeno desde perspectivas diversas. Simplificando una exhaustiva clasificación, es posible identificar dos enfoques fundamentales (Sánchez, 2007), por una parte, las teorías que se refieren a los factores de influencia del entorno y por el otro, las teorías que se refieren a factores individuales.

\subsubsection{Teorías sobre los factores del entorno que impactan al emprendedor}

La primera clasificación, es directamente influenciada por la denominada escuela o corriente contextual de pensamiento, que se caracteriza por centrarse en los factores del entorno como elementos explicativos del rendimiento del emprendedor, del mimo modo que en las redes de 
interacciones en las que se encuentra inmerso (Antonelli, 2008). Un autor de la misma escuela era Shumpeter (2013), quien sostiene que la persona emprendedora es aquella que con sus actividades genera inestabilidades en los mercados. Para el autor, el emprendimiento es un rasgo de comportamiento que tiene que ver con promover cambios en el entorno, y que las habilidades emprendedoras se aprenden, no son características necesariamente innatas al individuo.

El emprendedor persigue la oportunidad (Baumol, 1993), se compromete rápidamente, está dispuesto al cambio y se responsabiliza ante los diferentes escenarios que se le presentan (Stevenson, 2000). El planteamiento de estas teorías pone el énfasis en el mercado y en sus condiciones como agentes promotores del emprendimiento. Lo que sugiere que, si bien se requieren de cualidades especiales en la figura del emprendedor, estas son mediatizadas por el entorno, se desarrollan más fácilmente o no dependiendo del mercado, y que pueden adquirirse a través del aprendizaje, particularmente a través de la educación emprendedora.

\subsubsection{Teorías sobre los factores individuales que impactan al emprendedor}

Esta segunda clasificación, pueden ser integradas en la escuela o corriente conocida como psicológica. Esta corriente se ha centrado principalmente en encontrar los rasgos personales individuales que son compartidos por los emprendedores de éxito, cuya personalidad puede describirse por medio de un patrón específico de características relacionadas con la acción.

Dentro de esta corriente podemos situar a autores de la escuela austriaca como Von Mises (2016) o Kirzner (2015), quienes consideran que la competencia emprendedora responde a cualquier tipo de actividad que genere incertidumbre, y consideran a la persona emprendedora como aquella con capacidad de identificar oportunidades de negocio en los mercados, a través de un proceso de descubrimiento. 
En este sentido, las características de los individuos en un contexto económico determinado están relacionadas con el éxito del emprendedor, de modo que si son características que posee el individuo, pueden optimizarse a través de la educación emprendedora, pero, en definitiva, contrario a la primera corriente, estas características deben ser talentos que ya posea el individuo previo a su formación.

Ambas corrientes son ampliamente conocidas y aceptadas como expresiones de emprendimiento, sin embargo, a pesar de sus diferencias que pueden llegar a ser mutuamente excluyentes, ambas corrientes coexisten y en determinados contextos, se consideran que incluso se comparten en algunos individuos u organizaciones.

En la teoría, la identificación de los enfoques de emprendimiento permite plantear nuevas formas de pensamiento y, en la práctica, la compenetración de ambos modos de emprender parece favorecer su desarrollo (Dyer, 1995). A este respecto, existe una tendencia en los Estados Unidos más marcada hacia la corriente de corte contextual, en mucho, heredada por Schumpeter, mientras que, en Europa, la tendencia parece estar orientada hacia la escuela austriaca de carácter más psicológico.

\subsubsection{Educación de la mentalidad emprendedora}

Los estudiosos del fenómeno emprendedor han enfatizado diferentes aspectos del comportamiento emprendedor que pueden ser adquiridos a través de la formación, por ejemplo, Schumpeter (1883-1950), el economista austriaco, asoció a la mentalidad emprendedora con la innovación. Arthur Cole (1889-1980), colega de Schumpeter en Harvard, asoció a la mentalidad emprendedora con la actividad, propósito y creación de nuevas organizaciones. Peter Drucker (19092005), definió la mentalidad emprendedora como una disciplina, "la mayor parte de lo que escuchas sobre mentalidad emprendedora está equivocado", escribió en su 
libro Innovación y emprendimiento (1985) "no es magia, no es misterioso y no tiene nada que ver con los genes. Es una disciplina y, como cualquier disciplina, se puede aprender", además argumentó que la mentalidad emprendedora se extiende a todo tipo de organizaciones. Shapero y Sokol colaboradores de la Enciclopedia del Emprendimiento (Kent, Sexton \& Vesper, 1982), argumentaron que, desde una posición sociológica, todas las organizaciones e individuos tienen el potencial de ser emprendedores. Se centraron en las actividades más que en la composición organizativa al examinar la mentalidad emprendedora. En su opinión, ésta se caracteriza por la toma de iniciativas, la recolección de recursos, la autonomía y la asunción de riesgos por parte del individuo o la organización, con una amplia variedad de funciones y objetivos, lo cual coincide con que esta mentalidad es la base del crecimiento de toda organización.

Muchos han reconocido el impulso por desarrollar el espíritu emprendedor como una estrella en ascenso en la educación superior a lo largo de los últimos 20 años. El interés se ha expandido de las escuelas de negocios a muchos dominios académicos, incluyendo la ingeniería, tema de este libro. El interés de los estudiantes en el campo ha alimentado las demandas de educación práctica en la formación de proyectos innovadores, que, a su vez, ha llevado a una creciente preocupación por la relevancia de los negocios tradicionales en educación (Jones \& English, 2004; Bennis \& O`Toole, 2005).

El éxito de emprendedores de renombre y gran exposición como Bezos, Jobs y Gates, son un punto de referencia que despierta el interés de los estudiantes universitarios en desarrollar el espíritu emprendedor. Igualmente, en el comercio y medios electrónicos existen numerosos documentos, cursos, tutoriales y blogs respecto a la temática. Esto ha llevado a que incluso comiencen a generarse nuevas tendencias hacia campos del saber que antes no tenían ese 
impulso, como los campos biomédicos, donde existe un fuerte enfoque hacia el desarrollo de ciencia y tecnología para la solución de problemáticas específicas, que antes de los años 2000 no parecían tan importantes como lo son actualmente.

La educación emprendedora no es únicamente del dominio de escuelas de negocios, eso ha quedado en evidencia durante su evolución, en la actualidad el espíritu emprendedor es considerado un vehículo de cambio social en el mundo en desarrollo. Cada vez existe mayor interés en la innovación y nuevos emprendimientos dentro de disciplinas técnicas, como la ingeniería y las ciencias. Un estudio entre universidades canadienses muestra el incremento en colaboraciones (aunque no siempre a través de cursos formales o materias específicas, algunos son programas transversales comunes a diversos programas educativos) entre programas de ciencias, medicina e ingeniería (Menzies, 2004).

Organizaciones como la Alianza Nacional de Inventores e Innovaciones Colegiados (NCIIA), ahora llamada VentureWell (2021), han despertado el interés en el espíritu emprendedor entre los estudiantes de ciencias e ingenierías a través de una variedad de programas y apoyos. En particular, un número significativo de investigadores y profesionales, no relacionados con las escuelas de negocios, asisten y participan con mayor frecuencia a sus conferencias y congresos anuales, sólo por mencionar como ejemplo, que las afluencias a estos eventos, son evidencia del incremento del interés en temas que van desde la ingeniería y la innovación científica, hasta los proyectos en el mundo en desarrollo y la sostenibilidad ambiental.

Junto con el incremento en el interés por la educación emprendedora, han llegado convocatorias tanto en el ámbito popular, como en la prensa académica, que impulsan la mentalidad emprendedora en los estudiantes. Autores como Timmons (1989), Timmons \& Spinelli (2007) y McGrath (2000), hablan de personalidades únicas con atributos que 
diferencian a los emprendedores de otros líderes. McGrath (2000) incluso identifica la diferencia entre la gestión convencional y el liderazgo emprendedor con cinco elementos clave, como se puede observar en la Figura 16, donde en el primero, la búsqueda de oportunidades, el líder emprendedor crea un clima de apoyo a esta búsqueda; en el segundo, el encuadre, define el éxito en diferentes términos y articula la dirección estratégica; en el tercero, el registro de oportunidades, el líder emprendedor busca continuamente identificar nuevas oportunidades; En el cuarto, decide enfocar su pensamiento haciendo pequeñas inversiones que le permiten tomar mejores decisiones sobre las oportunidades que ha de aprovechar más adelante; y por último, el quinto elemento, la ejecución adaptativa, donde el líder emprendedor, utiliza la planeación impulsada por el descubrimiento, aprende sobre la marcha y adapta su ejecución a las realidades del mercado.

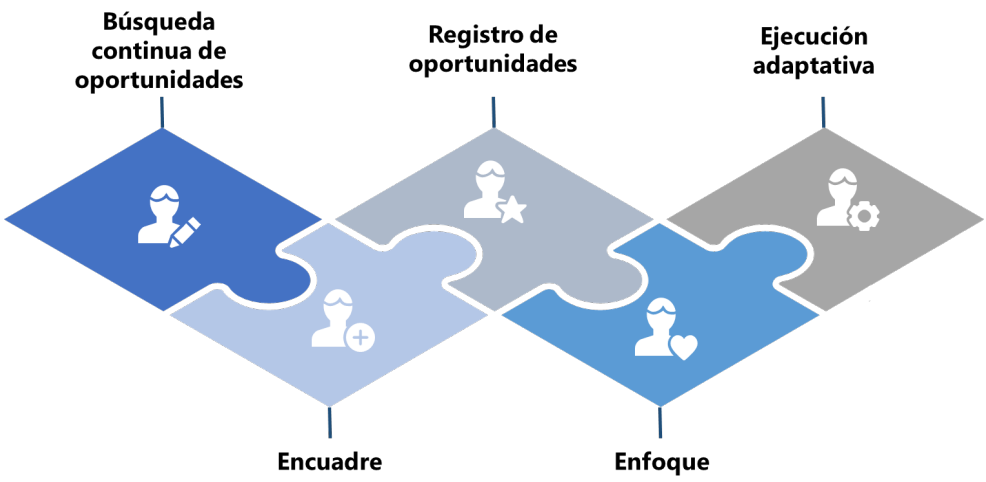

Figura 16. Atributos del liderazgo emprendedor según McGrath \& MacMillan (2000)

Fuente: Adaptación a la propuesta que proponen McGrath, R. G., \& MacMillan, I. C. (2000). The entrepreneurial mindset: Strategies for continuously creating opportunity in an age of uncertainty (Vol. 284). Harvard Business Press.

Por su parte, Timmons (2007) en su trabajo con Spinelli, identifican un conjunto de atributos centrales que consideran 
son fundamentales para el comportamiento emprendedor, a saber:

- Compromiso y determinación

- Liderazgo

- Inclinación por las oportunidades

- Tolerancia al riesgo

- Ambigüedad e incertidumbre

- Creatividad

- Autosuficiencia y adaptabilidad

- Motivación para sobresalir

- Coraje

Este llamado a la mentalidad emprendedora crea un desafío interesante para los investigadores en la identificación de a lo que se refieren con el término. En este sentido, se aborda el desafío cobre la base de dos líneas de investigación que se centran en la Autoeficacia, la creencia de que uno tiene su propia capacidad para subsanar una tarea, que se refiere a cómo es que los individuos atribuyen los resultados de sus vidas a fuerzas internas o externas. Es necesario examinar la relación entre estos dos constructos y la variable dependiente Intención de iniciar un negocio.

\subsection{Impacto de la mentalidad emprendedora en la intención}

Independientemente de las razones relacionadas con la personalidad y la cultura alrededor del emprendedor, como se ha visto en el capítulo primero, parecieran existir características comunes que definen a una mentalidad emprendedor, y se analizaron cinco de ellas. Pero ¿son estas cualidades intrínsecas a la naturaleza del sujeto o pueden aprenderse?

Derivado de la investigación, y partiendo de las cinco características definidas en el capítulo primero, es necesario ahondar en las 10 cualidades del perfil emprendedor que 
pueden educarse y aprender, como puede distinguirse en la Figura 17.

\begin{tabular}{|c|c|c|c|c|}
\hline LIDERAZGO & PODER & CREATIVIDAD & PASIÓN & CONFIANZA \\
\hline $\begin{array}{l}\text { Un buen líder } \\
\text { influye } \\
\text { positivamente en } \\
\text { su grupo de } \\
\text { trabajo, } \\
\text { promoviendo el } \\
\text { entusiasmo en pro } \\
\text { del logro de metas } \\
\text { y objetivos (Smith } \\
\text { \& Peterson, 1990). }\end{array}$ & $\begin{array}{l}\text { El poder es la } \\
\text { habilidad } \\
\text { potencial de una } \\
\text { persona para } \\
\text { ejercer influencia } \\
\text { sobre otra } \\
\text { persona o grupo } \\
\text { (Kaufmann, 1993). }\end{array}$ & $\begin{array}{l}\text { La creatividad es } \\
\text { la capacidad del } \\
\text { individuo para } \\
\text { introducir e } \\
\text { implementar } \\
\text { nuevas ideas y un } \\
\text { nuevo estilo de } \\
\text { trabajo (Belitski \& } \\
\text { Desai, 2016) }\end{array}$ & $\begin{array}{l}\text { La pasión es } \\
\text { conscientemente } \\
\text { accesibley } \\
\text { positiva, por } \\
\text { participar en } \\
\text { actividades } \\
\text { emprendedoras } \\
\text { significativas y } \\
\text { relevantes } \\
\text { (Cardon, Wincent, } \\
\text { Singh, Drnovsek, } \\
\text { 2009). }\end{array}$ & $\begin{array}{l}\text { Consiste en } \\
\text { conocer los } \\
\text { puntos fuertes } \\
\text { de cada uno y } \\
\text { explotarlos y } \\
\text { creer en lo que } \\
\text { se emprende } \\
\text { (Welter \& } \\
\text { Smallbone, 2006). }\end{array}$ \\
\hline DISCIPLINA & $\begin{array}{l}\text { BÚSQUEDA DE } \\
\text { OPORTUNIDADES }\end{array}$ & ENFOQUE & DETERMINACIÓN & $\begin{array}{l}\text { APRENDIZAJE } \\
\text { CONTINUO }\end{array}$ \\
\hline $\begin{array}{l}\text { La búsqueda de } \\
\text { oportunidades } \\
\text { con disciplina y } \\
\text { determinación } \\
\text { (McGrath \& } \\
\text { MacMillan, 2000). }\end{array}$ & $\begin{array}{l}\text { Búsqueda de } \\
\text { oportunidades } \\
\text { con pasión y } \\
\text { compromiso } \\
\text { (McGrath \& } \\
\text { MacMillan, 2000). }\end{array}$ & $\begin{array}{l}\text { Se enfocan en la } \\
\text { ejecución, } \\
\text { adaptándose al } \\
\text { cambio (McGrath } \\
\text { \& Mac Millan, } \\
\text { 2000). }\end{array}$ & $\begin{array}{l}\text { La determinación } \\
\text { es compromiso y } \\
\text { constancia. El } \\
\text { individuo } \\
\text { emprendedor es } \\
\text { persistente } \\
\text { (Timmons, 2007). }\end{array}$ & $\begin{array}{l}\text { No pierde de vista } \\
\text { el objetivo final y } \\
\text { aprende de los } \\
\text { errores (Higdon, } \\
\text { 2005). }\end{array}$ \\
\hline
\end{tabular}

Figura 17. Características de la mentalidad emprendedora que pueden aprenderse.

Fuente: Elaboración propia con información derivada de la investigación.

La mentalidad emprendedora está vinculada con la capacidad de pensamiento del individuo, buscando oportunidades en lugar de obstáculos, y diseñando ideas de solución a los problemas. El creciente cuerpo de literatura en el tema se inclina a considerar que la mentalidad emprendedora puede impulsar a un individuo a la acción, por lo que esto ha incrementado los programas de educación emprendedora a todos los niveles educativos e incluso de capacitación en el sector empresarial (Daniel, 2016; Cui, Sun \& Bell, 2019).

El fundamento de la creciente importancia de la educación emprendedora es que permite a los estudiantes tener la capacidad, comprensión, actitud y motivación relacionadas con el emprendimiento en un ambiente controlado. Fayolle y Gailly (2015) consideran que la educación emprendedora, 
independientemente de nivel educativo, promueve en los estudiantes dos importantes posturas que se reflejan en la mentalidad emprendedora. La primera, es que permite a los estudiantes crear una cultura que favorece el emprendimiento, y les permite comprender profundamente el espíritu emprendedor. El segundo, es que la educación emprendedora les brinda a estos estudiantes experiencia, de modo que puedan perder el miedo y tiendan a convertirse en emprendedores. Algunas investigaciones han demostrado la influencia significativa de la educación emprendedora con respecto a la intención de volverse emprendedores, como ejemplo se encuentran Westhead y Solesvik (2016), Maresch, Harms, Kailer y Wimmer-Wurm (2016), y Shinnar, Hsu, Powell y Zhou (2018), donde exponen que existe una correlación robusta entre educación emprendedora e intenciones emprendedoras reales.

\subsubsection{Competencias que favorecen la mentalidad emprendedora}

En la actualidad se están produciendo cambios globales en todo el mundo, incluida la automatización y la robotización, la digitalización y la formación de una sociedad interconectada, la internacionalización e integración, la tasa cada vez mayor de cambio en el medio ambiente y las condiciones socioeconómicas cambiantes que se derivan. El dinámico y acelerado siglo XXI presenta nuevos requisitos para los profesionales, deben demostrar que son adaptables, que pueden tomar parte en la movilidad, que están preparados para el aprendizaje para la vida y que poseen competencias universales orientadas a la práctica, al saber ser y al saber hacer (competencias blandas), mismas que permiten dominar de forma independiente varios tipos de actividades profesionales.

En consecuencia, existe una necesidad de profundización pedagógica sobre el desarrollo de sistemas integrados, métodos y tecnologías innovadoras, para la formación y 
evaluación de competencias y habilidades de metacognición que les permitan a los estudiantes aumentar la efectividad de su desempeño profesional, así como volverse un especialista que pueda desenvolverse en cualquier industria, manteniendo su relevancia y competitividad. Esta nueva realidad requiere nuevos enfoques de educación, nuevos resultados de aprendizaje y nuevas tecnologías para evaluar los logros de los estudiantes, el énfasis se está desplazando hacia el desarrollo de las competencias del siglo XXI (Boyatzis, 2008).

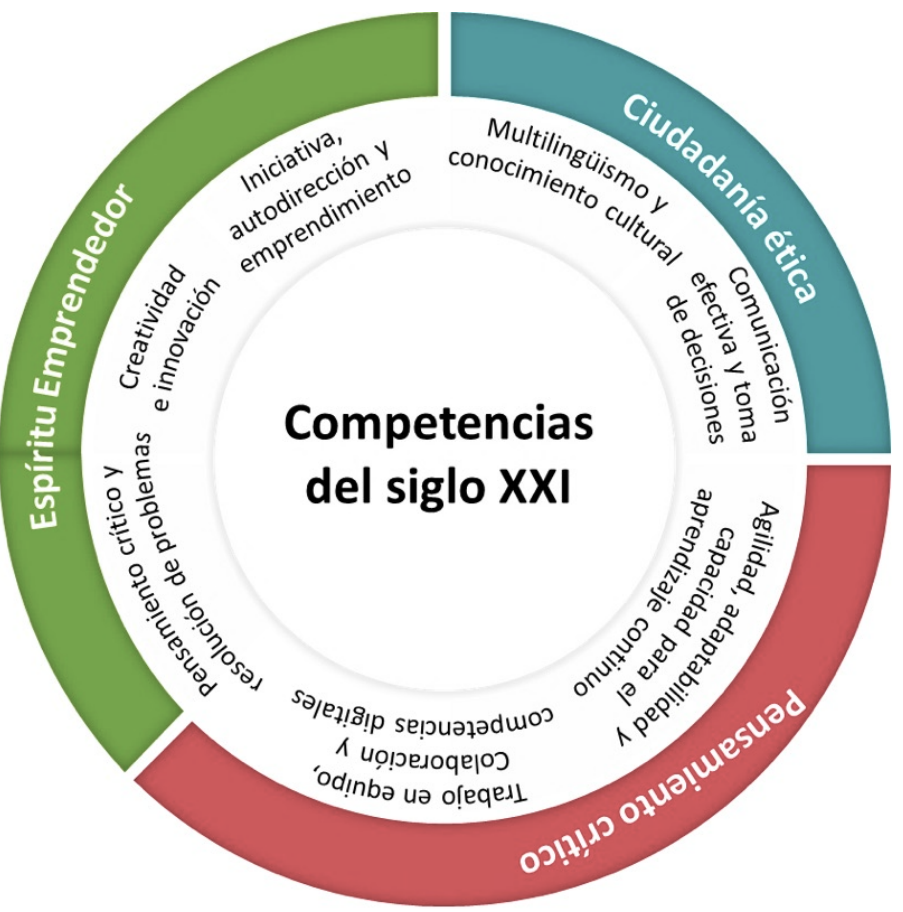

Figura 18. Competencias del siglo XXI.

Fuente: Elaboración propia con información derivada de la investigación. Adaptación de varios autores (Boyatzis, 2008; Hodge y Lear, 2011; Voogt y Roblin, 2010; Robles 2010).

En la Figura 18 puede observarse que la resolución de problemas, la toma de decisiones, la comunicación efectiva y el trabajo colaborativo, son ejemplo de las competencias del 
siglo XXI, que idealmente aplican a los profesionales en una economía de innovación, donde las necesidades y las oportunidades evolucionan más rápido y con mayor fluidez que nunca, por lo que la importancia de formarlos en emprendimiento es crucial, pues fortalece algunas de las habilidades más destacadas.

La forma en que los estudiantes se ven el mundo que les rodea afecta su capacidad de soñar y de luchar por lograr, por lo que los jóvenes necesitan una mentalidad que los prepare para reconocer las oportunidades, tomar la iniciativa e innovar frente a los desafíos.

El marco para describir esta mentalidad, con base en las competencias analizadas en la Figura 18, tiene relación con en el desarrollo de los siguientes principios:

a. Pensamiento crítico y resolución de problemas. La capacidad de aplicar un pensamiento orientado a procesos de alto nivel, considerar un tema desde una variedad de perspectivas posibles utilizando el razonamiento para la toma de decisiones.

b. Multilingüismo y conocimiento cultural. Esto le brinda la capacidad y voluntad de actuar con respeto, tolerancia y ser flexible cambiando acciones ante determinadas situaciones.

c. Comunicación efectiva y colaboración. La capacidad de expresar las ideas con claridad, de forma oral o escrita a un público objetivo, incluida la negociación y la persuasión de otros para que trabajen hacia un objetivo común.

d. Agilidad, adaptabilidad y capacidad para el aprendizaje continuo. Los éxitos repetidos a largo plazo se deben en realidad a la constante reinvención, a la agilidad y la capacidad de adaptación que el profesional tenga para responder a las necesidades cambiantes del entorno. 
e. Iniciativa, autodirección y emprendimiento. Si bien hay claramente componentes de actitud en las definiciones de profesionalismo, la mayor parte de ellas se centran en el comportamiento, los que con mayor frecuencia se incluyen son entre otros, la capacidad de tomar iniciativa, la autodirección, y el autocontrol, mismos que contribuyen a comprender la dinámica del entorno y su interacción con él.

f. Creatividad e innovación. Responde a los desafíos con ingenio, genera sugerencias para mejorar el trabajo y desarrolla enfoques e ideas innovadoras.

La importancia de poder orientar a los estudiantes a descubrir sus talentos y a descubrir que estas competencias del siglo XXI se pueden desarrollar por voluntad es muy valioso, el que comprendan que estas herramientas les abrirán oportunidades y les permitirán abrirse camino en un entorno complejo.

El educar en emprendimiento permite fortalecer la mentalidad emprendedora, siendo para los estudiantes el punto de partida para identificar y aprovechar al máximo las oportunidades, superar y aprender de los reveses en la vida, y a apreciar el éxito en una variedad de entornos. Las investigaciones muestran que los empleadores valoran la mentalidad emprendedora, pues aumenta los logros y el rendimiento educativos, además que es fundamental para la creación de nuevas empresas (Korte, 2018; Priestley, 2018; Wardana, Normanditya, Wibowo, Mahendra, Wobowo, Harmida \& Rohman, 2020)

\subsection{Impacto de la mentalidad emprendedora en el emprendimiento}

El espíritu emprendedor es importante por varias razones, como se ha visto hasta el momento, desde promover el cambio social, hasta impulsar la innovación. Con frecuencia se piensa en los emprendedores como activos nacionales que 
deben cultivarse, motivarse y remunerarse en la mayor medida posible. De hecho, algunas de las naciones más desarrolladas, como los Estados Unidos, son líderes mundiales debido en gran medida, a su capacidad de innovación, investigación y emprendedores con visión de futuro.

Los grandes emprendedores tienen la capacidad de cambiar la forma en que vivimos y trabajamos, a nivel local y nacional. Si tienen éxito, sus innovaciones pueden mejorar los niveles de vida $y$, además, de crear riqueza con iniciativas empresariales, también crean puestos de trabajo y contribuyen a una economía en crecimiento. La importancia de la mentalidad emprendedora no puede subestimarse.

La formación emprendedora es una herramienta de gran impacto social, y para muestra es necesario analizar algunas de las razones de su importancia.

\subsubsection{Los emprendimientos estimulan el crecimiento económico creando empleos}

Los nuevos productos y servicios creados por los emprendedores pueden producir un efecto en cascada, donde estimulan a las empresas o sectores relacionados que necesitan apoyar a la nueva empresa, fomentando el desarrollo económico.

Como ejemplo, algunas empresas de tecnología de la información generaron una nueva industria en la India durante la década de los noventa. La industria se expandió rápidamente y muchos otros sectores se beneficiaron de ella. Las empresas de industrias asociadas, como operaciones de centros de llamadas, empresas de mantenimiento de redes y proveedores de hardware, prosperaron igualmente. Instituciones de educación y formación generaron nuevos programas educativos en el área de Tecnologías de la Información, mismos que, al egresar, tenían empleos garantizados y bien remunerados (Mathur, 2006). 
De manera similar, los esfuerzos de desarrollo futuro en otros países requieren un sólido apoyo logístico, inversiones de capital y una fuerza laboral calificada. Desde el programador altamente calificado, hasta el trabajador de la construcción, la mentalidad emprendedora beneficia a una gran parte de la economía. Sólo en los Estados Unidos, las pequeñas empresas crearon 1.6 millones de puestos de trabajo netos durante 2019.

Los emprendedores a lo largo de la historia económica moderna han sido desproporcionadamente responsables de innovaciones verdaderamente radicales: el avión, el ferrocarril, el automóvil, el servicio eléctrico, el telégrafo y el teléfono, la computadora, el aire acondicionado, entre otros, y cada uno de ellos transformó, no sólo la industria, sino la vida de los consumidores, pues se convirtieron en plataformas para muchas otras industrias que, en combinación, han cambiado fundamentalmente economías enteras (Baumol, Litan \& Schramm, 2007).

La ineficacia de la política social en México debido a la crisis económica global, entre otras causas, ha tenido un efecto devastador en la región y los grupos sociales históricamente desfavorecidos. Los escenarios son altamente asimétricos y se reflejan en la distribución del ingreso y el bienestar (Aguirre, Lagunas, Rodríguez \& Campbell, 2019). En este contexto, el emprendimiento se considera el más importante elemento de desarrollo económico para la creación de empleo, la inclusión social, la reducción de la pobreza y el desarrollo de una cultura de innovación. Esto ha despertado el interés de políticos, académicos y organizaciones internacionales en procesos de creación de nuevos emprendimientos.

Naciones Unidas (2012) aprobó por unanimidad la resolución 67/202 Iniciativa Empresarial para el Desarrollo de acuerdo con la resolución aprobada por la Asamblea General el 21 de diciembre de 2012. Es de carácter polifacético y guarda relación con otras esferas de educación y capacitación, la 
tecnología y la innovación, el financiamiento y el fomento de la capacidad emprendedora. Toca desde un enfoque holístico y sistémico la formulación de políticas de fomento a la iniciativa empresarial que garantice la coordinación y la coherencia para el logro de un efecto positivo. Además, alienta a la comunidad internacional a apoyar los esfuerzos por promover la creación de microempresas, teniendo en cuenta los desafíos y oportunidades que representa el aumento y liberación del comercio. Por otra parte, reconoce formalmente que la mentalidad emprendedora es una herramienta importante para la reducción de la pobreza, la creación de desarrollo sostenible y la revitalización del medio ambiente.

Según el Monitor de Emprendimiento Global -GEM (Bosma, Hill, Ionescu-Somers, Kelley, Guerrero \& Schott, 2020), la mayoría de las condiciones macro de nuestro país ha disminuido en las puntuaciones en cuanto al apoyo de nuevos emprendimientos, particularmente en las áreas de gobernanza y regulaciones de mercado relacionadas. La condición de "política gubernamental: apoyo y relevancia", experimentó un declive más pronunciado en todas las condiciones, cayendo de 4.0 en 2019 a 2.6 en 2020, colocándolo en el puesto 43 de entre los participantes de este reporte, otros fueron los indicadores que han caído, y lo delicado, es que estas condiciones reflejan una evaluación negativa de cómo el gobierno ha respondido a la pandemia, disminuyendo la capacidad de los emprendedores para buscar nuevas oportunidades. Otro indicador "facilidad de entrada: cargas y regulaciones del mercado”, disminuyó de 4.4 en 2019 a 3.8 en 2020, ubicándolo en la posición 33 de entre las economías participantes. Esta baja puntuación sugiere que los emprendedores enfrentan más barreras para llevar sus productos y servicios al mercado que en el año inmediato anterior. 
GEM (Bosma et al., 2020) publica en su reporte que en México la educación emprendedora disminuyó su puntuación durante el inicio de la pandemia en 2020, sin embargo, mantuvo su puntuación en cuanto al seguimiento de proyectos emprendedores escolares. Esta disparidad en las puntuaciones en estos indicadores sugiere que, aunque la educación formal disminuyó durante la pandemia, en cuanto a estudios de educación continuo y seguimiento a proyectos de emprendimiento, mantuvo las oportunidades y su fortaleza durante los desafíos. Estos desafíos del 2020, para los emprendedores mexicanos también se extiende a las percepciones que la sociedad tiene de ellos. Para la condición "normas sociales y culturales" disminuyó de 6.1 en 2019 a 5.3 en 2020, esto puede significar que la receptividad de los consumidores a nuevos productos o servicios no se ve afectada a pesar de las condiciones en el entorno.

Claramente, algo se ha averiado dentro del motor económico y necesita una rápida reversión de esas tendencias para garantizar la prosperidad económica y, lo que es más importante, una participación más amplia en esa prosperidad, tanto ahora como en el futuro. Un impulso de la mentalidad emprendedora en nuestro país es fundamental para lograr mejores objetivos económicos nacionales por diversas razones:

- La mentalidad emprendedora mejora la productividad: pues inyecta a la economía un nuevo lote de empresas de mayor productividad, solucionando nuevos problemas, ofreciendo productos y servicios innovadores, aumentando la competencia entre las empresas existentes y eliminando, de manera natural, las menos productivas.

- La mentalidad emprendedora estimula la innovación: las nuevas empresas son desproporcionadamente responsables de la comercialización de nuevas innovaciones, en particular las innovaciones radicales que generan mercados de 
productos y servicios completamente nuevos, o bien que alteran sustancialmente los mercados existentes.

- La mentalidad emprendedora crea nuevos puestos de trabajo: las empresas nuevas y jóvenes, no las pequeñas empresas ya existentes, son el motor de la creación neta de empleo en la economía.

Durante la era industrial, en el mundo prevalecieron las economías de escala: cuanto más grande, mejor, y las empresas más grandes emplearon a la mayoría de las personas económicamente activas. Eso comenzó a cambiar con el declive de la manufactura y un cambio hacia actividades intensivas en conocimiento: las empresas más pequeñas y ágiles comenzaron a factorizar de manera más prominente en la economía durante la década de 1970 (Birch, 2000).

En la década de 1980, la noción de que las pequeñas empresas eran el motor de la creación de empleo se había grabado en piedra, era políticamente popular, consistente con la visión cultural y empíricamente verificable. Los datos y la narrativa eran claros, las pequeñas empresas representaban la mayor parte del empleo y la creación de nuevos puestos de trabajo.

Pero, algunos investigadores en el área económica comenzaron a desafiar este pensamiento a mediados de la década de 1990 y durante la década de 2000, con la ayuda de un gran avance en la disponibilidad de datos y su análisis, comenzó primeramente en Norteamérica, con información de la Oficina del Censo de Estados Unidos, cambiando este concepto por completo. Descubrieron que no son las pequeñas empresas las que impulsan la creación de nuevos puestos de trabajo, sino más bien las empresas nuevas y jóvenes (Davis y Haltiwanger, 1992). Estas investigaciones encontraron que después de ajustar por edad de la empresa, el "efecto de la pequeña empresa" con respecto a la creación de empleo neto, este desaparecía. De hecho, fuera de las empresas nuevas y jóvenes, las pequeñas empresas con años en el mercado, en su conjunto, son destructoras netas del 
empleo, puesto que algunas crean puestos de trabajo, mientras que en su mayoría los destruyen y eliminan, destacando que el segundo efecto es mayor estadísticamente.

Dicho de otra manera, las pequeñas empresas en su conjunto se disfrazan de creadoras de empleo en red, simplemente porque las nuevas empresas son también pequeñas. Desenredar la relación tamaño-edad, ha sido un avance crítico para el desarrollo de políticas, pues las pequeñas empresas tradicionales tienen características y objetivos fundamentales diferentes de las empresas orientadas al crecimiento en sus años de formación (lo que significa que deben distinguirse las empresas emergentes).

\subsubsection{Los emprendimientos mejoran la productividad}

Las empresas emprendedoras ayudan a generar nueva riqueza. Las empresas existentes pueden permanecer confinadas a los mercados existentes y pueden llegar a un límite en términos de ingresos. Los productos, servicios o tecnología nuevos y mejorados derivados de los emprendimientos permiten desarrollar nuevos mercados y crear nueva riqueza.

Además de generar nuevos puestos de empleo, como se ha visto en el punto anterior, generan mayores ingresos y contribuyen a un mejor ingreso nacional en forma de mayores ingresos fiscales y mayor gasto público. El gobierno puede utilizar estos ingresos para invertir en otros sectores en dificultades y en desarrollo de talento humano. Aunque la competencia saque del mercado a empresas y organizaciones existentes, se pueden generar nuevas políticas públicas que redirijan la especialización del capital humano que haya quedado sin empleo, a fin de capacitarlo en nuevas tecnologías y que se adapte a las nuevas realidades.

Durante la mayor parte de la historia económica, se ha asumido ampliamente que el crecimiento económico se deriva de mejoras en uno o ambos componentes principales de una economía: el capital y el trabajo. Para que una economía 
creciera, se pensaba, o el mercado laboral debía expandirse o la intensidad de capital tenía que aumentar de alguna manera.

El economista estadounidense Robert Solow (1957) demostró que la mayor parte el crecimiento económico no se puede atribuir a aumentos de capital y trabajo, sino sólo a ganancias en productividad (más producción por unidad de insumo) impulsadas por la innovación. A medida que las empresas y los trabajadores se vuelen más eficientes, los costos bajan, las ganancias y los ingresos aumentan, la demanda se expande, y el crecimiento económico y la creación de empleos se aceleran.

Desde entonces, los economistas se han hecho eco de la identificación de Solow de las ganancias de productividad impulsadas por la innovación como motor del crecimiento económico. Tanto es así, que Paul Krugman ganador del premio Nobel (1997) observó que la productividad no lo es todo, pero a la larga, lo es casi todo. La capacidad de un país para mejorar su nivel de vida a lo largo del tiempo depende casi por completo de su capacidad para aumentar su producción por trabajador, es decir, su productividad. Si esto es cierto, entonces ¿qué impulsa el crecimiento de la productividad? Corrientes de investigación han pretendido responder a este cuestionamiento (Jones, 2016), haciendo referencia a la eficiencia, o la forma en que se ensamblan los factores de producción. Una economía eficiente generará un mayor nivel de producción para un nivel dado de insumos (capital, trabajo, tecnología), en comparación con una economía menos eficiente. El crecimiento de la productividad se trata fundamentalmente de lograr más con menos.

Un aspecto clave de esta eficiencia es la reasignación de eficiencia, que no es otra cosa que la capacidad de los recursos (capital y trabajo) para fluir libremente hacia donde es más beneficioso. En una economía donde la eficiencia de reasignación es alta, las empresas más productivas permanecen en el negocio y crecen, mientras que las menos 
productivas, se contraen, o incluso, pueden llegar a cerrar. Haciendo un símil con el mundo del deporte, el entrenador se asegurará que los mejores jugadores permanezcan en el campo, mientras que los menos buenos permanecerán en la banca.

El proceso continuo de nacimiento, crecimiento, decadencia y muerte de las empresas es una característica natural, saludable y deseable de una economía flamante, pues mantiene los mercados competitivos, vibrantes, llenos de energía, innovación y modernidad. La importancia de la reasignación de eficiencia, aun cuando es menos emocionante que la productividad impulsada por las innovaciones tecnológicas revolucionarias es que esta primera impulsa el desempeño macroeconómico. De hecho, un grupo de destacados economistas ha identificado la desaceleración en la reasignación de eficiencia en la economía estadounidense durante las últimas dos décadas, como la principal responsable de la disminución en el crecimiento de la productividad que se ha generado (Decker, Haltiwanger, Jarmin \& Miranda, 2017). Por lo que la disminución en la tasa de creación de nuevas empresas -un indicador de nuevos emprendimientos- es el factor más importante que contribuye a la pérdida de productividad.

\subsubsection{Los emprendimientos generan un cambio social}

$\mathrm{Al}$ ofrecer bienes y servicios únicos, los emprendedores rompen con la tradición y reducen la dependencia de sistemas tecnológicos y tecnologías obsoletos. Esto puede resultar en una mejor calidad de vida, una moral mejorada y una mayor libertad económica.

Por ejemplo, el suministro de agua, en una región con escasez de agua, en ocasiones obliga a las personas a dejar de trabajar (y ser productivos) para buscar y recolectar agua. Esto tendrá un impacto en su negocio, en la productividad y capacidad para generar ingresos. Con un proyecto como el programa 
RAPID de Kenia (Mulongo, Nyachieo \& Kaberia, 2021), donde la Agencia de los Estados Unidos para el Desarrollo Internacional (USAID por sus siglas en inglés) en alianza con la Agencia Suiza para el Desarrollo Económico (SDC), desarrollaron una bomba innovadora y automática impulsada por sensores inteligentes, que llena los contenedores de agua de las personas automáticamente, lo que garantiza que más de 184,000 personas tengan un mejor acceso a agua potable, limpia y segura (Odhiambo, 2013). Este tipo de innovaciones garantiza que las personas puedan concentrarse en sus trabajos sin preocuparse por una necesidad básica como el agua. Esto hace que, al dedicar más tiempo al trabajo esto se refleje en crecimiento económico.

Un ejemplo más contemporáneo, los teléfonos inteligentes y las aplicaciones han revolucionado el trabajo y el juego en todo el mundo. Estos aparatos móviles no son exclusivos de los países o las personas alto poder adquisitivo, ya que más de 5,000 millones de personas en el mundo tienen dispositivos móviles considerados inteligentes (Taylor \& Silver, 2019). A medida que continúa el crecimiento del mercado para estos aparatos, los emprendimientos tecnológicos tienen un impacto profundo y duradero en el mundo. Además, la globalización de la tecnología significa que los emprendedores de los países en desarrollo tienen acceso a las mismas herramientas que sus homólogos en países con mayor desarrollo. También tienen la ventaja de un costo de vida más bajo, por lo que un joven emprendedor de un país en desarrollo puede competir con un producto existente multimillonario de un país desarrollado.

Los emprendedores fomentan con regularidad las empresas de otras personas de ideas afines. También invierten en proyectos comunitarios y brindan apoyo financiero a organizaciones benéficas locales. Esto permite un mayor desarrollo más allá de sus propias empresas. Algunos emprendedores exitosos, incluso invierten su dinero 
financiando buenas causas, desde la educación hasta la salud pública. Las cualidades que hacen que uno sea un emprendedor pueden ser las mismas cualidades que ayudan a motivar a los emprendedores a seguir adelante a través de la filantropía en un capítulo posterior de su vida.

\subsubsection{La mentalidad emprendedora impulsa la innovación}

La innovación es una importante fuerza que impulsa el crecimiento de la productividad, como se ha visto ya, y puede ser a través del surgimiento de nuevas tecnologías, la creación de algo nuevo o mejorado, o el desarrollo de algo de una manera superior. La innovación, por lo tanto, mejora la capacidad productiva de una economía mientras mantiene constantes los insumos (capital y trabajo). El crecimiento y la productividad aumenta el bienestar material de una sociedad, mejora el nivel de vida y es la principal fuente de prosperidad económica a largo plazo.

Si la innovación impulsa la productividad, ¿qué lo que impulsa la innovación? En pocas palabras, lo que induce la innovación son las nuevas ideas y conocimientos, o más precisamente, ideas y conocimientos comercialmente útiles.

En su obra fundamental sobre el crecimiento económico, Schumpeter escribió en 1942 sobre la destrucción creativa inherente a una economía capitalista, a lo que se refería, es que la innovación es una fuerza disruptiva constante y necesaria para el avance económico. El mismo Schumpeter (2013) escribió años más tarde sobre el papel central de los emprendedores en impulsar estos cambios, pues su función es reformar o revolucionar el patrón de producción mediante la explotación de una invención o, más en general, una posibilidad tecnológica no probada para producir un nuevo producto o producir uno viejo de una manera nueva, abriendo una nueva fuente de suministro de materiales o una nueva 
línea de productos, mediante la reorganización de una industria, entre otros ejemplos.

En otras palabras, las economías dependen de la mejora constante y de la competencia feroz, no crecen sin innovación, especialmente la innovación transformadora o disruptiva. Y este tipo de innovaciones dependen en gran medida de las contribuciones de los emprendedores.

Existe investigación que soporta este análisis. Los emprendedores desempeñan un papel desproporcionado en la comercialización de nuevos productos y, en esencia, todas las innovaciones más transformadoras han pasado a primer plano por parte de los emprendedores (Acs \& Audretsch, 1988). Baumol, Litan \& Schramm (2007) señalan que, a lo largo de la historia económica, han sido los emprendedores responsables de innovaciones verdaderamente radicales, no sólo han transformado determinada industria, sino que, en combinación con otros factores, han cambiado fundamentalmente economías enteras.

La creatividad, en general, es un precursor de la innovación, y la mentalidad emprendedora siempre se ha tratado justamente de la innovación. La combinación de creatividad y mentalidad emprendedora en la persona del emprendedor terminará inevitablemente en innovación empresarial y, por lo tanto, en creación de valor. No hace falta decir que la creatividad es inherente a los emprendedores, pues está en su naturaleza. De hecho, es esta creatividad innovadora lo que diferencia a un emprendedor de un empresario común o de un inversionista típico.

Se tiene la idea, se tienen los recursos e incluso se tiene mucha motivación y pasión para hacer realidad esa idea. Y entonces el emprendedor se encuentra en ese momento de concretar, hacer realidad y monetizar esa idea, a este proceso se le conoce como innovación. 
Muchos autores (Rowe \& Boise, 1974; Dewar \& Dutton, 1986; Rogers, 2010; Utterback, 1994; Afuah, 1998; Fischer, 2006; García \& Calantone; 2002; McDermott \& O’Connor, 2002; Pedersen \& Dalum, 2004) han combinado tecnología y perspectivas de mercado en su desarrollo de modelos teóricos de innovación. Algunos autores dicen que la innovación consiste en la generación de una nueva idea $y$ su implementación en un nuevo producto, proceso, o servicio, liderando el crecimiento dinámico de la economía impactando la creación de empleos (Urabe, Child \& Kagono, 1988). En general el concepto de innovación es bastante complejo y multifacético, su estudio depende del análisis de diversos puntos de vista teóricos y de conocimiento de variedad de modelos económicos, pero a pesar de todo esto, no existe una definición generalmente aceptada de innovación en la ciencia.

Schumpeter, que es considerado el fundador de la teoría de la innovación en economía general, consideró la innovación como el impacto económico de un cambio radical tecnológico, como puede ser el uso de nuevas combinaciones de fuerzas productivas existentes para resolver los problemas de la empresa (Schumpeter, 1982). Según Twiss y Goodridge (1989) la innovación es un proceso que combina ciencia, tecnología, economía y gestión, ya que se trata de lograr la novedad y ampliar desde el surgimiento de la idea hasta su comercialización en forma de producción, intercambio o consumo. Mientras que Afuah y Utterback (1997) se refieren a la innovación como nuevo conocimiento incorporado en productos, procesos y servicios, y clasifican las innovaciones según características tecnológicas, de mercado y administrativas (organizacionales).

\subsection{La innovación}

La innovación es uno de los términos más discutidos en el ámbito empresarial global en la actualidad, pero, conceptualizar lo que significa es complejo. Sin embargo, 
dado que el punto básico en la formación de emprendedores es la búsqueda de la innovación, se antoja importante definir cómo es que las empresas, los empresarios y los emprendedores deberían ver la innovación.

La innovación se puede describir de distintas maneras, ya sea por medio de palabras como: original, nuevo, nunca visto, nunca pensado, creativo, entre otras. Puede también describirse a través de las reacciones que provoca como sorpresa, asombro, admiración, entre otras. Lo cierto es que, al conocer innovaciones, es posible notar que se desafían las nociones convencionales de cómo se han hecho las cosas hasta ese punto, incluso se pueden llevar ideas de una industria a otra, de un sistema a otro, o de una región geográfica a otra.

La innovación es realmente un concepto altamente referido y usado, no obstante que sea confuso y complicado de definir. $\mathrm{Si}$ bien líderes empresariales, especialistas y autores concuerdan que es importante (Del Águila \& Meléndez, 2010; Zayas \& Sánchez, 2005; Del Río Cobián, 2000; Carrillo, Rosas \& Garrces, 2017; Jasso, 2004; Hossian, 2020), nadie parece estar de acuerdo en su conceptualización, pues aún que se refiere a expertos en innovación, surge una gran variedad entre las conceptualizaciones.

Pero entonces surgen algunos cuestionamientos, ¿̇en qué medida la innovación es inspiración y cuánto es trabajo duro? Si se trata principalmente de lo primero, la función de la formación es limitada, formar sólo a aquellos que tienen talento innovador. Sin embargo, si se tratara mayormente de lo segundo, entonces se debe desempeñar un papel más enérgico, establecer los roles y procesos correctos, metas claras y medidas relevantes y dar seguimiento revisando el proceso paso a paso. Peter Drucker (2014), con la magistral sutileza que le caracteriza, se sitúa en un punto intermedio. Si, estipula en su artículo, la innovación es un trabajo real y puede y debe gestionarse como cualquier otra función corporativa. 
Pero eso no significa que sea lo mismo que otras actividades comerciales. De hecho, la innovación es el trabajo de saber, más que de hacer.

Drucker (2014) sostiene que la mayoría de las ideas comerciales innovadoras provienen del análisis metódico de siete áreas donde se pueden identificar oportunidades, que incluso se ha visto ya en el capítulo I en la Figura 2, algunas de las cuales se encuentran dentro de empresas o industrias en particular y algunas otras que se encuentran en tendencias sociales o demográficas más amplias como puede advertirse a detalle en la Figura 19. Los emprendedores astutos se asegurarán de mantener un enfoque claro en las siete áreas donde se pueden encontrar oportunidades de forma sistemática. Pero el análisis debe ir más allá, una vez que se haya identificado un enfoque claro de oportunidad atractiva, todavía se necesita un salto de imaginación y creatividad para llegar a la respuesta correcta, a desarrollar una propuesta de valor que atienda la necesidad.

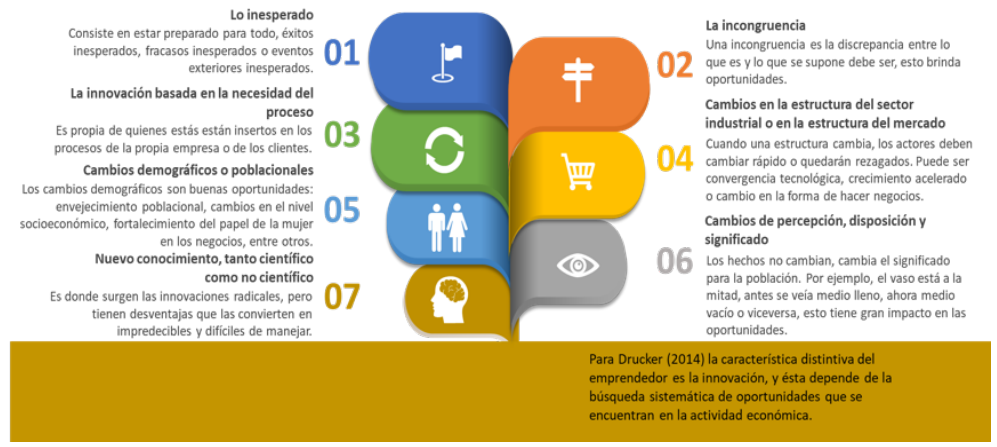

Figura 19. Búsqueda sistemática de oportunidad.

Fuente: Elaboración propia con información adaptada de Drucker, P. F.

(2014). Innovation and entrepreneurship. Routledge.

Como se señala en líneas anteriores, a pesar de mucha investigación en torno a la mentalidad emprendedora, lo que más destaca es que no importa que se emprenda para tener una mentalidad emprendedora, lo importante es que puede el 
individuo ser un médico, un contador, un músico, un periodista o académico, mientras se tenga el compromiso con la práctica sistemática de la innovación. Es decir, la práctica de observar el entorno, encontrar oportunidades, y estar dispuesto a planear y diseñar una propuesta de solución.

La innovación es la función específica del espíritu emprendedor, ya sea en una empresa existente, una institución de servicio público o una nueva empresa iniciada por un solo individuo en la cochera de su casa. Es el medio por el cual el emprendedor crea nuevos recursos productores de riqueza, o bien por medio de los cuales dota a los recursos existentes con un mayor potencial para crear riqueza.

En la actualidad existe confusión sobre la definición de mentalidad emprendedora. Algunos observadores utilizan el término para referirse a todas las pequeñas empresas, otros se refieren a todos los nuevos negocios. En la práctica, sin embargo, muchas empresas bien establecidas, e incluso maduras, se involucran en emprendimientos de gran éxito. El término, entones, no se refiere al tamaño o la etapa en el ciclo de vida de la empresa, sino a un cierto tipo de actividad. Y en el corazón de esta actividad está la innovación: el esfuerzo por crear un cambio enfocado y con propósito en el potencial económico o social de la misma empresa.

\subsubsection{Recursos de innovación}

Existen innovaciones que surgen de un destello de genialidad. Sin embargo, la mayoría de las innovaciones, especialmente las que han tenido éxito a la larga, son el resultado de una búsqueda consciente y decidida de oportunidades de innovación, como se ha visto en la Figura 19 y de las siete, cuatro son oportunidades que se dan dentro de la empresa o industria, y los otros tres, se dan fuera de la industria, en el entorno social o intelectual que le rodea.

Es cierto pensar que estas fuentes de oportunidad pueden superponerse, por diferentes que sean en la naturaleza de su 
riesgo, su dificultad y complejidad, y el potencial de innovación bien puede residir en más de un área a la vez. Pero juntas, representan la gran mayoría de todas las oportunidades de innovación que existe.

\section{A. Éxito y fracaso inesperados}

Dada la naturaleza de formación de emprendedores de este libro, es conveniente que se analicen a detalle cada una de las fuentes de oportunidad de innovación. A principios de la década de 1930, IBM desarrolló la primera máquina de contabilidad moderna diseñada para instituciones bancarias. Sin embargo, los bancos en 1933 no compraron equipos nuevos. Lo que salvó a la empresa para no ir a la quiebra, según una historia que solía contar su fundador, Thomas Watson, fue la explotación de un éxito inesperado, la Biblioteca Pública de Nueva York estaba interesada en comprar una máquina. A diferencia de los bancos, las bibliotecas en aquellos días tenían dinero, y Watson vendió más de un centenar de sus máquinas, de otro modo habría fracasado (IBM, 2021).

Quince años después, cuando se creía que las computadoras estaban diseñadas para trabajos científicos avanzados, las empresas mostraron inesperadamente un interés en una máquina que pudiera hacer nóminas. UNIVAC que en ese momento tenía la máquina más avanzada, rechazó las aplicaciones comerciales. Pero IBM (IBM, 2021) se percató que enfrentaba una oportunidad y un éxito inesperado, por lo que rediseñó lo que era en esencia la máquina de UNIVAC para aplicaciones como la nómina, y en cinco años se convirtió el líder en la industria informática de aquellos años, una posición que ha mantenido hasta años recientes.

El fracaso inesperado, por el contrario, puede ser igualmente importante para las oportunidades de innovación. Es de todos conocido que el Ford Edsel es el mayor fracaso de un coche nuevo en la historia de la industria automotriz (Aguilar, 2018). 
Sin embargo, lo que muy poca gente conoce es que el fracaso de Edsel fue la base de gran parte del éxito posterior de la empresa. Ford planeó Edsel, el automóvil diseñado con más cuidado hasta ese momento en la historia automotriz estadounidense, para brindar a la compañía una línea de productos completa con la que competir con General Motors. Cuando fue lanzado al mercado, a pesar de toda la planeación, la investigación de mercado y el diseño que se había realizado, la compañía se percató que algo estaba sucediendo en el mercado automotriz que iba en contra de las previsiones y suposiciones básicas sobre las que GM y todos los demás competidores habían estado diseñando y comercializando autos. El mercado ya no estaba segmentado principalmente por grupos de ingresos, sino que el nuevo principio de segmentación era lo que hoy conocemos como estilo de vida. La respuesta de Ford ante este nuevo escenario fue el lanzamiento del Mustang, un automóvil que le dio a la compañía una personalidad distinta a lo conocido en el mercado, y la restableció como líder de la industria.

Los éxitos y fracasos inesperados son fuentes tan productivas de oportunidades de innovación, porque la mayoría de las empresas las descartan, las ignoran e incluso las resienten (Drucker, 2014). El científico alemán Alfred Einhorn, quien en 1905 sintetizó la novocaína, el primer anestésico local sintético, tenía la intención de que se usara en procedimientos quirúrgicos importantes, como la amputación, sin embargo, los cirujanos, prefirieron la anestesia general para tales procedimientos. En cambio, la novocaína, encontró un gran atractivo entre los dentistas. Su inventor, pasó los años restantes de su vida viajando por diversas escuelas de odontología pronunciando discursos en los que prohibía a los dentistas hacer un mal uso de su noble invento en aplicaciones para las que no fue creado. Esto pareciera una historia graciosa, pero la realidad es que aún que no debería haber sucedido de esa forma, lo que fue un fracaso inesperado 
para la medicina, terminó siendo un éxito inesperado para la odontología.

\section{B. Incongruencias}

Alcon Laboratories fue una de las historias de éxito de la década de los años sesenta, porque Bill Conner, cofundador de la empresa, aprovechó una incongruencia en la tecnología médica. La operación de cataratas es el tercer o cuarto procedimiento quirúrgico más común en el mundo. Durante los últimos 300 años, los médicos lo sistematizaron hasta el punto de que el único paso arcaico que quedaba era el corte de un ligamento. Los cirujanos oculares habían aprendido a cortar el ligamento con total éxito, pero era un procedimiento tan diferente del resto de la operación y tan incompatible con él que a menudo lo temían, era determinadamente una incongruencia (Johnson, 2011).

Los médicos sabían, por más de 50 años, acerca de una enzima que podía disolver el ligamento sin necesidad de llegar a cortarlo. Todo lo que hizo Conner fue agregar un conservador de esta enzima a su medicamento, lo que le dio unos meses de vida útil. Los cirujanos oculares aceptaron de inmediato el nuevo compuesto y Alcon se encontró con un monopolio mundial (Johnson, 2011). Quince años después Nestlè compró la empresa por un precio exorbitante.

Esta incongruencia del mercado, entre expectativas y resultados, también puede abrir posibilidades de innovación. Durante los 50 años posteriores al cambio del siglo, los constructores navales y las compañías navieras trabajaron duro tanto para hacer que los barcos fueran más rápidos como para reducir su consumo de combustible. Aún así, cuanto más éxito tenían en aumentar la velocidad y reducir sus necesidades de combustible, peor se volvía la economía de los cargueros marítimos. Aproximadamente en 1950, el carguero oceánico estaba por ser descartado, si no estaba a punto de eliminarse ya. 
Sin embargo, todo lo que estaba mal era una incongruencia entre los supuestos de la industria y sus realidades. Los costos reales no provienen de trabajar (es decir de estar en el mar), sino de no hacer trabajo (es decir, permanecer inactivo en el puerto). Una vez que los emprendedores entendieron dónde estaban realmente los costos, las innovaciones fueron obvias: crearon el barco de carga y descarga, y el buque portacontenedores. Estas soluciones, que involucraban tecnología antigua, simplemente se aplicaron al carguero marítimo que los ferrocarriles y los camioneros habían estado usando durante 30 años (Juárez, 2021). Un cambio en el punto de vista, no en la tecnología en sí, cambió por completo la economía del transporte marítimo y lo convirtió en una de las industrias de mayor crecimiento de los últimos 30 años.

\section{Innovación en el proceso}

Lo que hoy conocemos como medios, tuvo su origen en dos innovaciones desarrolladas alrededor del año 1890 en respuesta a las necesidades de los procesos. Uno fue el Linotipo de Ottmar Mergenthaler (NIHF, 2021), que hizo posible producir periódicos rápidamente y en grandes volúmenes. La otra fue una innovación social, la publicidad moderna, inventada por los primeros verdaderos editores de periódicos, Adolph Ochs del New York Times, Joseph Pulitzer del New York World, y William Randolph Hearst. La publicidad les permitió distribuir noticias de forma prácticamente gratuita, con el beneficio del marketing.

Los emprendedores pueden considerar que las estructuras de la industria están ordenadas de manera inamovible, pero estas estructuras pueden cambiar, pueden combinarse, pueden rediseñarse, y a menudo lo hacen, de la noche a la mañana. Tal cambio crea una buena oportunidad para la innovación.

D. Cambio en la estructura del sector industrial o de la empresa

Una de las grandes historias de éxito de las empresas estadounidenses en las últimas décadas es la firma de corretaje 
de Donaldson, Lufkin \& Jenrette, recientemente adquirida por Equitable Life Assurance Society. DL\&J fue fundada en 1960 por tres hombres jóvenes, todos graduados de la Escuela de Negocios de Harvard, que se dieron cuenta de que la estructura de la industria financiera estaba cambiando a medida que los inversionistas institucionales se volvían dominantes (Voss, 1997). Estos jóvenes emprendedores prácticamente no tenían capital ni conexiones. Aún así, en unos pocos años, su firma se había convertido en líder en el movimiento hacia comisiones negociadas y en uno de los actores estelares de Wall Street. Fue el primero en incorporarse y salir a la bolsa como empresa pública.

De manera similar, los cambios en la estructura de la industria han creado enormes oportunidades de innovación para los proveedores de telecomunicaciones como: en transmisión (con surgimientos como Sprint en el servicio de larga distancia) y en equipos (con el surgimiento de empresas como Rolm en la fabricación de intercambios de sucursales privadas.

Cuando una industria crece rápidamente, es necesario que las empresas existentes contraataquen a los recién llegados que las desafían, de lo contrario, este puede quitarles su posición en el mercado. De hecho, cuando las estructuras del mercado o la industria cambian, los competidores tradicionales descuidan los segmentos de mayor crecimiento. Por lo que las innovaciones tienen mayores posibilidades de quedarse en el mercado.

\section{E. Cambios demográficos o poblacionales}

De las fuentes externas de oportunidades de innovación, la demográfica es la más confiable. Los eventos demográficos tienen plazos de entrega que pueden ser predecibles y, por lo tanto, conocidos. Por ejemplo, todas las personas que estarán en la fuerza laboral en los siguientes 15 años, ya han nacido. Sin embargo, debido a que estos datos generalmente se 
descuidan, para quienes observan, estos datos pueden explotarse generando grandes recompensas.

Los japoneses, por ejemplo, están delante en robótica porque prestaron atención a la demografía. Todos los países desarrollados tuvieron un incremento en nacimientos alrededor de 1970, además, hubo también una explosión educativa; se sabía por los datos que más de la mitad de los jóvenes continuaban con sus estudios más allá de la preparatoria. En consecuencia, el número de personas disponibles para el trabajo manual tradicional en la manufactura estaba destinado a disminuir porque ahora estaban mejor preparados, y esto ocurrió así en los años noventa. Todos pudieron haberlo esperado y planear algo en consecuencia, pero sólo Japón lo hizo y ahora tienen una ventaja de más de diez años en el desarrollo de robótica (Ruiz, 2016).

Lo mismo ocurrió con el éxito del Club Mediterranee (ahora conocido como Club Med) en el negocio de los viajes y los complejos turísticos. Para los años setenta, los observadores atentos podrían haber visto el surgimiento de un gran número de adultos jóvenes adinerados y educados en Europa y Estados Unidos, que no se sentían a gusto con el tipo de vacaciones que habían disfrutado sus padres de clase trabajadora, estos jóvenes eran clientes ideales para una nueva y exótica versión de su idea de vacaciones que les permite viajar por el mundo con cuotas prestablecidas.

Los emprendedores deben saber la importancia de la demografía. Las oportunidades de innovación son posibles gracias a los cambios en el número de personas, en su distribución por edad, educación, ocupaciones y ubicación geográfica, de esa forma es posible encontrar actividades empresariales más gratificantes y menos riesgosas. 


\section{F. Cambios de percepción}

El cambio de percepción del clásico ejemplo del vaso medio lleno o medio vacío hace más sentido que nunca. A medida que los emprendedores puedan cambiar la percepción sobre el vaso, abre grandes oportunidades de innovación.

Toda la evidencia fáctica indica, por ejemplo, que, en los últimos veinte años, la salud mundial ha mejorado a una velocidad sin precedentes, ya sea a medida que se disminuye la tasa de mortalidad del recién nacido, o que las tasas de supervivencia de los adultos mayores han mejorado, o que existe evidencia sobre la disminución de incidencia y mortalidad de cánceres, entre otros. Sin embargo, nunca se había visto tanta preocupación y miedo colectivo por el tema de salud, exista una suerte de hipocondría colectiva que se apodera de la sociedad. La percepción es distinta de la evidencia en datos, por lo que se puede decir que el vaso se encuentra claramente medio vacío en este rubro.

En lugar de regocijarse por las grandes mejoras en salud, la sociedad parece estar enfatizando lo lejos que se encuentra aún de la inmortalidad. Esta visión de las cosas ha creado muchas oportunidades para innovaciones: mercados para nuevas revistas sobre el cuidado de la salud, para clases de ejercicios especiales, para clínicas de meditaciones y spas, y todo tipo de alimentos y restaurantes de comida saludable. Algunos de los productos más innovadores en los últimos años surgen creando equipos de ejercicio en interiores o en la comodidad del hogar.

Si bien, un cambio de percepción no cambia los hechos, su significado o la interpretación que la sociedad le da, cambia muy rápidamente. La computadora tardó menos de dos años en cambiar de ser percibida como una amenaza pues, sólo las grandes corporaciones podrían tener acceso a una, y ahora es algo que uno compra con relativa frecuencia buscando contrarrestar el impuesto sobre la renta. La economía no 
necesariamente dicta este cambio, de hecho, puede resultar irrelevante. Lo que determina si la gente ve el vaso medio lleno o medio vacío, es el estado de ánimo en lugar de los hechos, y un cambio de estado de ánimo, a menudo desafía la cuantificación. La ventaja que hay en esto, es que, al ser concreto, puede definirse, puede probarse y, por lo tanto, puede aprovecharse para generar oportunidades de innovación.

\section{G. Nuevo conocimiento}

Entre las innovaciones que hacen historia, las que se basan en nuevos conocimientos, ya sean científicos, técnicos o sociales, ocupan un lugar destacado. Son las superestrellas de la mentalidad emprendedora, pues obtienen la publicidad y el dinero. Son lo que la gente suele decir cuando habla de innovación, aunque no todas las innovaciones basadas en el conocimiento son importantes.

Las innovaciones basadas en el conocimiento difieren de todas las anteriores en el tiempo que toman desarrollarse, en sus bajas tasas y en su previsibilidad, así como en los desafíos que plantean a los emprendedores. Como la mayoría de las superestrellas, pueden ser temperamentales, caprichosas y difíciles de dirigir. Tienen, por ejemplo, el plazo de entrega más largo de todas las innovaciones. Existe un lapso prolongado entre la aparición de nuevos conocimientos y su destilación en tecnología utilizable. Luego existe otro largo periodo antes de que esta tecnología aparezca en el mercado de productos, procesos o servicios. En general, el tiempo necesario de espera para la madurez de las invenciones es muchísimo más largo que en las demás innovaciones, es algo alrededor de treinta años (Drucker, 2014), una cifra que no se ha reducido apreciablemente a lo largo de la historia.

Estos largos periodos de germinación provocan que por mucho tiempo se sepa de una nueva innovación que está por llegar antes de que realmente lo haga. Tras este periodo, una 
explosión de entusiasmo tiene lugar, un gran número de emprendimientos es lanzado alrededor de esta actividad, teniendo gran repercusión en medios de comunicación, periodo que ronda los cinco años. Para luego cerrarse, y la entrada a la industria es prácticamente imposible. Trascurrido ese periodo, muy pocas empresas realmente sobreviven (Drucker, 2014).

Es difícil predecir la receptividad que tendrá una innovación en el mercado. Todas las otras innovaciones que se han estudiado explotan un cambio ya ocurrido. Satisfacen una necesidad planteada por el entorno, en cambio, las innovaciones basadas en nuevo conocimiento buscan provocar el cambio, buscan generar la necesidad en el usuario una vez lanzado al mercado, pues la demanda aún no existe. Esta característica particular, hace que la receptividad de la propuesta de valor sea arriesgada.

Para ser eficaz, la innovación de este tipo suele exigir no un tipo de conocimiento único, sino muchos. La computadora, por citar un ejemplo, requeriría no menos de seis ramas de conocimiento nuevo por separado: la aritmética binaria; la concepción de Charles Babbage de una máquina calculadora de la primera mitad del siglo XX; la tarjeta perforada de Herman Hollerith allá de 1890; el tubo de audio, un interruptor electrónico inventado en 1906; la lógica simbólica desarrollada entre 1910 y 1913 por Russell y North Whitehead; y, los conceptos de programación y retroalimentación que surgieron durante la Primera Guerra Mundial. Aunque todo el conocimiento estaba disponible en 1918, la primera computadora digital operativa no apareció sino hasta 1946 (Matich, 2001).

Los largos plazos de entrega y la necesidad de convergencia entre diferentes tipos de conocimiento explican el peculiar ritmo de la innovación basada en el conocimiento, sus atractivos y peligros. Durante un largo periodo de gestación, se habla mucho (y publicita mucho como se ha visto) y hay 
poca acción en realidad. Entonces, cuando los elementos convergen repentinamente, hay una tremenda emoción y especulación.

Entre 1880 y 1890, por ejemplo, se fundaron casi mil empresas de aparatos eléctricos en países desarrollados. Luego, como siempre ocurre, hubo un choque y una sacudida. Y para el año 1914, sólo 25 de ellas estaban aún en operación. De igual forma, a principios de los años veinte, existían entre 300 y 500 empresas fabricantes de automóviles en los Estados Unidos, en el año 1960, sólo cuatro de ellas sobrevivían.

Puede ser difícil, pero la innovación basada en el conocimiento se puede gestionar. El éxito requiere un análisis cuidadoso de los distintos tipos de conocimiento necesarios para hacerlo posible. También es necesario hacer un análisis cuidadoso de las necesidades y, sobre todo, de las capacidades de usuario previsto. Aunque parezca paradójico, la innovación basada en el conocimiento depende más del mercado que cualquier otro tipo de innovación. De Havilland, una empresa británica, diseñó y construyó el primer avión de pasajeros, pero no analizó lo que necesitaba el mercado, por lo tanto, no identificó dos factores clave: Uno era la configuración, es decir, el tamaño correcto con la carga útil adecuada para las rutas en las que un avión daría la mayor ventaja a una aerolínea. Otro factor era igualmente frívolo: ¿cómo podrían las aerolíneas financiar la compra de un avión tan caro? Debido a que De Havilland no realizó este análisis de usuario adecuado, dos empresas estadounidenses, Boeing y Douglas, se hicieron cargo de la industria de aviones comerciales a reacción (Wanhill, Molent, Barter \& Amsterdam, 2015). 


\section{La importancia del emprendimiento en la formación de ingenieros}

El emprendimiento es un concepto ampliamente definido como cualquier intento de creación o establecimiento de una nueva empresa o un nuevo modelo de negocio, incluido el autoempleo, una nueva organización empresarial o una extensión de un negocio existente, por un individuo o un grupo de personas físicas o morales (Reynolds, Hay \& Camp, 1999). El emprendimiento es un ingrediente indispensable en el desarrollo económico, y elemento determinante en la generación de empleos y riqueza, como se ha establecido desde el capítulo anterior.

No obstante, la naturaleza y el proceso de ese desarrollo económico puede variar considerablemente entre economías, sucede que, fomentar y desarrollar el espíritu emprendedor es un objetivo de políticas públicas en muchos países, mismos que coinciden que el conocimiento de las causas y consecuencias de esta práctica aún está lejos de ser ampliamente conocida a nivel global. Esta necesidad de conocer las causas y consecuencias, junto con la insuficiente estructura que monitoree y mida los impactos del emprendimiento es un gran reto global que la academia y la ciencia intentan descifrar.

La educación superior se considera un motor de desarrollo y crecimiento en la sociedad del conocimiento, por sus beneficios para impulsar la investigación, el conocimiento y la innovación tecnológica (Bouhajeb, Mefteh \& Ben Ammar, 2018). Por lo tanto, la relación entre la educación superior y el crecimiento económico ha sido un tema central de investigación en las ciencias sociales, particularmente para economía y administración, además que es un tema de investigación para las humanidades estudiándolo desde el enfoque de formación, conociéndose como educación emprendedora. 
El acopio de capital humano ha cobrado importancia debido al surgimiento de teorías del crecimiento desde Lucas (1988), Romer $(1989,1990)$ y Mankiw et al. (1992), quienes emplearon por primera ocasión en la ecuación de la producción al capital humano. Incluso, la teoría del capital humano que fuera desarrollada principalmente por Schultz (1961), Becker (1962) y Mincer (1974), ya hacía referencia al papel del capital humano en el proceso de producción, al igual que los incentivos para invertir en el desarrollo de habilidades, incluidas las distintas formas de escolarización, formación y capacitación.

Existe un sólido marco teórico del crecimiento económico y su relación con la educación (Greiner et al., 2016; Mankiw et al., 1992; Barro, Barro \& Sala-i-Martin, 2004). Una serie de investigaciones han confirmado la existencia de una correlación positiva entre el capital humano y el crecimiento económico. En la actualidad se sabe que la inversión en capital humano y la economía del crecimiento contribuyen al desarrollo económico.

La investigación sobre la relación del emprendimiento y la formación de ingenieros no es nada nuevo, de hecho, se remonta a principios del siglo pasado (Carlson, 1988). Sin embargo, fue hasta el estallido de la burbuja creada por las empresas en Internet en el siglo XXI que el espíritu emprendedor se convirtió en un tema de investigación generalizado, y de forma particular en la formación de ingenieros.

La idea de integrar el desarrollo emprendedor con la formación de ingenieros parece retomarse siempre que se presenta un pronóstico volátil o sombrío en la economía global. Por esta razón, es que actualmente se considera una de las asignaturas más comunes en las universidades, incluso existe investigación que confirma que al menos en las universidades en los Estados Unidos, se ha cuadruplicado la oferta de esta asignatura en programas de licenciatura en los 
últimos poco más de 30 años (Byers, Seelig, Sheppard \& Weilerstein, 2013).

La educación emprendedora en las escuelas de ingeniería mejora, no sólo un buen conjunto de habilidades empresariales, sino, además, las habilidades genéricas de los estudiantes de ingeniería con suficiente evidencia en investigaciones (Guzman, 2015; Barbe, Magids \& Thornton, 2003; Byers, Seelig, Sheppard \& Weilerstein, 2013; Doboli, Kamberova, Impagliazzo, Fu \& Currie, 2010; Jarrar \& Anis, 2016). La mayoría de las investigaciones han recomendado que estos programas deben no sólo ofertarse de manera aislada, sino que algunas de las competencias que estos buscan, deberían ser cubiertas de forma transversal en el programa educativo completo, de modo que se promueva el espíritu emprendedor más allá de sólo una asignatura y una calificación.

La realidad es que para que se promueva efectivamente el desarrollo de la capacidad emprendedora, se requiere de un marco institucional que facilite la cultura emprendedora a lo largo de los años en la universidad, que se promueva la interrelación y cooperación entre personas emprendedoras, organizaciones y diversos agentes que faciliten el aprendizaje $\mathrm{y}$ fomenten un ecosistema propicio.

La literatura sobre emprendimiento brinda importancia al papel del entorno, tanto en el fomento de la actividad emprendedora como en su impacto en el desarrollo de la economía (Bosma, 2013; Gnyawali \& Fogel, 1994). De modo que, para lograr una configuración de un ecosistema efectivo en la universidad, se requiere de un marco institucional que facilite y propicie una cultura emprendedora en los ámbitos individual, organizacional y académico.

Cualquier ánimo emprendedor comprende la percepción de oportunidades a partir del interés o intención de un individuo por emprender, así como la existencia de conductos que le 
permitan acceder a los recursos necesarios para llevar a cabo su actividad innovadora o productiva. Sin embargo, en la academia, esto se traduce a un entorno en donde los docentes de las diversas asignaturas fomenten el desarrollo de habilidades emprendedoras, que inciten a la investigación, a la resolución de problemas de forma innovadora, que los orillen al pensamiento crítico buscando soluciones fuera de lo establecido y que los inviten a romper paradigmas. Y eso, no se resuelve con el diseño de una asignatura en particular.

Guerrero y Santamaría-Velasco (2020) establecen que las instituciones incluyen el fomento, de maneras directas e indirectas, a la actividad emprendedora, a saber:

a. Las políticas públicas -de mercado (entradas/salidas), transacciones comerciales (impositivas), financieras (tasas de interés), entre otros- influyen indirectamente en la intencionalidad de un individuo por emprender, y directamente en su propia percepción de la posibilidad de acceder a recursos humanos, financieros y sociales a fin de llevarlo a cabo;

b. Las normativas -valores, comportamientos y estándares sociales aceptados que definen los modelos de referencia en una sociedad- influyen indirectamente en el interés o intencionalidad de un individuo por emprender e indirectamente en la factibilidad de tolerar o aceptar prácticas de negocios que se lleven a cabo en la sociedad de que se trate;

c. Las culturales-cognitivas -que significan la forma de hacer las cosas- influyen directamente sobre el capital social del individuo.

\subsection{Universidad y emprendimiento: conceptos y elementos}

La era actual es una basada en una economía del conocimiento, el movimiento de emprendimiento global al que se ha referido es imparable e irreversible. Este no es sólo 
un movimiento de innovación en la economía, sino que es un gran impulsor para la educación superior, puesto que lo reta a involucrarse en asuntos de impacto económico global.

En el campo de la innovación y el desarrollo tecnológico, la competencia se ha convertido en algo cotidiano en la educación superior, la capacidad de volverse una universidad como polo de desarrollo innovador es la clave. Buscando este propósito, es necesario formar profesionales altamente calificados y construir conocimiento de alto impacto, por lo que las universidades, ante este escenario, están obligadas a asumir la tarea de mejorar la competitividad básica del país en cuestión.

Ante los retos de esta cuarta revolución industrial, la industria 4.0, el cómo se promueva la innovación y fomente el espíritu emprendedor en las aulas universitarias, es la oportunidad que tienen las instituciones de educación superior de convertirse en ecosistemas promotores del emprendimiento y, por tanto, tener un alto impacto en el desarrollo económico de la región.

Estamos viviendo en una era de progresión donde las universidades deben lograr formar profesionistas con espíritu emprendedor, y desarrollar talento para la innovación. No sólo a través de la inclusión de asignaturas específicas, sino mediante un programa transversal que cultive competencias como el pensamiento crítico y la solución disruptiva de problemas que atañen a la sociedad, que promuevan la formación integral con un genuino interés por los problemas sociales y con valores tan fuertes como el compromiso y la responsabilidad social.

La innovación y la tecnología han generado importantes retos para la economía, donde la competencia se ha convertido en el tema central de los programas de desarrollo en todas las naciones. La capacidad de desarrollar universidades que se conviertan en núcleos de competitividad nacional se vuelve un importante reto. Esta debe formar personal calificado, 
creando las condiciones para que se construya conocimiento con responsabilidad social.

Por lo tanto, ante los retos de esta revolución empresarial, el cómo la innovación y el espíritu emprendedor se impulsen desde el sistema educativo es una importante oportunidad para la universidad. Esta oportunidad significa que debemos promover el empleo desde las aulas, creando mecanismos que construyan un complejo sistema donde se forme integralmente al profesional, permitiendo que descubran talentos y desarrollen una mentalidad emprendedora basada en el desarrollo de estos talentos.

Los graduados universitarios llegan a todos los campos, de ahí la transcendencia del reto, son ellos quienes mejorarán el entorno económico si son capaces de generar fuentes de empleo y contribuir al crecimiento económico en la sociedad.

El espíritu emprendedor es un requisito previo importante para la protección efectiva de los mecanismos institucionales de buen funcionamiento. En este contexto, las universidades forman personal altamente capacitado y calificado como una significativa fuerza que promueva el desarrollo de la educación empresarial, la cultura emprendedora y, por tanto, tener un impacto positivo en la calidad global del talento emprendedor y una cultura empresarial positiva que se refleje en condiciones favorables para la economía.

La calidad general del talento tiene una importancia de gran alcance. Y según Moreland (2006), cuando las universidades promueven la empleabilidad, también estarán promoviendo los elementos del emprendimiento. Sin embargo, para que esto conduzca al autoempleo en los egresados, se necesitan buenas estrategias integradoras. Los estudiantes deben comprender qué significa trabajar por cuenta propia, conocer el sistema, qué fuentes de ayuda están disponibles y dónde se encuentran los principales obstáculos, así como las herramientas para vencerlos. La educación superior ya tiene 
algunos años realizando esfuerzos para lograrlo, pero la oferta está restringida y, en la práctica, no está al alcance de todos los estudiantes por igual, depende de las orientaciones de estudio pues no es transversal a los programas, se trata generalmente de asignaturas independientes que se centran en compartir fundamentos teóricos.

\subsubsection{Emprendimiento como concepto}

Pero para entender el concepto emprendimiento necesitamos acudir a la historia. Desde los albores del siglo XXI, la importancia del emprendimiento comenzó a ser reconocido como un elemento de promoción del crecimiento económico, y las investigaciones científicas apuntan a encontrar cómo el espíritu emprendedor contribuye a ello.

Las definiciones principalmente reconocidas en cuanto al emprendimiento son:

a. "Aprovechar una oportunidad independientemente de los recursos disponibles" (Stevenson \& Jarillo, 1986);

b. "La forma de inferir, pensar y comportarse enfocándose en un enfoque general y un liderazgo específico basado en la importancia de reconocer las oportunidades" (Timmons, 1999);

c. "El espíritu de desafío y aventura que comercializa las oportunidades aprovechadas en riesgo" (Drucker,1995);

d. Hisrich \& Peters (1998) describieron el espíritu emprendedor como la capacidad de discernimiento que el emprendedor requiere para tomar decisiones;

e. Mientras que Song (2011) define el término como la voluntad de un emprendedor de crear un nuevo negocio a través de innovación en la gestión mostrando un espíritu que rompe paradigmas;

f. Park \& Ahn (2016) consideran que el espíritu emprendedor es un factor importante para mejorar su desempeño comercial, y necesitan dedicar esfuerzo para cultivar el negocio y volverlo competitivo. 
Podemos advertir que si bien, existen diversas conceptualizaciones de emprendimiento y espíritu emprendedor, estas varían conforme las situaciones en las empresas, en el entorno, en el tiempo y en el espacio donde se lleven a cabo. Para efectos de este libro, consideramos que la definición a emplear será la de Miller (1983), que establece que el espíritu emprendedor es un comportamiento que permite combinar o redistribuir los recursos innovadores, de emprendimiento, de toma de decisiones y de riesgo de un emprendedor a fin de crear un nuevo valor (producto o servicio).

El núcleo del espíritu emprendedor es positivo, con energía que desafía o cambia las convenciones existentes, que rompe paradigmas para encontrar soluciones a problemas $\mathrm{O}$ necesidades reales, cambiando el entorno, y todo, a través de una mente innovadora y creativa.

Por lo que cultivar el espíritu emprendedor a través de la formación del profesionista con una educación emprendedora, es de vital importancia.

Como ya se ha establecido, el emprendimiento es relevante para los diversos sectores, el tradicional y el tecnológico, para pequeñas y grandes empresas, así como, para distintas estructuras de propiedad. El espíritu emprendedor contribuye a la creación de empleo, al crecimiento y a la competitividad, además que permite el desarrollo de las regiones al optimizar el potencial y talento local.

El papel de los emprendimientos ha sido reconocido en últimas décadas, como uno de los elementos clave para el desarrollo, no sólo económico sino también social. Si bien, los gobiernos históricamente han dedicado esfuerzos a diseñar políticas y estrategias de apoyo a la actividad empresarial, la academia ha comenzado a centrar su interés en temas como el condicionamiento del espíritu emprendedor a fin de diseñar programas que lo promuevan. Según algunas 
investigaciones (Da Silva, Costa y De Barros, 2015; Sánchez, Torres \& García, 2014), la inversión en la educación emprendedora, particularmente en la formación de ingenieros, es una de las mejores inversiones de retorno que los países del mundo han comenzado a hacer.

Es posible observar que el emprendimiento, al igual que todo en la vida, ha cambiado y evolucionado. Los emprendedores exitosos, por lo tanto, son aquellos que aprenden a adaptarse a esos cambios. Esto puede causar extrañez, sin embargo, como se ha advertido en el análisis de conceptos, la definición básica de emprendimiento no ha cambiado mucho al paso de los años, que sigue siendo una persona que inicia un negocio a pesar de los riesgos financieros que conlleva la actividad, en búsqueda de obtener ganancias. Sin embargo, aunque los conceptos no han cambiado, el entorno empresarial y cultural sí han cambiado.

Si pensamos en un emprendedor en las décadas de los años cincuenta o sesenta es posible que hayan tenido un enfoque de mercado muy distinto a los actuales. El mundo ha evolucionado, y con la aceleración en el desarrollo científico tecnológico en los últimos 50 años, el espíritu emprendedor ha ayudado a impulsar esos cambios y a cambiar en el proceso.

Los emprendedores en su búsqueda por descubrir y desplegar mercados, han existido desde que el ser humano se decidió a comercializar con bienes y servicios. Esto significa que ha formado parte de nuestra evolución como especie, pues forma parte integral de nuestro desarrollo social, económico y de comportamiento. Como muestra podemos considerar el perfeccionamiento del comercio intra e internacional, que conduce a la conquista territorial y el progreso sociocultural.

El término "emprendedor" deriva del francés "entrependre", que significa emprender. Toma su significado más tradicional cuando en los años 1800, el economista Jean-Baptiste Say 
comienza a usarlo para definir al que inicia un emprendimiento.

Por muchos años se consideró que los emprendedores nacen, no se hacen. Siendo hasta la década de los años cincuenta que comienza a cambiar esta mentalidad, cuando en los Estados Unidos se emplea el concepto "educación emprendedora" e inician líneas de investigación sobre el estudio de la historia del emprendimiento. El primero en emplear este concepto fue el Dr. Frederick Terman (Lowood, 1982), un destacado ingeniero de la Universidad de Stanford y ampliamente reconocido como el "padrino de Silicon Valley", quien expresó con frustración ante constantemente ser ignorado en procesos por obtener fondos para su investigación, que no iba a dedicarse más a la investigación académica, y comienza creando cursos didácticos y prácticos para sus estudiantes alentándolos a emprender en la industria, labor que realizó con éxito pues construyó una próspera comunidad industrial de alta tecnología alrededor de la Universidad de Stanford.

Peter F. Drucker (1985) aclara las ideas sobre si en emprendimiento se nace o no con un espíritu emprendedor, argumentando que la mayor parte de lo que se escucha sobre el espíritu emprendedor está equivocado, pues no es magia, ni se trata de algo misterioso, y no tiene nada que ver con los rasgos o genes del individuo. Sino que se trata, en su propia definición, de una disciplina, y que, como cualquier otra disciplina, se puede aprender y desarrollar.

Hasta esos años, se conocía al emprendedor, generalmente, como individuos que vendían productos, un modelo de negocio bastante común en aquellos días, muy tradicionales en la actualidad. Un ejemplo más de cómo es que ha evolucionado el emprendimiento al paso de los años.

Es posible observar que ha habido otras características que han cambiado desde entonces. Es necesario advertir que la gran mayoría de los cambios en el entorno emprendedor, 
giran en torno a los notables desarrollos globales dentro de la tecnología y su impacto en la evolución de la sociedad.

La tecnología de la información ha sido uno de los impulsores sociales y económicos más importantes del último medio siglo, si no el de mayor trascendencia. Muchos países históricamente conservadores se han vuelto cada vez más progresistas socialmente y abiertos al comercio internacional, porque esa es la tendencia global. Casos como el de los Emiratos Árabes Unidos, un estado-nación considerado como el mejor clasificado en el Medio Oriente para hacer negocios según el Banco Mundial (World Bank, 2020), pues ofrece un entorno de impuestos relativamente bajos, además de innumerables beneficios que sorprenden y, por lo tanto, atraen a los emprendimientos de diversas partes del mundo.

Si bien la fabricación industrial ha experimentado un lento declive en los países desarrollados, el espíritu emprendedor en el área de tecnología se ha movido de maneras sorprendentes para colmar esos vacíos. Continuando con el ejemplo de los Emiratos, las empresas de base tecnológica (comercio electrónico, software y tecnología) representaron el 29\% de los nuevos negocios para el año 2017, esto como resultado de una iniciativa implementada en 2016 por la Cámara de Comercio de Dubai (Dubai Chamber of Commerce, 2021), la cual tenía como objetivo proporcionar claridad y orientación a los emprendedores a lo largo de su experiencia, aprovechando asociaciones del sector público y privado para promover la innovación y el desarrollo de un ecosistema empresarial favorecedor. Esto tiene impacto en todos los nuevos emprendimientos que, aunque no sean del sector tecnológico, es muy probable que estén utilizando el comercio electrónico, redes sociales, aplicaciones y sitios web como canales de comercialización y distribución.

El papel transformador del espíritu emprendedor para el desarrollo socioeconómico está bien documentado. Los emprendimientos aplican soluciones innovadoras para 
abordar los problemas locales que conducen al rompimiento del status quo y que tiene un efecto multiplicador en la mejora del empleo y la generación de riqueza, apoyando el crecimiento económico local, la creación de agrupaciones y comunidades de conocimiento y la mejora de la competitividad nacional.

Otro elemento de los que han marcado el cambio y evolución del emprendimiento es la diversidad. El salto de fe que se ha dado en el campo tecnológico ha venido acompañado de una progresión social marcada por un espíritu de apertura a las masas. Para visualizar esto, vale detenerse y observar que la imagen del emprendedor de los años cincuenta al que nos referíamos con anterioridad, ha variado considerablemente, y hoy pueden conocerse casos de emprendedores en jeans y zapatos deportivos, como Steve Jobs y Mark Zuckerberg, quienes evocan una imagen más fresca, diversa y diametralmente opuesta al clásico emprendedor de antaño.

Otro cambio notable en el rubro de la diversidad es que las mujeres ahora constituyen una proporción significativa al frente de emprendimientos. En los mercados emergentes, el G20 (OECD \& ILO, 2019) estima que las mujeres, ya sea en propiedad total o parcial, representa el $31 \%$ y el $38 \%$ respectivamente de las pequeñas y medianas emprensas (PYMES) registradas. Existen países donde las mujeres reportan tasas de emprendimiento iguales o incluso mayores que los hombres, uno de esos casos en Qatar. Las empresas propiedad de minorías también se encuentran en crecimiento, y es de notar que los emprendedores cada vez son más jóvenes, confirmando que en el tema de la diversidad mucho ha evolucionado el emprendimiento.

La tecnología, la publicidad y comercio en línea, las redes sociales y el correo electrónico, han permitido que personas que nunca pensaron podían ser emprendedores o personas ajenas al estereotipo común de empresario, lleguen al mercado e incluso al escenario global. En 2017, por primera 
vez en la historia, las personas que tenían acceso a Internet superaron a las que no lo tenían. Incluso en países con extrema pobreza y grandes territorios, como en África llegó a una penetración del 29\%, y del 60\% en Oriente Medio. Esto ha permitido acceso al conocimiento y la tecnología empresarial básica a un bajo costo y a los lugares más recónditos.

Otro de los grandes cambios en la evolución del emprendimiento es el de la educación. Una de las razones por la cuales los emprendedores son cada vez más jóvenes es el auge de la educación emprendedora. Las universidades están colaborando en el desarrollo de habilidades que favorecen los emprendimientos. Sin embargo, no sólo los cursos formales de instituciones de prestigio han aumentado, también los cursos de autoaprendizaje, a través de cursos en línea o videos gratuitos de coaching han incrementado las posibilidades para los interesados. El espíritu emprendedor ya no es dominio de las personas con ideas brillantes y un sueño, sino de aquellos con ideas brillantes y capacitación enfocada a la práctica.

Otro de los rasgos de evolución del emprendimiento es la ubicación (Audrersch, 2018). La tecnología significa también que es posible trabajar desde cualquier lugar, a gran velocidad y a gran escala. Ya no es necesario que el emprendedor viva dentro del rango de ciudad o país donde se encuentre su nicho de mercado, incluso no es necesario ubicarse cerca de donde esté el movimiento de dinero. Las grandes empresas están ampliando su fuerza laboral para incluir y aprovechar los servicios de nuevas empresas incluso en países en desarrollo. Cada vez en mayor medida se encuentran empresas a nivel mundial que buscan cambiar la forma en que gestionan su fuerza laboral para utilizar más contratistas, proveedores o distribuidores externos y ampliar sus horizontes.

Por último, otro de los indicadores de evolución en los emprendimientos es la ética social (Moore \& de Bruin, 2018; Karanda \& Toledano, 2018). Este significa un cambio más 
reciente que los anteriores, pero ha tenido mucho empuje en una sociedad cada vez más consciente de los problemas sociales, más participativa y exigente. La sociedad ha reclamado en los últimos años el deseo por frenar la codicia corporativa, a quien históricamente se culpa de los problemas con el cambio climático, contaminación, entre otros, y esto ha ido de la mano con la tendencia creciente de consumidores reflexivos y ambientalistas. Estos movimientos ya no son impulsados puramente por las ganancias, sino que han florecido los emprendedores éticos cuyo objetivo es construir una empresa con conciencia social que devuelva algo a la sociedad, explicado en el concepto de Responsabilidad Social Empresarial, que se entiende como organizaciones que impactan de manera directa e inmediata la vida de los ciudadanos y las comunidades a través de programas que impulsan el desarrollo económico, la educación o algunas otras causas sociales.

Casos de empresas como TOMS (Rasclyffe-Thomas, Roncha \& Varley, 2014), la zapatería, que tiene una política de uno por uno, que significa que, al comprar un par de zapatos de esa marca, ellos donan otro a una persona necesitada. Otro ejemplo es el caso de ECOSIA (Schmidt, Ruch, Decker \& Kolbe, 2012), el motor de búsqueda que aprovecha la situación global de promoción de modelos de negocio ecológicos. Siguiendo este concepto, tiene el objetivo de hacer una contribución ambiental positiva, donando la mayor parte de sus ingresos (80\%) al Fondo Mundial para la Naturaleza, quien planta árboles donde más se necesitan.

Si bien analizando la evolución del emprendimiento, podemos percatarnos de grandes cambios, existen algunas cosas que no han cambiado mucho. Se necesita la capacidad de resolver problemas, mostrar capacidad creativa para idear soluciones e innovación para echarlas a andar.

Existe también el espíritu emprendedor con atributos como la tenacidad y el enfoque en el cliente, que son características 
que de manera difícil se pueden enseñar en un aula y que en definitiva son necesarias para que un emprendimiento pueda ser exitoso.

Otras de las cosas que no pueden cambiar se refieren a la capacidad de afrontar el fracaso y aprender de ello, persistir y aprender a dar la vuelta a las situaciones de dificultad, son otras de las características o elementos del emprendimiento que son necesarios y no cambiarán. Junto a estos, se encuentran de igual forma la capacidad de gestión, la toma de decisiones, la planeación, entre otros que perfectamente pueden ser orientados y formados en el aula, mismos que, aunque la evolución de los emprendimientos siga su curso, éstos seguirán siendo habilidades del emprendedor que necesita formar y cultivar.

Es difícil en este momento poder definir hacia dónde se dirige la evolución futura del emprendimiento. Sin embargo, es posible percibir que, a cada vez mayor automatización, debería dar oportunidad para una mayor capacidad creativa del emprendedor. Seguramente se generarán nuevas metodologías didácticas que fomenten las ideas creativas, ejercicios que lo promuevan, al tiempo que se cultiven nuevas formas de validar las ideas creativas con mayor agilidad para seguir impulsando los desarrollos éticos y colaborativos.

\subsubsection{Elementos del emprendimiento y la educación emprendedora}

Existen diversas e incluso encontradas opiniones con respecto a los elementos del espíritu emprendedor. Schumpeter (1939), por ejemplo, definió el espíritu emprendedor como la fuerza impulsora de la modernización, teniendo como características el espíritu de búsqueda de innovación, la proactividad y la tendencia a correr riesgos. Mientras que Lassen, Gertsen \& Riis (2006), se refieren a las características del espíritu emprendedor comenzando con la 
autonomía, el ser aventurero, la innovación y la orientación al futuro.

Según Lichtenstein \& Lyons (2001), si se desea formar emprendedores, debemos ayudar a los estudiantes universitarios a desarrollar las habilidades y competencias necesarias, con base en sus propios talentos. Existe la creencia prevaleciente de que el espíritu emprendedor es un rasgo cuyos elementos impulsan a las personas que lo poseen a adoptar determinadas conductas (Schumpeter, 1991), de ser esto cierto, no puede entonces cumplirse con la función de formar emprendedores, pues sólo aquellos que poseen ciertos elementos podrían tener éxito. Sin embargo, investigaciones han sido incapaces de encontrar esos rasgos específicos que deben poseer las mentes emprendedoras exitosas.

Investigaciones recientes detallan características y elementos del espíritu emprendedor relacionadas con su naturaleza, como es el caso de Miller (1983), quien afirma que elementos como la proactividad, la innovación y la toma de decisiones en situaciones de riesgo, consisten en elementos que conforman el espíritu emprendedor de manera dominante.

Por lo que, pueden entonces estudiarse ciertas funcionas clave que realizan los emprendedores exitosos, como identificar oportunidades o necesidades en el mercado, diseñar y desarrollar soluciones creativas e innovadoras para satisfacer esas necesidades, y crear modelos de negocio y organizaciones que capturen y atiendan esas oportunidades de mercado.

Debido a que las acciones necesarias para desempeñar estas funciones con éxito serán diferentes en diferentes contextos, entornos y espacio, no se puede sugerir que todos los emprendedores adopten los mismos comportamientos. Es justamente la habilidad de cada emprendedor para realizar estas funciones lo que determina su éxito en el emprendimiento y el desarrollo de las habilidades y competencias que se lo permitan. 
Los talentos no se distribuyen de manera uniforme entre la población, es un hecho que los emprendedores se hacen y no nacen (Shefsky, 1996), como mencionábamos respecto a la teoría de los rasgos. El emprendimiento implica un conjunto de habilidades y competencias que son el resultado del cultivo y el desarrollo más que de una dotación innata, que en algunos casos puede darse. Dada la importancia de las habilidades, es sorprendente la medida en que se pasan por alto en el desarrollo emprendedor.

Al analizar a los emprendedores, la práctica actual es distinguirlos por características como el tipo de negocio (manufactura, tecnología, venta), demografía (americano, afroamericano, hispano, asiático, femenino, masculino, infantil), tamaño de la empresa (microempresa, pequeña, mediana, gran empresa) y ubicación geográfica (rural, urbana, ciudad universitaria). El problema es que estas distinciones son sólo descriptivas y no sirven de guía para la acción; es decir, no orientan en la determinación de la función del emprendedor o la toma de decisiones en alguna categoría particular. Sugieren erróneamente diferencias donde no las hay, y pueden llevar a los responsables a percibir distinciones y necesidades reales que existen entre los emprendedores dentro de esas categorías, sin aportar elementos de trascendencia. Los emprendedores pueden ser categorizados de manera más útil por sus niveles de habilidad o competencia y no por características o rasgos personales que poco o nada aportan al desarrollo del emprendimiento.

Aunque las diferencias existen, unos pueden ser altamente técnicos otros más experimentados. Lo que determina el potencial de éxito del emprendimiento se encuentra en sus niveles de habilidad para crear y operar nuevos negocios. El hecho de que los emprendedores tienen diferentes niveles de habilidad y competencia, no significa que deban ser tratados, apoyados o atendidos de manera distinta por el mercado. Cada caso es particular, en la formación de emprendedores, 
no existe tal cosa como una talla única. Rara vez los emprendedores, antes de comenzar su primer emprendimiento, ya poseen todas las habilidades y competencias necesarias para tener éxito. Estas se van desarrollando con la experiencia, mientras el emprendedor esté dispuesto y abierto a aprender.

Cuando se profundiza en las historias de emprendedores de éxito, se encuentran experiencias y relaciones cruciales que brindan la crianza o el cultivo necesario para desarrollar talentos o bien, para generar nuevas habilidades $\mathrm{O}$ competencias (Lichtenstein, 1992). Estas historias generalmente revelan la existencia de apoyos, ya sea de grupos de especialistas, experiencias brindadas por individuos cercanos, instancias de incubación de empresas, programas específicos de apoyo a emprendimientos en universidades, lo que estos brindan son la oportunidad de pertenecer a un ecosistema que brinda oportunidades para aprender, para participar en una serie de intentos y fracasos con aprendizajes significativos y que, con el tiempo, se fueran desarrollando esas habilidades y competencias.

El proceso de desarrollar esas habilidades y competencias no es una cuestión de "adquirir" información pasivamente, recibir servicios o adoptar las últimas prácticas comerciales. De ahí la importancia de una educación emprendedora transversal a los programas educativos, pues implica cambios significativos para hacer ajustes a las prácticas de los individuos, permitirles conocer sus propios talentos, y desarrollarlos de manera individual y por medio de actividades colaborativas. Volverse más hábil, a menudo implica cambios importantes, cualitativos, y a veces, difíciles en los comportamientos, capacidades, creencias e identidades personales, por ello la relevancia de la afirmación de Lichtenstein \& Lyons (2001), pues si verdaderamente queremos formar emprendedores, es necesario permitirles que experimenten, que participen de proyectos reales, 
promover su creatividad con sentido social, orientarlos en su propio proceso de crecimiento emprendedor (Alexander \& Langer, 1990; Bechard \& Toulouse, 1998).

Una transformación representa un salto a un nivel superior de funcionamiento. Es un cambio cualitativo, no cuantitativo. Mientras que el proceso de informar tiene lugar dentro de una estructura y un conjunto de habilidades existentes, la transformación implica un cambio en la estructura del individuo o empresa en sí, y la creación o desarrollo de nuevas capacidades. La diferencia entre información y transformación es similar a la que existe entre crecimiento y desarrollo. El crecimiento es un concepto de escala que ocurre dentro de las formas existentes de hacer las cosas. E desarrollo, por el contrario, significa encontrar nuevas formas de hacer las cosas que permitan el logro de posibilidades completamente nuevas (Lichtenstein \& Lyons, 2001).

Muchos profesionales del desarrollo empresarial (incluido el desarrollo de emprendimientos), operan bajo supuestos erróneos de que están ayudando a los emprendedores a desarrollar nuevas habilidades y competencias, y para hacerlo, les enseñan a redactar planes de negocio o brindándoles cursos de capacitación sobre cómo hacerlo. Cualquier formación que pueda completarse en un ciclo (tetramestre, semestre o año), sólo será capaz de proporcionar información, sin embargo, no podrá contribuir a la transformación del estudiante, pues no será capaz de desarrollar nuevas capacidades o habilidades. De la misma forma, participar en un proyecto de incubación de empresas (con asistencia técnica o financiera) sin la información técnica (administrativa, operacional, mercadológica y financiera) suficiente adquirida previamente, tampoco le será de provecho al estudiante, pues el valor de esos recursos se adquiere cuando el emprendedor tiene las habilidades necesarias para usarlos de manera efectiva (Glasmeier, Fuelihart, Feller \& Mark, 1998). Es el nivel de desarrollo del 
emprendedor lo que influye en la preparación, la voluntad y la capacidad para utilizar la asistencia técnica y financiera. Como resultado, la prestación de estas asistencias (en un proyecto de incubación) debe estar directamente relacionadas al nivel de desarrollo del emprendedor para que sean eficaces, esto ocurre pues no se tienen programas integrales de desarrollo emprendedor en las universidades, se siguen acogiendo a programas aislados (académicos y de incubación), que en ocasiones incluso, no tienen relación unos con otros.

\subsection{Situación de la educación emprendedora}

El desarrollo del espíritu emprendedor es uno de los temas académicos más discutidos en la actualidad, debido, como se ha establecido anteriormente, a su importancia en la contribución al desarrollo económico en todo el globo. Según Stamboulis y Barlas (2014), el espíritu emprendedor y las nuevas empresas se han convertido en un valioso potencial para el desarrollo y la economía, lo que se traduce en un crecimiento de la sociedad hacia la modernidad.

Desde la década de los años sesenta, según Da Silva et al. (2015), el número de cursos sobre fundamentos de emprendimiento en las universidades en los Estados Unidos habían incrementado exponencialmente, principalmente debido al creciente interés del gobierno por impulsar la creación de empresas y de esa forma aliviar el desempleo. Por lo que la educación emprendedora se abrió paso en medio de una serie de eventos que afortunadamente fue apoyada por las universidades.

Esta necesidad que de pronto enfrentan las universidades de cultivar la mentalidad emprendedora a fin de que los estudiantes puedan adaptarse a la transformación y mejora económica, así como la construcción y desarrollo de una cultura y economía emprendedora, ha sido abordado por las instituciones de distinta forma. Sin embargo, es de resaltar 
aquellas que tienen como común denominador estrategias de búsqueda de talentos y de formación en innovación, pues son éstas las que promueven un desarrollo emprendedor aprovechando la tecnología, y que se asientan en la formación de ingeniería dada su naturaleza.

Para Ruda, Martin y Danko (2012), luego de un análisis de las diversas estrategias de las instituciones de educación superior en Rusia y Alemania, conciben que para efectos de aprovechar las oportunidades regionales, locales y nacionales e impulsar positivamente la economía, es necesario establecer estrategias institucionales (de educación superior) que verdaderamente promuevan una cultura emprendedora, es decir, proyectos educativos en licenciatura, en particular en ingeniería, donde el resultado demuestre que el estudiante se encontró inmerso en la solución de una problemática, demostrando la capacidad de toma de decisiones y el diseño de una solución e implementación de una solución que en su conjunto, demuestre la competencia emprendedora. Según los mismos autores, en países como Estados Unidos y Japón, han promovido enérgicamente la educación emprendedora, soportando la formación universitaria con estrategias transversales a los programas educativos, y apoyos relevantes que efectivamente fomenten en los graduados el lanzar o iniciar un emprendimiento, lo que aumenta considerablemente la empleabilidad de los estudiantes, una medida importante para las mismas instituciones educativas en sus indicadores de calidad.

Hamilton, Crawford \& Suuberg (2005) afirman que, a pesar de la existencia del espíritu emprendedor durante mucho tiempo en sociedades organizadas, la idea de una educación emprendedora, como tal, es un concepto relativamente nuevo.

La educación emprendedora se centra en preparar a los estudiantes universitarios para ser empresarialmente responsables, conocer los procesos para el diseño y creación 
de modelos de negocio, la legislación aplicable, los riesgos asociados, los diversos modelos de gestión y que su aprendizaje los sumerja en aprendizajes aplicados a la vida real, no para navegar sólo en la teoría, sino que les implique y sensibilice de los problemas que aquejan a la sociedad y que se involucren en el diseño de soluciones, y entones aprendan de las experiencias y pierdan el miedo a intentarlo.

La educación emprendedora presenta una buena oportunidad profesional para estudiantes de ingeniería en particular, debido a la creciente importancia de las nuevas tecnologías, en todo el globo.

Como se ha establecido con anterioridad, si bien el emprendimiento ha estado presente siempre en el transcurso de la historia, es en años recientes que comienza a tomar mayor auge pues el autoempleo es una posibilidad real de superar los constantes y crecientes problemas económicos a nivel global. Es por esta razón, que la formación de competencias emprendedoras se vuelve un elemento imprescindible para que los profesionales se adapten a los nuevos mercados laborales con éxito.

El fenómeno del emprendimiento ha tomado relevancia en el ámbito educativo y de investigación científica, principalmente por la necesidad de conocer cómo se puede impulsar desde las aulas una educación emprendedora (Kantis, Ishida \& Kmori, 2002; Cornelius, Landström \& Peterson, 2006; Sánchez, Wars, Hernández \& Florez, 2017; Busenitz, West, Sheperd, Nelson, Chandler \& Zacharakis, 2003; Guerrero \& Santamaría-Velasco, 2020; Ferreira, Reis \& Miranda, 2015).

Este creciente interés académico en torno al emprendimiento tiene cimiento en la evidencia, a la que se refirió con anterioridad, respecto a su contribución al desarrollo económico, a la modernización y al rejuvenecimiento del tejido social-productivo, al relanzamiento de los espacios regionales, a la creación de políticas públicas de apoyo, a la 
dinamización del proceso innovador y a la generación de nuevos puestos de trabajo que impacten positivamente la economía (Sánchez, Ward, Hernández \& Florez, 2017).

A fin de comprender mejor la importancia de la educación emprendedora, es inminente entenderlo desde el grado e impacto del emprendimiento en la sociedad, pues contribuye al desarrollo socioeconómico de las sociedades de diversas formas, entre ellas:

a. Identificar las oportunidades existentes en el mercado. A través de la producción u distribución de bienes y servicios, las empresas emprendedoras buscan satisfacer las necesidades de los clientes y mejorar los medios de vida. La investigación de mercado constante proporciona información sobre las necesidades de los clientes existentes que informan las decisiones para proporcionar bienes y servicios.

b. Crear oportunidades de empleo. La actualización económica que puede estudiarse a través de cifras como las publicadas por el Banco Mundial, puede advertir que, a mayor creación de empleo, detrás puede advertirse que las políticas públicas ofrecen mayor facilidad para hacer negocios. El espíritu emprendedor ayuda a cerrar la brecha del desempleo a través de la creación de empresas comerciales formales e informales que emplean a millones de personas (Da Silva, Costa y De Barros, 2015; Doran, McCarthy \& O’Connor, 2018).

c. Contribuir al Producto Interno Bruto (PIB). A través del pago de impuestos, las empresas contribuyen a los ingresos públicos que, en consecuencia, facilitan el desarrollo económico. Las iniciativas emprendedoras contribuyen al PIB, lo que advierte de su importancia al aumentar los ingresos y financiar proyectos gubernamentales, además de contribuir al crecimiento económico (Sánchez, 2010).

d. Desarrollar infraestructura. Los emprendimientos empresariales abren el desarrollo de infraestructura en los 
municipios y regiones donde se establecen. La creación de empresas a menudo conduce al desarrollo de redes de transporte y comunicaciones, impulsadas por la necesidad de infraestructura creada por estas empresas.

e. Contribuir al desarrollo de la comunidad. A través de la participación en la responsabilidad social corporativa, los empresarios contribuyen y apoyan el desarrollo de la infraestructura en educación, servicios médicos, capacitación, tutoría empresarial y algunas otras necesidades sociales (Bueno \& Casani, 2007).

El fomento y desarrollo del espíritu emprendedor es vital para la economía de cualquier país, ya que respalda la contribución del gobierno en provisión de bienes y servicios. Por lo que es importante diseñar e implementar políticas públicas y estrategias que promuevan la educación emprendedora.

Es entonces necesario considerar que, la consolidación de estrategias que favorezcan la educación emprendedora adquiere relevancia. No sólo se trata de agregar una materia que les oriente en la teoría, sino que es importante resaltar el perfil emprendedor y los avances de este mismo con base en las competencias que el perfil del egresado debe adquirir, a fin de considerar la educación emprendedora de manera transversal a todos los programas educativos, para que los egresados puedan llegar a generar emprendimientos que promuevan el autoempleo y la generación de nuevos empleos.

Significa entonces que, aplicado al ámbito educativo, es preciso establecer en las universidades, programas integrales que propicien un ambiente que fomente la adquisición de actitudes emprendedoras, el desarrollo de una mentalidad emprendedora, que se incuben competencias que favorezcan que el profesionista se convierta en un agente de cambio para contribuir al desarrollo de emprendimientos desde un ecosistema propicio (Clark, 1998; Ratten, 2017; Sánchez, Ward, Hernández \& Florez, 2017; Liu, 2016; Guerrero \& Santamaría-Velazco, 2020), de modo que la retroalimentación 
positiva y de aprendizaje aumente las expectativas de un emprendimiento exitoso.

La planeación de cursos de base tecnológica puede ser una experiencia educativa gratificante, tanto para estudiantes como para profesores. Y proporciona a los estudiantes una experiencia simulada, pero realista, de la que obtengan una mayor comprensión de lo que significa realmente volverse emprendedor, y no quedarse en conocer sólo la teoría.

En el caso de los profesores, tienen la oportunidad de aprender de los programas de emprendimiento de otras instituciones, públicas o privadas, apegarse a las buenas prácticas, diseñar los cursos y programas más adecuados con base en la experiencia, de modo que se enfoquen en experimentar con desafíos, para lograr escalar y realmente transformar los talentos de sus estudiantes.

Los nuevos imperativos establecidos en la era de la sociedad del conocimiento, requieren de los estudiantes de ingeniería habilidades y competencias que abarcan un amplio y diverso rango de saberes, entre los que destacan el emprendimiento, el liderazgo y la toma de decisiones.

El propósito de la educación emprendedora no sólo debería ser la sensibilización y conocimiento de los fundamentos teóricos, como se ha descrito anteriormente, sino adentrarse en el descubrimiento de talentos y búsqueda de habilidades y competencias emprendedoras y empresariales, con rigor metodológico en el ámbito de una confluencia interdisciplinaria que produzca los resultados esperados, que significa el fomento de nuevos emprendimientos comerciales por parte de los estudiantes o graduados.

La educación superior juega un papel fundamental para sentar las bases para el desarrollo de esas competencias. Tradicionalmente la educación empresarial se enfocaba sólo a las escuelas de negocios, sin embargo, en una época en la que la tecnología lidera el avance empresarial y económico, es 
necesario expandir las fronteras de disciplinas rigurosas e involucrar a los estudiantes en proyectos multidisciplinarios.

La educación emprendedora consiste en formar a los estudiantes en el proceso, conocimiento y diseño de soluciones de emprendimiento innovadoras, por lo que las competencias y habilidades que se requiere desarrollar difieren de las que otras asignaturas trabajan. Sólo por mencionar un ejemplo, en una asignatura como Tecnologías de la Información, se centrar en diseñar una propuesta de solución a un problema, mientras que en Formación de Emprendedores, no sólo se diseña e implementa la solución, sino que se enfoca en el análisis de la necesidad del cliente proponiendo una propuesta de valor integral, lo que impulsa el desarrollo de la competencia comunicativa, liderazgo, análisis de mercado, negociación, perfilado y atención del cliente, ingeniería, toma de decisiones, entre otros.

Para Yang y Zhao (2014) si las instituciones de educación superior cultivaran activamente la capacidad emprendedora en sus estudiantes, mejorarían el sistema de gestión de la educación en innovación, emprendimiento y el sistema de educación empresarial en lo general, pues crearían el ecosistema necesario que promueva y fomente de forma más natural el entrenamiento donde se desarrollen estas competencias, volviéndose universidades emprendedoras.

Por lo tanto, en este sentido, las instituciones de educación superior deberían prestar más atención al desarrollo de las competencias en sus estudiantes, en especial a los estudiantes de ingeniería, como universidades emprendedoras, mientras que la fundamentación teórica puede ser alcanzada por los propios estudiantes, entre líneas, durante el desarrollo de estos proyectos multisciplinarios.

Una universidad emprendedora responde entonces, generando una transferencia de tecnología basada en el conocimiento, con la promoción de emprendimientos 
basados en desarrollo tecnológico y el perfeccionamiento de capital humano altamente calificado.

Considerando los requisitos profesionales, muchos de los institutos de investigación en ciencia e ingeniería requieren que sus miembros tengan formación empresarial. La educación empresarial es particularmente relevante porque juega un papel preponderante en el desarrollo de proyectos industriales conjuntos de SET (de las siglas en inglés para ciencia, ingeniería y tecnología), dado que la capacidad empresarial y la orientación a la atención de necesidades del cliente es reconocida por el gobierno y, por lo tanto, existen programas fiscales y económicos que los favorecen buscando la competitividad (Da Silva et al., 2015).

Los académicos reconocen ampliamente que la investigación en las universidades es crucial para la innovación y el emprendimiento. Gran parte de la literatura sobre investigación universitaria, sin embargo, evoca un modelo lineal de ciencia que se centra en el desarrollo de productos y deja muy poca evidencia de la importancia del desarrollo de patentes y licencias, que debería ser más natural para los centros de investigación universitarios. Esta perspectiva corre el riesgo de que las instituciones de educación superior pierdan el foco sobre la diversidad de opciones y formas en que la ciencia y la empresa pueden entrelazarse, y las innumerables convenciones en que pueden colaborar.

Existen programas de ingeniería que enfatizan la importancia de la innovación tecnológica ofreciendo optativas que los promuevan, entre ellas las de educación emprendedora. La integración de este tipo de asignaturas en los programas de ingeniería, por lo general se enfocan en el diseño final de la solución, y no se detienen a ver el detalle del desarrollo de competencias y habilidades emprendedoras en los estudiantes, que debería ser parte fundamental, sin embargo, el tiempo en una sola asignatura no es suficiente para cubrir 
lo que se requiere (Dahm, Riddell, Merrill, Harvey \& Weiss, 2013).

La formación de ingenieros tiene un papel inherente al desarrollo y formación de emprendedores. Dado que el emprendimiento es un proceso dinámico con visión empresarial, diseño, cambio y creación para la solución de problemas, la formación de ingenieros aporta energía y pasión hacia la creación e implementación de soluciones creativas e innovadoras de forma continua. Las escuelas de ingeniería se han mantenido pasivas ante tal escenario, lo que ha resultado en un desperdicio de talentos y posibilidades de desarrollo emprendedor, pues de forma congénita, se deberían formar ingenieros emprendedores, si se les permitiera desarrollar sus talentos y habilidades naturales con mentalidad empresarial.

\subsubsection{Rutas de la ingeniería hacia la educación emprendedora}

En años recientes la formación de ingenieros ha experimentado un periodo de innovación (Graham, 2012). El aumento en el costo de la educación, la cambiante economía global, el énfasis en las oportunidades profesionales y los avances en cuanto al entendimiento de la forma en que los estudiantes aprenden, han generado la creación de nuevas iniciativas y modelos pedagógicos que han enmarcado estas nuevas propuestas de educación en ingeniería, adaptando a los egresados a las competencias del siglo XXI (Lattuca, Terenzini, Knight \& Ro, 2014).

Mientras es comúnmente aceptado que los egresados de ingeniería sean expertos técnicos, esto ya no es suficiente en el mercado. Las responsabilidades de un profesional de la ingeniería van más allá de la solución de problemas técnicos que impliquen resolver problemas y orientar soluciones. Ahora se espera que los ingenieros desempeñen un papel en el mercado que implique no sólo la identificación y atención de las necesidades del cliente, sino que sean estos abordados 
mediante el diseño de propuestas de solución técnica creativas e innovadoras (Kriewall \& Mekemson, 2010).

La profesión de ingeniero debe responder a las prioridades nacionales, los grandes desafíos globales, las dinámicas necesidades de mano de obra del mercado, y debe estar igualmente abierto a todos. De modo que, algunas instituciones de educación superior han explorado activamente varios medios de innovación pedagógica implementando programas de emprendimiento específicamente diseñado para programas de ingeniería (Bilén, Kisenwether, Rzasa \& Wise, 2005; Ochs, Walkins \& Boothe, 2001).

Históricamente, la educación emprendedora para ingenieros se ha considerado en gran medida como una subdisciplina de la educción en negocios y se ofrece como una asignatura genérica y electiva, normalmente plagada de fundamentos teóricos, planeación empresarial y análisis de casos, normalmente de empresas extranjeras. En los últimos años, algunas escuelas de ingeniería han comenzado a promover la educación emprendedora como un mecanismo para el desarrollo de la fuerza laboral de innovación dentro del campo de la ingeniería (Duderstadt, 2010).

Dentro de las escuelas de ingeniería, los profesores e investigadores han aprovechado los avances en la innovación educativa para ofrecer una variada gama de oportunidades de emprendimiento para los estudiantes, desde cursos simples ofrecidos en asignaturas teórico-prácticas, hasta cursos integrales basados en resolución de problemas reales en conjunto con la industria, de modo que se pueden ofrecerse certificaciones, o especializaciones en una programación extracurricular para acelerar el desarrollo de competencias, teniendo el soporte de un ecosistema emprendedor dentro de la universidad donde confluyan distintas asignaturas, se desarrollen proyectos multidisciplinarios y concursos. Estos esquemas son altamente favorecedores en el fomento de una 
profesión ingenieril creativa, innovadora y colaborativa, que respeta la inclusión.

Si bien la educación emprendedora se ha convertido en un mecanismo comúnmente aceptado para desarrollar talento humano de calidad, también en cierto que la diversidad y la multidisciplinariedad juegan un importante papel en la innovación (Talke, Salomo \& Rost, 2010). Por lo que, es sustancial comprender cómo es que los enfoques actuales de educación emprendedora impactan en la diversidad y la inclusión, con el propósito de confirmar si generan ecosistemas favorecedores para el desarrollo de la mentalidad emprendedora.

En el entorno global, el debate sobre el rumbo que ha de tomar la formación de ingenieros coincide en que los motores económicos de los países dependen de mejorar la competitividad técnica, y eso no se alcanza sólo egresando una mayor cantidad de ingenieros, sino que es necesaria una formación más amplia que sólo una formación técnica.

La formación de ingenieros debe volverse más atractiva en aras de generar una mayor retención de estudiantes, impulsando enfoques pedagógicos de aprendizaje activo, por ejemplo, de esa forma, la formación sea más práctica e involucrando a los estudiantes en el desarrollo de casos junto a la industria, en aras de buscar mayor relevancia para los problemas sociales y ambientales actuales.

En este sentido, al analizar estos grandes temas hacia donde se dirige la formación de ingenieros, la formación emprendedora pareciera una mera distracción, sin embargo, el fomento a la mentalidad emprendedora es la clave para cambiar la formación de ingenieros, pues, es una fuerza disruptiva positiva que permite que la educación de ingenieros sea más práctica y orientado a resultados. 


\subsection{Razones para fomentar la educación emprendedora en programas universitarios de ingeniería}

Como se ha establecido anteriormente, con los recientes desarrollos tecnológicos, la globalización y la revolución de Internet, el entorno de mercado en los negocios ha cambiado. Con mercados impulsados y centrados por el cliente, sus necesidades en entornos altamente competitivos han llevado a muchas empresas en diversos países a participar en actividades offshore (fuera de sus fronteras), incluso para el desarrollo de actividades complementarias no de competencias centrales. Esto ha afectado las oportunidades laborales para egresados en ingeniería. Lo que hace que sea cada vez más importante que los ingenieros comprendan y se adapten a las complejidades de un entorno altamente cambiante y que sean capaces de crear puestos de trabajo para sí mismos y a través de iniciativas empresariales.

Las pequeñas y medianas empresas están experimentando un rápido crecimiento, y esto ha permitido que la empleo y el autoempleo para ingenieros igualmente aumente (Nichols \& Armstrong, 2003). Por lo tanto, se ha vuelto imperativo para los ingenieros desarrollar una mentalidad emprendedora dadas las circunstancias. La evidencia reciente sugiere un cambio gradual en la formación del ingeniero, que culturalmente se asociaba con la mentalidad de emplearse una vez concluidos los estudios universitarios, lo que significa que el cambio de paradigma sea ahora que tenga una mentalidad emprendedora y buscar oportunidades en el mercado para construir y emprender con independencia (Wang \& Kleppe, 2001).

Existe un consenso sobre la necesidad de impartir habilidades emprendedoras en los programas universitarios de ingeniería (Patel \& Basu, 2006). El objetivo general es desbloquear la habilidad natural del ingeniero de generar ideas innovadoras usando el pensamiento creativo, mejorando así las posibilidades de que estos estudiantes desarrollen la 
competencia necesaria para emprender, con una perspectiva de encontrar necesidades $y$ atenderlas proponiendo soluciones viables, buscando oportunidades de manera proactiva, tomando riesgos calculados y ejecutando el pensamiento de diseño. Existe literatura que avala que mientras el estudiante de ingeniería tenga mayores oportunidades de preparación en los fundamentos de la educación emprendedora, mejores condiciones tendrán para enfrentar la posibilidad de desarrollar soluciones de ingeniería que aborden las necesidades de los clientes en un mercado cada vez más global (Nichols \& Armstrong, 2003; Liu, 2016; Yang \& Zhao, 2014; Sánchez, Torres \& García, 2014; Da Silva, Costa \& De Barros, 2015; Jarrar \& Anis, 2016). Esto al mismo tiempo, contribuye positivamente al éxito en el emprendimiento. No obstante, existe un debate continuo sobre la mejor forma de impartir estas habilidades de emprendimiento en la formación emprendedora de ingenieros. El enfoque más común adoptado por un número creciente de universidades es introducir cursos de emprendimiento en el plan de estudios de ingeniería. Hoy muchas universidades ofrecen programas con materias que preparan teóricamente a los estudiantes en la creación de emprendimientos.

Existen diversas razones por las cuales las universidades han optado por incluir materias de formación de emprendedores en los planes de carrera de ingeniería, algunas de las más recurrentes son:

a. Los ingenieros, con su conocimiento en los avances científico-tecnológicos, se encuentran en una excelente posición para iniciar nuevas empresas de base tecnológica.

b. La educación emprendedora ofrece a los estudiantes de ingeniería la oportunidad de convertirse en emprendedores, naturalmente los atrae y motiva.

c. La educación emprendedora proporciona visibilidad y potencial de ingresos a la universidad con los 
emprendimientos académicos, cuando se tiene la infraestructura en las universidades de programas específicos que promuevan la creación de emprendimientos o programa de incubación.

d. La comunidad universitaria y la sociedad a la que sirven, se benefician del empleo y los ingresos generados a través de los nuevos emprendimientos.

e. La educación emprendedora exitosa tiene el potencial de generar nuevas industrias que resulten en beneficios para la comunidad científica y académica, incluso a nivel regional y nacional.

Si bien muchas universidades y escuelas de ingeniería reconocen ahora la necesidad de incorporar la educación emprendedora en sus planes de estudio, debaten aún sobre la mejor manera de hacerlo.

Esto implica evaluar aspectos curriculares como la calidad y el número de emprendimientos, la variedad de los cursos, el valor de invitar conferencistas a programas específicos de empresa en el aula para compartir experiencias y motivar al emprendimiento, capacitar a los profesores para que adecuadamente involucren competencias transversales en la cátedra programada, y en general programas que motiven y promuevan el aprendizaje experiencial.

Existen casos, aunque pocos, de universidades que combinan el aprendizaje en el aula con la experiencia de la industria (Creed et al., 2002; Aguilar et al., 2016), estos programas tienen el propósito de invitar a profesionales de la ingeniería en ejercicio en actividades académicas, generando un impacto sistemático en los estudiantes y su formación que se consolide progresivamente, no sólo en la generación de egresados más capacitados para el mundo laboral, sino mayor capacidad de capital y talento humano para la industria misma. Este tipo de programas incentiva a los estudiantes si se les invita a descubrir sus talentos, y encontrar que éstos pueden tenerlos 
y ser desarrollados a fin de familiarizarse con conceptos y habilidades de emprendimiento.

La educación emprendedora aún tiene mucho camino por recorrer, como se ha visto hasta ahora, sin embargo, los esfuerzos de algunas instituciones de educación superior generan programas que aventajen a sus estudiantes a través de rutas menos convencionales que incitan al emprendimiento, fomentando su participación en actividades extracurriculares que potencian sus talentos y celebran la creatividad y la innovación. 


\section{Redefinición de la formación de ingenieros emprendedores}

La educación emprendedora es ampliamente reconocida como un campo importante de estudio y práctica. Lo anterior se ha enfatizado en el capítulo tercero. En una investigación reciente, Landström y Harirchi (2019) señalan que la educación y el aprendizaje emprendedores ocuparon el tercer lugar entre los diez temas más interesantes y prometedores en la investigación en emprendimiento, debido a su relevancia y potencial para mejorar el bienestar social; como se ha desarrollado en los capítulos primero y segundo. Dicho esto, existe menor énfasis en la educación para el emprendimiento en ciencia, tecnología e ingeniería, a pesar de que la atención reciente en la creación de nuevas empresas se ha centrado en los "unicornios" tecnológicos (aquellas empresas cuyas valoraciones en la oferta pública inicial superan los mil millones de dólares estadounidenses).

En consecuencia, la educación para el emprendimiento en ciencia, tecnología e ingeniería sigue siendo un tema relativamente inexplorado que ofrece una variedad de oportunidades para la investigación académica. En este capítulo se tiene el objetivo de crear y fortalecer, aún más, las conexiones entre la educación en ciencia y tecnología (gestión) y los campos de la educación en emprendimiento. Ofreciendo una mejor comprensión de cómo las diferentes dimensiones de la educación para el emprendimiento en ciencia, tecnología e ingeniería (como contexto, programas, ontología, axiología, pedagogías, modelos de enseñanza, contenidos y mecanismos de apoyo), impactan en el proceso emprendedor en ciencia y tecnología (Fayolle \& Gailly, 2008).

$\mathrm{Al}$ explorar las brechas entre las prácticas de enseñanza y aprendizaje predominantes y las necesidades reales, se pretende resaltar los desafíos que enfrentan los científicos e ingenieros para convertirse en emprendedores exitosos, bien preparados y capacitados. Esto implica que el 
emprendimiento tecnológico, debe ser aprendido por estudiantes de ingeniería, ciencia y tecnología, mediante el uso de modelos y metodologías activas, es decir, aprender haciendo.

La educación emprendedora preparara a los estudiantes de cualquier área de ingeniería, en el conocimiento, las herramientas y las actitudes que se requieren para identificar las oportunidades (necesidades o problemas) y darles vida (propuesta de solución) a través de proyectos innovadores. Los estudiantes de ingeniería que participan en programas de emprendimiento durante la universidad, obtienen conocimientos y competencias que no alcanzan en sus programas educativos de especialidad, y que son solicitados por los organismos de certificación y acreditación a nivel mundial, como son la comprensión y el pensamiento de diseño (design thinking), empatía con los usuarios finales, gestión de equipos multidisciplinarios, comunicación efectiva, pensamiento y análisis crítico, la comprensión de conceptos básicos de negocios, figuras de protección de propiedad intelectual, el desarrollo de un perfil emprendedor competitivo y la resolución de problemas complejos, por mencionar algunos (ABET, 2021; ANECA, 2021; ENAEE, 2021; OECD, 2005, 2021; World Economic Forum, 2009, 2018; ANFEI, 2016; CACEI, 2018).

Muchas organizaciones académicas están llamando la atención sobre la necesidad de hacer cambios urgentes en los planes de estudio y los métodos de aprendizaje, necesarios para la transformación social continua en un mundo cambiante y controlado por la tecnología. Habilidades transversales como la capacidad de pensar de manera creativa, disruptiva y crítica, tomar riesgos e iniciativa, y trabajar en equipos multidisciplinarios de forma colaborativa, son fundamentales para garantizar talento humano calificado para adaptarse a esta transformación. 
Publicaciones recientes de grupos académicos, profesionales e incluso organizaciones gubernamentales, afirman que el pensamiento de diseño tiene el poder de estimular estas competencias sociales e impulsar la innovación en las organizaciones y la educación (Owen, 2006; Lockwood, 2010; Brenner \& Ubernickel, 2016; Prud'homme van Reine, 2017; Taricani, 2021; Auernhammer \& Roth, 2021). El pensamiento de diseño es más que un modelo para innovación. Se refiere a una combinación de mentalidades, procesos y conjuntos de herramientas que ayudan a las personas a desarrollar empatía dentro del contexto del problema, generar ideas y soluciones creativas, y analizar y ejecutar de forma sistemática y racional, soluciones adecuadas para el mismo contexto.

La razón por la que se ha decidido que el pensamiento de diseño sea el modelo implementado para la promoción de la mentalidad emprendedora, es porque se tiene evidencia en la literatura que la promoción del pensamiento de diseño favorece la transversalidad, y es dirigida por los docentes quienes rediseñan sus cursos aplicando nuevos enfoques pedagógicos como el aprendizaje activo, generando impactos favorables en la formación profesional de los estudiantes universitarios (Nakata \& Hwang, 2020).

La investigación centrada en el desarrollo de competencias emprendedoras en los planes de estudio universitarios tiene dos vertientes. Los partidarios de la primera argumentan que la formación del espíritu emprendedor debería centrarse en el desarrollo de habilidades blandas. Su lógica es sencilla de entender: estas habilidades son la clave para el desarrollo emprendedor, incluida la competencia comunicativa, la toma de riesgos, la toma de decisiones, el liderazgo y la capacidad de evaluar las perspectivas de desarrollo.

Por lo tanto, uno de los principales teóricos de esta perspectiva de la orientación de la educación emprendedora, Johannisson (1991), ha identificado cinco competencias que necesita desarrollar un emprendedor: comprender por qué 
quieren ser emprendedores, saber cómo hacerlo, tener conocimiento de con quién deben interactuar para que su negocio sea exitoso, tener una idea de cuándo lanzar su proyecto, y ser consciente de la necesidad de contar con habilidades generales y de conocimiento.

Muchos investigadores contemporáneos han examinado la importancia y el papel de las habilidades blandas en la formación de competencias emprendedoras en el sistema educativo. Por ejemplo, Kusmintarti, Thoyib, Maskie y Ashnar (2016), centrados en este mismo aspecto, sugieren estudiar la influencia de los cursos que desarrollan habilidades blandas sobre la eficacia de emprendedores graduados. Prestando importancia en que los planes de estudio de educación emprendedora, independientemente de la disciplina, se enfoquen en el desarrollo de estas habilidades.

Al mismo tiempo, el papel de las habilidades blandas en los programas educativos se discute a menudo en el contexto de las competencias universales (incluida la emprendedora) que deben desarrollarse de forma transversal, y no sólo en las disciplinas empresariales, sino mayormente en disciplinas técnicas, científicas y de ingeniería (Subach, Munukutla, Magrane \& Popovich, 2007; Pedrazzini, 2012).

Los partidarios del segundo punto de vista argumentan que el desarrollo de las habilidades técnicas entre futuros emprendedores es de gran importancia también. Consideran que un emprendedor no puede tener éxito sin las habilidades instrumentales relevantes para su particular área de negocio. Partiendo de este punto de vista, el objetivo principal de la educación emprendedora deberá ser desarrollar habilidades profesionales especializadas en un área en particular, mientras que, a las habilidades blandas, se les deja en un papel secundario, pues se considera que estas habilidades se pueden desarrollar en un contexto extracurricular, a través de actividades de negocio. 
Ciertamente los partidarios de esta corriente, no han sugerido excluir los cursos enfocados en el desarrollo de habilidades blandas de los programas de educación emprendedora. Sin embargo, señalan que tales disciplinas no deben ser prolíficas y deben proporcionar un conjunto de requisitos mínimos (Bowe, Taylor, Smith, Zuckerman \& Moore, 2003; Carassa, 1987).

Sin embargo, los programas de educación emprendedora no sólo incluyen módulos y cursos dirigidos a formar competencias técnicas o habilidades blandas. En esencia, la estructura de cualquier programa, incluidos los de educación emprendedora, deben comprender al menos tres criterios. El primero es que incluya módulos y cursos destinados a desarrollar competencias técnicas de la disciplina en la que se encuentren. El segundo, debe incluir disciplinas enfocadas en generar, desarrollar y fortalecer las habilidades blandas. Finalmente, un tercero que no tenga un enfoque en habilidades o competencias, sino que más bien los prepare en temas de ética, humanidades, matemáticas, física, historia o estudios culturales, que son aquellos que les brindan una formación integral.

De modo que, si el programa de estudios contiene un equilibrio entre estos tres grandes rubros, entonces el egresado tendrá un perfil que le proporcione, por un lado, los conocimientos generales, y por los otros dos, una adecuada formación de habilidades y competencias que se esperan de un experto en su disciplina. Como tal, la distribución de asignaturas dentro de un programa educativo, determina su enfoque, características y resultados.

A la luz de esto, puede observarse una tendencia emergente, sectores económicos que han surgido recientemente y se desarrollan con rapidez en una economía basada en el conocimiento, y destacando lo que tiene como base la propiedad intelectual, pues se ha desarrollado la economía de la innovación. El mercado está cambiando y exige de las 
universidades formar especialistas en estos nuevos sectores de la economía. El emprendimiento en estos nuevos campos de actividad demanda nuevas y más creativas competencias y habilidades, por lo cual, esto supone un complicado reto para las instituciones educativas.

Para poder cumplir con el reto, las instituciones de educación superior necesitan cambiar los enfoques tradicionales de formar profesionales, deben dar el ejemplo e innovar empleando nuevos enfoques pedagógicos y dejar de lado los tradicionales modelos expositivos. No es posible formar ingenieros emprendedores con modelos donde el docente sea el que transmite conocimiento al estudiante. Es necesario emplear estrategias de metodologías activas, centradas en el estudiante, donde sea él mismo quien construya el nuevo conocimiento, y que, a través de la guía del docente, descubra sus talentos y los aplique en la generación de modelos de negocio que respondan a problemáticas sociales, con innovadoras propuestas de valor. El problema principal será encontrar el equilibrio adecuado entre cursos que forman conocimiento fundamental, habilidades técnicas y competencias blandas, de modo que los estudiantes puedan tener un aprendizaje significativo.

\subsection{Ingenieros emprendedores}

El mundo está cambiando dinámicamente y está intensamente interconectado; así mismo, la innovación seguirá evolucionando rápidamente, razón por la cual, los involucrados en el desarrollo de tecnología deben trabajar colaborativamente en equipos multidisciplinarios. El panorama educativo y pedagógico actual, también se enfrenta a cambios importantes. La llegada de Internet, por ejemplo, ha cambiado fundamentalmente la forma en que se publica el contenido dentro del proceso de enseñanza y aprendizaje. Pero también el contenido en sí se ha adaptado a las tendencias globales. 
Barber, Madden, Mayo y Agarwala (2020) presentaron una experiencia práctica dirigida a las actitudes emprendedoras de los estudiantes de ingeniería. El estudio describió los esfuerzos para crear cursos de licenciatura que combinen competencias de la disciplina ingenieril con la formación basada en competencias de la educación emprendedora. El trabajo combinó un curso de diseño de ingeniería tomado por estudiantes tanto de negocios como de ingeniería, junto con un curso de formación emprendedora. Se formaron equipos mixtos de estudiantes de ingeniería y negocios a fin de que trabajaran en proyectos que se presentarían a inversionistas ángeles.

Gorlewicz y Jayaram (2020) comparten su experiencia en la integración de las 3 c's (curiosidad, conexiones y creación de valor) de la educación emprendedora, alineado al modelo de KEEN, la cual es una iniciativa empleada por escuelas de ingeniería alrededor del mundo, que favorece las redes de colaboración de ingenieros emprendedores (Rae \& Melton, 2017), en una serie de tres cursos de ingeniería, en dinámica y control. Los cursos que comienzan desde uno de dinámica de segundo año hasta otros más avanzados muestran a los docentes una manera de cómo comenzar el desarrollo de las actitudes emprendedoras de los estudiantes de ingeniería en el programa educativo. En otra investigación, investigadores aplicaron un recorrido emprendedor en estudiantes de segundo año de un programa de posgrado en ingeniería, en el que los estudiantes están inscritos al recorrido como programa. Este les asegura que las propuestas de los estudiantes para iniciar una start up estén listas, enviando altos riesgos de fallas iniciales. Las propuestas exitosas, fueron aquellas con miembros del equipo con antecedentes complementarios, generalmente diferentes a la ingeniería y que por lo tanto estaban acostumbrados a trabajar en equipos multidisciplinarios, eso permite que la visión del proyecto sea más amplia y la propuesta de valor más acertada. Los autores concluyeron que se percibe claramente el enfoque en la 
creación de valor, más allá de cualquier solución técnica (Martínez \& Crusat, 2019).

Ciampi et al., discutieron la inclusión del curso "trabajar con comunidades" en el tercer año de un programa de ingeniería. El curso brinda a los estudiantes la oportunidad de trabajar como consultores para fomentar una comunidad emprendedora en la sociedad. Durante el curso, los estudiantes desarrollaron habilidades, como la de tomar riesgos y convertir el fracaso de hoy en el éxito de mañana. Los estudiantes adquirieron la capacidad de evaluar su propio desempeño y hacer ajustes (Ciampi, da Rocha-Brito, Amaral, Vasconcelos \& Barros, 2016).

A la luz de la integración de la educación emprendedora en los programas educativos de ingeniería, Barba-Sánchez y Atienza-Sahuquillo, estudiaron el impacto de las motivaciones emprendedoras sobre las intenciones emprendedoras de los futuros ingenieros. Una contribución positiva de la mentalidad emprendedora, respaldada por la comprensión de la importancia de la independencia de los futuros ingenieros en cualquier tipo de economía y apoyo financiero familiar. Además, el estudio muestra también un efecto moderador en la educación emprendedora sobre las intenciones, motivar a los futuros ingenieros también se logra a través de la exhibición de start ups exitosas, la realización de talleres sobre generación de ideas, lluvia de ideas, creación de modelos de negocios y organización de concursos de modelos de negocio (Barba-Sánchez \& Atienza-Sahuquillo, 2018).

Iacobucci y Micozzi (2012) evaluaron cursos de emprendimiento en una universidad italiana y discutieron los problemas y las oportunidades futuras de la educación emprendedora. Los principales problemas encontrados, son el número limitado de cursos en emprendimiento que ofrecen las universidades italianas debido a la centralización del sistema de educación superior, el método de enseñanza y el escaso número de académicos especializados en el tema con 
falta de cooperación entre las diversas instituciones de educación. Otros problemas encontrados incluyen un problema cultural, puesto que los estudiantes prefieren comenzar una carrera en el sector público y obtener una carrera en cualquier área buscando emplearse, antes que emprender.

Esto pone de manifiesto la necesidad de brindar mayor importancia a la educación emprendedora en las escuelas de ingeniería y ciencias, lo que inspira a empresas emergentes en sectores de alta tecnología y mejora las actitudes y la conciencia emprendedora entre los estudiantes (Iacobucci \& Micozzi, 2012).

Como se puede advertir, el ingeniero emprendedor necesita tener competencias técnicas, así como, una amplia gama de competencias requeridas más allá de la formación técnica en ingeniería, como se ha descrito anteriormente. En el ámbito de este libro, un ingeniero emprendedor es alguien que tiene una sólida formación en ingeniería y habilidades personales, interpersonales y de organización, que le permiten actuar sobre oportunidades e ideas, transformando el entorno al convertirlos en valor económico, cultural o social en beneficio de la sociedad que le rodea.

El futuro ingeniero debe desarrollar habilidades y rasgos emprendedores, tales como: sentido de la iniciativa, la capacidad de estar motivado y perseverancia ante los contratiempos y obstáculos, pensamiento analítico y crítico, capacidad para trabajar de forma estructurada y sistemática, la capacidad de tomar decisiones frente a la incertidumbre, así como, la identificación de oportunidades y la evaluación, presentación de ideas y modelos de negocio, además de la planeación y gestión de proyectos de emprendimiento. En resumen, que los ingenieros emprendedores deben formarse para que sean capaces de convertir las ideas creativas en acciones, tomando como impulsor de la innovación su formación ingenieril (UNESCO, 2010). 
La innovación es a menudo una consecuencia de una formación participativa y abierta en un ambiente de trabajo colaborativo y multidisciplinario (NAE, 2004). Cuando los estudiantes de ingeniería logran trabajar de esta forma en un ambiente de aprendizaje desafiante, logran desarrollar grandes proyectos, porque implica una coordinación de esfuerzos por reunir varias disciplinas, para proporcionar una propuesta de valor contribuyendo de forma complementaria cada uno desde su especialidad, de modo que la propuesta resulta realmente innovadora dando resultados útiles a la problemática encontrada.

Resulta enriquecedor analizar las experiencias de los equipos de trabajo en el aula, y ver cómo es que los miembros de los equipos enfrentan el reto de afrontar los potenciales talentos y limitaciones de los demás miembros del equipo, y que todo ello resulte en sinergias interesantes como actividades multidisciplinarias. Estos futuros ingenieros tendrán la oportunidad de trabajar con personas de otros dominios y experiencias, esto implica no sólo la simple colaboración, sino que requiere desarrollar habilidades sociales como la negociación, la competencia comunicativa, el liderazgo y el trabajo colaborativo, pues deben integrar datos, conceptos, perspectivas, y metodologías varias para poder encuadrar mejor la manera de resolver problemáticas reales, a través del fomento de la creatividad y la innovación generando propiedad intelectual para una competitividad sostenible.

Cuando se alcanzan estos objetivos educacionales en las actividades planeadas en el aula, se logra preparar de forma pertinente y adecuada a los futuros ingenieros que requieren más que sólo competencias técnicas. Pues al ingresar al mercado laboral, estas competencias específicas de la disciplina pronto se volverán obsoletas, y será su habilidad por actualizarse lo que les permitirá mantenerse vigentes en el mercado laboral. Sin embargo, las competencias blandas desarrolladas por su perfil emprendedor son atemporales y le 
serán útiles para resolver desafíos complejos en un contexto global y altamente demandante.

Algunos de los grandes retos de la ingeniería sólo podrán ser atendidos por perfiles de ingenieros emprendedores $\mathrm{e}$ innovadores, que sean capaces de aplicar la ingeniería y la tecnología a los problemas y desafíos que estos retos demandan, como la ayuda que el mundo en desarrollo requiere, la lucha contra el cambio climático, la restauración y mejora de la infraestructura urbana en las grandes ciudades, el combate a la escasez del agua, lograr que la energía renovable sea asequible, la universalidad de expedientes clínicos, entre muchos otros.

El pensamiento crítico y el actuar ético, son competencias que se esperan de un futuro ingeniero, pues con el desarrollo de la ciencia y la tecnología, es un desafío para el ingeniero promover aplicaciones técnicas que sean sostenibles y busquen el cuidado y utilidad a la sociedad en general. Para ello, se requiere que los estudiantes de ingeniería con perfil emprendedor se formen con estricto apego a la metodología científica, pues deben establecer vínculos con investigadores e institutos de investigación, de modo que las soluciones propuestas sean adecuada y correctamente fundamentadas en la ciencia.

Según Come, Fouger, Hawwash \& Van Petegem (2013), todos los ingenieros deben estar abiertos a la implementación de los resultados de la investigación, y la necesidad de involucrarse ellos mismos creativamente en actividades de investigación y desarrollo.

En conformidad con estas tendencias, el lugar de trabajo en el futuro será cada vez más dinámico e intensivo en conocimientos que lo que es actualmente. Por lo tanto, es necesario hacer adaptaciones a la manera en que en las instituciones de educación superior se forma a los ingenieros emprendedores. La historia tiene demostrado que a menudo 
es el emprendedor el que reacciona oportuna y eficazmente a los cambios, pues es quien aprovecha las oportunidades emprendedoras basadas en estos cambios en el entorno. Ante este contexto, es evidente que el emprendimiento y la educación emprendedora están adquiriendo una importancia significativa.

\subsection{La universidad emprendedora}

Con el fin de preparar eficazmente a los estudiantes para estos nuevos entornos de trabajo, la educación emprendedora de primer nivel debe implementarse en todo el sistema educativo y de manera transversal. La educación emprendedora se refiere a las actitudes y habilidades que los estudiantes deben desarrollar y potenciar. Debido a su papel específico en el sistema educativo, las universidades suelen estar siempre entre las primeras en revelar y adaptarse a los cambios.

En el contexto de la educación emprendedora, hay algunas universidades que se conocen como universidades emprendedoras, como Stanford, el Instituto Tecnológico de Massachussets (MIT) y Harvard, son de las líderes y más conocidas. Estas universidades han implementado la educación emprendedora en sus programas educativos, programas transversales y actividades extracurriculares (Klofsten, Fayolle, Guerrero, Mian, Urbano \& Wright, 2019; Etzkowitz, 2020; Cerver-Romero, Ferreira \& Fernandes, 2021; O’Reilly, Robbins \& Scanlan, 2019). En la actualidad, sus programas de educación emprendedora funcionan como modelos de buenas prácticas para otras universidades, mismas que tienen el objetivo de instalar conceptos similares dados los buenos resultados.

Desafortunadamente, la situación en México es bastante diferente, pues la educación emprendedora, en general, y la promoción de la mentalidad emprendedora, en particular, aún no son tan comunes. De hecho, existe poca literatura al respecto, con casos muy puntuales como el Instituto 
Tecnológico y de Estudios Superiores de Monterrey (Guerrero \& Urbano, 2012; Guerrero, Urbano, Cunningham \& Gajón, 2018).

La universidad como mercado laboral, se tornó global, tecnológica, innovadora y competitiva, lo que significa una absoluta transformación pasando de una institución tradicionalmente enfocada en sus dos principales funciones: la docencia y la investigación, a la llamada tercera función, o la colaboración entre la universidad y los agentes externos como parte de la formación de los estudiantes universitarios, lo que las vuelve una universidad emprendedora.

La universidad necesita dar respuesta a las necesidades de una economía basada en el conocimiento para preparar a los futuros profesionales con las habilidades y competencias necesarias para ser competitivos, no sólo local sino globalmente. Por esta razón, el emprendimiento debe instruirse y desarrollarse en las distintas disciplinas, desde las ciencias hasta las humanidades, y no sólo en escuelas de administración y negocios, como solía pensarse (Sam \& Van Der Sijde, 2014).

Sam \& Van Der Sijde (2014) resumen tres revoluciones emprendidas por universidades a lo largo de la historia. Primero, la incorporación de la investigación como área de formación de los estudiantes para trabajar en otras áreas que no eran académicas o de docencia (Etzkowitz, 2001, 2003, 2008, 2011). En segundo lugar, docencia e investigación universitaria dirigido a un desarrollo socioeconómico para la creación de nuevas empresas locales basadas en el conocimiento y venta de tecnología (Etzkowitz, 2001). Y, en tercer lugar, la transferencia de tecnología o la cooperación universidad-empresa en la que la universidad está en el desarrollo socioeconómico o servicio a la comunidad (Sam \& Van Der Sijde, 2014, p. 900). 
Esta última revolución o función de la universidad es bastante controvertida y aún debatida, es un cambio en la relación de la universidad, el gobierno y las empresas. Las universidades pueden, según Etzkowitz (2012), dar un paso atrás en la iniciativa emprendedora proactiva, y tomar un papel de regiones innovadoras al alcanzar la madurez, de modo que la "universidad pueda proporcionar nuevos modelos para la interacción social" (p.774), en la que se incrementa la permeabilidad al medio y los recursos se utilizan estratégicamente. Esto significa un cambio de gestión universitaria de un enfoque de abajo hacia arriba por uno de arriba hacia abajo y, por lo tanto, es todo un desafío para la universidad tradicional que aún se enfoca en la docencia y la investigación.

La universidad emprendedora participa en alianzas, redes y negocios a través de actividades con empresas públicas y privadas y el gobierno, a fin de encontrar colaboración e interacciones con el objetivo de vincular la educación, la investigación y las actividades con las tecnologías, los intereses sociales y el desarrollo económico (Guerrero \& Urbano, 2012).

Para Guerrero y Urbano (2012) el modelo de universidad emprendedora debe tener las siguientes características:

1. Factores formales: estructura organizacional y de gobierno empresarial, medidas de apoyo para emprendimientos, educación emprendedora.

2. Factores informales: actitudes de la comunidad universitaria hacia la mentalidad emprendedora, la enseñanza de metodologías emprendedoras en desarrollo de proyectos, modelos de buenas prácticas y sistemas de recompensas.

3. Recursos: talento humano, capital financiero, físico y comercial.

4. Capacidades: prestigio y estatus, redes y alianzas, localización. (p. 46) 
La universidad emprendedora puede definirse como una institución de educación superior que salvaguarda el conocimiento, la transferencia y la comercialización de iniciativas de emprendimiento innovador con las partes interesadas, la propia institución educativa, el gobierno y las empresas con recursos financieros y organizacionales con capacidad de conformar relaciones vinculadas (Kalenyuk \& Dyachenko, 2016).

La gran mayoría de las universidades realiza actividades de promoción del emprendimiento, por ejemplo, tener una incubadora de proyectos de emprendimiento, ofrecer asignaturas aisladas de educación emprendedora, sin embargo, eso no les cataloga como universidades emprendedoras. Para Sam y Van Der Sijde (2014), la universidad emprendedora puede asumir diferentes roles en la sociedad, dentro del proceso de innovación y colaborando en el ecosistema emprendedor de la comunidad. El emprendimiento también puede asumir diferentes funciones: comercial, social, cultural y cívico (Etzkowitz, 2013).

Es un hecho que las universidades están ampliando sus funciones y roles, que en opinión de Etzkowitz (2001, p. 24) este proceso se conoce como bi-evolución, pues la universidad está pasando de ser sólo transmisora de conocimiento, a estar más en contacto con las partes interesadas, y pasando de formar sólo individuos, a una formación colectiva, a desarrollar investigación con sentido en vinculación con la industria, respondiendo creativamente a problemas reales, atendiendo necesidades sociales, e incluyendo programas bien estructurados de incubación de empresas emprendedoras, incubadoras en red y redes de incubación con la industria (Etzkowitz, 2001).

De modo que la universidad está buscando formas en las que puede volverse económicamente independiente, generando sus propios ingresos y, al mismo tiempo, esto ha aumentado su contribución y papel en el ámbito local e internacional. La 
misión de las universidades no es sólo la formación, sino la de comercializar el conocimiento, y a través de ello, contribuir activamente al desarrollo de las economías regionales (Wong, Ho \& Singh, 2007).

El objetivo de una universidad emprendedora, no se constriñe únicamente a la generación y transferencia de tecnología en términos de start ups o algunos otros tipos de emprendimiento, sino en liderar la creación de pensamiento, mentalidad, acciones y el establecimiento de emprendimientos (Audretsch, 2014, p. 319). Por ello, el cambio de la universidad tradicional es una realidad, y la necesidad de estos cambios superan las barreras reales dentro de las propias estructuras y estrategias universitarias (Brennan, Wall \& McGowan, 2005; Etzkowitz, 2003). Por lo tanto, el dilema al que se enfrentan las universidades es cómo involucrarse en este fenómeno.

La universidad es un lugar propicio para la innovación y una incubadora natural; puede tener una estructura de apoyo que favorezca la creación de un ecosistema en el que profesores, investigadores y estudiantes encuentren lo necesario para diseñar y crear un emprendimiento, es decir, tienen la forma de proveer un marco intelectual, comercial y de vinculación, que favorezca estos emprendimientos.

En los últimos años, el dominio de la universidad emprendedora ha recibido una mayor atención de los especialistas. En particular, existen algunos modelos teóricos que se centran en la explicación del fenómeno emprendedor universitario (Gibb, 2012; Clark, 1998; Markuerkiaga, Errasti \& Igartua, 2014; O’Shea, Allen, Morse, O Gorman \& Roche, 2007; Salamzadeh, Salamzadeh \& Daraei, 2011). Sin embargo, poco se conoce sobre los factores que contribuyen al surgimiento de esta universidad emprendedora (Guerrero \& Urbano, 2012; Rothaermel, Agung \& Jiang, 2007), pues hacen falta estudios empíricos que analicen la influencia de estos factores, de modo que ofrezcan una oportunidad de aportes 
importantes que brinden no sólo reportes de buenas prácticas, sino orientaciones sobre el proceso que deben seguir las universidades tradicionales.

Basado en la literatura sobre la universidad emprendedora, Markuerkiaga et al. (2014), desarrollan un marco integrador para medir el emprendimiento académico. La investigación consta de tres elementos principales: factores externos de apoyo al emprendimiento, factores de apoyo al emprendimiento y resultados universitarios del emprendimiento.

El entorno externo se identifica como un componente del marco propuesto debido a su papel fundamental en la teoría y la investigación sobre la mentalidad emprendedora (Covin \& Slevin, 1991). El concepto de entorno externo tiene la intención de incluir aquellas fuerzas y elementos externos a los límites de las universidades que afectan su organización. Estas dimensiones incluyen la institucional, legal y el contexto administrativo.

El entrono interno de la organización es un factor importante para medir la capacidad del emprendimiento académico. Han sido muchos los autores que han intentado definir un marco para la universidad emprendedora analizando diferentes factores (Pei-Lee \& Chen-Chen, 2008; Clark, 1998; Guerrero, Urbano \& Kirby, 2006; Gibb, 2012; Kirby, 2006; Salamzadeh et al., 2011; Sporn, 2001; Wong, Ho \& Singh, 2007). La misma literatura muestra que los más citados son la misión, la estrategia, el diseño organizacional, la alineación y soporte desde el equipo directivo, las políticas y procedimientos, la internacionalización, los programas de formación extracurricular, la inclusión de profesionales de empresa y organizaciones en el desarrollo y diseño de los programas educativos, fondos de apoyo al emprendimiento, formación de emprendedores para la planta académica y las metodologías activas, importante punto que se ha analizado en capítulos anteriores. 
Existen diversas formas de medición de la universidad emprendedora, ciertamente algunas investigaciones muestran de forma clara que la tercera misión de esta universidad está relacionada con el desarrollo económico y social del entorno (Benneworth, 2007; Guenther \& Wagner, 2008; Guerero, Urbano \& Kirby, 2006; Philpott, Doodle, O’Reilly \& Lupton, 2011; Meyer, 2011; Mohar, et al., 2010), y que a su vez, tiene grandes fortalezas en los estudios académicos y actividades de emprendimiento (Philpott, Doodle, O’Reilly \& Lupton, 2011).

Según Markuerkiaga, et al. (2014), son nueve las actividades académicas de emprendimiento las que constituyen una universidad emprendedora: formadora de empresas spin-off (empresas creadas como resultado de proyectos de investigación académica con apoyo institucional), formación de empresas de estudiantes derivadas de programas de incubación, generación de patentes y licencias, vinculación con el sector industrial a través de convenios de colaboración en diseño y desarrollo, consultorías, cursos de educación emprendedora, movilidad académica e industrial, divulgación científica y participación en redes de emprendimiento.

\subsection{La eficiencia en los procesos de formación de ingenieros}

Se ha definido anteriormente la importancia del fomento a la mentalidad emprendedora en el ámbito académico se trata básicamente de lograr que los estudiantes exploten oportunidades emprendedoras. Una oportunidad emprendedora brinda la posibilidad de atender al cliente y sus necesidades de una manera más satisfactoria, además que, puede generar ventajas competitivas, pueden mejorar el equilibrio del mercado o, por el contrario, pueden destruir industrias enteras mediante la introducción de ofertas novedosas llevándose al mercado. 
Actualmente existen numerosas organizaciones, por ejemplo, Global Entrepreneurship Monitor (GEM). Global Entrepreneurship and Development Index (GEDI), Regional Entrepreneurship and Development Index (REDI), entre otras, que tienen como objetivo identificar tanto los requisitos previos, como los factores críticos de éxito que promueven la mentalidad emprendedora. A través de encuestas, estas organizaciones evalúan y comparan la capacidad individual de los sujetos de estudio. Además, revelan las capacidades públicas y sociales de los estados nación y las regiones. Estas capacidades se describen a través de varios indicadores. Entre ellos se encuentran, por ejemplo, la velocidad de transferencia de conocimientos de la ciencia al público, la facilidad de acceso a tecnologías novedosas, la percepción de los emprendedores y la mentalidad emprendedora en una sociedad, la facilidad para contratar y retener personal altamente capacitado, el grado de burocracia para iniciar un negocio, el tamaño y proximidad de las redes de expertos, la facilidad de obtener financiamiento y con qué condiciones, entre otros.

Además de estos indicadores, la calidad de la formación en emprendimiento y la educación disponible son otro factor de éxito crucial. Idealmente la educación emprendedora debería comenzar desde los niveles básicos en la infancia, y entonces, irse intensificando con la madurez del estudiante hasta llegar al nivel superior. Lo que vuelve de gran importancia la formación emprendedora en la universidad, pues son catalizadores del desarrollo tecnológico y el crecimiento económico. Para cumplir con esta responsabilidad, los programas educativos deben incluir en su diseño instruccional el desarrollo de competencias transversales como el emprendimiento, el pensamiento crítico, la creatividad, la resolución de problemas, la innovación, el liderazgo, la toma de decisiones y el diseño de modelos de negocio que atiendan problemáticas sociales. 
La necesidad de incluir estas competencias en los programas educativos de ingeniería es trascendental. Las escuelas de ingeniería deben incluir en los diseños de sus programas los principios naturales de la ingeniería, analizar entradas y salidas y mejorar la eficiencia de los procesos para la formación de talento humano. La aplicación de principios de ingeniería en la formación de ingenieros tiene sentido porque es un sistema que transforma a los estudiantes en ingenieros. En una fábrica se espera la llegada en crudo de los insumos, al igual que las escuelas de ingeniería, donde llegan perfiles variados y complejos. En ambos entornos, es necesario diseñar y operar el sistema de producción, haciendo los ajustes necesarios para adecuar las salidas a las necesidades del entorno, y cumplir con los objetivos del sistema. Las dos metas primarias tanto de la escuela como de la industria, es maximizar el valor agregado para el cliente, minimizando el costo de producción.

La industria hace esto reduciendo las tasas de desperdicio (deserción de estudiantes), reduciendo el retrabajo (estudiantes que no están bien preparados, que reprueban y deben tomar las asignaturas de nuevo), eliminando los tiempos de espera (estudiantes que terminan sus programas educativos fuera de su cohorte), asegurando que cuentan con la más alta tecnología para hacerlo (las mejores estrategias pedagógicas para desarrollar los talentos de los estudiantes).

La educación en ingeniería tiene sus propios estándares de garantía de calidad, la Junta de Acreditación para Ingeniería y Tecnología (ABET según sus siglas en inglés) es un organismo no gubernamental que asegura la calidad de las escuelas de ingeniería a nivel mundial. A través de procesos minuciosos de auditoría, se aseguran que los programas cumplan con los objetivos establecidos cumpliendo los mínimos requeridos y estableciendo indicadores homologados a nivel mundial, lo que significa que es un procesamiento especializado. 
En la industria, las empresas manufactureras trabajan dando mejores resultados al aplicar métodos como el mapeo de flujo de valor, Six Sigma, Justo a Tiempo, Kanban, entre otros, con el fin de evitar errores y acumulación de materia prima en inventarios y productos no terminados. Esto les ha permitido medir y ser cada vez más eficientes, centrándose en actividades esenciales.

Estas sencillas ideas de hacer coincidir la cantidad de trabajo realizado en un producto con su tasa de demanda, sin desperdiciar tiempo en actividades que los clientes no necesitan, hace que los procesos de manufactura se mantengan esbeltos y eficientes. Para que esto sea aplicado a la formación de ingenieros, el trabajo y el procesamiento debe ser visto desde el punto de vista de las necesidades de los estudiantes. Algunas preguntas pueden aplicar para identificar las necesidades:

- ¿Cómo saber si la escuela está agregando valor al proceso de aprendizaje?

- ¿Cómo se puede cuantificar el aprendizaje?

- ¿Cómo son los retrasos en el aprendizaje y cómo evitarlos?

- ¿Se cuenta con un sistema de producción que elimine retrabajos?

- ¿Se tiene claro el proceso exitoso de aprendizaje para replicarlo?

- ¿Qué constituye la puntualidad en la entrega, tasas de rendimiento, costo de producción y flexibilidad del sistema?

Estas preguntas son básicas y similares a las preocupaciones que enfrentan los ingenieros de diseño. Son los primeros pasos en el diseño de mejoras en los sistemas. Los métodos para lograr estos objetivos serán diferentes de institución a institución, porque las escuelas trabajan con intangibles como el conocimiento y las competencias, pero los aspectos 
operativos de procesamiento, son similares a los de una fábrica.

La educación superior tiene en gran medida la producción en masa y la estandarización de producto dentro del enfoque de procesado del estudiante, aunque la academia afirma que lo aborrece. Las actividades de aprendizaje de los estudiantes están actualmente programadas en masa, independientemente de la tasa de aprendizaje real del estudiante en lo individual. Sin embargo, los avances tecnológicos, están abriendo posibilidades para los estudiantes y el contexto mismo, porque además del modelo tradicional, en la actualidad existen diversos modelos de entrega a considerar, por ejemplo, hoy los estudiantes tienen más opciones en la elección de la forma de entrega del conocimiento, clases presenciales, clases semipresenciales, clases totalmente en línea, clases híbridas con sesiones síncronas y asíncronas, muchos cursos en línea abiertos (MOOC) y modelos basados en competencias.

Cada uno de los modelos ofrece sus propias ventajas, los estudiantes hoy pueden elegir el mejor modelo con respecto a lo que ofrecen, revelando que pueden elegir entre el ritmo de entrega, los módulos de interés, la conveniencia, los costos, la flexibilidad, entre otros.

Lo que quiere decir que la personalización en la educación es en este momento un hecho y que será un proceso que irá acelerando en el futuro. Escuelas que transitan de sistemas por lotes (carreras con asignaturas establecidas), al flujo por pieza (programas flexibles que cada estudiante construye según sus necesidades e intereses), lo que significa una personalización de la educación y por tanto tiene mayor valor para los estudiantes. Esto les brinda oportunidades variadas a los estudiantes, pudiendo elegir entre terminar antes su programa educativo o bien, tener dos especializaciones en los mismos cuatro o cinco años. 
Levine (1989) especuló sobre el futuro de la educación superior haciendo un análisis detallado de los cambios que ocurrieron en la década de los noventa, e identificando cinco poderosas fuerzas que serían las que harían los cambios más drásticos hacia el futuro. El primero, el surgimiento de una economía de la información; segundo, los cambios demográficos; tercero, las nuevas tecnologías; cuarto, la privatización de la educación superior; por último, la convergencia de organizaciones productoras de conocimiento. Han pasado dos décadas y los planteamientos de Levine se han cumplido, ahora tenemos una educación superior individualizada, enfocada hacia el aprendizaje y no más en la enseñanza, y orientada hacia el desarrollo de competencias.

Combinadas esas tendencias con la realidad, poco más de veinte años más tarde el mismo Levine (2021) considera que hoy las universidades deben prepararse para cinco nuevas realidades:

1. Los nuevos productores y distribuidores de contenido continuarán ingresando al mercado, impulsando la competencia y las opciones de los consumidores, al mismo tiempo que reducirán los costos de la educación. Se enfatizarán en tecnologías digitales, rechazarán la educación basada en el tiempo y lugar, crearán títulos de bajo costo, ofrecerán educación basada en competencias y resultados, y otorgarán credenciales no tradicionales. Aquellos que ya están en el mercado incluyen líderes de la industria de marca y agencias culturales que son más accesibles y convenientes que las grandes universidades, pues ofrecen una combinación de programas basados en competencias y cursos de especialización orientados a los intereses particulares. También son más baratos y ágiles que las instituciones de educación superior tradicionales, que tienen más probabilidades de experimentar contracciones y cierres. 
2. Disminuirá el control institucional de la educación superior y aumentará el poder de los consumidores de educación superior (estudiantes y empleadores). En una variedad de campos de conocimiento (se pueden considerar como buenos ejemplos lo que ha ocurrido con la industria de la música, el cine y los periódicos), el advenimiento de la economía del conocimiento global y digital multiplicó el número de proveedores y divulgadores de contenido y ha dado a los consumidores la posibilidad de elegir entre qué, dónde, cuándo y cómo del contenido que consumen. Lo mismo ocurrirá con la educación superior. La revolución digital pondrá más poder en manos del estudiante, que tendrá más opciones sobre todos los aspectos de su propia educación.

3. Con acceso casi universal a dispositivos digitales e Internet, los estudiantes buscarán en las universidades lo mismo que obtienen de las industrias de la música, el cine y los periódicos. Al igual que lo hacen con esas industrias, los estudiantes buscarán en cualquier momento y lugar la accesibilidad y la educación personalizada que se adapte a sus circunstancias. Los colegios y universidades tendrán que separar cada vez más sus programas y servicios para que los estudiantes puedan comprar a precios asequibles, sólo lo que necesitan o quieren comprar, ya no comprarán todo el lote (programa educativo de 5 años).

4. Un modelo de economía del conocimiento basado en resultados eclipsará el modelo de la era industrial de educación superior en masa basada en procesos. En el futuro, la educación superior se centrará en los resultados que queremos que logren los estudiantes, lo que queremos que aprendan, no en cuánto tiempo queremos que se les enseñe. Los estudiantes no aprenden al mismo ritmo, ni de la misma forma, y la explosión de nuevos contenidos producidos por museos, empresas de software, minoristas y otras organizaciones dentro y fuera del ámbito educativo, se está volviendo tan heterogénea, que el progreso 
académico de los estudiantes no se puede traducir en uniforme, medidas de tiempo o proceso. El único denominador común que todos comparten es que producen resultados: todo lo que los estudiantes aprenden como consecuencia de la experiencia.

5. El predominio de las titulaciones con plazos determinados y la educación "por si acaso" disminuirá. Mientras tanto, las certificaciones sin título y la educación "justo a tiempo" aumentarán en estatus y valor. Se verá un restablecimiento entre el valor asignado a los títulos, que alguna vez fueron muy apreciados por indicar un nivel de habilidad y conocimiento para estar preparados para el futuro, y ahora se revalorará la educación "justo a tiempo", que está orientada al presente y es más inmediata. La creciente necesidad de mejorar y volver a capacitarse causada por la automatización, la explosión del conocimiento y, el acelerador que ha supuesto la pandemia, inclinará la balanza hacia programas educativos que estén estrechamente alineados con el mercado laboral y que propicien certificados, micro-credenciales e insignias, dejando a los títulos atrás.

No es necesario especular sobre el futuro de la educación superior para poder ver que estas realidades de las que habla Levine (2021), están presentándose como una realidad ya. Algunos de estos temas en particular han podido ser mucho más visibles luego de la pandemia, existen hoy en día nuevos productores de educación lejanos a las instituciones de educación superior tradicionales. Resulta interesante analizar algunas de estas situaciones ocurrir, ¿qué deben hacer las universidades? ¿Cómo estos cambios pueden considerarse en las aulas a fin de plantear una alternativa de personalización para los estudiantes en las aulas?

\subsection{La transformación de la educación de ingenieros}

La educación superior se transformó en los siglos XIX y XX para satisfacer las necesidades de una economía industrial, 
analógica y emergente. En la actualidad, la educación superior se está transformando de nuevo, esta vez para satisfacer las necesidades de una economía del conocimiento global y digital. Los académicos no están de acuerdo en esencia, sin embargo, esta transformación está en curso (Levine, 2021) y no existe forma de detenerla, es necesario adaptarse para sobrevivir.

Según Levine y Van Pelt (2021) algunas de las grandes y más prestigiosas universidades del mundo (como es el caso de la Universidad de Harvard), según su presidente, Lawrence Bacow, consideran que la educación superior se adaptará gradualmente a las condiciones cambiantes del entorno, como lo ha hecho históricamente, manteniendo su misión y estructura actuales. En contraste, uno de sus profesores de la escuela de negocios, Clayton Christensen, argumentó que los cambios serán de tal magnitud que alterarán la educación superior como la conocemos en la actualidad, haciendo obsoletos muchos de los modelos tradicionales, llevando a algunas de estas grandes instituciones de educación superior a la bancarrota.

¿Cuáles son esos cambios y dónde comienzan a verse? Algunas de estas visiones de futuro comienzan a vislumbrarse. Por ejemplo, en el sector de la educación técnica, comienza a verse algo de esto, que va más allá de las universidades tradicionales. Comienzan a surgir una mezcla de iniciativas, organizaciones, programas y servicios, con y sin fines de lucro, diversos e independientes que ofrecen especializaciones técnicas en temas y áreas que la misma educación superior formal fue abandonando. Rechazan la educación basada en un tiempo y lugar, creando especializaciones sin título y a bajo costo, adoptando una educación basada en competencias o resultados, enfatizando las tecnologías digitales, y enfocándose en poblaciones subrepresentadas ofreciendo certificaciones pioneras (Craig, 2018; Levine \& Van Pelt, 2021). 
Este sector engloba las organizaciones del conocimiento, que van desde bibliotecas y museos, hasta empresas de medios corporativos. Está en apogeo, tanto en términos de inscripciones como del número de proveedores que buscan brindar alternativas más baratas, más rápidas, más accesibles, y más convenientes a la oferta tradicional.

Está surgiendo una nueva clase de universidades y escuelas. En tiempos de profundos cambios sociales, las instituciones innovadoras emergen como alternativas profundamente diferentes a las instituciones de educación superior tradicionales. Durante la Revolución Industrial, surgieron las primeras universidades de investigación, como Johns Hopkins, la Universidad de Cornell, el MIT, entre otras, todas ellas definieron los contornos de la educación superior de una sociedad industrializada.

Las instituciones emergentes, están impulsando una agenda para una economía del conocimiento global y digital. Ya no están ancladas a una nación en particular, sino que ahora se centran en ofrecer una educación en línea basada en competencias que prescinde de medidas como el tiempo (clases y trámites presenciales), lo que permite a los estudiantes moverse a su propio ritmo, independientemente de donde se encuentren, un ejemplo es la Western Governors University. Otra, la Universidad de la Gente (University of the People), ha reducido drásticamente el costo de la educación universitaria. Perdue University Global, representa la fusión entre la educación superior con y sin fines de lucro que ofrece accesibilidad y asequibilidad bajo el amparo de una institución de marca. Y comienzan a surgir los institutos comunitarios virtuales como Calbright College, que se especializan en programas de certificación de actualización y reciclaje (Levine \& Van Pelt, 2021).

Una tercera y última línea que se debe visualizar, son las instituciones de educación superior que tienen programas de educación continua que comienzan a fortalecerse. Muchas de 
estas instituciones de educación superior tienen problemas de endeudamiento o problemas financieros en general, y a través de la diversificación de sus programas de educación continua, con fuertes convenios de vinculación con la industrial, surgen nuevos programas de certificación y especialización, que, en principio, se busca no sean competencia directa, pero que eventualmente generan una viable y nada despreciable fuente de ingresos propios para estas instituciones. Esto las hace competitivas de nuevo, les permite ser creativas y generar programas innovadores, que, si son bien cuidados, les permitirá volverse parte del núcleo de estas instituciones.

Estas posibilidades surgen con características propias y rompen los paradigmas establecidos por las tradicionales instituciones de educación superior. Los programas basados en competencias, han cambiado el enfoque de la educación de tipo presencial y cátedra tradicional, y se enfocan a los resultados del aprendizaje. Han roto con los calendarios semestrales o anuales, y se enfocan en la educación variable en el tiempo, con acceso a los cursos las 24 horas del día, los 7 días de la semana, y la instrucción justo a tiempo. Los programas no ofrecen títulos al término, sino microcredenciales, sobre todo aquellos que ofrecen actualización de áreas de especialidad.

A su vez han surgido nuevos enfoques para el precio de la matrícula, por ejemplo, suscripciones o el ofrecer los mismos programas que las instituciones de educación superior tradicional a precios mucho más competitivos.

Estos cambios aún se encuentran desconectados, sin embargo, es posible que a través de ellos se pueda tener una visión previa de lo que probablemente será la nueva educación superior en la economía del conocimiento global y digital, sobre todo, luego de la pandemia.

Las sociedades industriales estandarizan el tiempo y los procesos a la manera de una línea de montaje, una de las 
tecnologías más exitosas de la era industrial. Sin embargo, en una economía del conocimiento no es posible continuar con estos procesos de estandarización, por el contrario, es necesario iniciar proyectos y programas de personalización de la educación. El tiempo y el proceso son variables. La educación superior de la era emergente tendrá que abrazar estas variables cambiantes. Debe basarse en resultados en lugar del tiempo y el proceso. Debe aprender más que enseñar. Debe estar centrado en los estudiantes y no en los profesores.

Las iniciativas observadas, se mueven precisamente en esas direcciones. Apuntan a un futuro basado en resultados, independiente del tiempo, fundamentalmente dirigido a través de tecnologías digitales, individualizado y disponible en todo tiempo y lugar. 


\section{Innovación en el aula: transformación de la educación emprendedora}

El presente capítulo es fruto del trabajo de investigación en el aula. Luego de exponer en capítulos anteriores la importancia de los conceptos, las teorías, los modelos y el impacto real de los emprendedores en la sociedad. Es momento de presentar la aplicación de todo lo visto en un modelo educativo funcional. Ha sido un trabajo de más de tres años de aplicación de diversos prototipos de diseño instruccional aplicando metodologías activas en la formación de ingenieros emprendedores, hasta haber encontrado un modelo efectivo.

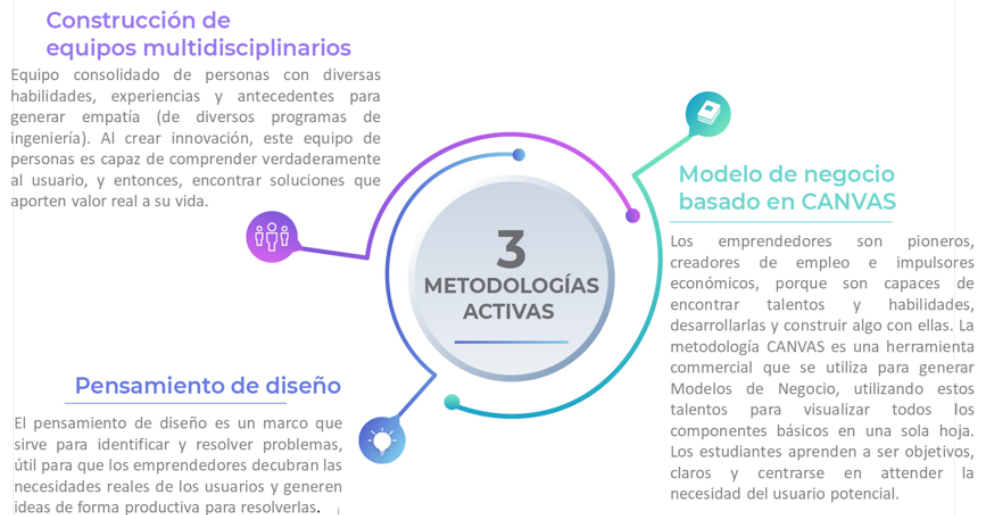

Figura 20. Proceso de pensamiento de diseño.

Fuente: Elaboración propia, basado en información derivada de la investigación. La figura presenta la propuesta de un Modelo de

Formación de Ingenieros Emprendedores que transforma la práctica.

Al cabo de estos años de aplicar diversos prototipos de diseño instruccional, se ha encontrado que el modelo que se presenta en la Figura 20, es el que representa los mejores resultados, pues tiene como fundamento la metodología de pensamiento de diseño (Brown, 2008), que es un proceso estructurado que favorece la innovación a partir de la necesidad real del usuario; además, de sumar la Metodología CANVAS (Osterwalder, Pigneur, Oliveira \& Ferreira, 2011) como herramienta de 
diseño del Modelo de Negocio, y como tercer punto, la construcción de equipos multidisciplinarios, que, con base a la experiencia, es una oportunidad de generar mejores proyectos considerando los distintos talentos y experiencias de los miembros de los equipos.

\subsection{Planteamiento del problema}

Las escuelas de ingeniería han aumentado recientemente sus esfuerzos por formar a sus egresados en emprendimiento, por una parte, debido a los requisitos de los organismos externos de acreditación internacional $y$, por otra, debido a las demandas sociales, aunado a lo ya expuesto en capítulos anteriores sobre los beneficios para las economías (Weilerstein \& Byers, 2016).

El crecimiento de programas de educación emprendedora experimentado en la formación de ingenieros, incluso ha superado al crecimiento experimentado en las mismas escuelas de negocios (Weilerstein \& Byers, 2016; Huang-Saad, Morton \& Libarkin, 2018; Zappe, 2018; Huang-Saad, Bodnar \& Carberry, 2020). Estos cambios en los programas educativos de ingeniería, se suman a aquellos que iniciaron y se remontan a Grinter (1955), quien introdujo el diseño en la formación de ingenieros, después de que los estudiantes obtenían una sólida base técnica en ciencias básicas, particularmente en matemáticas. Este cambio es uno de los tantos que ha experimentado la educación de ingenieros en las últimas décadas y que comenzaban a delinear un perfil de ingeniero con mayores competencias profesionales a través del aprendizaje activo.

Los cambios que ahora se enfatizan en los programas de estudio de ingeniería alrededor del mundo, se deben en parte también a los cambios en los criterios de evaluación 2000 establecidos por la Junta de Acreditación para Ingeniería y Tecnología (ABET) desde 1997, donde se introduce un 
enfoque basado en resultados para evaluar los programas de ingeniería (Prados, Peterson \& Lattuca, 2005).

ABET evalúa y acredita más de cuarenta y un mil programas educativos en ingeniería en 812 escuelas y universidades en 32 países (ABET, 2021), mismos que son requeridos que demuestren los resultados de sus estudiantes. Los estudios sobre la implementación de dichos programas proveen evidencia sobre cómo los docentes han integrado las necesidades de la industria en las evaluaciones de los cursos, incluida la incorporación de las competencias necesarias para tener éxito en empresas más pequeñas como los emprendimientos, por ejemplo, el ir más allá de las expectativas mínimas o mostrar pensamiento crítico y divergente en la búsqueda de soluciones (Hilliger, Miranda \& Pérez-Sanagustín, 2017).

En los Estados Unidos, existen programas como KEEN (Kern Entrepreneurial Engineering Network) han financiado programas e iniciativas para escuelas y facultades de ingeniería. Otro esfuerzo es REES (Research, in Engineering Education Symposium) de la Universidad de Stanford. La división de la Sociedad Americana por la Educación en Ingeniería (ASEE), entre muchas otras iniciativas a lo largo de los últimos treinta años (Aparicio, Iturralde \& Maseda, 2019).

Existen esfuerzos en países de América Latina, como Chile, que formuló una iniciativa gubernamental en 2012, llamada "Nueva Ingeniería 2030" que provee financiamiento directo a universidades con el propósito de apoyar los esfuerzos por promover la investigación aplicada, el desarrollo tecnológico, la innovación y el fomento al emprendimiento en sus programas educativos (Celis \& Hilliger, 2016).

En Europa, el Plan de Acción sobre mentalidad emprendedora 2020 (European Commission, 2013), desarrolló un plan para que la educación emprendedora 
amplíe la necesidad de una educación que promueva el desarrollo tecnológico. Los objetivos relacionados con ser más emprendedores han ejercido una presión considerable sobre instituciones de educación superior alrededor del mundo, buscando que promuevan el emprendimiento de manera transversal a sus programas educativos, fomentando el desarrollo de habilidades y competencias emprendedoras en sus estudiantes de ingeniería.

La mentalidad emprendedora en el contexto del aprendizaje de la ingeniería se ha presentado como el logro de conocimiento emprendedor, desarrollo de una mentalidad y habilidades emprendedoras. Sin embargo, la exigencia va más allá, pues requiere que sean abordadas a través del análisis y solución de problemas reales, mostrando otras competencias y habilidades como la comunicativa, el liderazgo, las competencias sociales, adaptación al cambio, hacer frente a la incertidumbre, entre otros (Duval-Couetil, Kisenwether, Tranquillo \& Wheadon, 2015; London, Bekki, Brunhaver, Carberry \& McKenna, 2018).

La falta de referencias explícitas al desarrollo de la mentalidad emprendedora y el número relativamente grande de programas acreditados por ABET que ofrecen alguna variación de los cursos de emprendimiento, sugieren la necesidad de un marco común para evaluar y definir los objetivos del curso relacionados con la educación emprendedora en programas de ingeniería.

A través de un análisis de la literatura existente (Miranda, Goñi, Berhane \& Carberry, 2020), aunado a la propia experiencia en el aula, se consideraron tres grandes problemáticas que no estaban siendo abordadas en los modelos tradicionales de enseñanza en la educación emprendedora: 1) Emprendimiento, se promueve en la práctica o solo se teoriza; 2) La descontextualización del emprendimiento; y, 3) Dominio y especificidad en la educación emprendedora. A fin de cubrir estas problemáticas, 
es necesario la adopción de metodologías activas y de real inmersión en el pensamiento de diseño, para que el estudiante pueda promover su formación práctica, contextualizando el contenido teórico y dominando el grado de especificidad necesario según sea el caso.

Merece una ilustración específica el aspecto de la formación (refiriéndose a la enseñanza), el elemento a través del cual el emprendimiento de los estudiantes en el aula, toma forma y se concreta en proyectos que verdaderamente den solución a las necesidades de los usuarios. Lackéus (2015) identifica tres enfoques metodológicos que se pueden emplear en la educación emprendedora usando el pensamiento de diseño:
a. Enseñar sobre
b. Enseñar para
c. Enseñar a través (p.10)

En opinión del autor, enseñar sobre la mentalidad emprendedora significa un enfoque teórico y cargado de contenido que tiene como objetivo la comprensión general del fenómeno. Es el enfoque más común empleado en las universidades de todo el mundo (Mwasalwiba, 2010). Con respecto a enseñar para la mentalidad emprendedora, significa que se emplea un enfoque de orientación ocupacional que tiene como objetivo que los estudiantes emprendedores, tengan los conocimientos y habilidades necesarios para echar a andar un modelo de negocio. Por último, enseñar a través, significa un enfoque basado en procesos y, a menudo, basado en la experiencia en el que los estudiantes a traviesan un verdadero proceso de aprendizaje emprendedor (Kyrö, 2018). Este enfoque, a menudo se apoya en la definición más amplia de la mentalidad emprendedora,y puede integrarse en otras materias de los programas educativos, de modo que puede atenderse de manera transversal y no aislado en una sola asignatura. 
Lo que parece interesante es que, en la educación superior, pareciera natural la visión ampliada del concepto emprendimiento, que va más allá del conocimiento (sobre), o el conocimiento y las habilidades (para). De hecho, pareciera que de manera natural el enfoque integrado de la enseñanza se adapta a través de un modelo integral en la formación emprendedora, de modo que sea relevante tanto para el estudiante como para la sociedad (Lackéus, 2015).

Si se construye un enfoque integral, pude tener consecuencias potenciales en la difusión de un enfoque al emprendimiento, pues es una visión procedimental en la educación emprendedora, que no solo se dirige exclusivamente a la creación de empresas, sino que debe estar abierta a todas las áreas de trabajo de la ciudadanía, y la sociedad.

Se ha discutido ya, en el capítulo cuarto, la imperiosa necesidad de hacer ajustes a los modelos de formación de ingenieros emprendedores, es momento ahora de analizar nuevas metodologías a fin de lograrlo.

De igual forma se ha analizado que la mentalidad emprendedora es un catalizador revolucionario en las perspectivas de la nueva economía mundial, los desafíos en la seguridad laboral debido a la fuerte competencia y la inseguridad laboral, y que existen evidencias del impacto que tiene en el desarrollo de naciones industrializadas, pues intrínsecamente, se considera un elemento para nivelar la competencia en un entorno altamente exigente, complejo y saturado, de modo que provee bienestar económico a los estados nación.

Si bien se reconoce que los emprendedores generan un impacto positivo en el desarrollo económico, el mercado busca también talento humano con actitud proactiva, solucionadores de problemas y con independencia, incluso para trabajar contratados en empresas existentes. $Y$ es que debe considerarse que el emprendedor no es solo aquel que 
crea nuevos emprendimientos, sino también aquella persona que se involucra en nuevas actividades, incluso dentro de una organización, para solucionar de forma innovadora problemáticas existentes (Bosma, 2013). Estas actividades implican generar ideas, formular la concepción del proyecto, reunir los recursos necesarios, llevar a cabo la actividad elegida buscando brindar los beneficios esperados a la organización. Global Entrepreneurship Monitor (GEM) informa que solo alrededor del 5\% de los empleados en promedio, son capaces de liderar tales procesos. Este mismo informe destaca que son los ingenieros quienes muestran un compromiso relativamente alto con el emprendimiento (Bosma, 2013), dado que la combinación de experiencia tecnológica con la formación emprendedora y un enfoque de negocio, conduce a resultados prometedores en términos de generación de innovaciones que se reivindican como combustible del crecimiento económico, es entonces, esta predisposición natural de los ingenieros la que, debe desarrollarse en una etapa temprana de la vida profesional a través de la educación emprendedora.

El pensamiento de diseño, definido en términos generales como la combinación de herramientas, procesos y mentalidades que los diseñadores utilizan para resolver problemas, se ha agregado cada vez más a los programas educativos en escuelas que no son de diseño, como las escuelas de negocios o de ingeniería (Dunne \& Martin, 2006; Garbuio, Dong, Lin, Tschang \& Lovallo, 2018; Glen, Suciu \& Baughn, 2014): Esta tendencia de utilizar conceptos de pensamiento de diseño se ha dado como respuesta al panorama emprendedor cambiante hacia nuevos paradigmas con problemas que no son susceptibles de indagación basados en las habilidades analíticas puras que se enseñan tradicionalmente en las escuelas de negocios (Martin \& Golsby-Smith, 2017). 
La educación emprendedora, a pesar de ser un área de enfoque relativamente reciente, ha sido uno de los campos empresariales pioneros en la implementación del pensamiento de diseño, pues provee a los estudiantes un enfoque más productivo de la experiencia, y les permite internalizar los conocimientos y habilidades necesarios para iniciar una experiencia de emprendimiento.

Varios desarrollos han contribuido al uso generalizado del pensamiento de diseño en la pedagogía del emprendimiento. Primero, la incertidumbre inherente al contexto emprendedor ha hecho que diferentes actores (por ejemplo, empresarios, educadores, mentores y estudiantes), estén más abiertos a desviarse de las estrategias analíticas tradicionales como la redacción de planes de negocio, que de nada sirve para un nuevo emprendimiento (Blank \& Dorf, 2012). En segundo lugar, ha habido movimientos como el Lean Startup (Ries, 2011) que han contextualizado los principios del pensamiento de diseño para el contexto emprendedor. Y, en tercer lugar, el cambio en la investigación sobre la mentalidad emprendedora, que ahora reconoce que se pueden crear oportunidades subrayando la necesidad de poder diseñar una solución.

Si bien estos desarrollos han transformado realmente la forma en que se percibe la educación emprendedora, la multitud de marcos y herramientas que se aprovechan para proporcionar un enfoque basado en el diseño para la educación emprendedora ha supuesto un conflicto, como se ha establecido desde el capítulo primero de este libro. Por ello la importancia de establecer un marco teórico integrador como ha quedado de manifiesto en el capítulo I.

\subsection{Los orígenes del pensamiento de diseño y su propuesta de aplicación al contexto emprendedor}

Los orígenes del término pensamiento de diseño se remontan a los campos de la arquitectura y el diseño. El término fue 
acuñado en un libro escrito por Peter Rowe (1987), profesor de arquitectura y planeación urbana en la Escuela de Diseño de Harvard. En este libro se asoció con la forma nominal, ya que discutió la relación entre formas y funciones. Sin embargo, el pensamiento de diseño, como lo conocemos hoy en día, se centra más en la forma verbal, el proceso de diseño (Liedtka, 2013). Aunque el término ha estado en uso durante las últimas tres décadas, las raíces intelectuales del concepto se remontan al movimiento de la ciencia del diseño a fines de la década de los años sesenta y principios de los setenta, cuando el diseño se popularizó como una metodología para la resolución de problemas. La publicación de La Ciencia de los Artificial de Herbert Simon (1969), fue un evento importante que condujo al uso generalizado de la metodología de diseño en ingeniería, arquitectura, planeación urbana, medicina e informática (Romme, 2003).

Se han ofrecido innumerables definiciones para delinear el concepto de pensamiento de diseño, como se ha visto en el capítulo primero a través de la Figura 6, misma que resume las diversas definiciones o conceptualizaciones según autor y año, como puede verse, existe una diversidad significativa en las definiciones propuestas, lo que habla de la naturaleza multidisciplinaria, multinivel e intrínsecamente compleja de este concepto. Mientras que a primera vista esta multiplicidad de definiciones puede suscitar algunas preocupaciones sobre la viabilidad de las investigaciones académicas sobre el tema, algunos estudiosos creen que un concepto tan rico como el pensamiento de diseño merece múltiples perspectivas.

$\mathrm{Al}$ hacer un análisis a profundidad de las definiciones que se presentan en la Figura 6, se puede advertir que resaltan tres categorías potenciales dentro de las definiciones: mentalidad, proceso y herramientas (Brenner \& Uebernickel, 2016). La perspectiva de la mentalidad se centra en las características cognitivas y conductuales del agente de resolución de problemas. Incluye dimensiones como el enfoque del usuario, 
el encuadre de problemas, la visualización, la experimentación y la diversidad de ideas (Carl, Rauth \& Elmquist, 2016). La perspectiva del proceso delinea diferentes etapas de un esfuerzo de resolución de problemas. Empatizar, definir, idear, crear prototipos y probar, son las etapas más comunes empleadas en una perspectiva de proceso hacia el pensamiento de diseño. Por último, la perspectiva de las herramientas destaca los conjuntos de marcos y técnicas que utiliza un diseñador para resolver problemas.

Si bien el término diseño, es habitualmente asociado a la apariencia estética de los productos, el diseño como disciplina tiene como objetivo ulterior promover el bienestar de la vida de las personas (Vianna, Vianna, Adler, Lucena \& Russo, 2012). Fue precisamente la forma en que los diseñadores perciben las cosas e interactúan con ellas, lo que ha llamado la atención de los gestores, permitiendo nuevas rutas de innovación emprendedora.

El diseñador ve como un problema todo aquellos que afecta negativamente o impide la experiencia (no se constriñe a lo cognitivo, puede ser lo emocional, funcional o lo estético), y el bienestar en la vida de las personas (considerando todos los aspectos de la vida, como el trabajo el esparcimiento, lo social, entre otros). Por ello, los beneficios de la metodología se concentran en identificar problemas y buscar soluciones viables (Vianna, et al., 2012).

El diseñador puede captar los problemas que afectan el bienestar de las personas dentro de su diversidad, y entiende la necesidad de recabar información de su entorno, contexto, experiencias personales y los procesos en la vida de los usuarios, a fin de abarcar una visión más amplia y compleja identificando de mejor manera las barreras y generando alternativas de solución reales y no estimadas. Esta inmersión permite identificar las causas y consecuencias de los problemas y ser más asertivo al momento de buscar soluciones. 
El pensamiento de diseño en la literatura emprendedora es un concepto relativamente nuevo, sin embargo, ha estimulado significativamente a los académicos a estudiar este concepto y su aplicación en diferentes áreas de negocios. Libros (Liedtka, King \& Bennett, 2013; Liedtka \& Ogilvie, 2011; Liedtka, Salzman \& Azer, 2017; Lockwood, 2010; Martin \& Martin, 2009; Martin, Christiansen \& Antonelli, 2013) y artículos (Beckman \& Barry, 2007; Brown, 2008; Kolko, 2015) han sido los resultados de estos esfuerzos. Sin embargo, en los últimos años, el concepto se ha estudiado cada vez más con una lente académica (Liedtka, 2015; Elsbach \& Stigliani, 2018; Micheli, Wilner, Bhatti, Mura \& Beverland, 2019; Siedel \& Fixon, 2013).

El uso del pensamiento de diseño en la investigación y la práctica emprendedora ganó impulso con los trabajos de Roger Martin de la Rotman School of Management de la Universidad de Toronto. Martin (2009) considera que el pensamiento de diseño tiene el potencial de ser el núcleo de la ventaja competitiva. Propone que los pensadores del diseño son aquellos que pueden cambiar entre los modos analítico e intuitivo para lograr avances estratégicos. Los trabajos de David Kelly y Tim Brown en su consultoría IDEO y la Escuela de Diseño de la Universidad de Stanford, han sido otro impulso importante para las aplicaciones comerciales generalizadas del pensamiento de diseño.

Brown (2008) considera la innovación como el núcleo del pensamiento de diseño y define el pensamiento de diseño como un enfoque de la innovación centrado en el ser humano, que se basa en el conjunto de herramientas del diseñador para integrar las necesidades de las personas, las posibilidades de la tecnología y los requisitos del éxito empresarial (p. 18). El modelo de proceso de innovación propuesto por la Escuela de Diseño de Stanford ha sido un modelo influyente de pensamiento de diseño, y es uno de los 
tres fundamentos del modelo propuesto en este libro, mismo que se describe en la Figura 21.

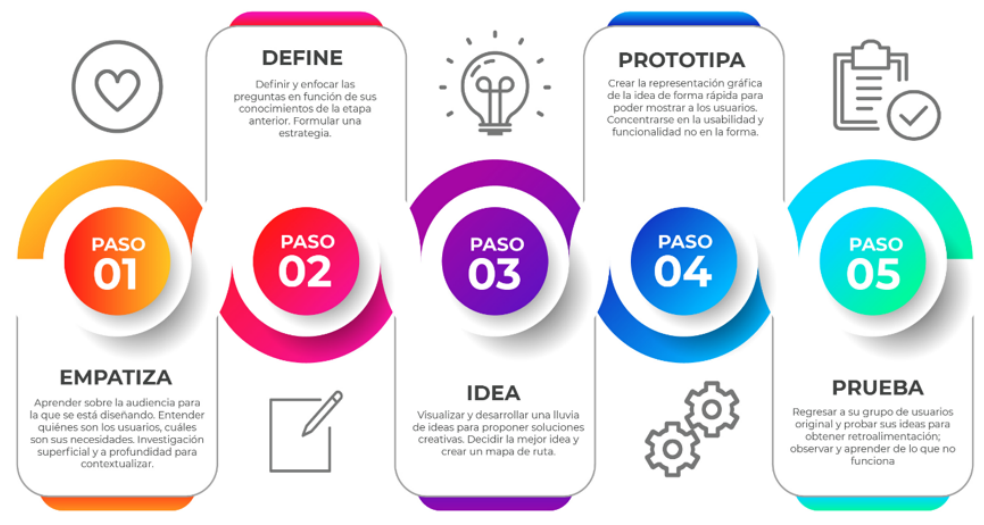

Figura 21. Proceso de pensamiento de diseño aplicado al modelo propuesto.

Fuente: Adaptado de Brown, T. (2009). Change by design: How design thinking creates new alternatives for business and society. Collins Business. La figura presenta el proceso de innovación del modelo de pensamiento de diseño (design thinking).

Analizando cada una de las etapas presentadas en la Figura 21, se tiene que: en el paso 1, es necesario que los emprendedores empaticen con las necesidades del usuario, y capturen a través de la observación, la interacción y la inmersión en la experiencia de quien tiene la necesidad a fin de vivir la experiencia. En el paso 2, es necesario que definan sintetizando lo observado en el paso anterior, de modo que se tenga información clara del punto de vista del usuario. En el paso 3, a través de una exploración extensa, se generen una amplia gama de posibles soluciones. En el paso 4, se elabora el prototipo de aquella idea considerada como la más viable por el equipo de emprendedores, de modo que las posibles soluciones planteadas en el punto anterior, se transformen en medios tangibles para facilitar la interacción con los usuarios y aprender de ellos. 
La innovación liderada por el diseño constituye una visión complementaria del mercado que une el desarrollo o integración de nuevas tecnologías, con la apertura y atención a nuevos mercados. De modo que los emprendimientos que parten de la metodología de pensamiento de diseño, producen soluciones que atribuyen nuevos significados y que estimulan diversos aspectos (cognitivo, emocional y kinestésico) involucrados en la experiencia humana, contrario al análisis de mercado que solía enseñarse en las aulas, pues solo se enfoca en comercializar productos o servicios para generar utilidades.

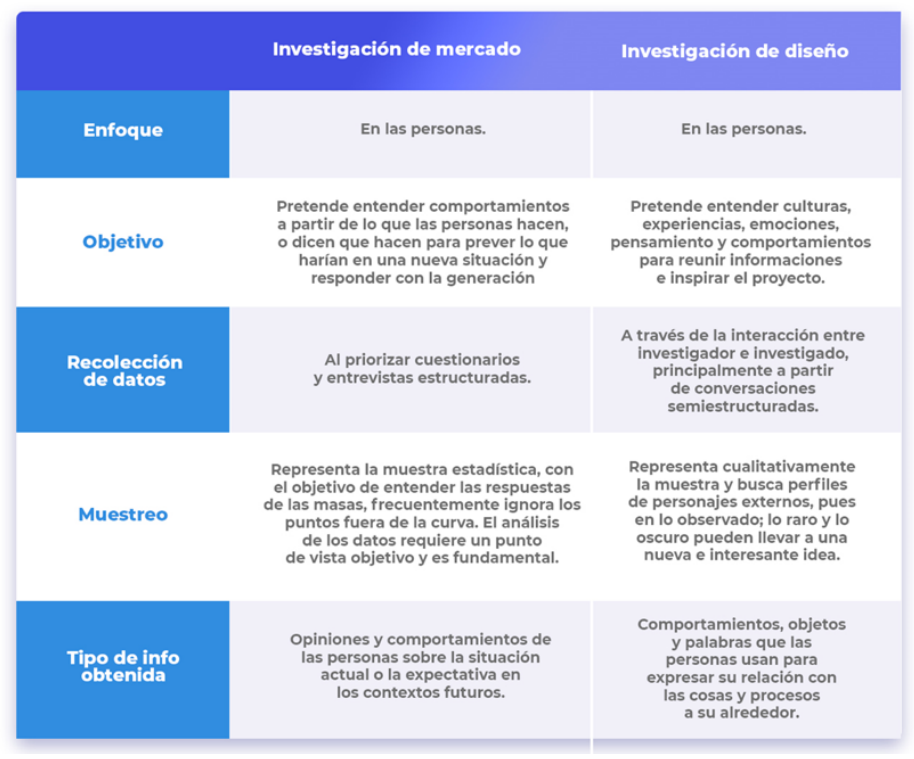

Figura 22. Métodos usados para la aplicación del pensamiento de diseño en el aula.

Fuente: Adaptado de Vianna, M., Vianna, Y., Adler, I. K., Lucena, B., \& Russo, B. (2012). Design thinking. Inovación en los Negocios. MJV

Press. La figura presenta el acercamiento de métodos aplicados al pensamiento de diseño en comparación con los de mercadeo.

Este capítulo presenta un conjunto de métodos usados en el proceso de pensamiento de diseño, que, aplicados a la educación emprendedora, resultan potentes herramientas 
alternativas de innovación para estudiantes de ingeniería. Estos métodos se pueden equiparar a los de un análisis de mercado, como se presenta en la Figura 22.

Sobre la base de los principios básicos del pensamiento de diseño, una serie de desarrollos han dado como resultado una atención más explícita al pensamiento de diseño en la investigación, la práctica y la educación emprendedora. Primero, la literatura sobre el modelo efectual (effectuation término como se conoce en inglés) de Sarasvathy (2001), el cual se basa en gran medida en los principios centrales del pensamiento de diseño, al estudiar la toma de decisiones emprendedoras. El emprendimiento, como deseo de desarrollar y construir un negocio, integrado por múltiples riesgos, ha generado en las últimas décadas la implementación del modelo causal, sin embargo, no siempre ha traído buenos resultados para los nuevos emprendimientos. Por este motivo, aparece el modelo efectual, como una lógica de experiencia empresarial al que los nuevos emprendedores pueden recurrir en la etapa inicial y de mayor incertidumbre, aumentando la posibilidad de éxito. En la Figura 23 se encuentra una explicación más profunda y en comparativa entre los dos modelos. Elementos como la creación de prototipos, la toma de decisiones colaborativa y el aprovechamiento de contingencias, enfatizan la lógica del modelo efectual, que se asemeja al pensamiento de diseño.

En segundo lugar, la educación emprendedora ha aprovechado la filosofía del pensamiento de diseño en la creación e implementación de programas educativos. Un claro ejemplo es el de Lean Startup, que, a partir de introducir una serie de herramientas y procesos, este enfoque enfatiza la experimentación, la creación de prototipos, la retroalimentación de los clientes y la creación conjunta en el proceso de creación de un nuevo modelo de negocio (Blank \& Dorf, 2012; Osterwalder \& Pigneur, 2010). 


\begin{tabular}{|c|c|c|}
\hline & MODELO CAUSAL & MODELO EFECTUAL \\
\hline \multirow[t]{2}{*}{$\begin{array}{l}\text { Punto de partida del } \\
\text { razonamiento y la acción }\end{array}$} & $\begin{array}{l}\text { Orientación a la meta: ¿Qué medios se } \\
\text { necesitan para lograr una determinada } \\
\text { meta? }\end{array}$ & $\begin{array}{l}\text { Orientación al proceso: ¿Qué objetivos se } \\
\text { pueden alcanzar con los recursos } \\
\text { disponibles? }\end{array}$ \\
\hline & $\begin{array}{l}\text { Metas claramente especificadas y } \\
\text { establecidas }\end{array}$ & $\begin{array}{l}\text { Metas esperadas y en posibilidad de } \\
\text { evolucionar }\end{array}$ \\
\hline \multirow[t]{4}{*}{ Predisposición al riesgo } & $\begin{array}{l}\text { Toma de decisiones en base a la previsión } \\
\text { financiera. }\end{array}$ & $\begin{array}{l}\text { Toma de decisiones sobre la base de lo que } \\
\text { las personas pueden y están dispuestas a } \\
\text { arriesgar (incluido no financieras) }\end{array}$ \\
\hline & $\begin{array}{l}\text { Cálculo del valor actual neto. } \\
\text { Máxima rentabilidad esperada. }\end{array}$ & Determinación de pérdidas asequibles. \\
\hline & Compromisos de recursos elevados por & Limitar el riesgo a la baja. \\
\hline & adelantado. & Operaciones comerciales ajustadas. \\
\hline \multirow[t]{4}{*}{ Actitud con respecto a terceros } & Amenaza de la competencia & Las partes pueden ganar trabajando juntas. \\
\hline & Selección cuidadosa de los socios en alianza. & Las partes interesadas autoseleccionadas. \\
\hline & $\begin{array}{l}\text { Las relaciones se limitan a lo que se } \\
\text { considera necesario. }\end{array}$ & $\begin{array}{l}\text { Confianza basada en el compromise: los } \\
\text { socios se benefician al hacer (pequeños) }\end{array}$ \\
\hline & $\begin{array}{l}\text { Confianza contractual: contratación } \\
\text { extensive para restringir comportamientos } \\
\text { oportunistas. }\end{array}$ & $\begin{array}{l}\text { compromisos creibles para unirse al curso de } \\
\text { acción. }\end{array}$ \\
\hline Contingencias en el entorno & $\begin{array}{l}\text { Las contingencias son desviaciones } \\
\text { indeseables del plan. }\end{array}$ & $\begin{array}{l}\text { Las contingencias ofrecen nuevas } \\
\text { oportunidades. }\end{array}$ \\
\hline
\end{tabular}

Figura 23. Comparativa entre el modelo causal y el modelo efectual Fuente: Adaptado de Smolka, K. M., Verheul, I., Burmeister-Lamp, K., \& Heugens, P. P. (2018). Get it together! Synergistic effects of causal and effectual decision-making logics on venture performance.

Entrepreneurship Theory and Practice, 42(4), 571-604. La figura presenta una comparativa entre el modelo causal y el modelo efectual en la toma de decisiones emprendedoras.

Hacer un análisis completo del enfoque Lean Startup, está más allá del alcance de este manuscrito, sin embargo, en la Figura 24, puede encontrarse un resumen de algunas de las herramientas y procesos más comunes que se aprovechan en la educación y práctica emprendedora. De hecho, esta tabla no pretende ser exhaustiva, pero, es representativo de una amplia gama de herramientas y procesos que tienen un tema de pensamiento de diseño en su columna vertebral. Además, que dos de estas herramientas, el Modelo CANVAS y el CANVAS de la propuesta de valor, son aplicadas en el modelo instruccional propuesto.

En años recientes, la creciente atención generada por enfoques pedagógicos como Lean Startup, ha provocado algunos otros intentos de combinar la literatura sobre oportunidades emprendedoras y la ciencia del diseño. Dimov (2016), por ejemplo, esboza una perspectiva de la ciencia del diseño para el emprendimiento, que se enfoca en 
problematizar la acción emprendedora en busca de oportunidades como efectos del diseño. En su opinión, un enfoque de la ciencia del diseño para motivar la mentalidad emprendedora "combina una perspectiva de acción como un modo de experimentación y un generador de nueva información con la naturaleza del diseño como la creación de productos hacia un propósito" (Dimov, 2016, p. 32). Todo esto apunta a la importante y trascendente oportunidad de aplicar el pensamiento de diseño en el desarrollo de emprendimientos.
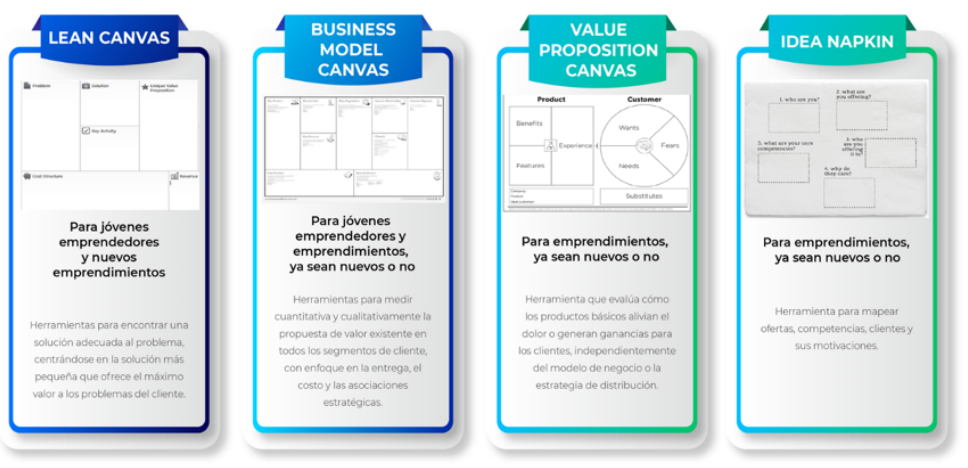

Figura 24. Resumen de herramientas de pensamiento de diseño en educación emprendedora.

Fuente: Adaptado de Sarooghi, H., Sunny, S., Hornsby, J., \& Fernhaber, S. (2019). Design thinking and entrepreneurship education: Where are

we, and what are the possibilities? Journal of Small Business

Management, 57, 78-93. La figura presenta cuatro herramientas y procesos que emplean pensamiento de diseño y que son usados en la educación emprendedora.

\subsection{Transición del modelo tradicional al modelo de aprendizaje activo en la educación emprendedora}

Sobre la base de la revisión anterior de la investigación y la práctica del pensamiento de diseño, es preciso facilitar y formalizar el uso del pensamiento de diseño en la educación emprendedora con una perspectiva más académica. Se 
propone una estrategia didáctica basada en la búsqueda y diseño de oportunidades, como se describe en la Figura 25.

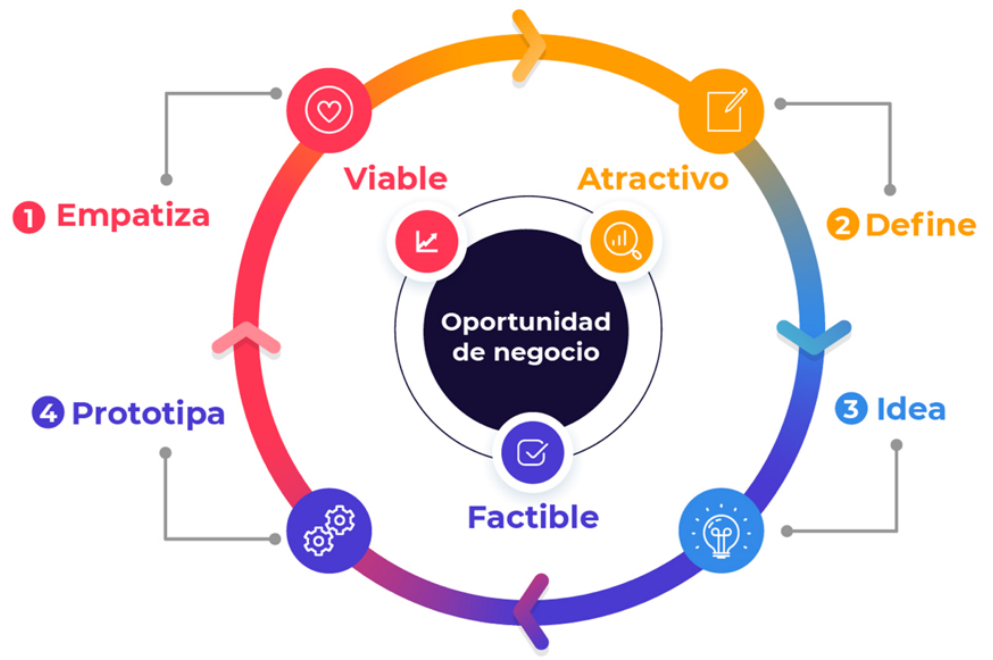

Figura 25. Propuesta de estrategia didáctica basada en la búsqueda de la oportunidad de negocio.

Fuente: Adaptado de Sarooghi, H., Sunny, S., Hornsby, J., \& Fernhaber, S. (2019). Design thinking and entrepreneurship education: Where are we, and what are the possibilities? Journal of Small Business Management, 57, 78-93. La figura presenta la propuesta didáctica aplicada como prototipo en la investigación.

En el esquema tradicional, la educación emprendedora en la universidad de estudio radica en la impartición de una sola asignatura "Formación de emprendedores" de carácter optativa, es decir, no todos los estudiantes de la escuela de ingeniería toman la asignatura, y no existe un ecosistema de soporte que promueva la innovación en los estudiantes. Si bien, se cuenta con un Centro de Emprendimiento, éste no es abierto para todos los estudiantes, se eligen solo algunos proyectos que son los que se incuban. La descripción general del curso mencionado se presenta en la Figura 26, y es de destacar que se trabaja aún con la teoría y desarrollo de un Plan de Negocio, y el curso es meramente teórico pues, 
aunque se tiene como proyecto integrador final donde elaboran un modelo de negocio, desarrollan solo la idea y no construyen el prototipo.

\begin{tabular}{|c|c|c|c|}
\hline $\begin{array}{c}\text { Fase I. Fundamentos } \\
\text { de la empresa }\end{array}$ & $\begin{array}{l}\text { Fase II. Propiedad } \\
\text { intellectual y } \\
\text { prospección comercial }\end{array}$ & $\begin{array}{c}\text { Fase III. Desarrollo } \\
\text { empresarial }\end{array}$ & $\begin{array}{c}\text { Fase IV. Innovación } \\
\text { para la competitividad } \\
\text { empresarial }\end{array}$ \\
\hline $\begin{array}{l}\text { Conceptos básicos que } \\
\text { fundamentan a una } \\
\text { empresa con el } \\
\text { propósito de } \\
\text { desarrollar un plan } \\
\text { estratégico de negocios. }\end{array}$ & $\begin{array}{l}\text { Gestionar la creación } \\
\text { de obras intelectuales } \\
\text { a través del Desarrollo } \\
\text { del Modelo de Negocio } \\
\text { CANVAS, a fin de } \\
\text { identificar las figuras } \\
\text { jurídicas bajo las que } \\
\text { se puede proteger } \\
\text { dicha obra. }\end{array}$ & $\begin{array}{l}\text { Administrar un } \\
\text { Proyecto empresarial } \\
\text { estableciendo cada } \\
\text { uno de los elementos } \\
\text { del Plan de Negocios } \\
\text { para su formalización. }\end{array}$ & $\begin{array}{l}\text { Resolver problemas de } \\
\text { inventiva mediante el } \\
\text { uso de diferentes } \\
\text { herramientas } \\
\text { metodológicas como la } \\
\text { TRIZ. }\end{array}$ \\
\hline
\end{tabular}

Figura 26. Descripción general del curso regular de Formación de Emprendedores.

Fuente: Creación propia conforme al contenido analítico del programa.

La figura presenta la representación gráfica del programa analítico de

Formación de Emprendedores de la Universidad de estudio.

El escenario ideal para que una propuesta académica transformacional funcione, debe estar dentro de un ecosistema emprendedor en la institución de educación superior donde se aplique, esto facilitaría el uso del pensamiento de diseño en la creación y entrega de programas educativos, donde el emprendimiento sea transversal a estos, y no solo tomando una asignatura aislada.

La Figura 27 muestra el funcionamiento de un ecosistema emprendedor dentro de una universidad, a través del cual el estudiante de ingeniería pueda desarrollar sus habilidades y competencias de modo que favorezca el emprendimiento. Al tener una planta académica y de investigación con perfil emprendedor, se organizan los contenidos de las asignaturas donde se desarrolle tecnología o proyectos, a través de metodologías activas, se motiva al emprendimiento aplicando el pensamiento de diseño, orientar el trabajo del estudiante como respuesta a problemáticas reales, a través de momentos de inmersión e investigación, para empatizar con quienes viven la necesidad y proponer soluciones viables con base tecnológica. Al hacerlo, se reconoce que existen múltiples 
herramientas y procesos que contribuyen a una mentalidad de pensamiento de diseño, y, por lo tanto, emprendedora.

El objetivo de las instituciones de educación, debe ser el equipar a los formadores de ingenieros en emprendimiento, para ofrecer estas experiencias educativas basadas en el diseño para los estudiantes. En la educación emprendedora es necesario generar programas satélites que soporten la formación en las unidades de aprendizaje a fin de que, este ecosistema que se muestra en la Figura 27, apoye las iniciativas de emprendimiento de los estudiantes, y no solo eso, sino que, al desarrollar proyectos de cualquier asignatura, aplique la metodología centrada en el usuario (pensamiento de diseño).

ENSEÑANZA
- Mentalidad emprendedora promovida
por el docente en el aula en el
desarrollo de proyectos
(independientemente de la asignatura)
- Equipo interdisciplinario
- Desarrollo de competencias y
habilidades blandas (liderazgo,
comunicación efectiva y toma de
decisiones, entre otras)
- Formación emprendedora transversal

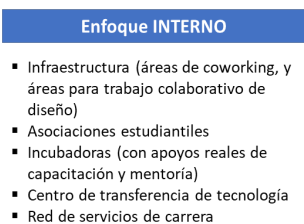

ACTIVIDADES EXTRACURRICULARES

- Competencias y concursos de proyectos

- Conferencias y Seminarios de expertos

- Talleres prácticos dirigidos por emprendedores

- Networking de estudiantes con investigadores $y$ docentes

- Día de promoción a la innovación

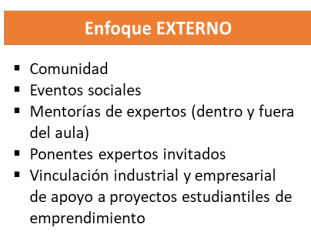

Figura 27. Ecosistema emprendedor en una universidad.

Fuente: Adaptado de Grecu, V., \& Denes, C. (2017). Benefits of entrepreneurship education and training for engineering students. In MATEC web of conferences (Vol. 121, p. 12007). EDP Sciences. La figura presenta el ecosistema emprendedor que favorece una educación emprendedora.

La decisión de desarrollar un prototipo de asignatura en el que el abordaje de los temas de emprendimiento fuera de manera práctica, y no solo teórica, llevó un proceso de transición, mismo que se muestra en la Figura 28. La transición inició con la crítica al método tradicional expositivo, en el que el 
papel del estudiante era meramente de espectador. Esto provocaba que el alumno se distrajera con facilidad y soslaya la participación en clase. En una primera etapa, se inició con una transición hacia un modelo de aula invertida en el que, a través de materiales previamente elaborados, el estudiante se adentraba en los nuevos conceptos. De modo que durante las sesiones áulicas se privilegiaba la participación a través de actividades variadas. Sin embargo, no se cumplía adecuadamente con el objetivo de aprendizaje que era elaborar un Modelo de Negocio de forma colaborativa.

Luego de dos semestres con el prototipo de Modelo de aula invertida, fue necesario transitar al Modelo de aprendizaje activo, pues los estudiantes requerían actividades en las que se motivara y promoviera el trabajo colaborativo. Durante el último año, se ha puesto en marcha el prototipo de aprendizaje activo que ha planteado los mayores retos, $y$, sin embargo, ha tenido un gran impacto en los estudiantes.

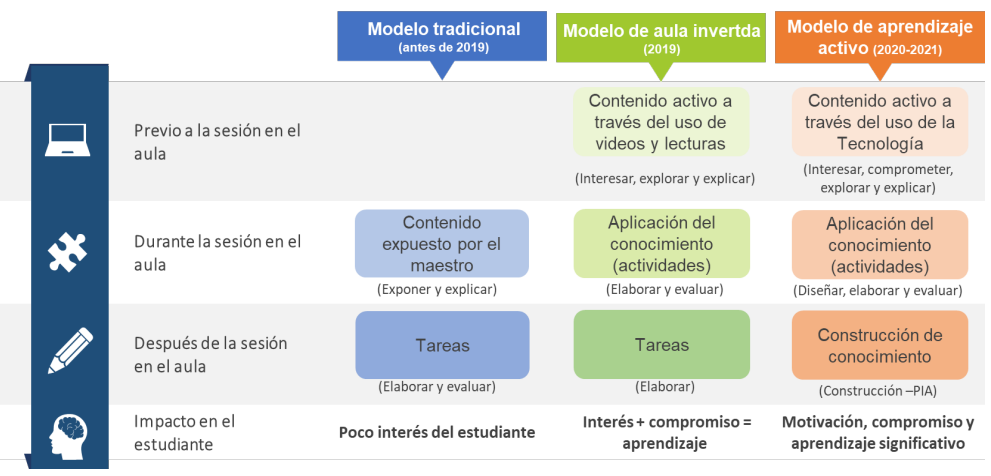

Figura 28. Proceso de transición del modelo tradicional al modelo de aprendizaje activo

Fuente: Adaptado de Alfaro, N.G., Zambrano, M., Habib, L. (2020).

Estrategias pedagógicas mediante aula invertida para lograr un aprendizaje activo. APublicaciones CIEAL. La figura presenta el proceso de evolución desde el modelo tradicional al modelo de aprendizaje activo en la asignatura de formación de emprendedores.

El transitar de un modelo de aprendizaje tradicional al modelo de aprendizaje activo supone muchos retos. Los mayores 
retos de aprendizaje encontrados en el proceso, se refieren a cómo solucionaríamos los problemas que se presentaban en la transición. El contexto complejo de la actualidad demanda de egresados de ingeniería con perfiles complejos, donde se evidencia, no solo el conocimiento científico-técnico, sino también el desarrollo de competencias como el trabajo colaborativo y la integración de saberes conceptuales, procedimentales y actitudinales, para dar solución a diversos problemas. Por lo tanto, la formación de ingenieros debe dar como resultado perfiles de egreso que traspasan las fronteras de una disciplina y área de conocimiento específica. Es por esta razón que trabajar en actividades que promuevan el trabajo colaborativo, y específicamente en equipos multidisciplinarios, era uno de los mayores retos.

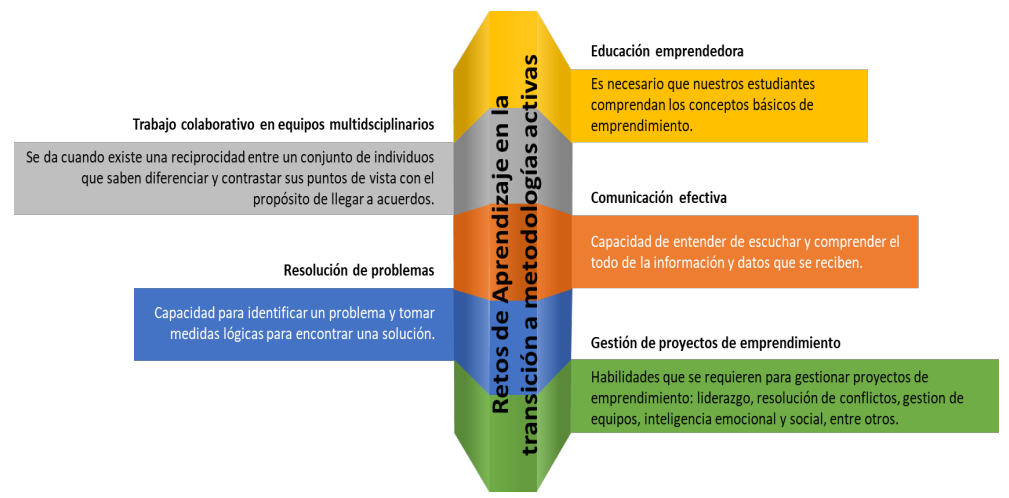

Figura 29. Mayores retos de aprendizaje en la transición a un modelo activo.

Fuente: Elaboración propia con información derivada de la investigación. La figura presenta los mayores retos de aprendizaje del proceso de transición a un Modelo de aprendizaje activo en emprendimiento para ingenieros.

En este sentido, es necesario incluir actividades que promuevan perfiles de ingenieros creativos, imaginativos, innovadores, capaces de trabajar en equipos multidisciplinarios de forma colaborativa, que puedan trabajar con cualquier persona en cualquier lugar. Para ello, es 
necesario desarrollar habilidades de aprendizaje continuo, con una actitud de adaptabilidad a los cambios.

El pensamiento lineal y estático que solía formarse en un modelo tradicional, resulta ineficiente e insuficiente al afrontar los retos a los que nos enfrentamos en la actualidad, y que seguramente se volverán más complejos en el futuro. El pensamiento estratégico ha evolucionado con los cambios. Este es característico de quienes se cuestionan todo, que son individuos inquietos y creativos, capaces de conformar y trabajar en equipos multidisciplinarios de forma colaborativa, y quienes están preparados para resolver problemas. De modo que, el prototipo tenía que incluir y considerar todos estos retos, como puede observarse en la Figura 29.

En el aula de formación de ingenieros emprendedores en la institución donde se llevó a cabo la investigación, se aplicaban métodos tradicionales de enseñanza, centrada en el docente y su cátedra, y partiendo del desarrollo de un plan de negocios elaborado a base de supuestos. Sin embargo, no es posible solucionar problemas con el mismo tipo de pensamiento que los crearon. Los resultados difícilmente trascienden innovadores si partimos de falsos datos que recolecta el emprendedor. Es decir, si el emprendedor intenta construir una solución pensando de manera lineal, entonces desarrolla una solución producto de su experiencia y su propia idea de la necesidad, que obtiene a través de cuestionarios dirigidos, y entonces presenta una propuesta que es innovadora, sí, pero que no propiamente resuelve el problema para el usuario real, porque no llegó a conocerse a profundidad el problema, no se empatizó con la necesidad, y tampoco considera las vivencias, emociones, ni necesidades reales del usuario, quien es el que vive la problemática.

El pensamiento de diseño abre nuevas posibilidades al desarrollo de proyectos de emprendimiento. Pues permite al emprendedor construir una solución pensando de manera deductiva, aplicando el pensamiento estratégico, entonces 
desarrolla una solución disruptiva, que responde al problema empáticamente, es decir, la solución propuesta resuelve de manera natural y encaja en él, y por lo tanto al usuario le parecerá útil.

Para ello, se encontró que el siguiente paso que había que dar una vez elegidas las metodologías activas que se presentaron en la Figura 20, era la reconfiguración de contenidos en el curso de Formación de emprendedores, para quedar como Gestión de proyectos de emprendimiento, y tener la estructura general que se muestra en la Figura 30.

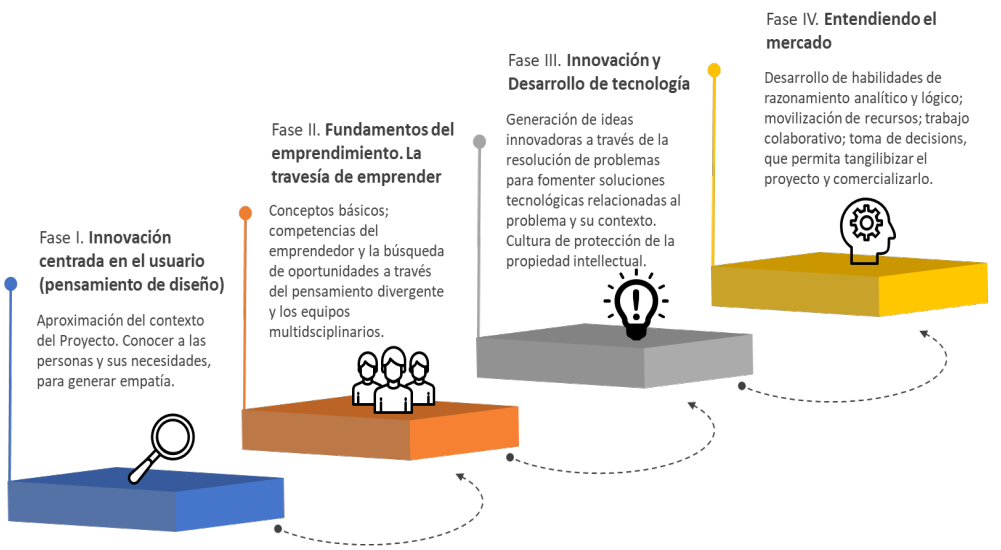

Figura 30. Descripción general del curso prototipo de Gestión de proyectos de emprendimiento.

Fuente: Elaboración propia. La figura presenta la descripción general del curso que se propone de Gestión de proyectos de emprendimiento.

\subsection{Modelo de diseño instruccional para la propuesta de transformación}

La educación emprendedora necesita un entorno especializado, se ha visto ya la importancia del ecosistema, sin embargo, es necesario que en el aula se motive a que los estudiantes, para que desarrollen una mentalidad emprendedora para cambiar el entorno que los rodea. 
El proceso de desarrollo de habilidades emprendedoras es inherente a la experiencia, y si bien, como se observó en el primer capítulo no se tenía un marco teórico integrador, se desarrolló un marco (capítulo I, Figura 1) que permitiera establecer las prioridades de contenido, en aras de diseñar una asignatura de gestión de proyectos de emprendimiento diseñada para ingenieros.

El desarrollo del pensamiento crítico y de aplicación de conocimiento es de fundamental importancia en la formación de estudiantes de ingeniería. Es necesario incorporar nuevas metodologías que ayuden a una formación en competencias y habilidades adaptadas a los nuevos y complejos entornos. El aprendizaje experiencial se considera un procedimiento secuencial y cíclico, y se fundamenta en la idea que el conocimiento se produce a través de las acciones provocadas por una experiencia concreta, la cual se transforma en una conceptualización abstracta y permite aplicarse a nuevas situaciones, formando un proceso continuo e interactivo que genera nuevos aprendizajes (González, Marchueta \& Vilche, 2011).

El aprendizaje experiencial, se sostiene en las ideas de John Dewey, para quien la construcción de conocimiento a partir de una experiencia concreta se representa como un proceso cíclico de interrelación entre los distintos modos de aprendizaje: experiencia concreta $(\mathrm{CE})$, observación reflexiva (RO), conceptualización abstracta (AC) y experimentación activa (AE). Estos cuatro modos están dialécticamente relacionados en dos pares independientes: (CE-AC) y (ROAE). El primer par corresponde a la forma en que el estudiante capta la experiencia, mientras que el último, a la forma en que transforma la experiencia en conocimiento.

El aprendizaje es un proceso de relación bilateral entre experiencia y teoría. No es suficiente con una experiencia para producir conocimiento, es necesaria la modificación de las estrategias cognitivas del individuo. Además, la experiencia 
cobra sentido cuando se relaciona con el conocimiento previo, y se desarrollan estructuras conceptuales que permiten aplicar el nuevo conocimiento ante nuevas situaciones dadas. Itin (1999) propone un modelo que integra las cuatro fases de Dewey, y a través del cual el aprendizaje experiencial es un proceso formativo que implica al individuo física, social, intelectual, cognitiva y emocionalmente, por una experiencia concreta que le ofrece u reto con un nivel de riesgo y fracaso. Es precisamente este modelo el que se empleó como guía para el diseño instruccional planteado, pues se espera que el estudiante observe y analice la situación problemática, formule una hipótesis o propuesta de valor, experimente a través de prototipos y aplique su creatividad en todo el proceso, buscando generar una solución innovadora en la construcción de conocimiento.

\subsubsection{Fundamentos del diseño instruccional propuesto}

Partiendo del concepto de diseño instruccional, esta es una tarea de planeación que se puede definir como el proceso de crear experiencias de aprendizaje, que hacen la adquisición de conocimientos y el desarrollo de habilidades más eficiente y atractivo.

Este proceso establece los criterios que facilitan el desarrollo de experiencias de aprendizaje a fin de garantizar:

- Diseño de calidad

- Objetivos de aprendizaje claros

- Contenidos cuidadosamente estructurados

- Cargas de trabajo equilibradas para los estudiantes

- La integración de actividades relevantes y útiles

- Medios de interacción (sincrónicos y asincrónicos)

- Evaluación ligada a los fines de aprendizaje declarados para el estudiante

Dicho esto, y considerando que se ha elegido una propuesta de aprendizaje experiencial, las estrategias centradas en la 
generación de aprendizaje que se ha elegido para este prototipo son:

- Solución de problemas reales (analizan problemas para proponer soluciones viables que pueden no ser únicas)

- Análisis de casos (promueven la integración de nuevo conocimiento, negociación, toma de decisiones y solución de problemas)

- Trabajo colaborativo (las propuestas de solución se desarrollan colaborativamente)

- Simulaciones (el desarrollo de prototipos se hace en simuladores virtuales, pues no se llegan a construir físicamente evitando comprometer a los estudiantes con altos costos)

El modelo pedagógico que se emplea para el diseño instruccional del prototipo propuesto, se enfoca en el logro de proyectos adaptados al contexto, atendiendo la necesidad del usuario y respondiendo creativamente en la propuesta innovadora de solución. Lackéus (2015) enuncia dos sentidos en los que la educación emprendedora se vuelve un vehículo para la innovación, el primero es que se enfoca en la identificación de oportunidades para crear empresas y generar empleo, y la segunda, en un sentido más amplio, orientado hacia el desarrollo personal del emprendedor, su iniciativa y creatividad orientado a metas concretas. El autor asegura que emprender son "los conocimientos, destrezas, habilidades y actitudes que afectan la disposición y capacidad para realizar un trabajo..." (Lackéus, 2015, p. 12). Lo que significa que las habilidades y competencias emprendedoras se desarrollan de manera intencional, explícita o implícitamente en la educación emprendedora, particularidades como: el liderazgo, la búsqueda de oportunidades, la innovación, el pensamiento crítico, la empatía, la adaptabilidad, la resolución de problemas (Ramírez-Montoya \& Beltrán, 2019). 
Para abordar el diseño instruccional, se aplica el Modelo ADDIE (por sus siglas en inglés Analysis, Design, Development, implementation and Evaluation- Análisis, diseño, desarrollo, implementación y evaluación). Por lo que revisaremos cada una de las fases.

\subsubsection{Fase 1. Análisis}

En esta fase, se consideraron el contexto institucional, el entorno en el que se lleva a cabo el proceso de aprendizaje, las características y perfiles de los estudiantes, y el propio perfil del docente, como se observa en la Figura 31. El propósito del análisis es definir el punto de partida del diseño. Aunque no siempre se cuenta con la información detallada con respecto a cada uno de los elementos, es posible hacer una reflexión no exhaustiva, o un proceso indagatorio que permita obtener la información suficiente.

\begin{tabular}{|l|l|}
\hline Contexto Institucional & $\begin{array}{l}\text { Contenido } \\
\text { (proceso de } \\
\text { aprendizaje) }\end{array}$ \\
\hline - Política de calidad & - Antecedentes \\
- Visión & - Descripción y \\
- Misión & especificaciones \\
- Valores & $\begin{array}{l}\text { Objetivos de } \\
\text { aprendizaje }\end{array}$ \\
- Infraestructura & Resultados \\
- Políticas & esperados \\
- Tequitucionales & Requerimientos \\
\hline
\end{tabular}
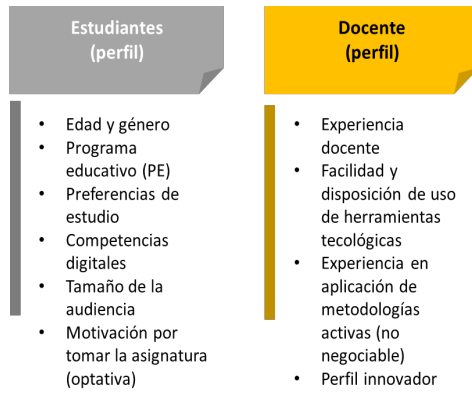

Figura 31. Fase de Análisis en Diseño instruccional.

Fuente: Elaboración propia con información de VIllarreal Rodríguez, M. (2018). El diseño de entornos digitales de aprendizaje. La figura presenta la descripción de los elementos necesarios para poder diseñar el curso de

Gestión de proyectos de emprendimiento.

Se propone una transformación de la perspectiva de enseñanza de emprendimiento para ingenieros, pues en un ambiente de aprendizaje diverso, el aprendizaje se adapta a cada estudiante, a su entorno formativo, este es el nuevo paradigma de la educación. El aprendizaje ya no debe estar estrictamente ligado a tiempo y lugar, sino que sea cual sea el 
camino del estudiante, la personalización del aprendizaje se convierte en la norma que consistirá en que los enfoques y apoyos de aprendizaje estarán hechos a la medida de cada estudiante.

La personalización significa que los métodos educativos tradicionales deben evitarse, y que deben darse cabida a modelos alternativos y activos, de modo que sean útiles para el propósito del aprendizaje. Pero también, debe cambiar la forma en que se diseñen las actividades que conforman los ambientes de aprendizaje, los recursos que se emplean en el aula y extra aula, la forma en que se establecen las prácticas, aplicando prácticas espaciales para permitir al estudiante desarrollar competencias y habilidades, además debe permitirse una intercalación de contenido a fin de evitar que el estudiante olvide aprendizajes y garantizar su uso y aplicación.

Otro aspecto importante de la personalización es la medición, no es posible mejorar lo que no se mide. La evaluación de las estrategias aplicadas en la enseñanza deben ser medidas, a través de formularios de percepción a los estudiantes, pero también con trabajos de análisis crítico entre docentes, como por ejemplo los trabajos de pares pedagógicos, donde se invite a otros colegas docentes a analizar la práctica educativa que se lleva a cabo en el aula, de modo que se pueda trabajar en áreas de oportunidad.

$\mathrm{Y}$ un aspecto adicional que debe considerarse en el diseño es la retroalimentación, esta debe ser cuidadosamente diseñada para que sea efectiva, debe darse pronto al estudiante para que pueda reconvenir en la construcción de conocimiento, si el docente tarda en dar la retroalimentación, permite que el estudiante trabaje sin orientación y puede generar retrabajos innecesarios.

Los compromisos en el ámbito de la práctica docente en esta transformación son amplios, pero debe entenderse que es 
necesaria la disposición del docente a fin de que funcione y se puedan llegar a los objetivos de aprendizaje esperados. No se pueden esperar resultados diferentes si la práctica docente no cambia, es necesario evolucionar, adaptarse al nuevo contexto. Eso es lo que realmente significa una educación centrada en el estudiante. Esto vuelve al docente en un agente de aprendizaje, un mentor, facilitador y colaborador, que debe tener un perfil creativo, empático y colaborativo.

Por lo tanto, el perfil del docente debe permitir que su labor se concentre en guiar, orientar y dirigir el desempeño del estudiante, independientemente del caso que estén resolviendo los estudiantes. Como puede advertirse en la Figura 32.

1 Explicar claramente materiales, actividades y procesos, para que el estudiante 1 tenga claro lo que se espera de el/ella

2 Dejar claro al alumno que el profesor quiere ayudarle a aprender y es solo una guia Definir claramente los objetivos de la asignatura y relacionarlos con la
realidad 4 Dejar claro cómo cada concepto está relacionado con los demás de la

5 Realizar actividades formativas de manera que ayude a la retención de los conocimientos

6 Dejar que los estudiantes dirijan, solo orientar y usar el sentido del humor

7 Introducir ideas estimulantes sobre la temática para abrir el debate

Figura 32. Labor del docente en las metodologías activas propuestas. Fuente: Creación propia con fundamento en la teoría de Clegg (1993). La figura presenta los elementos de la labor docente en la metodología propuesta para el curso Gestión de proyectos de emprendimiento.

\subsubsection{Fase 2. Diseño}

Como se ha visto en el punto anterior, la fase del análisis brinda un punto de partida para el diseño de la experiencia de aprendizaje. En esta fase, es necesario especificar cómo es que aprenderá el estudiante, determinando el enfoque pedagógico y el alcance que tendrá el uso de la tecnología. Deben especificarse cómo se conforman y sustentan los procesos de 
enseñanza y aprendizaje, y establecer la estrategia del qué, cómo, cuándo y dónde sucede el aprendizaje mediado por la tecnología. En la Figura 33 pueden observarse los elementos de la fase de diseño que se han trabajado en el prototipo.

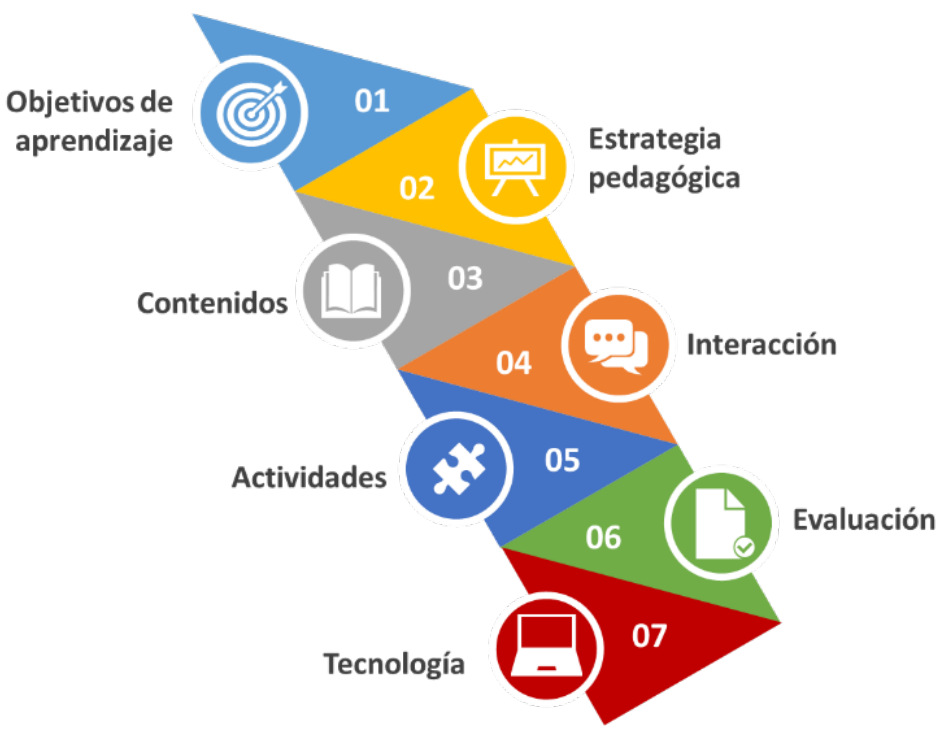

Figura 33. Elementos de la Fase de Diseño.

Fuente: Elaboración propia. La figura presenta los elementos de la fase de diseño del curso Gestión de proyectos de emprendimiento.

\section{Objetivos de aprendizaje}

Los estudiantes aprenden más y mejor cuando la estrategia de enseñanza concuerda con su estilo de aprendizaje, y pueden darle significado a su aprendizaje cuando se les obliga a salir de su zona de confort, a través de actividades bien planeadas y dirigidas que los orillen a esforzarse más.

En la Figura 34 puede observarse los objetivos de aprendizaje del prototipo, que son el primer elemento a considerar. 


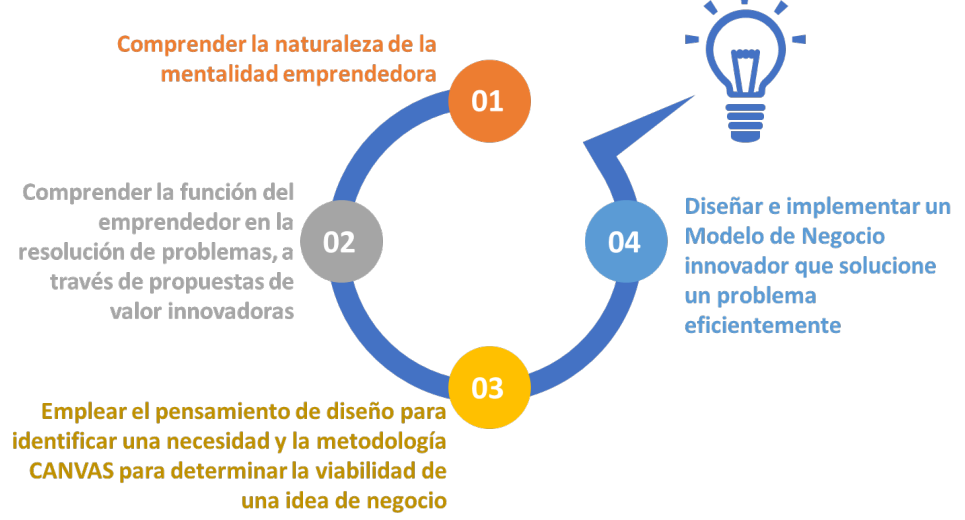

Figura 34. Objetivos de aprendizaje.

Fuente: Elaboración propia. La figura presenta los objetivos de aprendizaje del curso Gestión de proyectos de emprendimiento, lo que van a lograr los estudiantes al término de este.

\section{Estrategia pedagógica}

En cuanto a la estrategia, es el procedimiento organizado, formalizado y orientado a la obtención de una meta claramente establecida, como lo son los objetivos de aprendizaje ya declarados.

La estrategia pedagógica empleada es basada en el uso y aplicación de metodologías activas y el aprendizaje experiencial, dados los hallazgos de la investigación ya establecidos en los capítulos anteriores. Las metodologías activas empleadas, quedaron declaradas en la Figura 20. Particularmente la razón de emplear el pensamiento de diseño es que este permite combinar empatía (con el contexto de un problema), creatividad (en la generación de ideas, percepciones y soluciones), y racionalidad para analizar y combinar las soluciones con el contexto. Se busca que los estudiantes sean al mismo tiempo empáticos y analíticos, racionales y emocionales, metódicos e intuitivos. Que sean capaces de mantener la espontaneidad, mientras trabajan 
orientados a objetivos, aún que se encuentren bajo presión o con limitaciones de recursos.

El pensamiento de diseño está centrado en el ser humano, por lo que la comprensión de las necesidades y motivaciones de las personas son lo más importante. Además, promueve un enfoque colaborativo, lo que facilita el trabajo con otros, particularmente en equipos multidisciplinarios (estudiantes de diversos programas educativos y perfiles).

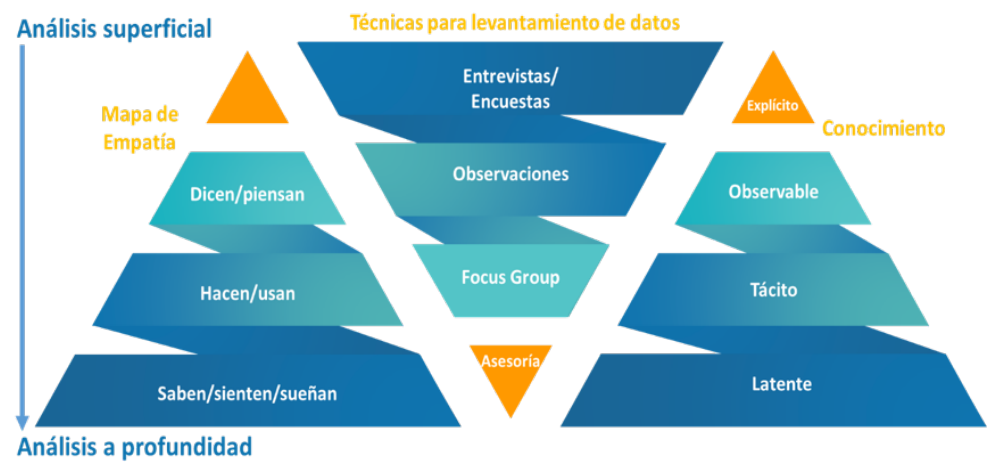

Figura 35. Proceso de inmersión dentro del pensamiento de diseño aplicado en el prototipo.

Fuente: Adaptado de Vianna, M., Vianna, Y., Adler, I., Lucena, B., \& Russo, B. (2012). Design thinking: business innovation. MJV Tecnologia ltda, Rio de Janeiro. La figura presenta los pasos dentro del proceso de inmersión en el pensamiento de diseño, donde el estudiante investiga a profundidad sobre el contexto de la problemática a fin de empatizar.

El economista Herbert Simon ganador del Premio Nobel, ha argumentado que las disciplinas aplicadas están mejor atendidas por planes de estudio basados en el diseño (You \& Hands, 2019). El pensamiento de diseño es un proceso de divergencia y convergencia que requiere de habilidades de observación, síntesis, búsqueda y generación de alternativas, pensamiento crítico, retroalimentación, representación visual, creatividad, resolución de problemas y creación de valor, como es el caso del proceso de inmersión como se presenta en la Figura 35. Considerar el diseño como la base para la 
creación de la experiencia de aprendizaje, coadyuva a que los estudiantes identifiquen y actúen en oportunidades de emprendimiento únicas, aplicando un conjunto de herramientas de observación, trabajo de campo y comprensión de la creación de valor en múltiples grupos de partes interesadas.

En el centro de la conformación de la mentalidad emprendedora está la oportunidad y la explotación de oportunidades, como se definía ya en la secuencia didáctica declarada en la Figura 25.

En las versiones anteriores de la materia de emprendimiento, se daba por sentado que la oportunidad de negocio estaba ya identificada, y se centran solo en la evaluación de oportunidades, pero se prestaba poca atención a cómo se había identificado la oportunidad más allá de una discusión unilateral por parte de los miembros del equipo de estudiantes. En la propuesta de este prototipo, el proceso debe certificar, a través de herramientas de inmersión, la oportunidad real expuesta por el usuario y entonces explotar estas a través de propuestas de valor (Sarasvathy, 2009).

\section{Contenidos}

Con respecto al contenido, ha quedado ya declarado en la Figura 30, donde se especifica la estructura general del curso prototipo con los temas por case. Es necesario ahondar en los recursos que se usarán para presentar los contenidos, es decir, los saberes conceptuales, procedimentales, actitudinales y de valores, asociados al emprendimiento.

Se convierte esencial que los contenidos se adapten a formatos electrónicos, a fin de poder ser copiados, transmitidos y distribuidos a través de la plataforma que se emplee para llevar la asignatura, de modo que facilite los propósitos. Los contenidos se presentaron de la forma que expone la Figura 36. 

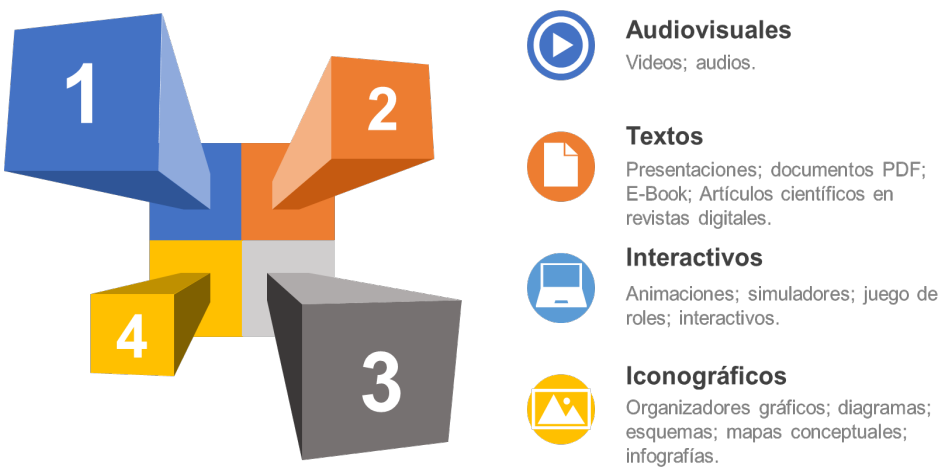

Figura 36. Recursos para presentar contenido.

Fuente: Elaboración propia. La figura presenta los objetivos de aprendizaje del curso Gestión de proyectos de emprendimiento, lo que van a lograr los estudiantes al término de este.

\section{Interacción}

En lo que respecta a la interacción, esta se define como la comunicación entre el docente y el estudiante, entre el estudiante y los recursos, o bien entre estudiantes. La interacción tiene lugar para dos propósitos, el primero, es la aclaración de dudas, preguntas, exposición de ideas y conceptos, o bien, aquella que se lleva a cabo entre pares o con los recursos, para colaborar y construir conocimiento.

Bernard, et al. (2009) señalan, que en cuanto mayor sea la interacción de los estudiantes con los recursos, con los compañeros de clase y con el docente, mayor será el efecto positivo que esta interacción tenga en el aprendizaje de los estudiantes.

En el prototipo, la interacción se da tanto de manera sincrónica como asincrónica en el ambiente de aprendizaje, siempre potenciada a través del uso de la tecnología.

\section{Actividades}

Las actividades son el elemento esencial para activar, reforzar y potenciar el aprendizaje significativo del estudiante. En los 
entornos de aprendizaje, promueven la autonomía e independencia del participante, pues le permite realizar sus actividades conforme a su propio ritmo, ruta, tiempo y estrategias de estudio establecidas por el mismo. Lo que permite que se haga responsable de sus propios procesos de aprendizaje.

Las actividades que se integran a las experiencias de aprendizaje deben responder al logro de objetivos declarados, ya sea para el desarrollo de competencias o la adquisición de conocimientos.

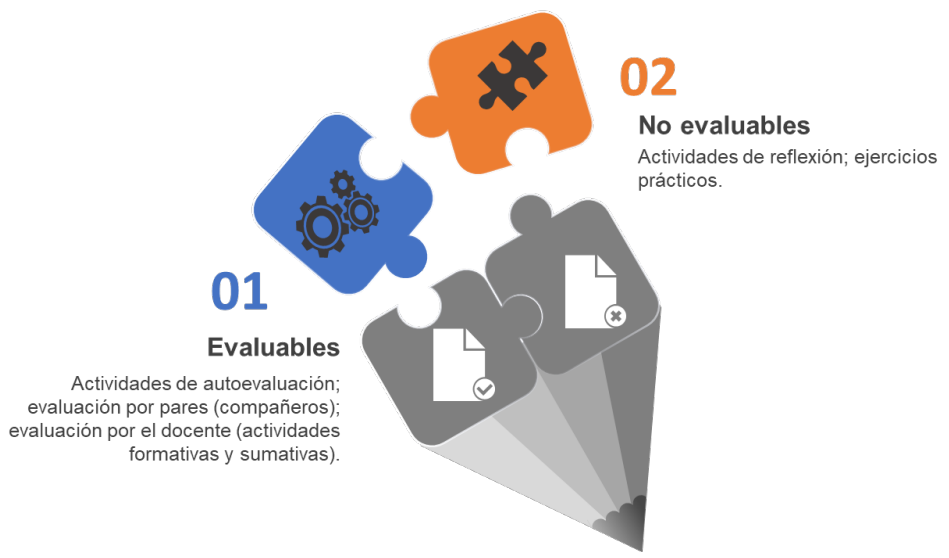

Figura 37. Composición de las actividades en el prototipo.

Fuente: Elaboración propia. La figura presenta los tipos de actividades que se diseñaron en el prototipo propuesto.

La dificultad que esto presenta para el docente es grande, pues se espera que el diseño de actividades sea innovador y que reten al estudiante a promover procesos cognitivos de aprendizaje, a saber:

- Que promuevan una interacción sincrónica y asincrónica

- Que combinen trabajo individual y colaborativo

- Que el intercambio sea multidisciplinario

- Y que deje evidencia del desarrollo y los resultados 
Las actividades pueden ser variadas, algunas son para presentar contenido, otras para reforzar contenido, otras pueden planearse para practicar y otras pueden diseñarse para evaluar, como se muestra en la Figura 37.

En el prototipo propuesto, el estudiante adquiere experiencia a través de actividades y prácticas en una base no competitiva. La información se proporciona de manera formal aplicando la estrategia de aula invertida a través de videos previamente elaborados, el apoyo de los compañeros está presente en todas las actividades, pues se realizan de forma colaborativa. Al dejar los nuevos conceptos a sesiones asincrónicas y de forma individual, la discusión sincrónica ayuda a los participantes a interactuar entre sí, debatiendo para ir resolviendo la problemática particular de cada equipo.

En este entorno, la retroalimentación se proporciona personalmente por parte del tutor/docente sobre las necesidades individuales y de cada equipo. Esto ocurre, pues cada uno tiene problemáticas distintas que resolver, y conforme a sus experiencias previas y perfiles individuales, las propuestas son igualmente únicas. Por lo que el docente debe enfocarse en orientar el desempeño de los equipos de manera que lo requieran, promoviendo la reflexión y el desarrollo de talentos, así como, centrándose en el procedimiento, pues los resultados son distintos dependiendo del caso que estén resolviendo.

Es evidente que la educación emprendedora tiene como objetivo llevar al aula lo complicado y multivariado que puede ser el proceso de emprendimiento. El estudiante a menudo tiene que reflexionar para reaccionar en situaciones que parecen inciertas o únicas para él. Adopta la reflexión, no sólo para darse cuenta de una situación problemática, sino también para hacer propuestas de solución que la cambien.

Uno de los elementos más importantes en el diseño instruccional de la propuesta es el trabajo colaborativo, como 
se ha establecido al inicio de este capítulo, el prototipo propuesto se centra en privilegiar el trabajo en equipo para la construcción de conocimiento, por lo que, como puede observarse en la Figura 38, estas son las competencias que se busca desarrollen los estudiantes durante el proceso de construcción del Modelo de Negocio.

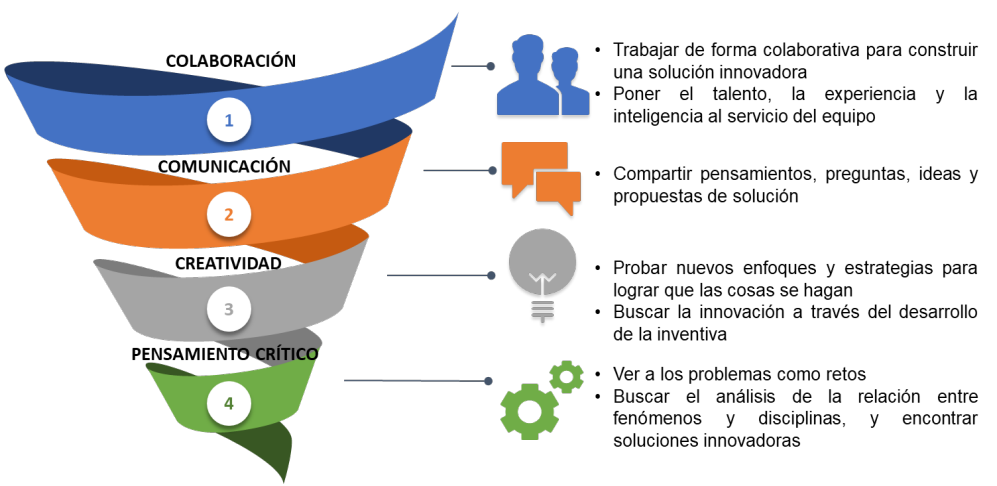

Figura 38. Construcción de equipos multidisciplinarios y sólidos con base en las competencias del siglo XXI.

Fuente: Adaptado de Claxton, G., Costa, A., \& Kallick, B. (2016). Hard thinking about soft skills. Educational leadership, 73(6). La figura presenta las competencias que se privilegian en la construcción de equipos multidisciplinarios en el prototipo propuesto.

\section{Evaluación}

La evaluación permite conocer, no solo la calidad del aprendizaje del estudiante, sino también, las estrategias pedagógicas aplicadas por el docente. Este proceso se facilita con el uso de herramientas tecnológicas, pues es posible diseñar instrumentos para recopilar información sobre el desempeño del participante, analizar la información obtenida, registrar las evidencias y tomar las decisiones pertinentes para mejorar los resultados obtenidos.

\section{Tecnología}

La plataforma en que se planteó el prototipo es el aprendizaje combinado (blended learning, como se conoce en inglés). Por lo 
que la tecnología no solo se emplea de manera ocasional, sino que forma parte de la estructura en la que está diseñado el curso. Se emplea un sistema de gestión del conocimiento (learning management system, LMS como se conoce en inglés) como plataforma cerrada en la que se llevan las sesiones síncronas y asíncronas, donde solo los estudiantes registrados tienen acceso a los contenidos. Este sistema permite llevar registros de consultas, trabajos, actividades, en diversos formatos, como videos, y documentos compartidos, cosa que facilita las métricas para la analítica de datos (con el propósito de personalización del aprendizaje, como se ha descrito anteriormente).

Las herramientas tecnológicas pueden ser de interacción o de evaluación, las primeras sirven para compartir y trabajar, y las segundas para los registros de evaluación, principalmente de evaluaciones sumativas.

\subsubsection{Fase 3. Desarrollo}

En esta fase se generaron los contenidos, los materiales y los recursos didácticos que se definieron en la fase de diseño. Ya en la secuencia didáctica se han definido los recursos educativos que integran la experiencia de aprendizaje, partiendo de ahí, entonces se construyen los contenidos para dichos recursos, siguiendo un guión instruccional. Mayormente los recursos se construyeron para el propósito particular del prototipo, sin embargo, también se emplean recursos educativos abiertos.

Una vez que se construyen los recursos, haciendo uso de diversas herramientas, es necesario entonces colocarlos en el entorno de aprendizaje que se ha diseñado. Se trabajaron en recursos que se pudieran adaptar y reutilizar en diversas situaciones. Se organizaron los recursos de manera que pudieran ser encontrados con facilidad. Todos los recursos tienen un propósito en particular, y todos los contenidos 
tienen diversos recursos para facilitar el tránsito educacional del estudiante.

Una vez que se integraron los recursos al entorno de aprendizaje, fue necesario asegurar que se contara con la infraestructura y requerimientos tecnológicos necesarios:

- Asegurar que todos los estudiantes cuenten con los requerimientos tecnológicos necesarios para el uso de las herramientas seleccionadas

- Verificar licencias y permisos que aplican

- Consideraciones de atención a los diferentes estilos de aprendizaje

\subsubsection{Fase 4. Implementación}

El propósito de esta fase es la ejecución de la experiencia de aprendizaje con la participación activa de los estudiantes. Es importante para esta fase desarrollar las rutas de aprendizaje que facilitarán el transitar del estudiante por todo el proceso de aprendizaje.

Durante la implementación, se propone que el docente mantenga un papel activo en la interacción y comunicación con los recursos y los estudiantes, por lo que se sugieren las siguientes actividades durante el curso:

- Enviar mensajes de bienvenida

- Publicar desde la primera sesión, el encuadre, toda la estructura del programa, los recursos, las actividades y fechas de vencimiento, a fin de que el estudiante esté bien enterado de lo que es importante

- Aclaración de dudas inmediatas y guía de los trabajos al interior de los equipos (cada sesión)

- Participación en los espacios de interacción (equipos)

- Retroalimentación y seguimiento constante, sobre todo en las evaluaciones sumativas, no debe dejar pasar el tiempo (si la actividad vence, la revisión y retroalimentación no 
debe dejar pasar más de una semana a fin de que el estudiante sepa cuáles son sus áreas de oportunidad)

- Moderación y facilitación de debates y discusiones

- Publicación de calificaciones en tiempo y forma

- Enviar mensajes de cierre de periodo lectivo

\subsubsection{Fase 5. Evaluación}

En esta fase se mide la eficacia y eficiencia de la instrucción, es importante que la evaluación esté presente durante todo el proceso de diseño y al finalizar la impartición.

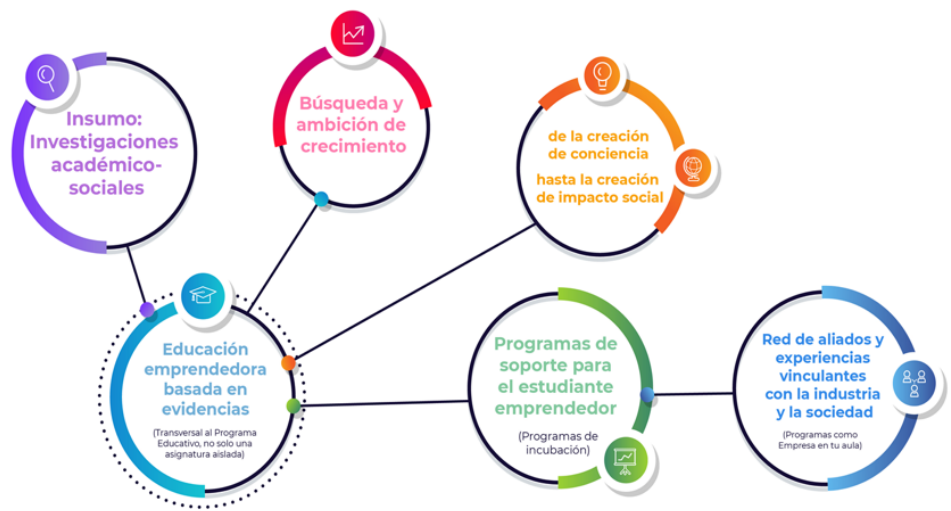

Figura 39. Ecosistema universitario que favorece la formación de ingenieros emprendedores.

Fuente: Elaboración propia. La figura presenta la conformación de un ecosistema universitario favorecedor para la formación de ingenieros emprendedores.

En la evaluación y para el prototipo en particular, se sugiere que las evaluaciones de parte de los estudiantes se consideren instrumentos de percepción, a fin de conocer qué opinan los estudiantes de las actividades, de los recursos, de los contenidos, de la experiencia de aprendizaje en general. Sin embargo, para el tema de las estrategias aplicadas, se recomienda que el docente invite a colegas a observar su práctica didáctica a fin de recibir críticas que le permitan potenciar sus fortalezas y trabajar sobre sus áreas de 
oportunidad. Esto es lo que se conoce como pares pedagógicos (Santos, Alves, Ferreira \& Costa, 2015).

Luego de haber concluido las 5 fases del diseño instruccional, en la Figura 39 se muestra el ecosistema básico que se ha implementado para soporte del prototipo propuesto.

\subsection{Reflexiones finales}

La investigación en educación emprendedora puede facilitar la colaboración multidisciplinaria. Este libro sugiere diversos medios de colaboración, ya que se basa en diferentes publicaciones en sociología, psicología, educación, economía, negocios e ingeniería.

La más importante reflexión es que la educación emprendedora conduce a un impacto que se extiende más allá de la creación de nuevas empresas, promueve también habilidades y competencias que son muy útiles en todos los niveles personales y profesionales del individuo. Este libro ha dejado claro que no se trata solo de formar emprendedores, sino que es necesario innovar en la formación a fin de poder motivar a la innovación.

La empatía, la autonomía de aprendizaje, el aprendizaje autoregulado, el aceptar riesgos, el aplicar la creatividad, el pensar fuera de la caja, son solo algunas de las principales habilidades que tanto docentes, como investigadores y estudiantes deberían aprender. Esta perspectiva impacta a la práctica docente, a la investigación, a los futuros ingenieros y por lo tanto a la sociedad.

Los pasos futuros en el desarrollo de la educación emprendedora deben ser evaluar los programas actuales, las asignaturas y la infraestructura en las instituciones de educación superior a fin de crear verdaderos ecosistemas que favorezcan la formación de ingenieros emprendedores. La práctica debe superar toda teoría. 


\section{Referencias bibliográficas}

\section{Capítulo I.}

Alexoaei, A. P. (2020). The relevance of national competitiveness for the entrepreneurial environment. Romanian Economic Journal, 23(77), 64-76.

Amit, R., Brander, J., \& Zott, C. (1998). Why do venture capital firms exist? 'Theory and Canadian evidence. Journal of business Venturing, 13(6), 441-466.

Amit, R., Glosten, L., \& Muller, E. (1993). Challenges to theory development in entrepreneurship research. Journal of Management studies, 30(5), 815834.

Ang, S. H., \& Hong, D. G. (2000). Entrepreneurial spirit among east Asian Chinese. Thunderbird International Business Review, 42(3), 285-309.

Audretsch, D. B., \& Thurik, A. R. (2000). Capitalism and democracy in the 21 st century: from the managed to the entrepreneurial economy. Journal of evolutionary economics, 10(1), 17-34.

Audretsch, D. B., Carree, M. A., \& Thurik, A. R. (2001). Does entrepreneurship reduce unemployment? (No. 01-074/3). Tinbergen Institute discussion paper.

Audretsch, D. B., Carree, M. A., Van Stel, A. J., \& Thurik, A. R. (2002). Impeded industrial restructuring: the growth penalty. Kyklos, 55(1), 8198.

Aulet, W., \& Murray, F. (2013). A tale of two entrepreneurs: Understanding differences in the types of entrepreneurships in the economy. Available at SSRN 2259740.

Baron, R. A. (1998). Cognitive mechanisms in entrepreneurship: Why and when enterpreneurs think differently than other people. Journal of Business venturing, 13(4), 275-294.

Belitski, M., \& Desai, S. (2016). Creativity, entrepreneurship and economic development: city-level evidence on creativity spillover of entrepreneurship. The Journal of Technology Transfer, 41(6), 1354-1376.

Bird, B. (2019). Toward a theory of entrepreneurial competency. In Seminal ideas for the next twenty-five years of advances. Emerald Publishing Limited. 
Bork, R. H. (1978). The Antitrust Paradox: A Policy at War with Itself, New York: Basic Books.

Busenitz, L. W., \& Barney, J. B. (1997). Differences between entrepreneurs and managers in large organizations: Biases and heuristics in strategic decision-making. Journal of business venturing, 12(1), 9-30.

Cardon, M.S., Wincent, J., Singh, J., Drnovsek, M. (2009). The Nature and Experience of Entrepreneurial Passion, The Academy of Management Review, vol. 34, no. 3, pp. 511-532.

Carree, M., Van Stel, A., Thurik, R., \& Wennekers, S. (2002). Economic development and business ownership: an analysis using data of 23 OECD countries in the period 1976-1996. Small business economics, 19(3), 271-290.

Carree, M.A. \& A.R. Thurik. (1999). Industrial structure and economic growth, in: D.B. Audretsch and A. R. Thurik (eds.) Innovation, Industry Evolution and Employment, Cambridge, UK: Cambridge University Press, 86-110.

Caruana, A., Morris, M. H., \& Vella, A. J. (1998). The effect of centralization and formalization on entrepreneurship in export firms. Journal of small business management, 36(1), 16.

Casson, M. (2003). The Entrepreneur: An Economic Theory. Edward Elgar Publishing.

Chandler, A. (1977). The Visible Hand: The Managerial Revolution in American Business, Cambridge, MA: Harvard University Press.

Chen, M. H., Chang, Y. Y., Wang, H. Y., \& Chen, M. H. (2017). Understanding creative entrepreneurs' intention to quit: The role of entrepreneurial motivation, creativity, and opportunity. Entrepreneurship Research Journal, 7(3).

Clark, J., \& White, G. W. (2010). Experiential learning: A definitive edge in the job market. American Journal of Business Education (AJBE), 3(2), 115118.

D’Mello, J. F. (2019). Universal basic income and entrepreneurial pursuit in an autonomous society. Journal of Management Inquiry, 28(3), 306-310.

Daley, J. (2013). Are entrepreneurs born or made. Entrepreneur, September 19thpp, 20-22.

Dennis, W. J. (1993). A small business primer: Charts and graphs illustrating the importance and role of American small business. NFIB Foundation. 
Diandra, D., \& Azmy, A. (2020). Understanding definition of entrepreneurship. International Journal of Management, Accounting and Economics, 7(5), 235-241.

Dimitriadis, E., Anastasiades, T., Karagiannidou, D., \& Lagaki, M. (2017). Creativity and entrepreneurship: The role of gender and personality. International Journal of Business and Economic Sciences Applied Research (IJBESAR), 11(1).

Doty, D. H., \& Glick, W. H. (1994). Typologies as a unique form of theory building: Toward improved understanding and modeling. Academy of management review, 19(2), 230-251.

Dunne, D., \& Martin, R. (2006). Design thinking and how it will change management education: An interview and discussion. Academy of Management Learning \& Education, 5(4), 512-523.

Fayolle, A., Gailly, B., \& Lassas-Clerc, N. (2006). Assessing the impact of entrepreneurship education programmes: a new methodology. Journal of European industrial training.

Foer, A.A. (2001) Small business and antitrust, Small Business Economics 16 (1), 3-20.

Fried, V. H., Bruton, G. D., \& Hisrich, R. D. (1998). Strategy and the board of directors in venture capital-backed firms. Journal of business venturing, 13(6), 493-503.

Futterer, F., Schmidt, J., \& Heidenreich, S. (2018). Effectuation or causation as the key to corporate venture success? Investigating effects of entrepreneurial behaviors on business model innovation and venture performance. Long Range Planning, 51(1), 64-81.

Galbraith, J.K. (1967). The New Industrial State, Boston, MA: Houghton Mifflin.

Gartner, W. B. (1990). What are we talking about when we talk about entrepreneurship? Journal of Business Venturing, 5(1), 15-28.

Giacomin, O., Janssen, F., Guyot, J. L., \& Lohest, O. (2011). Opportunity and/or necessity entrepreneurship? The impact of the socio-economic characteristics of entrepreneurs.

Gieure, C., del Mar Benavides-Espinosa, M., \& Roig-Dobón, S. (2019). Entrepreneurial intentions in an international university environment. International Journal of Entrepreneurial Bebavior \& Research.

Hall, A. R. (2015). Governpreneurship: Establishing a Thriving Entrepreneurial Spirit in Government. Journal of Entrepreneurship and Public Policy. 
Hechavarría, D. M., \& Welter, C. (2015). Opportunity types, social entrepreneurship and innovation: Evidence from the panel study of entrepreneurial dynamics. The International Journal of Entrepreneurship and Innovation, 16(4), 237-251.

Ireland, R. D., \& Hitt, M. A. (1999). Achieving and maintaining strategic competitiveness in the 21st century: The role of strategic leadership. Academy of Management Perspectives, 13(1), 43-57.

Johansson-Sköldberg, U., Woodilla, J., \& Çetinkaya, M. (2013). Design thinking: past, present and possible futures. Creativity and innovation management, 22(2), 121-146.

Katz, J. A. (2003). The chronology and intellectual trajectory of American entrepreneurship education: 1876-1999. Journal of business venturing, 18(2), 283-300.

Kaufmann, A. E. (1993). El poder de las organizaciones. Ediciones de la Universidad de Alcalá de Henares, ESIC.

Keeley, L., Walters, H., Pikkel, R., \& Quinn, B. (2013). Ten types of innovation: The discipline of building breakthroughs. John Wiley \& Sons.

Kim, Y. J., \& Park, H. G. (2014). A Study on the Effects of the Entrepreneurial Orientation on Management Performance: Focused on the Manufacturer in the Small Businesses. Journal of the Society of Korea Industrial and Systems Engineering, 37(4), 251-258.

Kuratko, D. F., \& Hornsby, J. S. (1996). Developing entrepreneurial leadership in contemporary organizations. Journal of Management Systems, 8(4), $17-27$.

Laukkanen, M. (2000). Exploring alternative approaches in high-level entrepreneurship education: creating micromechanisms for endogenous regional growth. Entrepreneurship \& Regional Development, 12(1), 25-47.

Leonard, H.S., \& Lang, F. (2010). Leadership development via action learning. Advances in Developing Human Resources, 12(2), 225-240.

Londhe, B. R. (2014). Marketing mix for next generation marketing. Procedia Economics and Finance, 11, 335-340.

MacMillan, I. C., \& Katz, J. A. (2002). Idiosyncratic Milieus of Entrepreneurial Research: The need for comprehensive theories. Entrepreneurship: Critical Perspectives on Business and Management, 3(1), 405.

Magistretti, S., Dell'Era, C., \& Doppio, N. (2020). Design sprint for SMEs: an organizational taxonomy based on configuration theory. Management Decision. 
Marshall, D. R., Meek, W. R., Swab, R. G., \& Markin, E. (2020). Access to resources and entrepreneurial well-being: A self-efficacy approach. Journal of Business Research, 120, 203-212.

McGrath, R. G., \& MacMillan, I. C. (2000). The entrepreneurial mindset: Strategies for continuously creating opportunity in an age of uncertainty (Vol. 284). Harvard Business Press.

McGrath, R. G., MacMillan, I. C., \& Scheinberg, S. (1992). Elitists, risktakers, and rugged individualists? An exploratory analysis of cultural differences between entrepreneurs and non-entrepreneurs. Journal of business venturing, 7(2), 115-135.

Merriam-Webster. (2004). Merriam-Webster's collegiate dictionary (Vol. 2). Merriam-Webster.

Miller, D. (2011). Miller (1983) revisited: A reflection on EO research and some suggestions for the future. Entrepreneurship theory and practice, 35(5), 873-894.

Miner, John B. (2000), 'Testing a psychological typology of entrepreneurship using business founders', Journal of Applied Behavioral Science, Vol 36, No 1, pp 43-70.

Mitchell, R. K., Smith, B., Seawright, K. W., \& Morse, E. A. (2000). Crosscultural cognitions and the venture creation decision. Academy of management Journal, 43(5), 974-993.

Momete, D. C. (2015). Fostering innovation and entrepreneurial culture in Romania through engineering higher education programs. Procedia Economics and Finance, 22, 168-174.

Moroz, P. W., \& Hindle, K. (2012). Entrepreneurship as a process: Toward harmonizing multiple perspectives. Entrepreneurship theory and Practice, 36(4), 781-818.

Morris, M. H., Kuratko, D. F., \& Schindehutte, M. (2001). Towards integration: understanding entrepreneurship through frameworks. The international journal of entrepreneurship and innovation, 2(1), 35-49.

Morris, M. H., Pryor, C. G., \& Schindehutte, M. (2012). Entrepreneurship as experience: How events create ventures and ventures create entrepreneurs. Edward Elgar Publishing.

Morris, Michael (1998), Entrepreneurial Intensity, Quorum Books, Westport, CT

Nair, K. R. G., \& Pandey, A. (2006). Characteristics of entrepreneurs: an empirical analysis. The Journal of Entrepreneurship, 15(1), 47-61. 
Plaschka, G. R., \& Welsch, H. P. (1990). Emerging structures in entrepreneurship education: Curricular designs and strategies. Entrepreneurship theory and Practice, 14(3), 55-71.

Ramadani, V., Gërguri-Rashiti, S., \& Fayolle, A. (Eds.). (2015). Female entrepreneurship in transition economies: Trends and challenges. Springer.

Ratnatunga, J., \& Romano, C. (1997). A “citation classics" analysis of articles in contemporary small enterprise research. Journal of Business Venturing, 12(3), 197-212.

Reynolds, P. D., Hay, M., \& Camp, S. M. (1999). Global entrepreneurship monitor. Kansas City, Missouri: Kauffman Center for Entrepreneurial Leadership.

Rugtvedt, L. (2006). Closing Speech. Entrepreneurship Education in Europe: Fostering Entrepreneurial mindsets through Education and learning. Final Proceedings, OLSO, 26-27.

Sahut, J. M., \& Peris-Ortiz, M. (2014). Small business, innovation, and entrepreneurship. Small Business Economics, 42(4), 663-668.

Sanchez, J. C. (1993). The long and thorny way to an organizational taxonomy. Organization Studies, 14(1), 73-92.

Schumpeter, J.A. (1942). Capitalism, Socialism and Democracy, New York: Harper and Row.

Senges, M. (2007). Knowledge entrepreneurship in universities. Practice and strategy in the case of Internet based innovation appropriation (Doctoral dissertation, Universitat Oberta de Catalunya).

Shane, S. (2000). Prior knowledge and the discovery of entrepreneurial opportunities. Organization science, 11(4), 448-469.

Shane, S., \& Venkataraman, S. (2000). The promise of entrepreneurship as a field of research. Academy of management review, 25(1), 217-226.

Shim, S., \& Eastlick, M. A. (1998). Characteristics of Hispanic female business owners: an exploratory study. Journal of Small Business Management, 36(3), 18.

Smith, P., \& Peterson, M. (1990). Liderazgo, organizaciones y cultura: un modelo de dirección de sucesos. Pirámide.

Spigel, B., \& Harrison, R. (2018). Toward a process theory of entrepreneurial ecosystems. Strategic Entrepreneurship Journal, 12(1), 151-168. 
Stam, E., \& Van Stel, A. (2011). Types of entrepreneurships and economic growth. Entrepreneurship, innovation, and economic development, 7895.

Stewart Jr, W. H., Watson, W. E., Carland, J. C., \& Carland, J. W. (1999). A proclivity for entrepreneurship: A comparison of entrepreneurs, small business owners, and corporate managers. Journal of Business venturing, 14(2), 189-214.

Timmons, J., Smollen, L., \& Dingee, A.L. (1985). New venture creation (2nd ed). Homewood, Irwin.

Van Stel, A., Carree, M., \& Thurik, R. (2005). The effect of entrepreneurial activity on national economic growth. Small business economics, 24(3), 311321.

Vesper, K. H. (1990). New venture strategies. University of Illinois at Urbana-Champaign's Academy for entrepreneurial leadership historical research reference in entrepreneurship.

Vesper, K. H., \& Gartner, W. B. (1997). Measuring progress in entrepreneurship education. Journal of Business venturing, 12(5), 403-421.

Wang, L., Ali, M., Kim, H. J., Lee, S., \& Hernandez-Perlines, F. (2021). Individual entrepreneurial orientation, value congruence, and individual outcomes: Does the institutional entrepreneurial environment matter? Business Strategy and the Environment.

Wang, S. M., Yueh, H. P., \& Wen, P. C. (2019). How the new type of entrepreneurship education complements the traditional one in developing entrepreneurial competencies and intention. Frontiers in psychology, 10, 2048.

Welter, F., \& Smallbone, D. (2006). Exploring the role of trust in entrepreneurial activity. Entrepreneurship Theory and Practice, 30(4), 465-475.

Yi, G. (2021). From green entrepreneurial intentions to green entrepreneurial behaviors: The role of university entrepreneurial support and external institutional support. International Entrepreneurship and Management Journal, 17(2), 963-979.

Zahra, S. A., \& Covin, J. G. (1995). Contextual influences on the corporate entrepreneurship-performance relationship: A longitudinal analysis. Journal of business venturing, 10(1), 43-58. 


\section{Capítulo II.}

Aguilar, N. T. Á., Elizondo, J. A. C., \& Cubero, A. T. (2016). Fundamentación del Proyecto "La empresa en tu aula". ANFEI Digital, (5).

Alexander, C. N., \& Langer, E. J. (1990). Higher stages of human development: Perspectives on adult growth. Oxford University Press.

Audretsch, D. R. (2018). Entrepreneurship, economic growth, and geography. Oxford Review of Economic Policy, 34(4), 637-651.

Barbe, D. F., Magids, S. A., \& Thornton, K. S. (2003, November). Holistic approach for technology entrepreneurship education in engineering. In 33rd Annual Frontiers in Education, 2003. FIE 2003. (Vol. 1, pp. T2D1). IEEE.

Barro, R. J., Barro, R. J., Sala-i-Martin, X., \& Xavier, I. (2004). Economic growth. MIT press.

Bechard, J. P., \& Toulouse, J. M. (1998). Validation of a didactic model for the analysis of training objectives in entrepreneurship. Journal of business venturing, 13(4), 317-332.

Becker, G. S. (1962). Investment in human capital: A theoretical analysis. Journal of Political Economy, 70(5, Part 2), 9-49.

Bilén, S. G., Kisenwether, E. C., Rzasa, S. E., \& Wise, J. C. (2005). Developing and assessing students' entrepreneurial skills and mind-set. Journal of Engineering Education, 94(2), 233-243.

Bosma, N. (2013). The Global Entrepreneurship Monitor (GEM) and its impact on entrepreneurship research. Foundations and Trends in Entrepreneurship, 9(2). doi:10.1561/0300000033

Bouhajeb, M., Mefteh, H., \& Ben Ammar, R. (2018). Higher Education and Economic Growth: the importance of innovation. ISSN 2174-3835. Atlantic Review of Economics (ARoEc), 1(2).

Bueno, E. \& Casani, F. (2007). La tercera misión de la Universidad: enfoques e indicadores básicos para su evaluación. Economía Industrial, 366, 43-59.

Busenitz, L. W., West III, G. P., Shepherd, D., Nelson, T., Chandler, G. N., \& Zacharakis, A. (2003). Entrepreneurship research in emergence: Past trends and future directions. Journal of management, 29(3), 285-308.

Byers, T., Seelig, T., Sheppard, S., \& Weilerstein, P. (2013). Entrepreneurship: Its Role in Engineering Education. The Bridge, 43(2). 
Carlson, W. B. (1988). Academic entrepreneurship and engineering education: Dugald C. Jackson and the MIT-GE cooperative engineering course, 1907-1932. Technology and Culture, 29(3), 536-567.

Clark, B. R. (1998). Creating entrepreneurial universities: Organizational pathways of transformation. Issues in higher education. Elsevier Science Regional Sales, 665 Avenue of the Americas, New York, NY 10010 (paperback: ISBN-0-08-0433545; hardcover: ISBN-0-08-0433421).

Cornelius, B., Landström, H., \& Persson, O. (2006, May). Entrepreneurship Research: Towards a Domain Approach to Knowledge. In 14th Nordic conference on Small Business Research (pp. 11-13).

Creed, C. J., Suuberg, E. M., \& Crawford, G. P. (2002). Engineering entrepreneurship: An example of a paradigm shift in engineering education. Journal of Engineering Education, 91(2), 185-195.

Da Silva, G. B., Costa, H. G., \& De Barros, M. D. (2015). Entrepreneurship in engineering education: A literature review. International Journal of Engineering Education, 31(6), 1701-1710.

Dahm, K., Riddell, W., Merrill, T., Harvey, R., \& Weiss, L. (2013). Implementing Entrepreneurial Assignments in a Multidisciplinary, SophomoreLevel Design Course. Advances in Engineering Education, 3(3), n3.

Doboli, S., Kamberova, G. L., Impagliazzo, J., Fu, X., \& Currie, E. H. (2010, October). A model of entrepreneurship education for computer science and computer engineering students. In 2010 IEEE Frontiers in Education Conference (FIE) (pp. T4D-1). IEEE.

Doran, J., McCarthy, N., \& O'Connor, M. (2018). The role of entrepreneurship in stimulating economic growth in developed and developing countries. Cogent Economics \& Finance, 6(1), 1442093.

Drucker, P. F. (1985). Innovation and entrepreneurship. Routledge.

Drucker, P. F. (1995). People and performance: The best of Peter Drucker on management. Routledge.

Dubai Chamber of Commerce and Industry (2021). Dubai StartUp Outlook 2021: Key insights for entrepreneurs and investors.

Duderstadt, J. J. (2010). Engineering for a changing world. In Holistic engineering education (pp. 17-35). Springer, New York, NY.

Ferreira, M. P., Reis, N. R., \& Miranda, R. (2015). Thirty years of entrepreneurship research published in top journals: analysis of citations, cocitations and themes. Journal of Global Entrepreneurship Research, 5(1), 17. 
Glasmeier, A. K., Fuelihart, K., Feller, I., \& Mark, M. M. (1998). The relevance of firm-learning theories to the design and evaluation of manufacturing modernization programs. Economic Development Quarterly, 12(2), 107124.

Gnyawali, D. R., \& Fogel, D. S. (1994). Environments for entrepreneurship development: key dimensions and research implications. Entrepreneurship theory and practice, 18(4), 43-62. doi:10.1177/104225879401800403

Graham, R. H. (2012). Achieving excellence in engineering education: the ingredients of successful change. London: Royal Academy of Engineering.

Greiner, A., Semmler, W., \& Gong, G. (2016). The forces of economic growth: a time series perspective. Princeton University Press.

Guerrero, M., \& Santamaría-Velasco, C. A. (2020). Ecosistema y actividad emprendedora en México: un análisis exploratorio. Perfiles latinoamericanos, 28(55), 227-251.

Guzman, S. C. (2015). How intellectual movements among external and internal actors shape the college curriculum: the case of entrepreneurship education in engineering (Doctoral dissertation, University of Michigan).

Hamilton, C. H. E. L. S. E. A., Crawford, G. P., \& Suuberg, E. M. (2005). A technology-based entrepreneurship course. International Journal of Engineering Education, 21(2), 239-256.

Jarrar, M., \& Anis, H. (2016). The impact of entrepreneurship on engineering education. Proceedings of the Canadian Engineering Education Association (CEEA).

Jasso, J. (2004). Relevancia de la innovación y las redes institucionales. Red Aportes.

Kantis, H., Ishida, M., \& Komori, M. (2002). Empresarialidad en economías emergentes: Creación y desarrollo de nuevas empresas en América Latina y el Este de Asia.

Karanda, C., \& Toledano, N. (2018). The promotion of ethical entrepreneurship in the Third World: Exploring realities and complexities from an embedded perspective. Business Horizons, 61(6), 881-890.

Kriewall, T. J., \& Mekemson, K. (2010). Instilling the entrepreneurial mindset into engineering undergraduates. The journal of engineering entrepreneurship, 1(1), 5-19. 
Lassen, A. H., Gertsen, F., \& Riis, J. O. (2006). The nexus of corporate entrepreneurship and radical innovation. Creativity and Innovation Management, 15(4), 359-372.

Lattuca, L., Terenzini, P., Knight, D., \& Ro, H. K. (2014). 2020 Vision: Progress in preparing the engineer of the future.

Lichtenstein, G. (1992). The significance of relationships in entrepreneurship: A case study of the ecology of enterprise in two business incubators. Unpublished doctoral dissertation, University of Pennsylvania, Philadelphia.

Lichtenstein, G. A., \& Lyons, T. S. (2001). The entrepreneurial development system: Transforming business talent and community economies. Economic Development Quarterly, 15(1), 3-20.

Liu, X. (2016, September). Research on entrepreneurship ecosystem of entrepreneurial university. In 2016 4th International Education, Economics, Social Science, Arts, Sports and Management Engineering Conference (IEESASM 2016). Atlantis Press. https://doi.org/10.2991/ieesasm16.2016.245

Lowood, H. (1982) Frederick E. Terman: Life and Career. In The Frederick E. Terman Papers: A Guide to the Collection. Stanford, CA: Stanford University Archives.

Lucas Jr, R. E. (1988). On the mechanics of economic development. Journal of monetary economics, 22(1), 3-42.

Mankiw, N. G., Romer, D., \& Weil, D. N. (1992). A contribution to the empirics of economic growth. The Quarterly Journal of Economics, 107(2), 407-437.

Miller, D. (1983), "The correlates of entrepreneurship in three types of firms", Management Science, Vol. 29 No. 7, pp. 770-791

Mincer, J. (1974). Schooling, Experience, and Earnings. Human Behavior \& Social Institutions No. 2.

Moore, C., \& de Bruin, A. (2018). Ethical entrepreneurship in Entrepreneurship: New Perspectives in a global age (pp. 43-56). Routledge.

Moreland, N. (2006). Entrepreneurship and higher education: an employability perspective (Vol. 6). York: Higher Education Academy.

Nichols, S. P., \& Armstrong, N. E. (2003). Engineering entrepreneurship: Does entrepreneurship have a role in engineering education? IEEE Antennas and Propagation Magazine, 45(1), 134-138. 
Ochs, J. B., Watkins, T. A., \& Boothe, B. W. (2001). Creating a truly multidisciplinary entrepreneurial educational environment. Journal of Engineering Education, 90(4), 577-583.

OECD \& ILO. (2019). Women at Work in G20 countries: Progress and policy action. Organization for Economic Cooperation and Development and International Labour Organization.

Park, J.H. \& Ahn, T.U. (2016), “A Study on the Influence of Young Entrepreneurs' Entrepreneurship and Entrepreneurial preparation upon the Entrepreneurial Performance: Centered on Mediated Effect of Entrepreneurial infra system using", Asia-Pacific Journal of Business Venturing and Entrepreneurship, Vol. 11 No. 1, pp. 39-47

Patel, M., \& Basu, A. (2006, June). How to Weave Entrepreneurship into Engineering Education: The Experience at San José State University. In 2006 Annual Conference \& Exposition (pp. 11-703).

Radclyffe-Thomas, N., Roncha, A., \& Varley, R. (2014). Ethical Brand Building and the Collaborative Fashion Brand: Flying the Flag for Social Entrepreneurship-TOMS a Case Study.

Ratten, V. (2017). Entrepreneurial universities: the role of communities, people and places. Journal of Enterprising Communities: People and Places in the Global Economy.

Reynolds, P. D., Hay, M., \& Camp, S. M. (1999). Global Entrepreneurship Monitor: Executive Report. Kaufman Centre for Entrepreneurial Leadership, 3.

Romer, P. M. (1989). Human capital and growth: theory and evidence (No. w3173). National Burean of Economic Research.

Romer, P. M. (1990). Endogenous technological change. Journal of Political Economy, 98(5, Part 2), S71-S102.

Ruda, W., Martin, T. A., \& Danko, B. (2012). Comparing Start-up Propensities and Entrepreneurship Characteristics of Students in Russia and Germany. Acta Polytechnica Hungarica, 9(3), 97-113.

Sánchez García, J. C., Ward, A., Hernández, B., \& Florez, J. L. (2017). Educación emprendedora: Estado del arte. Propósitos y Representaciones, 5(2), 401-473.

Sánchez, J. C. (2010). Evaluación de la Personalidad Emprendedora: Validez Factorial del Cuestionario de Orientación Emprendedora (COE). Revista Latinoamericana de Psicología, 42(1), 41-52. 
Sánchez, P., Torres, B. Á., \& García, A. I. (2014). Improving transferable skills in engineering education through a pre-incubation semester. The International Journal of Engineering Education, 30(4), 862-875.

Schmidt, N. H., Ruch, T. J., Decker, J., \& Kolbe, L. M. (2012). Ecosia. org: The Business Case of a Green Search Engine. In Green Business Process Management (pp. 217-232). Springer, Berlin, Heidelberg.

Schultz, T. W. (1961). Investment in human capital. The American economic review, 1-17.

Schumpeter, J. (1991). Comments on a plan for the study of entrepreneurship. In R. Swedberg (Ed.), Joseph A. Schumpeter: The economics and sociology of capitalism (pp. 406-428). Princeton, NJ: Princeton University Press.

Schumpeter, J.A. (1939), Business Cycles: A Theoretical, Historical, and Statistical Analysis of the Capitalist Process, McGraw-Hill, New York, NY and London.

Shefsky, L. E. (1996). Entrepreneurs are made not born. New York: McGraw-Hill.

Song, J.G. (2011), "An empirical study on the relationship of entrepreneurship and innovation performance for venture business: focusing on the mediation social capital", Doctor's thesis, Graduate School of Venture Hoseo University.

Stamboulis, Y., \& Barlas, A. (2014). Entrepreneurship education impact on student attitudes. The International Journal of Management Education, 12(3), 365-373.

Stevenson, H.H. \& Jarillo, J.C. (1986), "Preserving entrepreneurship as companies grow", Journal of Business Strategy, Vol. 7 No. 1, pp. 10-23

Talke, K., Salomo, S., \& Rost, K. (2010). How top management team diversity affects innovativeness and performance via the strategic choice to focus on innovation fields. Research Policy, 39(7), 907-918.

Timmons, J.A. (1999), New Venture Creation: Entrepreneurship in the 21 th Centuries, 6th ed., Homewood, IL, Irwin.

Wang, E. L., \& Kleppe, J. A. (2001). Teaching invention, innovation, and entrepreneurship in engineering. Journal of Engineering Education, 90(4), 565570 .

World Bank. (2020). Doing Business 2020. Washington, DC: World Bank. DOI:10.1596/978-1-4648-1440-2 
Yang, D., \& Zhao, X. (2014). Study on Evolutionary Path of University Students' Entrepreneurship Training. Mathematical Problems in Engineering, 2014.

\section{Capítulo III.}

Acs, Z. J., \& Audretsch, D. B. (1988). Innovation in large and small firms: an empirical analysis. The American Economic Review, 678-690.

Afuah, A. N., \& Utterback, J. M. (1997). Responding to structural industry changes: a technological evolution perspective. Industrial and Corporate Change, 6(1), 183-202.

Aguilar, A. (18 de junio de 2018). Edsel FORD: el mayor fracaso de la historia del automóvil. https://www.topgear.es/noticias/garaje/edsel$\underline{\text { ford-264951 }}$

Aguirre, M. C. D., Lagunas, E. A., Rodríguez, S. V. M., \& Campbell, A. C. (2019). Entrepreneurship as a Boost of Economic Growth in Mexico and Chile. In Regional Integration in Latin America. Emerald Publishing Limited.

Antonelli, C. (2008). Localised technological change: towards the economics of complexity. Routledge.

Baumol, W. J., Litan, R. E., \& Schramm, C. J. (2007). Good capitalism, bad capitalism, and the economics of growth and prosperity. Yale University Press.

Birch, D. L. (2000). The job generation process. Small business: Critical perspectives on business and management, 2, 431-465.

Bosma, N., Hill, S., Ionescu-Somers, A., Kelley, D., Guerrero, M., Schott, T. (2020). Global Entrepreneurship Monitor: 2020/2021 Global Report. London: Babson.

Boyatzis, R. E. (2008). Competencies in the 21st century. Journal of Management Development.

Carree, M. A., \& Thurik, A. R. (2010). The impact of entrepreneurship on economic growth. In Handbook of entrepreneurship research (pp. 557594). Springer, New York, NY.

Carrillo, F. A. H., Rosas, N. C. C., \& Garrces, M. A. A. (2017). Importancia de la innovación y su ejecución en la estrategia empresarial. INNOVA Research Journal, 2(5), 88-105.

Cui, J., Sun, J., \& Bell, R. (2019). The impact of entrepreneurship education on the entrepreneurial mindset of college students in China: The me- 
diating role of inspiration and the role of educational attributes. The International Journal of Management Education, 100296.

Daniel, A. D. (2016). Fostering an entrepreneurial mindset by using a design thinking approach in entrepreneurship education. Industry and Higher Education, 30(3), 215-223.

Davis, M. H., Hall, J. A., \& Mayer, P. S. (2016). Developing a new measure of entrepreneurial mindset: Reliability, validity, and implications for practitioners. Consulting Psychology Journal: Practice and Research, 68(1), 1-28.

Davis, S. J., \& Haltiwanger, J. (1992). Gross job creation, gross job destruction, and employment reallocation. The Quarterly Journal of Economics, 107(3), 819-863.

Decker, R. A., Haltiwanger, J., Jarmin, R. S., \& Miranda, J. (2017). Declining dynamism, allocative efficiency, and the productivity slowdown. American Economic Review, 107(5), 322-26.

Del Águila Obra, A. R., \& Meléndez, A. P. (2010). Factores determinantes de la innovación en empresas de economía social. La importancia de la formación y de la actitud estratégica. CIRIEC-España, revista de economía pública, social y cooperativa, (67), 129-155.

Del Río Cobián, E. (2000). La importancia de la innovación organizativa para la obtención de los beneficios derivados de la introducción de las tecnologías de la información. Universidad Complutense de Madrid.

Dewar, R. D., \& Dutton, J. E. (1986). The adoption of radical and incremental innovations: An empirical analysis. Management science, 32(11), 1422-1433.

Drucker, P. F. (1998). The discipline of innovation. Harvard Business Review, 76(6), 149-157.

Drucker, P. F. (2014). Innovation and entrepreneurship. Routledge.

Farashah, A. D. (2013). The process of impact of entrepreneurship education and training on entrepreneurship perception and intention: Study of educational system of Iran. Education+ Training. 55(8), pp. 868-885.

Fayolle, A., \& Gailly, B. (2015). The impact of entrepreneurship education on entrepreneurial attitudes and intention: Hysteresis and persistence. Journal of small business management, 53(1), 75-93.

Fischer, M. M. (2006). Innovation, knowledge creation and systems of innovation. Innovation, networks, and knowledge spillovers: Selected essays, $169-187$. 
Garcia, R., \& Calantone, R. (2002). A critical look at technological innovation typology and innovativeness terminology: a literature review. Journal of Product Innovation Management: An international publication of the product development \& management association, 19(2), 110-132.

Haynie, J. M., Shepherd, D., Mosakowski, E., \& Earley, P. C. (2010). A situated metacognitive model of the entrepreneurial mindset. Journal of business venturing, 25(2), 217-229.

Hossain, M. (2020). Frugal innovation: Conception, development, diffusion, and outcome. Journal of Cleaner Production, 121456.

IBM Archives. (20 de noviembre de 2021). Chronological History of IBM. https://www.ibm.com/ibm/history/history/decade 1940.html

Johnson, S. (Ed.). (2011). The Innovator's Cookbook: Essentials for Inventing what is Next. Penguin.

Jones, C. I. (2016). The facts of economic growth. In Handbook of macroeconomics

Juárez, C. (23 de junio de 2021). Innovación en la distribución de mercancías: del barco eléctrico al tren lunar. https://thelogisticsworld.com/innovacion/innovacion-en-ladistribucion-de-mercancias-del-barco-electrico-al-tren-lunar/

Kent, C. A., Sexton, D. L., \& Vesper, K. H. (1982). Encyclopedia of entrepreneurship. University of Illinois at Urbana-Champaign's Academy for Entrepreneurial Leadership Historical Research Reference in Entrepreneurship.

Knight, F. (1921). Risk, Uncertainty, and Profit [Versión electrónica]. Boston, MA: Hart, Schaffner \& Marx. http://www.econlib.org/library/Knight/knRUP.html Consultada 12/03/2018. (Vol. 2, pp. 3-69). Elsevier.

Korte, R. (2018). Identifying as an entrepreneur: A Social Identity Perspective of the Entrepreneurial Mindset. Advances in Engineering Education, 7(1), n1.

Krueger Jr, N. F., Reilly, M. D., \& Carsrud, A. L. (2000). Competing models of entrepreneurial intentions. Journal of business venturing, 15(5-6), 411432.

Krugman, P. R. (1997). The age of diminished expectations: US economic policy in the 1990s. MIT Press. 
Lindberg, E., Bohman, H., Hulten, P., \& Wilson, T. (2017). Enhancing students' entrepreneurial mindset: a Swedish experience. Education + Training. 59(7), 68-779.

Maresch, D., Harms, R., Kailer, N., \& Wimmer-Wurm, B. (2016). The impact of entrepreneurship education on the entrepreneurial intention of students in science and engineering versus business studies university programs. Technological forecasting and social change, 104, 172-179.

Mathur, S. K. (2006). Indian information technology industry: past, present and future and a tool for national development. Journal of Theoretical and Applied Information Technology, 2(2), 50-79.

Matich, D. J. (2001). Redes Neuronales: Conceptos básicos y aplicaciones. Universidad Tecnológica Nacional, México, 41.

McDermott, C. M., \& O'Connor, G. C. (2002). Managing radical innovation: an overview of emergent strategy issues. Journal of Product Innovation Management: an international publication of the product development \& management association, 19(6), 424-438.

Mill, J. S., Ashley, S. W. J., \& Ortiz, T. (1951). Principios de economía política: con algunas de sus aplicaciones a la filosofía social. Fondo de Cultura Económica.

Mulongo, M., Nyachieo, J., \& Kaberia, D. (17 de noviembre de 2021). Kenya Rapid Program Background. Millennium Water Alliance. https://mwawater.org/programs/kenya-program-background/

Nabi, G., Liñán, F., Fayolle, A., Krueger, N., \& Walmsley, A. (2017). The impact of entrepreneurship education in higher education: A systematic review and research agenda. Academy of Management Learning \& Education, 16(2), 277-299.

Naciones Unidas (2012). 67/202, Iniciativa empresarial para el desarrollo. Periódico Oficial de las Naciones Unidas publicado el 27 de febrero de 2013. A/RES/67/202 Consultado en https://undocs.org/es/A/RES/67/202

National Inventors Hall of Fame [NIHF] (20 de octubre de 2021). Ottmar Mergenthaler: Linotype Composing Machine. https://www.invent.org/inductees/ottmar-mergenthaler

Naumann, C. (2017). Entrepreneurial mindset: A synthetic literature review. Entrepreneurial Business and Economics Review, 5(3), 149-172.

Neavill, G. B. (1990). Carl Schlesinger, ed., The Biography of Ottmar Mergenthaler, Inventor of the Linotype (Book Review). The Library Quarterly, 60(3), 263. 
Odhiambo, M. O. (2013). The ASAL policy of Kenya: Releasing the full potential of arid and semi-arid lands-An analytical review. Nomadic Peoples, 17(1), 158-165.

Pedersen, C. Ø., \& Dalum, B. (2004). Incremental versus radical changethe case of the digital north Denmark Program.

Péreznieto, P., \& Harding, J. H. (2013). Investing in youth in international development policy: Making the case. ODI project report. London: Overseas Development Institute.

Pfeifer, S., Šarlija, N., \& Zekić Sušac, M. (2016). Shaping the entrepreneurial mindset: Entrepreneurial intentions of business students in Croatia. Journal of Small Business Management, 54(1), 102-117.

Priestley, D. (2018). Entrepreneur revolution: How to develop your entrepreneurial mindset and start a business that works. John Wiley \& Sons.

Rogers, E. M. (2010). Diffusion of innovations. 4th Edition. Simon and Schuster.

Rowe, L. A., \& Boise, W. B. (1974). Organizational innovation: Current research and evolving concepts. Public Administration Review, 34(3), 284-293.

Ruiz, M. S. (12 de agoto de 2016). El paraíso de los robots: por qué Japón es la capital del imperio de las máquinas. https://www.eldiario.es/hojaderouter/tecnologia/japon-maquinasrobots-humanoides-automatas-inteligencia-artificial 1 3869766.html

Sánchez, J.C. (2007). Psicología y emprendedorismo. Un recuerdo especial a José Luis Vega Vega. International Journal of Developmental and Educational Psychology, 2, 221-136.

Say, J.-B. (2001). Tratado de economía política. México: Fondo de Cultura Económica.

Schumpeter, J. A. (1982). The theory of economic development: An inquiry into profits, capital, credit, interest, and the business cycle (1912/1934). Transaction Publishers, 1, 244.

Schumpeter, J. A. (2013). Capitalism, socialism and democracy. Routledge.

Shinnar, R. S., Hsu, D. K., Powell, B. C., \& Zhou, H. (2018). Entrepreneurial intentions and start-ups: Are women or men more likely to enact their intentions? International Small Business Journal, 36(1), 60-80.

Sirgo, J. M. A. (1994). La mixtificación de las miniacerías. Noticias de la Unión Europea, (111), 33-34. 
Solow, R. M. (1957). Technical change and the aggregate production function. The review of Economics and Statistics, 312-320.

Stamboulis, Y., \& Barlas, A. (2014). Entrepreneurship education impact on student attitudes. The International Journal of Management Education, 12(3), 365-373.

Stogdill, R. M. (1974). Handbook of leadership: A survey of theory and research. Free Press.

Taylor, K., \& Silver, L. (2019). Smartphone ownership is growing rapidly around the world, but not always equally. Pew Research Center, 5 .

Twiss, B. C., \& Goodridge, M. (1989). Managing technology for competitive advantage: integrating technological and organisational development: from strategy to action. Trans-Atlantic Publications.

Urabe, K., Child, J., \& Kagono, T. (Eds.). (1988). Innovation and management: International comparisons. Berlin: de Gruyter.

Utterback, J. (1994). Mastering the dynamics of innovation: How companies can seize opportunities in the face of technological change. University of Illinois at Urbana-Champaign's Academy for Entrepreneurial Leadership Historical Research Reference in Entrepreneurship.

Von Mises, L. (1996). Human Action: a treatise on economics, ed. Bettina Bien Graves, 4th revised edition. Irvington-on-Hudson: Foundation for Economic Education.

Voss, B. (1997). The Contrarian Manager: Business Lessons Learned in the Trenches... and Some of the Fun I Had Along the Way! The Journal of Business Strategy, 18(5), 52.

Wanhill, R. J. H., Molent, L., Barter, S. A., \& Amsterdam, E. (2015). Milestone case histories in aircraft structural integrity.

Wardana, L. W., Narmaditya, B. S., Wibowo, A., Mahendra, A. M., Wibowo, N. A., Harwida, G., \& Rohman, A. N. (2020). The impact of entrepreneurship education and students' entrepreneurial mindset: the mediating role of attitude and self-efficacy. Heliyon, 6(9), e04922.

Westhead, P., \& Solesvik, M. Z. (2016). Entrepreneurship education and entrepreneurial intention: Do female students benefit? International Small Business Journal, 34(8), 979-1003.

Zayas, J. M., \& Sánchez, P. V. (2005). Factores determinantes de la competitividad de los servicios: la importancia de la innovación. ICE, Revista de Economía, (824). 
Zupan, B., Cankar, F., \& Setnikar Cankar, S. (2018). The development of an entrepreneurial mindset in primary education. European Journal of Education, 53(3), 427-439.

\section{Capítulo IV.}

ABET. (2021). ABET. Consultado en Accreditation Board for Engineering and Technology: https://www.abet.org/accreditation/accreditationcriteria/criteria-for-accrediting-engineering-programs-2020-2021/

ANECA. (2021). ANECA. Consultado em Agencia Nacional de Evaluación de la Calidad y Acreditación: http://www.aneca.es/Documentos-y-publicaciones/Observatorio-de-laCalidad-del-Sistema-Espanol-de-Universidades/Informes-sobre-lamejora-de-la-calidad-al-servicio-de-los-objetivos-de-la-educacionuniversitaria/Marco-para-la-autoevaluacion-de-las-universida

ANFEI. (2016). IMPORTANCIA DEL EMPRENDIMIENTO EN LA FORMACIÓN INTEGRAL DEL INGENIERO EN MÉXICO. ANFEI Digital. Consultado en https://www.anfei.mx/revista/index.php/revista/article/view/296

Audretsch, D. B. (2014). From the entrepreneurial university to the university for the entrepreneurial society. The Journal of Technology Transfer, 39(3), 313-321.

Auernhammer, J., \& Roth, B. (2021). The origin and evolution of Stanford University's design thinking: From product design to design thinking in innovation management. Journal of Product Innovation Management.

Barba-Sánchez, V., \& Atienza-Sahuquillo, C. (2018). Entrepreneurial intention among engineering students: The role of entrepreneurship education. European research on management and business economics, 24(1), 53-61.

Barber, D., Madden, L., Mayo, D., \& Agarwala, R. (2020). Two-course integration with student collaboration: Rapid prototyping and entrepreneurship. Entrepreneurship Education, 3(1), 57-76.

Benneworth, P. (2007). Seven samurai opening up the ivory tower? The construction of Newcastle as an entrepreneurial university. European Planning Studies, 15(4), 487-509.

Bowe, N., Taylor, L., Smith, K., Zuckerman, R., \& Moore, D. (2003). Getting engineers to think and act like entrepreneurs, in ASEE Annual Conference Proceedings, June 22-25, 2003, American Society for Engineering Education, Nashville, pp. 5913-5924. 
Brennan, M. C., Wall, A. P., \& McGowan, P. (2005). Academic entrepreneurship: Assessing preferences in nascent entrepreneurs. Journal of Small Business and Enterprise Development.

Brenner, W., \& Uebernickel, F. (2016). Design thinking for innovation. Research and Practice.

CACEI. (2018). CACEI. Consultado en Consejo de Acreditación de la Enseñanza de la Ingeniería: http://cacei.org.mx/docs/marco ing 2018.pdf

Carassa, F. (1987). The Education of Engineers and the Relationship with industry and services, European Journal of Engineering Education, Vol. 12, No. 3, pp. 231-235.

Cerver Romero, E., Ferreira, J. J., \& Fernandes, C. I. (2021). The multiple faces of the entrepreneurial university: a review of the prevailing theoretical approaches. The Journal of Technology Transfer, 46(4), 1173-1195.

Ciampi, M. M., da Rocha Brito, C., Amaral, L., Vasconcelos, R., \& Barros, V. F. (2016, September). Engineering challenging entrepreneurship practice. In International Conference on Interactive Collaborative Learning (pp. 444-452). Springer, Cham.

Clark, B. R. (1998). Creating Entrepreneurial Universities: Organizational Pathways of Transformation. Issues in Higher Education. Elsevier Science Regional Sales.

Come, F., Fouger, X., Hawwash, K., \& Van Petegem, W. (2013). SEfi@ 40. Driving engineering education to meet future challenges. SEFI, Brussels.

Covin, J. G., \& Slevin, D. P. (1991). A conceptual model of entrepreneurship as firm behavior. Entrepreneurship theory and practice, 16(1), 7-26.

Craig, R. (2018). A new U: Fastert cheaper alternatives to college. BenBella Books.

ENAEE. (2021). ENAEE. Consultado en European Network for Accreditation of Engineering Education: https://www.enaee.eu/eur-acesystem/standards-and-guidelines/\#standards-and-guidelines-for-accreditation-of-engineering-programmes

Etzkowitz, H. (2001). The second academic revolution and the rise of entrepreneurial science. IEEE Technology and Society Magazine, 20(2), 1829.

Etzkowitz, H. (2003). Research groups as "quasi-firms: The invention of the entrepreneurial university. Research Policy, 32(1), 109-121. 
Etzkowitz, H. (2008). The triple helix: University-industry-government innovation in action. New York, N.Y.: Routledge.

Etzkowitz, H. (2011). The triple helix: Science, technology and the entrepreneurial spirit. Journal of Knowledge based Innovation in China, 3(2), 76-90.

Etzkowitz, H. (2012). Triple helix clusters: Boundary permeability at university-industry-government interfaces as a regional innovation strategy. Environment and Planning C: Government and Polity, 30(5), 766-779.

Etzkowitz, H. (2013). Can a teaching university be an entrepreneurial university? Centre for Innovation Management Research (CIMR), 1-35.

Etzkowitz, H. (2020). Entrepreneurial University. The International Encyclopedia of Higher Education Systems and Institutions, 386-391.

Fayolle, A., \& Gailly, B. (2008). From craft to science: Teaching models and learning processes in entrepreneurship education. Journal of European industrial training.

Gibb, A. (2012). Exploring the synergistic potential in entrepreneurial university development: towards the building of a strategic framework. $A n$ nals of Innovation \& Entrepreneurship, 3(1), 16742.

Gorlewicz, J. L., \& Jayaram, S. (2020). Instilling curiosity, connections, and creating value in entrepreneurial minded engineering: Concepts for a course sequence in dynamics and controls. Entrepreneurship Education and Pedagogy, 3(1), 60-85.

Guenther, J., \& Wagner, K. (2008). Getting out of the ivory tower-new perspectives on the entrepreneurial university. European Journal of International Management, 2(4), 400-417.

Guerrero, M., \& Urbano, D. (2012). The development of an entrepreneurial university. The journal of technology transfer, 37(1), 43-74.

Guerrero, M., Urbano, D., Cunningham, J. A., \& Gajón, E. (2018). Determinants of Graduates' Start-Ups Creation across a Multi-Campus Entrepreneurial University: The Case of Monterrey Institute of Technology and Higher Education. Journal of Small Business Management, 56(1), 150-178.

Guerrero-Cano, M., Urbano, D., \& Kirby, D. (2006). A literature review on entrepreneurial universities: An institutional approach.

Iacobucci, D., \& Micozzi, A. (2012). Entrepreneurship education in Italian universities: trend, situation and opportunities. Education+ Training.

Johannisson, B. (1991), University training for entrepreneurship: Swedish approaches, Entrepreneurship \& Regional Development: An International Journal, Vol. 3, No. 1, pp. 67-82. 
Kalenyuk, I. R. Y. N. A., \& Dyachenko, A. (2016). Entrepreneurial universities in a world educational system. International Economic Policy, (2), 5974.

Kirby, D. A. (2006). Creating entrepreneurial universities in the UK: Applying entrepreneurship theory to practice. The Journal of Technology Transfer, 31(5), 599-603.

Klofsten, M., Fayolle, A., Guerrero, M., Mian, S., Urbano, D., \& Wright, M. (2019). The entrepreneurial university as driver for economic growth and social change-Key strategic challenges. Technological Forecasting and Social Change, 141, 149-158.

Kusmintarti, A., Thoyib, A., Maskie, G., Ashnar, K. (2016), Entrepreneurial characteristics as a mediation of entrepreneurial education influence on entrepreneurial intention, Journal of Entrepreneurship Education, Vol. 19, No. 1, pp. 24-37.

Landström, H. \& Harirchi, G. (2019), That's interesting! in entrepreneurship research, Journal of Small Business Management, 57 (S2), 507-529.

Levine, A. (1989). Shaping Higher Education's Future. Demographic Realities and Opportunities 1990-2000. Jossey-Bass, Inc., Publishers, PO Box 44305, San Francisco, CA 94144-4305.

Levine, A., \& Van Pelt, S. J. (2021). The Great Upheaval: Higher Education's Past, Present, and Uncertain Future. JHU Press.

Levine, A., \& Van Pelt, S.J. (4 de octubre de 2021). The Future of Higher Ed is occurring at the margins. Inside Higher Ed. Recuperado de: https://www.insidehighered.com/views/2021/10/04/higher-educationshould-prepare-five-new-realities-opinion

Lockwood, T. (2010). Design thinking: Integrating innovation, customer experience, and brand value. Simon and Schuster.

Markuerkiaga, L., Errasti, N., \& Igartua, J. I. (2014). Success factors for managing an entrepreneurial university: Developing an integrative framework. Industry and Higher Education, 28(4), 233-244.

Martínez, M., \& Crusat, X. (2019, April). The Entrepreneurship Journey: Fostering Engineering Etudents' Entrepreneurship by Startup Creation. In 2019 IEEE Global Engineering Education Conference (EDUCON) (pp. 120-123). IEEE.

Meyer, G. D. (2011). The reinvention of academic entrepreneurship. Journal of Small Business Management, 49(1), 1-8. 
Milian, R. P., \& Gurrisi, M. (2017). The online promotion of entrepreneurship education: a view from Canada. Education + Training.

Mohar, Y. Zulkiflee, A. S., Hassan, F., Zuhairuse, M. D., Mohammad, F. M., \& Zaharim, A. (2010). Academic entrepreneurship and innovation in higher education: An integrated framework for Malaysian Universities. In 6th WSEAS/IASME International Conference on Educational Technologies, Sousse, Tunisia.

Nakata, C., \& Hwang, J. (2020). Design thinking for innovation: Composition, consequence, and contingency. Journal of Business Research, 118, 117128.

National Academy of Engineering, U. S. [NAE]. (2004). The engineer of 2020: Visions of engineering in the new century. Washington, DC: National Academies Press.

O’Reilly, N. M., Robbins, P., \& Scanlan, J. (2019). Dynamic capabilities and the entrepreneurial university: a perspective on the knowledge transfer capabilities of universities. Journal of Small Business \& Entrepreneurship, 31(3), 243-263.

OCDE, Eurostat \& Tragsa. (2005). Manual de Oslo: Guía para la recogida e interpretación de datos sobre innovación. Comisión Europea.

OECD (2021), OECD SME and Entrepreneurship Outlook 2021, OECD Publishing, Paris, Consultado en https://doi.org/10.1787/97a5bbfe-en

O'Shea, R. P., Allen, T. J., Morse, K. P., O'Gorman, C., \& Roche, F. (2007). Delineating the anatomy of an entrepreneurial university: the Massachusetts Institute of Technology experience. R\&D Management, 37(1), $1-16$.

Owen, C. L. (2006). Design thinking: Driving innovation. The Business Process Management Institute, 1-5.

Pedrazzini, S. (2012, September). Emphasizing soft skill learning and training as part of an engineering curriculum revision. In Proceedings of the 40th SEFI Annual Conference (pp. 128-139).

Pei-Lee, T., \& Chen-Chen, Y. (2008). Multimedia University's experience in fostering and supporting undergraduate student technopreneurship programs in a triple helix model. Journal of Tecbnology Management in China.

Philpott, K., Dooley, L., O'Reilly, C., \& Lupton, G. (2011). The entrepreneurial university: Examining the underlying academic tensions. Technovation, 31(4), 161-170. 
Prud'homme van Reine, P. (2017). The culture of design thinking for innovation. Journal of Innovation Management, 5(2), 56-80.

Rae, D., \& Melton, D. E. (2017). Developing an entrepreneurial mindset in US engineering education: an international view of the KEEN project. The Journal of Engineering Entrepreneurship, 7(3).

Rothaermel, F. T., Agung, S. D., \& Jiang, L. (2007). University entrepreneurship: a taxonomy of the literature. Industrial and corporate change, 16(4), 691-791.

Salamzadeh, A., Salamzadeh, Y., \& Daraei, M. (2011). Toward a systematic framework for an entrepreneurial university: a study in Iranian context with an IPOO model. Global Business and Management Research: An International Journal, 3(1), 31-37.

Sam, C., \& Van Der Sijde, P. (2014). Understanding the concept of the entrepreneurial university from the perspective of higher education models. Higher Education, 68(6), 891-908.

Sporn, B. (2001). Building adaptive universities: Emerging organisational forms based on experiences of European and US universities. Tertiary Education \& Management, 7(2), 121-134.

Subach, J., Munukutla, L., Magrane, J., \& Popovich, C. (2007, June). Universities And Industry Create Engineer Entrepreneurs to Fuel Innovation. In 2007 Annual Conference \& Exposition (pp. 12-1518).

Taricani, E. (Ed.). (2021). Design Thinking and Innovation in Learning. Emerald Group Publishing.

UNESCO. (2010). Engineering Report: Issues Challenges and Opportunities for Development. United Nations Educational, Scientific and Cultural Organization. [Online]. Available: http://unesdoc.unesco.org/images/0018/001897/189753e.pdf

Wong, P. K., Ho, Y. P., \& Singh, A. (2007). Towards an "entrepreneurial university" model to support knowledge-based economic development: the case of the National University of Singapore. World Development, 35(6), 941-958.

World Economic Forum. (2009). Educating the Next Wave of Entrepreneurs: Unlocking Entrepreneurial Capabilities to Meet the Global Challenges of the 21st Century, A Report of the Global Education Initiative. Switzerland.

World Economic Forum. (2018). The Inclusive Development Index 2018 Summary and Data Highlights. 


\section{Capítulo V.}

Dunne, D., \& Martin, R. (2006). Design thinking and how it will change management education: An interview and discussion. Academy of Management Learning \& Education, 5(4), 512-523.

Garbuio, M., Dong, A., Lin, N., Tschang, T., \& Lovallo, D. (2018). Demystifying the genius of entrepreneurship: How design cognition can help create the next generation of entrepreneurs. Academy of Management Learning \& Education, 17(1), 41-61.

Glen, R., Suciu, C., \& Baughn, C. (2014). The need for design thinking in business schools. Academy of management learning \& education, 13(4), 653-667.

Martin, R. L., \& Golsby-Smith, T. (2017). Management is much more than a science. Harvard business review, 95(4), 128-135.

Brenner, W., \& Uebernickel, F. (2016). Design thinking for innovation. Research and Practice.

Dorst, K. (2011). The core of 'design thinking'and its application. Design studies, 32(6), 521-532.

Ries, B. T. (2011). Facilitating effective virtual reality for architectural design. University of Minnesota.

Simon, H. A. (1969). The sciences of the artificial. Cambridge, MA.

Blank, S., \& Dorf, B. (2012). The startup owner's manual: The step-bystep guide for building a great company. K \& S Ranch. Inc, California. PubMed Abstract OpenURL.

Rowe, P. G. (1987). Design thinking. MIT press.

Liedtka, J. (2018). Why design thinking works. Harvard Business Review, 96(5), 72-79.

Romme, A. G. L. (2003). Making a difference: Organization as design. Organization science, 14(5), 558-573.

Bosma, N. (2013). The Global Entrepreneurship Monitor (GEM) and its impact on entrepreneurship research. Foundations and Trends in Entrepreneurship, 9(2).

Carlgren, L., Rauth, I., \& Elmquist, M. (2016). Framing design thinking: The concept in idea and enactment. Creativity and Innovation Management, 25(1), 38-57. 
Sarooghi, H., Sunny, S., Hornsby, J., \& Fernhaber, S. (2019). Design thinking and entrepreneurship education: Where are we, and what are the possibilities? Journal of Small Business Management, 57, 78-93.

Liedtka, J., King, A., \& Bennett, K. (2013). Solving problems with design thinking: Ten stories of what works. Columbia University Press.

Liedtka, J., \& Ogilvie, T. (2011). Designing for growth: A design thinking tool kit for managers. Columbia University Press.

Liedtka, J., Salzman, R., \& Azer, D. (2017). Democratizing innovation in organizations: teaching design thinking to non-designers. Design Management Review, 28(3), 49-55.

Lockwood, T. (2010). Design thinking: Integrating innovation, customer experience, and brand value. Simon and Schuster.

Martin, R., \& Martin, R. L. (2009). The design of business: Why design thinking is the next competitive advantage. Harvard Business Press.

Martin, R. L., Christensen, K., \& Antonelli, P. (2013). Rotman on design: The best on design thinking from Rotman magazine. University of Toronto Press.

Beckman, S. L., \& Barry, M. (2007). Innovation as a learning process: Embedding design thinking. California management review, 50(1), 25-56.

Brown, T. (2008). Design thinking. Harvard business review, 86(6), 84.

Kolko, J. (2015). Design thinking comes of age.

Liedtka, J. (2015). Perspective: Linking design thinking with innovation outcomes through cognitive bias reduction. Journal of product innovation management, 32(6), 925-938.

Elsbach, K. D., \& Stigliani, I. (2018). Design thinking and organizational culture: A review and framework for future research. Journal of Management, 44(6), 2274-2306.

Micheli, P., Wilner, S. J., Bhatti, S. H., Mura, M., \& Beverland, M. B. (2019). Doing design thinking: Conceptual review, synthesis, and research agenda. Journal of Product Innovation Management, 36(2), 124-148.

Seidel, V. P., \& Fixson, S. K. (2013). Adopting design thinking in novice multidisciplinary teams: The application and limits of design methods and reflexive practices. Journal of Product Innovation Management, 30, 1933. 
Osterwalder, A., Pigneur, Y., Oliveira, M. A. Y., \& Ferreira, J. J. P. (2011). Business Model Generation: A handbook for visionaries, game changers and challengers. African journal of business management, 5(7), 22-30.

Lackéus, M. (2015). Entrepreneurship in education: What, why, when, how. Background paper.

Mwasalwiba, E. S. (2010). Entrepreneurship education: a review of its objectives, teaching methods, and impact indicators. Education + training.

Kyrö, P. (2018). The conceptual contribution of education to research on entrepreneurship education. In A research agenda for entrepreneurship education. Edward Elgar Publishing.

De Monbrun, M., Finelli, C. J., Prince, M., Borrego, M., Shekhar, P., Henderson, C., \& Waters, C. (2017). Creating an instrument to measure student response to instructional practices. Journal of Engineering Education, 106(2), 273-298.

Vianna, M., Vianna, Y., Adler, I. K., Lucena, B., \& Russo, B. (2012). Design thinking. Inovación en los Negocios. MJV Press.

Weilerstein, P., \& Byers, T. (2016). Guest editorial: Entrepreneurship and innovation in engineering education. Advances in Engineering Education, 5(1), 1-9.

Huang-Saad, A. Y., Morton, C. S., \& Libarkin, J. C. (2018). Entrepreneurship assessment in higher education: A research review for engineering education researchers. Journal of Engineering Education, 107(2), 263-290.

Zappe, S. E. (2018). Avoiding Construct Confusion: An Attribute-Focused Approach to Assessing Entrepreneurial Mindset. Advances in Engineering Education, 7(1), n1.

Huang-Saad, A., Bodnar, C., \& Carberry, A. (2020). Examining current practice in engineering entrepreneurship education.

Grinter, L. E. (1955). Report on evaluation of engineering education. Journal of Engineering Education, 46(1), 25-63.

Prados, J. W., Peterson, G. D., \& Lattuca, L. R. (2005). Quality assurance of engineering education through accreditation: The impact of Engineering Criteria 2000 and its global influence. Journal of Engineering Education, 94(1), 165-184.

Hilliger, I., Miranda, C., \& Pérez-Sanagustín, M. (2017, June). Does the Revision of ABET Student Outcomes Include the Competencies Required to Succeed in Start-Ups and Entrepreneurial Companies? In 2017 ASEE Annual Conference \& Exposition. 
European Commission (EC). (2013). Entrepreneurship 2020 action plan: reigniting the entrepreneurial spirit in Europe. European Commission, Brussels, Belgium.

Celis, S., \& Hilliger, I. (2016, June). Redesigning Engineering Education in Chile: How Selective Institutions Respond to an Ambitious National Reform. In 2016 ASEE Annual Conference \& Exposition.

Aparicio, G., Iturralde, T., \& Maseda, A. (2019). Conceptual structure and perspectives on entrepreneurship education research: A bibliometric review. European Research on Management and Business Economics, 25(3), 105-113.

Duval-Couetil, N., Kisenwether, E., Tranquillo, J., \& Wheadon, J. (2015). Exploring the intersection of entrepreneurship education and ABET accreditation criteria. The Journal of Engineering Entrepreneurship, 6(2), 44-57.

London, J. S., Bekki, J. M., Brunhaver, S. R., Carberry, A. R., \& McKenna, A. F. (2018). A Framework for Entrepreneurial Mindsets and Behaviors in Undergraduate Engineering Students: Operationalizing the Kern Family Foundation's" 3Cs". Advances in Engineering Education, 7(1), n1.

Miranda, C., Goñi, J., Berhane, B., \& Carberry, A. (2020). Seven Challenges in Conceptualizing and Assessing Entrepreneurial Skills or Mindsets in Engineering Entrepreneurship Education. Education Sciences, 10(11), 309.

Sarasvathy, S. D. (2001, August). Effectual reasoning in entrepreneurial decision making: existence and bounds. In Academy of management proceedings (Vol. 2001, No. 1, pp. D1-D6). Briarcliff Manor, NY 10510: Academy of Management.

Blank, G., \& Dorf, B. (2012). El manual del propietario de la startup-la guía paso a paso para construir una gran Cultura Organizacional. Percadero, CA.: K\&S Ranch.

Osterwalder, A., \& Pigneur, Y. (2010). Business model generation: a handbook for visionaries, game changers, and challengers (Vol. 1). John Wiley $\&$ Sons.

Smolka, K. M., Verheul, I., Burmeister-Lamp, K., \& Heugens, P. P. (2018). Get it together! Synergistic effects of causal and effectual decisionmaking logics on venture performance. Entrepreneurship Theory and Practice, 42(4), 571-604. 
Dimov, D. (2016). Toward a design science of entrepreneurship. In Models of start-up thinking and action: Theoretical, empirical and pedagogical approaches. Emerald Group Publishing Limited.

Grecu, V., \& Denes, C. (2017). Benefits of entrepreneurship education and training for engineering students. In MATEC web of conferences (Vol. 121, p. 12007). EDP Sciences. https://doi.org/10.1051/matecconf/201712112007

Alfaro, N.G., Zambrano, M., Habib, L. (2020). Estrategias pedagógicas mediante aula invertida para lograr un aprendizaje activo. APublicaciones CIEAL.

González, M. L., Marchueta, J., \& Vilche, E. A. (2011). Modelo de aprendizaje experiencial de Kolb aplicado a laboratorios virtuales en Ingeniería en Electrónica. In I Jornadas Nacionales de TIC e Innovación en el Aula.

Itin, C. M. (1999). Reasserting the philosophy of experiential education as a vehicle for change in the 21 st century. Journal of experiential Education, 22(2), 91-98.

Adaptado de Claxton, G., Costa, A., \& Kallick, B. (2016). Hard thinking about soft skills. Educational leadership, 73(6).

Ramírez-Montoya, M. S., \& Beltrán Hernández de Galindo, M. J. (2019). Innovación en el diseño instruccional de cursos masivos abiertos (MOOC's) para desarrollar competencias de emprendimiento en sustentabilidad energética.

VIllarreal Rodríguez, M. (2018). El diseño de entornos digitales de aprendizaje.

Sarasvathy, S. D. (2009). Effectuation: Elements of entrepreneurial expertise. Edward Elgar Publishing.

You, X., \& Hands, D. (2019). A Reflection upon Herbert Simon's Vision of Design in The Sciences of the Artificial. The Design Journal, 22(sup1), 1345-1356.

Clegg, S. R. (1993). Narrative, power and social theory. Narrative and social control: Critical perspectives, 21, 15-45.

Bernard, R., Abrami, P., Borokhovski, E., Wade, A., Tamim, R., Surkes, M., \& Bethel, E. (2009). Un metaanálisis de tres tipos de tratamientos de interacción en educación a distancia. Revisión de Investigación Educativa, 79(3), 243-289. 
Santos, F. L., Alves, R., Ferreira, C., \& Costa, H. M. (2015). Experiências Pedagógicas no Ensino Superior: pares pedagógicos e interdisciplinaridade. Revista Docência do Ensino Superior, 5(2), 9-30.

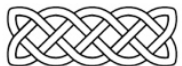


Se terminó de imprimir en el mes de enero de 2022 en los talleres de Editorial Labýrinthos; se usó la familia tipografíca: Garamond en $22,18,14,12,11,10,9$ y 8 puntos.

El tiro consta de 1000 ejemplares. Primera edición enero de 2022. 


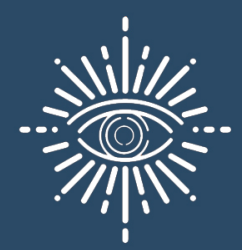

LABYRINTHOS

Este libro brinda al lector una visión amplia de la educación emprendedora en la formación de ingenieros, ofreciendo una perspectiva sobre los desafíos que se han identificado en la evolución de la investigación en el tema. El análisis de un marco teórico integrador, el impacto detel emprendimiento en la formación de perfiles ingenieriles én la actualidad, así como, el impacto de la educación emprentẹtora en la innovación.

Finalmente se propone un modele de diseño instruccional adoptando los elementos analizados, buscando redefinir y transformar la educación emprendedora para estudiantes de ingeniería mediante la aplicación de metodologías activas, como el pensamiento de diseño.

Este libro está centrado en la práctica docente bajo indicadores medibles, evidencias científicas, análisis de datos y percepciones de los estudíantes a lo largo de más de 3 años. Ha fortalecido la prácticà docente de quienes han estado involucrados en el proyecto, $y$ ha beneficiado a los estudiantes que han pasado por estas aúlas. Se ha expuesto en un lenguaje sencillo y gráficamente descrito, para favorecêr su aplicaciön. Es el deseo auténtico de la autora, que esto séa de beneficio para todo aquel quien lo lea, ya sea docente o estudiante. 